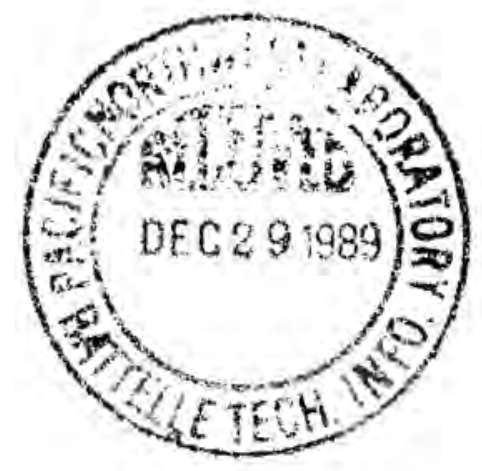

\title{
RELY: A Reliability Modeling System for Analysis of Sodium-Sulfur Battery Configurations
}
C. J. Hostick
H. D. Huber
J. V. Dovey
R. B. Grinde
W. H. Doggett
J.S. Littlefield
J. A. Dirks
F. M. Cuta

June 1987

Prepared for the U.S. Department of Energy under Contract DE-AC06-76RLO 1830

Pacific Northwest Laboratory

Operated for the U.S. Department of Energy by Battelle Memorial Institute 


\title{
DISCLAIMER
}

This report was prepared as an account of work sponsored by an agency of the United States Government. Neither the United States Government nor any agency thereof, nor Battelle Memorial Institute, nor any of their employees, makes any warranty, expressed or implied, or assumes any legal liability or responsibility for the accuracy, completeness, or usefulness of any information, apparatus, product, or process disclosed, or represents that its use would not infringe privately owned rights. Reference herein to any specific commercial product, process, or service by trade name, trademark, manufacturer, or otherwise, does not necessarily constitute or imply its endorsement, recommendation, or favoring by the United States Government of any agency thereof, or Battelle Memorial Institute. The views and opinions of authors expressed herein do not necessarly state or reflect those of the United States Government or any agency thereof, or Battelle Memorial Institute.

\author{
PACIFIC NORTHWEST LABORATORY \\ operated by \\ BATTELLE MEMORIAL INSTITUTE \\ for the \\ UNITED STATES DEPARTMENT OF ENERGY \\ under Contract DE-AC06-76RLO 1830
}

\begin{tabular}{|c|c|}
\hline \multicolumn{2}{|c|}{$\begin{array}{l}\text { Printed in the United States of America } \\
\text { Available from } \\
\text { National Technical Information Service } \\
\text { United States Department of Commerce } \\
5285 \text { Port Royal Road } \\
\text { Springfield, Virginia } 22161\end{array}$} \\
\hline \multicolumn{2}{|c|}{$\begin{array}{l}\text { NTIS Price Codes } \\
\text { Microfiche A01 }\end{array}$} \\
\hline \multicolumn{2}{|c|}{ Printed Copy } \\
\hline Pages & $\begin{array}{l}\text { Price } \\
\text { Codes }\end{array}$ \\
\hline $001-025$ & A02 \\
\hline $026-050$ & $\mathrm{~A} 03$ \\
\hline $051-075$ & $\mathrm{~A} 04$ \\
\hline $076-100$ & A05 \\
\hline $101-125$ & $A 06$ \\
\hline $126-150$ & A07 \\
\hline $151-175$ & $A 0 B$ \\
\hline $176-200$ & A09 \\
\hline $201-225$ & A010 \\
\hline $226-250$ & A011 \\
\hline $251-275$ & $A 012$ \\
\hline $276-300$ & $A 013$ \\
\hline
\end{tabular}


RELY: A RELIABILITY MODELING SYSTEM FOR ANALYSIS OF SODIUM-SULFUR BATTERY CONFIGURATIONS
C. J. Hostick
J. V. Dovey
H. D. Huber
R. B. Grinde
W. H. Doggett
J. A. Dirks
J. S. Littlefield
F. M. Cuta

June 1987

Prepared for

the U.S. Department of Energy

under Contract DE-AC06-76RLO 1830

Pacific Northwest Laboratory

Richland, Washington 99352 



\section{SUMMARY}

In support of the Office of Energy Storage and Distribution of the U.S. Department of Energy (DOE), Pacific Northwest Laboratory has produced a microcomputer-based software package, called RELY, to assess the impact of sodiumsulfur cell reliability on constant current discharge battery performance. The Fortran-based software operates on IBM microcomputers and IBM-compatibles that have a minimum of $512 \mathrm{~K}$ of internal memory. The software package has three models that provide the following: 1) a description of the failure distribution parameters used to model cell failure, 2) a Monte Carlo simulation of battery life, and 3) a detailed discharge model for a user-specified battery discharge cycle.

Cell failure is modeled as occurring randomly, using a uniform distribution for failure rates due to freeze-thaw and a Weibull distribution for failure due to wearout. The description of the failure distribution parameters assists the user in determining these parameters, and provides typical distribution parameter values based on available sodium-sulfur test data.

The Monte Carlo simulation estimates expected battery life for a variety of user-specified battery configurations. Performance requirements are entered in terms of battery capacity, and failures are modeled as producing either open or closed circuit post-failure resistances. Multiple simulations of battery life can be run to obtain a mean and standard deviation for battery life estimates.

The detailed discharge model for a user-specified discharge cycle was developed by using a current-voltage, depth-of-discharge model of sodium-sulfur cell performance. This model estimates battery discharge performance at constant discharge current in terms of its voltage and power. The model takes into consideration the number and type of failed cells that can be expected for the specified cycle, and provides the user with the option of adding switches within the battery configuration to minimize the impact of failed cells. 

CONTENTS

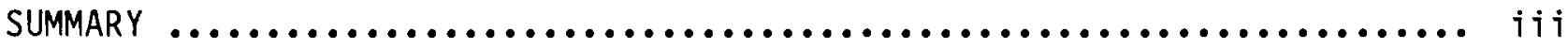

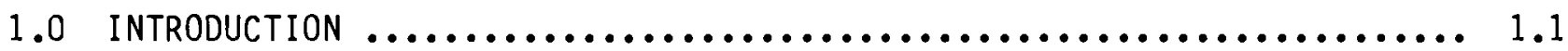

2.0 RELY USER'S GUIDE $\ldots \ldots \ldots \ldots \ldots \ldots \ldots \ldots \ldots \ldots \ldots \ldots \ldots \ldots \ldots \ldots \ldots . \ldots \ldots$

2.1 GETTING STARTED $\ldots \ldots \ldots \ldots \ldots \ldots \ldots \ldots \ldots \ldots \ldots \ldots \ldots \ldots \ldots . \ldots \ldots \ldots \ldots$

2.2 Reference guide $\ldots \ldots \ldots \ldots \ldots \ldots \ldots \ldots \ldots \ldots \ldots \ldots \ldots \ldots \ldots, 2.5$

3.0 EXAMPLE APPLICATIONS $\ldots \ldots \ldots \ldots \ldots \ldots \ldots \ldots \ldots \ldots \ldots \ldots \ldots \ldots \ldots \ldots \ldots . \ldots \ldots$

3.1 THE LIFE-CYCLE MODEL $\ldots \ldots \ldots \ldots \ldots \ldots \ldots \ldots \ldots \ldots \ldots \ldots \ldots \ldots, 3.2$

3.2 DETAiled discharge MOdel $\ldots \ldots \ldots \ldots \ldots \ldots \ldots \ldots \ldots \ldots \ldots \ldots \ldots, 3.10$

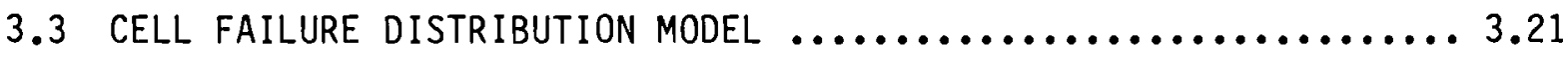

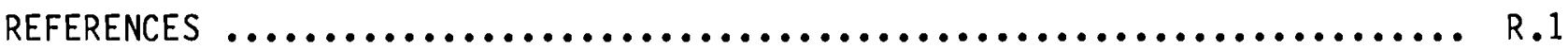

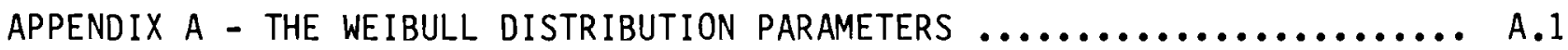

APPENDIX B - MODELING APPROACH $\ldots \ldots \ldots \ldots \ldots \ldots \ldots \ldots \ldots \ldots \ldots \ldots \ldots \ldots \ldots \ldots \ldots . \ldots \ldots$

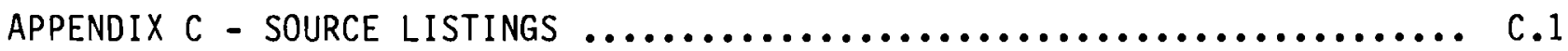

APPENDIX D - MODEL VERIFICATION $\ldots \ldots \ldots \ldots \ldots \ldots \ldots \ldots \ldots \ldots \ldots \ldots \ldots \ldots \ldots . \ldots . \ldots . \ldots$

D.1 VERIfiCATION OF THE LIFE CYCLE MODEL.................. D.1

0.1 .1 System I $\ldots \ldots \ldots \ldots \ldots \ldots \ldots \ldots \ldots \ldots \ldots \ldots \ldots \ldots \ldots, 0.2$

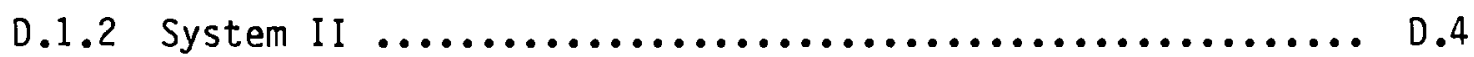

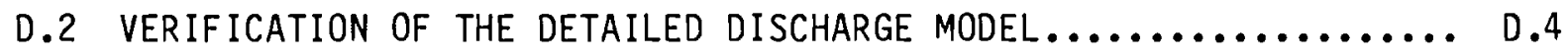




\section{FIGURES}

1.1 Sodium-Sulfur Battery Reliability Model $\ldots \ldots \ldots \ldots \ldots \ldots \ldots \ldots \ldots . . . . .2$

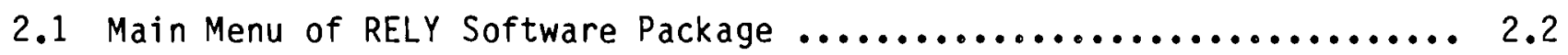

2.2 Battery Representation Showing Cells, Strings, and Modules ........ 2.6

2.3 Representation of Cell in Detailed Discharge Model ............... 2.7

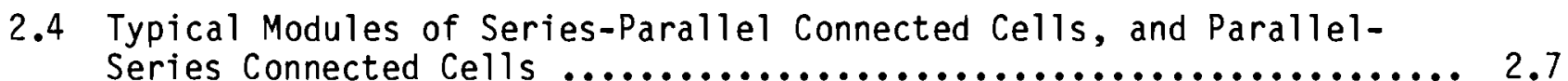

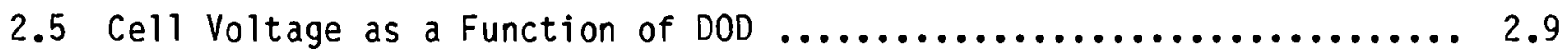

2.6 Closed Circuit Failure in Life-Cycle Model .................... 2.9

2.7 Closed Circuit Failure in Detailed Discharge Model .............. 2.10

2.8 Failure Switch Operation $\ldots . \ldots \ldots \ldots \ldots \ldots \ldots \ldots \ldots \ldots \ldots \ldots \ldots \ldots \ldots . . . \ldots \ldots$

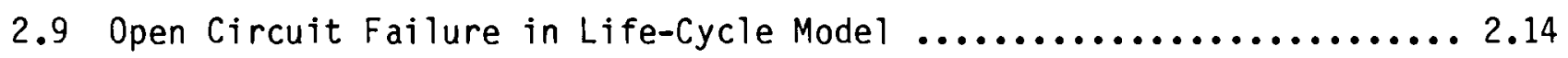

2.10 Open Circuit Failure in Detailed Discharge Model ................. 2.14

3.1 Suggested Use of the RELY Software Package $\ldots \ldots \ldots \ldots \ldots \ldots \ldots \ldots . \ldots . . \ldots$

3.2 Input Screen for Battery Test Configuration in Life-Cycle Model .... 3.4

3.3 Arrangement of Cells, Strings, and Modules in Example Battery

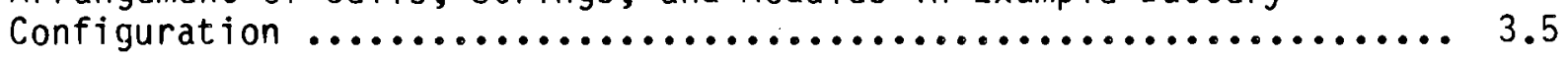

3.4 Input Screen for Performance Requirements in Life-Cycle Model ...... 3.6

3.5 Input Screen for Freeze-Thaw Failures in Life-Cycle Model .......... 3.7

3.6 Input Screen for Failures Due to Wearout in Life-Cycle Model ....... 3.8

3.7 Output Screen from Life-Cycle Model ........................ 3.11

3.8 Main Menu for Detailed Discharge Model $\ldots \ldots \ldots \ldots \ldots \ldots \ldots \ldots \ldots \ldots . . . \ldots \ldots$

3.9 Input Screen to Select Editing Screens for Detailed Discharge Model ................................................... 3.13

3.10 Input Screens for Editing Battery Performance Data in Detailed Discharge Model .......................................... 3.14 
3.11 Screen Display of Battery Configuration for Detailed Discharge Model

3.12 Output Screen from Detailed Discharge Model ...................... 3.19

3.13 Input Screen for Analysis of Results from Detailed Discharge Model

3.14 Input Screen for Graphics Output from Detailed Discharge Model ..... 3.20

3.15 Graphics Output from Detailed Discharge Model $\ldots \ldots \ldots \ldots \ldots \ldots \ldots . . . . .22$

3.16 Partial Table of Cell Status at Time Battery Failed ............... 3.23

3.17 Input Screen for Failure Distribution Model $\ldots \ldots \ldots \ldots \ldots \ldots \ldots \ldots . . . . .25$

3.18 Input Screen for Example Weibull Distribution (Option A) $\ldots \ldots \ldots \ldots . .3 .25$

3.19 Input Screen for Example Weibull Distribution (Option B) $\ldots \ldots \ldots \ldots . .26$

3.20 Weibull Probability Density Function Illustrated by Cell Failure

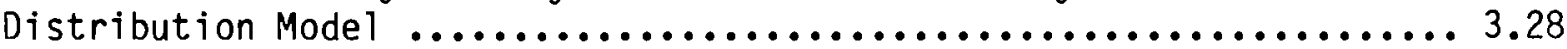

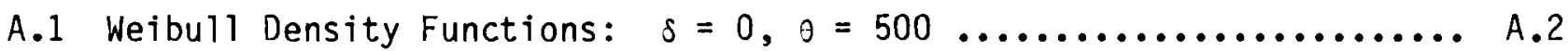

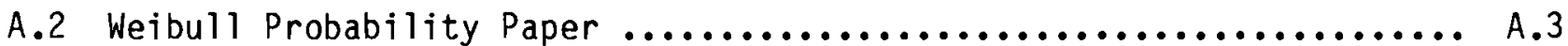

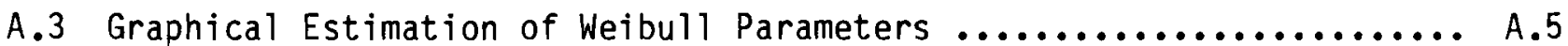

B.1 Block Diagram of DOS Batch File BATTERY.BAT ................... B.2

B.2 Block Diagram of Program RELY $\ldots \ldots \ldots \ldots \ldots \ldots \ldots \ldots \ldots \ldots \ldots \ldots \ldots$, B.4

B.3 Block Diagram of Subroutine SIMULAT $\ldots \ldots \ldots \ldots \ldots \ldots \ldots \ldots \ldots \ldots \ldots \ldots$ B.7

B.4 Generation of Weibull Random Numbers for Location $\delta=0$,

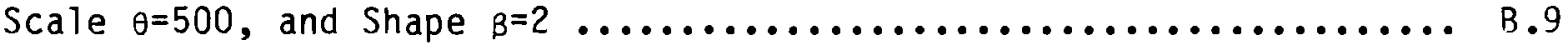

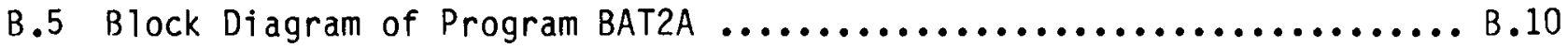

D.1 Model Verification Battery Configuration $\ldots \ldots \ldots \ldots \ldots \ldots \ldots \ldots \ldots$. D.2 


\section{TABLES}

A.1 Example Failure Cycles, Ranks, and Median Rank Values Used to Estimate Weibul1 Parameters ................................ A.

B.1 Summary of Supporting Subroutines $\ldots \ldots \ldots \ldots \ldots \ldots \ldots \ldots \ldots \ldots \ldots \ldots \ldots$

B.2 Summary of GRAFMATIC Subroutines Called by Programs RELY and

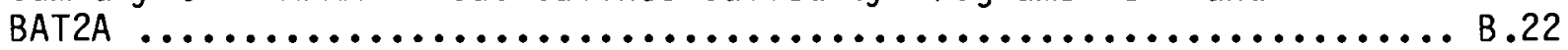

D.1 Individual Cell Wearout Cycles $\ldots \ldots \ldots \ldots \ldots \ldots \ldots \ldots \ldots \ldots \ldots \ldots \ldots \ldots \ldots . \ldots . \ldots$ 


\section{$1.0 \quad$ INTRODUCTION}

The Energy Storage Division of the U.S. Department of Energy (DOE) is sponsoring research at Pacific Northwest Laboratory (PNL) to develop microcomputer-based software to assist battery developers in their research and development activities. This report describes the RELY software package; a reliability model for analyzing sodium-sulfur battery configurations during constant current discharge conditions.

This software is microcomputer-based and can be executed on IBM computers and IBM-compatibles that have a minimum of $512 \mathrm{~K}$ of internal memory. A schematic of the software is shown in Figure 1.1. The software package consists of 1) a description of the failure distribution parameters used to model cell failure, 2) a Monte Carlo simulation of the battery life (in cycles), and 3) a detailed discharge model for a user-specified discharge cycle.

The Cell Failure Distribution Description is a graphical package that assists the user in understanding the parameters in the Weibull failure distribution. The graphical package also provides typical values for failure distribution parameters based on the most recent sodium-sulfur test data. The failure distribution graphics can help users determine whether the Weibull parameter estimates obtained from their bench test data are adequate.

The second part of the software package is the Life-Cycle Model which produces an estimate of the expected battery life. It models cell failures using stochastic modeling techniques; a uniform distribution is assumed for freeze-thaw failures and a Weibull distribution is used for wearout failures. Cells are modeled as either "good" or failed and battery performance requirements are stated in terms of the number of good cells required. Failed cells are modeled as having either open or closed circuit post-failure resistances. The user specifies the expected percentage of each post-failure resistance for both types of failures. Using Monte Carlo simulation techniques, multiple simulations of battery life can be run to obtain a mean and standard deviation for the battery life estimates.

The Detailed Discharge model is the third component of the software package; it provides a detailed discharge analysis of a user-specified battery 


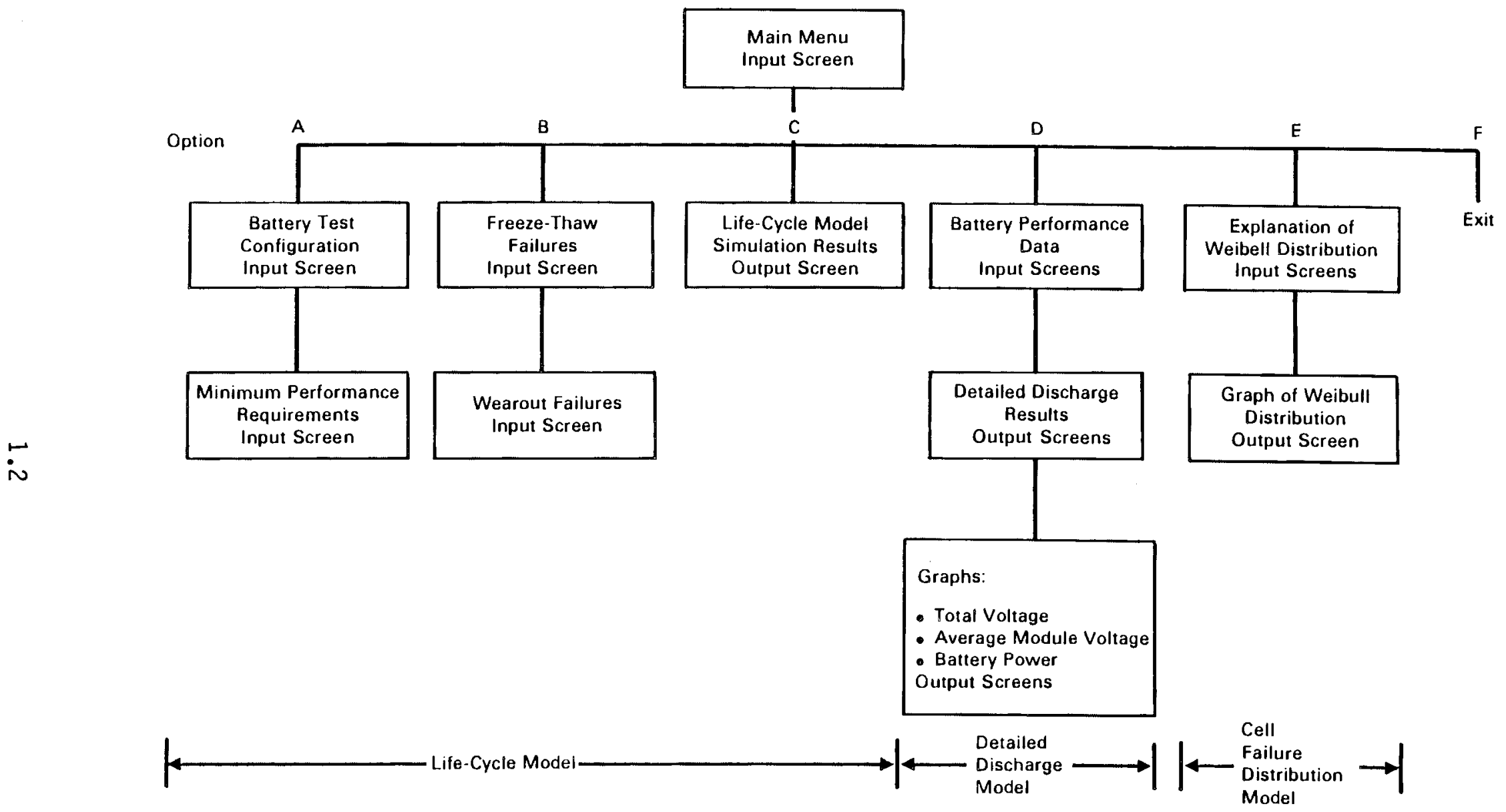

FIGURE 1.1. Sodium-Sulfur Battery Reliability Model 
discharge cycle. The model was formulated using a current-voltage, depth-ofdischarge model of sodium sulfur cell performance (DOE 1977). The model estimates battery discharge performance at constant discharge current in terms of voltage and power. Following the completion of the battery cycle life simulation, the Detailed Discharge Model can be used to test cycles near the end of the estimated battery life. In this manner, the battery life estimate can be verified using more exact battery performance measures (i.e., the ability of the battery to meet power requirements as opposed to a good cell count). The model accounts for the failed cells that can be expected for the specified cycle, and provides the user with the option of adding switches within the battery configuration to minimize the impact of the failed cells.

Battery configurations of up to 8,000 cells (up to 20 cells/string, 20 strings/module, and 20 modules/battery) can be modeled. Larger configurations can be modeled by grouping multiple cells into modules, and entering module data when cell data is requested. For example, large load leveling systems of 800,000 cells could be represented by grouping cells into modules of 100, and entering the resulting module characteristics as cell data into the model.

A user's guide for the RELY software is provided in Chapter 2.0. Chapter 3.0 contains example applications illustrating the input and output screens for the three modeling components of the software package. A method for estimating Weibull distribution parameters from bench test data is provided in Appendix A. The modeling approach for the software package is described in Appendix $B$, the source code is listed in Appendix $C$, and model verification calculations are shown in Appendix 0 . 



\subsection{RELY USER'S GUIDE}

This chapter serves as a brief introduction and reference guide for the RELY software package. Since the model is menu-driven and largely selfexplanatory, the user is urged to run the model as soon as a working copy of the diskette is made. Section 2.1 describes how to copy the diskette. Section 2.2 is an alphabetical reference guide which explains the major concepts and terminology encountered. Ideally, this reference guide should be used while the model is being run, so that the user obtains a "hands-on" knowledge of the terminology.

The RELY software package was developed using Microsoft Fortran version 3.3 (Microsoft, Inc. 1985) for IBM-PC or compatible computers. The package displays results on the screen and/or writes to disk files. In addition, graphs of the results can be displayed on the screen; these graphs were developed using the GRAFMATIC graphics library (Microcompatibles 1983). The models of the software package are linked together with the Disk Operating System (DOS) (Microsoft, Inc. 1983) batch file "BATTERY."

The menus guide the user through the process of entering and analyzing a battery system. Figure 2.1 shows the main menu of the RELY software package. This menu provides the primary interface to the user in analyzing a battery system.

\subsection{GETTING STARTED}

This section describes the preliminary steps for running the RELY software package.

\section{HARDWARE REQUIREMENTS}

An IBM PC or compatible computer with at least $512 \mathrm{~K}$ of RAM and one floppy disk drive is needed to run the RELY model (a hard disk or second floppy drive is required for large applications). A color/graphics adapter is required to display graphs. 


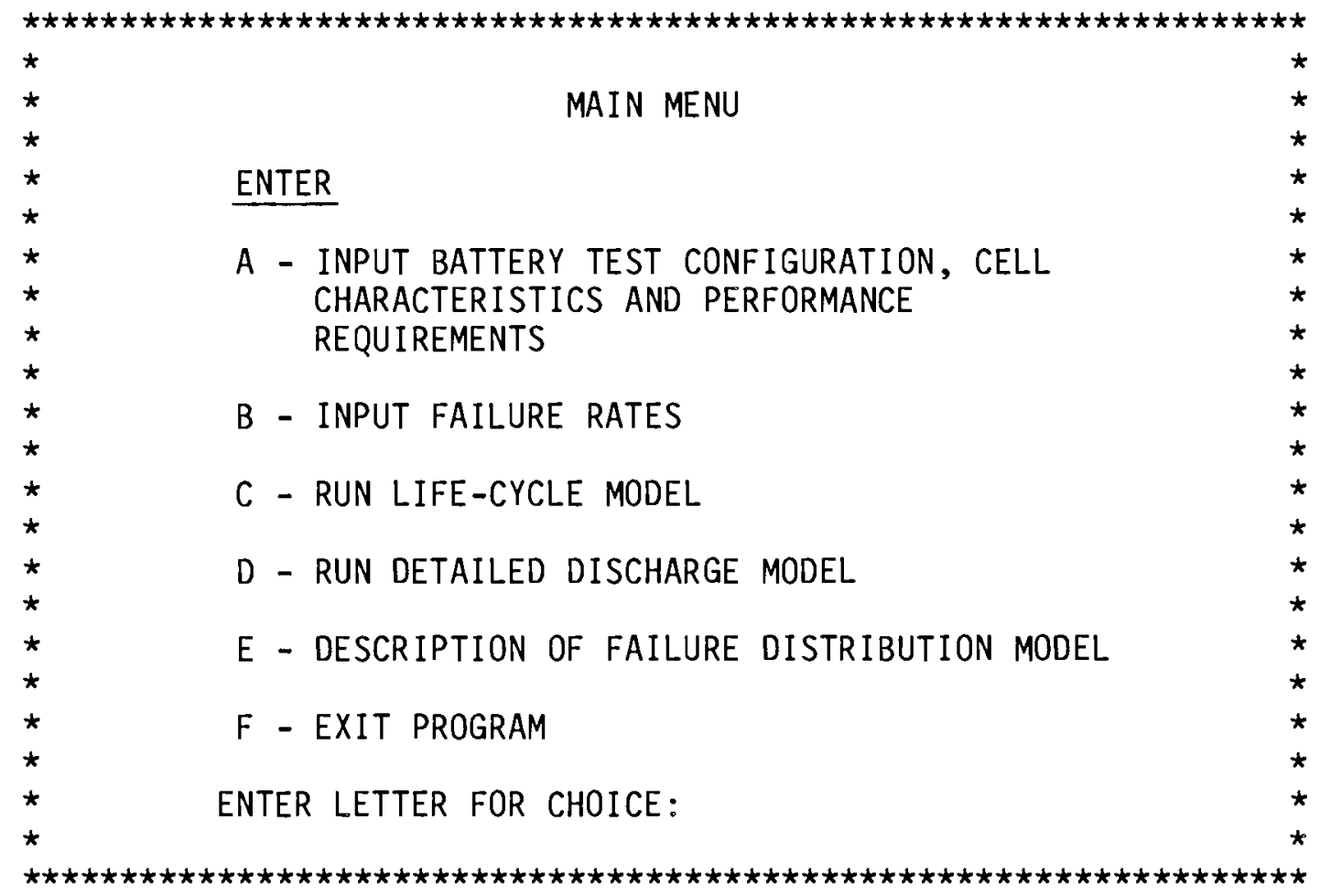

\section{FIGURE 2.1. Main Menu of RELY Software Package}

A copy of Disk Operating System (DOS) version 2.0 or higher is also necessary.

MAKING A WORKING COPY OF THE RELY MODEL

For smaller battery configurations, the following disk setup procedure is used.

Floppy Disk Users

1. Format a new disk with the /S option.

2. Be sure the DOS file COMMAND.COM is on the new disk.

3. Copy the DOS file ANSI.SYS to the new disk.

4. Copy all files from the RELY distribution disk to the newly formatted disk with the COPY *.* command. Do not use the DISKCOPY command or you will destroy the progress made in steps $1-3$. 
5. You now have a working copy of the RELY disk. Place the original disk in a safe place. Before using the battery model, re-boot the system to make sure that ANSI.SYS is loaded.

The above disk setup procedure is adequate for smaller battery configurations. However, large systems may create files that exceed the disk's capacity. In these cases, you can use a second disk as a data disk for the files generated by the model. Follow the additional steps below to create a data disk.

Creating a Data Disk

1. Format a new disk. The /S option is not required.

2. Copy the BATTERY.BAT file from your working RELY disk to this new disk.

3. Edit the BATTERY.BAT file on the new disk. Insert "A:" in front of the commands "RELY" and "BAT2A" in this batch file.

4. Erase the BATTERY.BAT file on your working RELY disk (optional).

5. Insert the working RELY disk in drive $A$ and your new data disk in drive $B$.

6. Make $B$ the default drive.

7. Type "BATTERY" <Return> to run the model.

An alternative to the above procedure is to follow steps 1 and 2, and edit the BATTERY.BAT file to insert "PATH=A:" immediately after the "ECHO OFF" command. Then follow steps 4-7 as above.

Hard Disk Users

1. Create a new directory, such as RELY.

2. Insert the original RELY disk in drive $A$ and enter the newly created directory. The prompt should now be similar to "C RELY>." 
3. Issue the following DOS commands:

COPY $A:{ }^{*}$. EXE 〈RETURN>

COPY $A:{ }^{*}$.BAT 〈RETURN>

4. Make sure that there is a path to DOS and that the command DEVICE=ANSI.SYS is in your CONFIG.SYS file.

5. You have now installed RELY on your hard disk. Place the original diskette in a safe place. Before using the battery model, re-boot the system to make sure that ANSI.SYS is loaded.

STARTING THE BATTERY MODEL

From the appropriate drive/directory prompt, type "BATTERY" <RETURN>. The model is menu-driven and designed to be self-explanatory, so step-by-step instructions are not provided. For further information and help with a particular concept or term, consult the reference guide in Section 2.2.

When the Main Menu appears (similar to Figure 2.1), Options A, B, and C must be selected in sequential order to run the Life-Cycle Model. Option $D$ can then be selected to run the Detailed Discharge Model. Option E can be selected at any time to introduce the user to the Weibull distribution.

NOTE: If the menus of the program do not come onto the screen from the top to the bottom, but rather scroll up from the bottom of the screen, check to be sure that the device driver ANSI.SYS is loaded. 


\subsection{REFERENCE GUIDE}

This section provides an alphabetical list of the terms used in the RELY sof tware package.

BAT2A.OUT

Output file created by the DETAILED DISCHARGE MODEL which contains results of the discharge analysis.

BAT2A.TMP

File created by the LIFE-CYCLE MODEL which contains information about the battery configuration and individual cells. This file is used by the DETAILED DISCHARGE MODEL.

BAT2A.\$DF

File created by the DETAILED DISCHARGE MODEL (Option 4 on main menu) which contains user-specified test conditions, cell parameters, and cell internal resistances. If this file is present when the Detailed Discharge Model is started, these values are loaded and replace the default values.

\section{BATTERY}

Energy storage device consisting of individual CELLS. CELLS are connected in series to form STRINGS. STRINGS are connected in parallel to form MODULES and MODULES are connected in series to form a BATTERY. See Figure 2.2. BATTERY configurations of up to 8,000 cells (up to 20 cells/string, 20 strings/module, and 20 modules/battery) can be modeled.

BATTERY CONFIGURATION

The number of CELLS comprising a STRING, STRINGS comprising a MODULE, and MODULES comprising a BATTERY. 


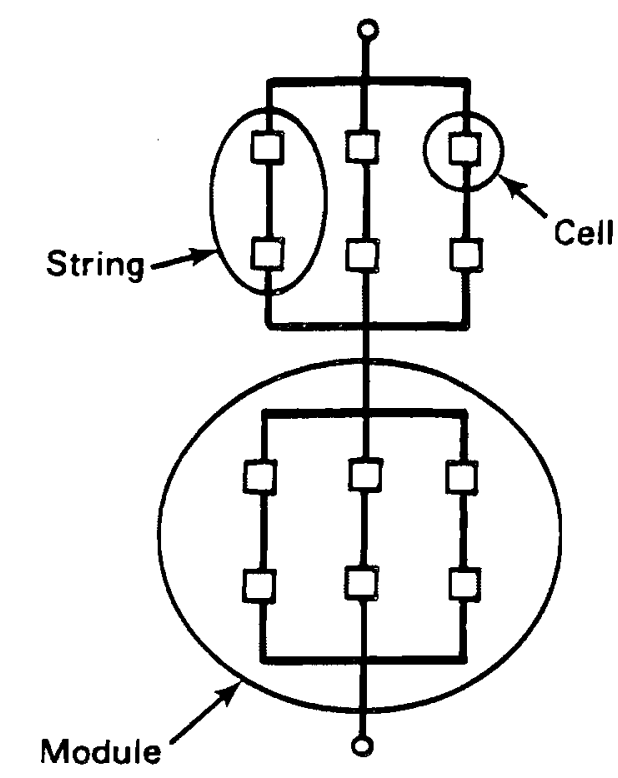

FIGURE 2.2. Battery Representation Showing Cells, Strings, and Modules

\section{BATTERY PERFORMANCE REQUIREMENTS}

In the Life-Cycle Model the BATTERY performance requirements are specified as the minimum numbers of operating 1) CELLS required for STRING operation, 2) STRINGS required for MODULE operation, and 3) MODULES required for BATTERY operation.

\section{CELL (a1so see BATTERY)}

In the Life-Cycle Model a cell is the smallest entity considered. A cell is classified as either good or bad, without reference to its capacity or voltage.

In the Detailed Discharge Model, a cell is modeled as an open circuit voltage with an internal resistance. The Detailed Discharge Model assumes that charging a cell to less than 5\% DEPTH OF DISCHARGE is impractical or impossible since the internal resistance rises so quickly for greater levels of charge. Thus, at 5\% DEPTH OF DISCHARGE the cell is able to discharge, but is not able to charge any further. This is represented by the diode in Figure 2.3 . 


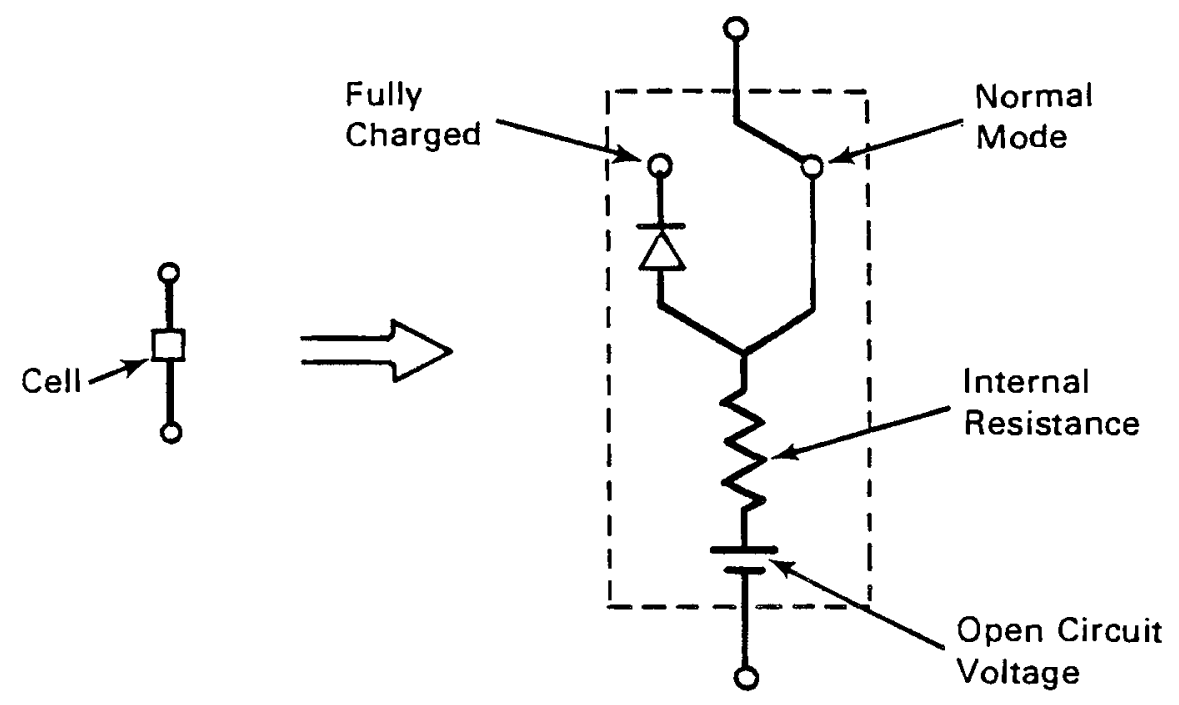

FIGURE 2.3. Representation of Cell in Detailed Discharge Model

\section{CELL-AGING FAILURE}

See WEAROUT FAILURE.

\section{CELL CONNECTION}

The method by which cells are to be connected. Figure 2.4 shows the two connection alternatives.
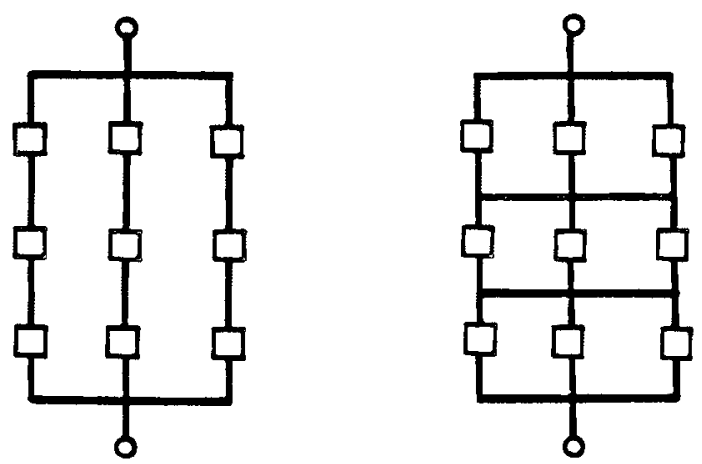

FIGURE 2.4. Typical Modules of Series-Parallel Connected Cells (1eft) and Parallel-Series Connected Cells (right) 
CELL INTERNAL RESISTANCE

The output impedance of a cell. The user inputs this parameter in the Detailed Discharge Model as a function of the cell's state of discharge, in $10 \%$ discharge increments. By default it is a constant 35 mohms until changed by the user.

CELL PARAMETERS

Characteristics of an individual cell which are necessary to model a battery system. These are determined by the user from bench-test data.

CELL VOLTAGE (also see CELL and FULLY CHARGED CELL CAPACITY)

The open circuit voltage of a cell. This quantity varies according to the Depth of Discharge (DOD). DOE is defined as one minus the THEORETICAL CAPACITY. Figure 2.5 explains the parameters needed in the Detailed Discharge Model. The FULLY CHARGED CELL CAPACITY is equal to $95 \%$ of the THEORETICAL CELL CAPACITY when the default value for the LOWER ELECTROLYTE FAILURE VOLTAGE $(1.78$ volts) is used. Changing the LOWER ELECTROLYTE FAILURE VOLTAGE will result in a DOD greater or less than $100 \%$ at the time of OVER-DISCHARGE FAILURE. Thus, the FULLY CHARGED CELL CAPACITY can be greater or less than $95 \%$ of the THEORETICAL CELL CAPACITY. However, in no case will the cell be at a DOD less than $5 \%$.

\section{CLOSED CIRCUIT FAILURE}

FAILURE MODE in which a CELL acts as a closed (short) circuit after it fails.

In the Life-Cycle Model, a closed circuit failure results in zero resistance through the failed cell (effectively deletes the cell from the battery). See Figure 2.6.

In the Detailed Discharge Model, the open circuit voltage is $V_{0}$ and the internal resistance is $R_{0}$ when the cell is operating. When a cell suffers a closed circuit failure, the internal resistance is set to the CLOSED CIRCUIT FAILURE RESISTANCE value $\left(R_{f}\right)$ when the cell is operating. The open circuit 


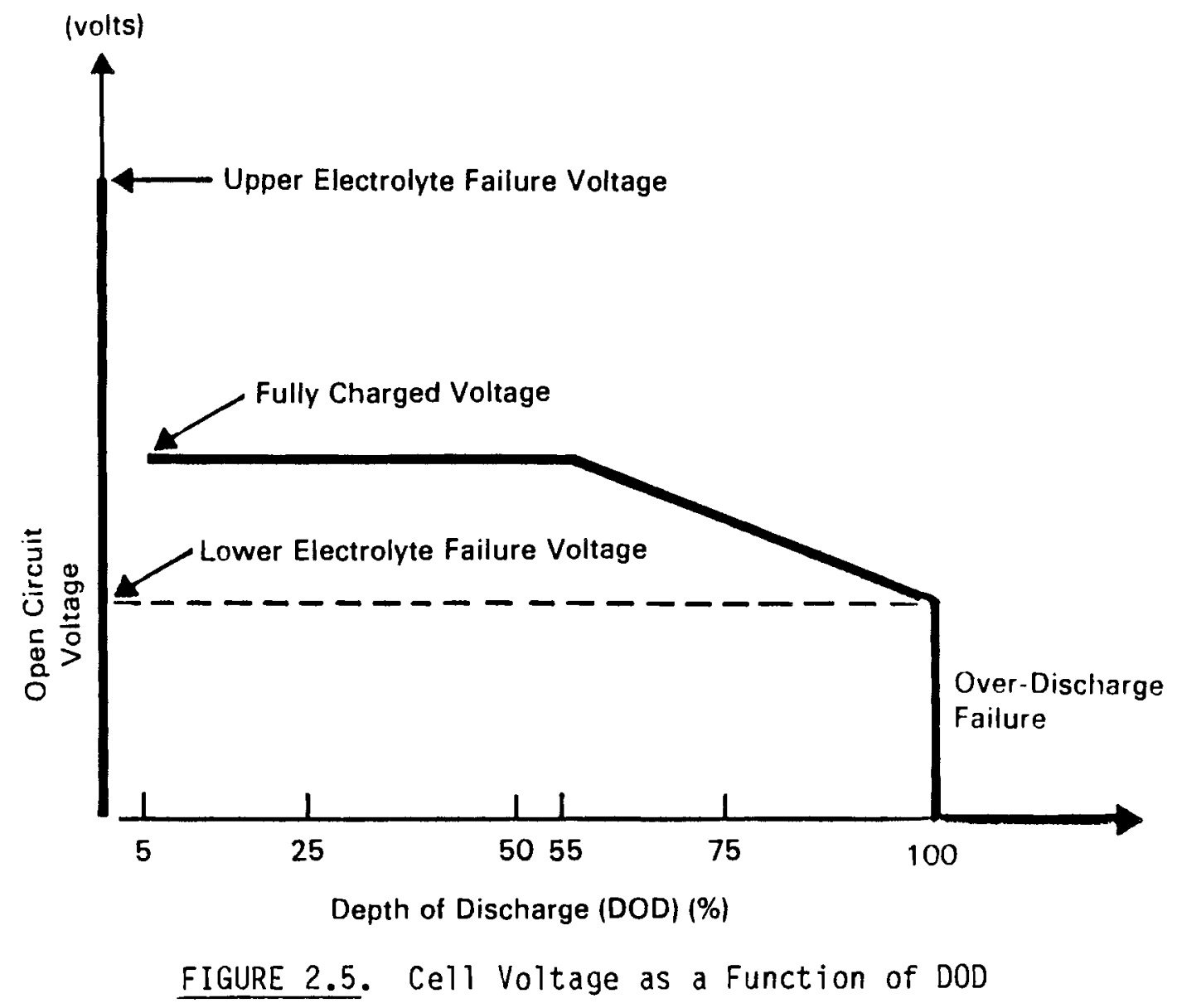

3 Cells Operating

Result of Closed

?

Circuit Failure
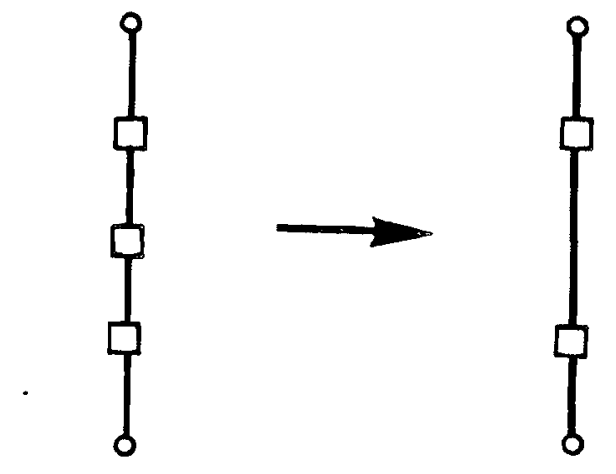

FIGURE 2.6. Closed Circuit Failure in Life-Cycle Model 
cell voltage drops to zero $\left(V_{f}\right)$. The CLOSED CIRCUIT FAILURE RESISTANCE parameter should be obtained from the user's bench-test data on the cell. See Figure 2.7.

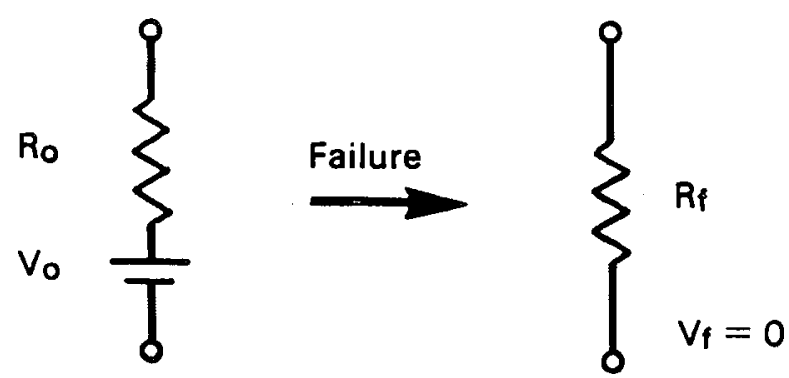

FIGURE 2.7. Closed Circuit Failure in Detailed Discharge Model

\section{CLOSED CIRCUIT FAILURE RESISTANCE}

A CELL PARAMETER equal to the typical resistance of a cell that has suffered a CLOSED CIRCUIT FAILURE.

CYCLE TO ANALYZE

The particular discharge cycle which the user selects to simulate in the Detailed Discharge Model. Appears in the TEST CONDITIONS menu.

DEPTH OF DISCHARGE (DOD)

The percentage of a cell's capacity which has been used thus far. Equal to one minus the remaining amp-hours (as a fraction of the cell theoretical capacity).

DETAILED DISCHARGE MODEL

The RELY sub-model which analyzes a specific cycle of the battery's lifetime. Detailed voltage-current-resistance information is obtained as a function of discharge time. 


\section{DISCHARGE CURRENT}

User-specified TEST CONDITION: the constant current (amps) output by the battery during the test.

\section{DURATION OF TEST}

User-specified total time (hours) for which the battery is to be discharged. Appears in the TEST CONDITIONS menu.

\section{FAILURE DISTRIBUTION MODEL}

The RELY sub-model which introduces the user to the WEIBULL DISTRIBUTION. Their are two parts to this sub-model. Based on user-specified Weibu11 parameters, the first part of the model generates the actual WEIBULL DISTRIBUTION density function and the second part simulates the density function based on 100 to 1,000 cell failures.

FAILURE MODE

Type of failure suffered by a cell, either closed or open circuit.

\section{FAILURE SWITCH}

When a cell fails in the Detailed Discharge Model, it effectively becomes a resistor. Without failure switches, the resistance is equal to either the CLOSED CIRCUIT or OPEN CIRCUIT FAILURE RESISTANCE. If failure switches are used, however, the cell is removed from the circuit as shown in Figure 2.8 . Only one failure switch type may be selected by the user, and it protects against all FAILURE MODES.

\section{FREEZE-THAW FAILURE}

When cells are allowed to cool after charge-discharge cycle, and later are re-heated to operating temperature, this is called a FREEZE-THAW. The components of the cell undergo thermal stresses, and may fail during reheating. 


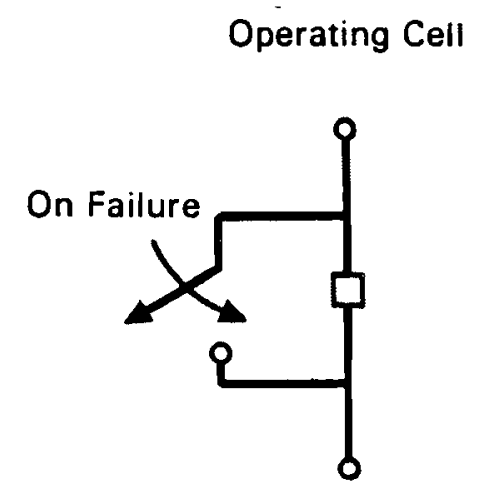

\section{Switch Closes \\ On Failure}

(a) Closed Circuit Failure Switch

\section{Operating Cell}

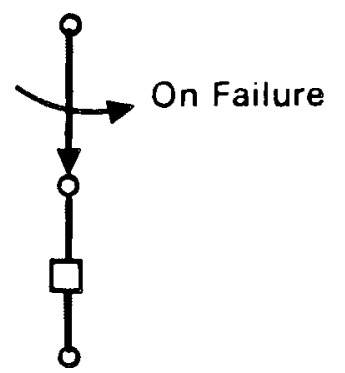

(b) Open Circuit Failure Switch

FIGURE 2.8. Failure Switch Operation

FREEZE-THAW FAILURE RATE

The probability that an individual cell will fail during a single FREEZETHAW.

FULLY CHARGED OPEN CIRCUIT CELL VOLTAGE

See CELL VOLTAGE.

\section{FULLY CHARGED CELL CAPACITY}

A CELL PARAMETER equal to the working capacity of the cell (in amp-hours). When the default value for the LOWER ELECTROLYTE FAILURE VOLTAGE (1.78 volts) is used, the FULLY CHARGED CELL CAPACITY is equal to $95 \%$ of the THEORETICAL 
CELL CAPACITY. If the electrolyte is assumed to fail at a higher voltage than the default, the FULLY CHARGED CELL CAPACITY will be less than 95\% of the THEORETICAL CELL CAPACITY. Conversely, if the electrolyte is assumed to fail at a lower voltage than the default, the FULLY CHARGED CELL CAPACITY will be greater than $95 \%$ of the THEORETICAL CELL CAPACITY. This value is calculated in the Detailed Discharge Model.

\section{LIFE-CYCLE MODEL}

The RELY sub-model which estimates a battery's useful life based on the BATTERY CONFIGURATION, BATTERY PERFORMANCE REQUIREMENTS, and failure rates and modes. Voltages, resistances, and capacities are not considered in this submodel. The Life-Cycle Model must be executed prior to the execution of the Detailed Discharge Model.

\section{LOWER ELECTROLYTE FAILURE VOLTAGE}

See CELL VOLTAGE.

MODULE

See BATTERY.

\section{OPEN CIRCUIT FAILURE}

FAILURE MODE in which a cell acts as an open circuit after it fails.

In the Life-Cycle Model, an open circuit failure causes the entire string to fail. See Figure 2.9.

In the Detailed Discharge Model, the open circuit voltage is $V_{0}$ and the internal resistance is $R_{0}$ when the cell is operating. When a cell suffers an open circuit failure, the internal resistance is set to the OPEN CIRCUIT FAILURE RESISTANCE $\left(R_{f}\right)$. The open circuit cell voltage drops to zero $\left(V_{f}\right)$. The OPEN CIRCUIT FAILURE RESISTANCE parameter should be obtained from the user's bench-test data on the cell. See Figure 2.10. 

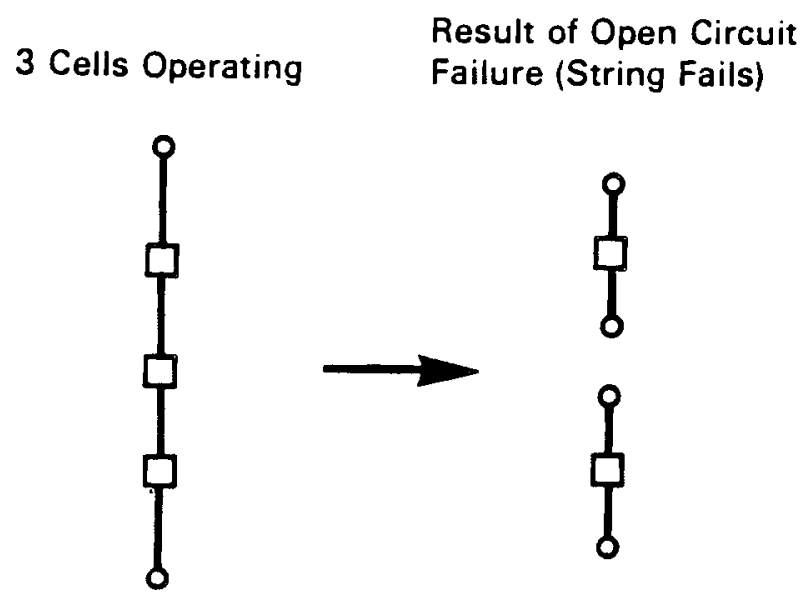

FIGURE 2.9. Open Circuit Failure in Life-Cycle Model

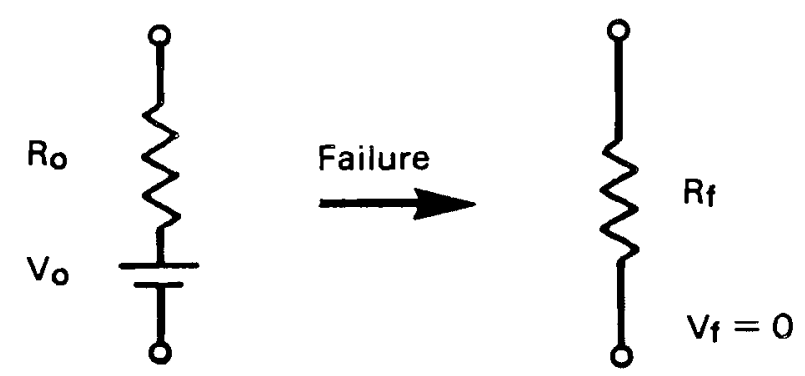

FIGURE 2.10. Open Circuit Failure in Detailed Discharge Model

OPEN CIRCUIT FAILURE RESISTANCE

A CELL PARAMETER equal to the typical resistance of a cell that has suffered an OPEN CIRCUIT FAILURE.

OVER DISCHARGE FAILURE

The FAILURE MODE of a cell if it fails due to over-discharging (also called under-voltage electrolyte failure). Specified as a CELL PARAMETER.

OVER-DISCHARGED CELL

A cell which has been discharged completely (i.e., there is no remaining charge). When this happens, the cell fails. See CELL VOLTAGE. 
OVER-VOLTAGE FAILED CELL

A cell which has received a voltage greater than the UPPER ELECTROLYTE FAILURE VOLTAGE. When this happens, the cell fails.

OVER-VOLTAGE FAILURE

A CELL PARAMETER which is the FAILURE MODE of a cell if it fails due to an over-voltage.

POST-FAILURE RESISTANCE

In the Life-Cycle Model, another term for the FAILURE MODE.

In the Detailed Discharge Model, open and closed circuit failure modes are treated individually. See OPEN CIRCUIT FAILURE and CLOSED CIRCUIT FAILURE.

RELY.OUT

Output file created by the Life-Cycle Model which contains results of the simulation. Created only if the user selects "F" when asked if results should be displayed on the screen or written to a disk file.

STRING

See BATTERY.

TEST CONDITIONS

Conditions which the user sets for a particular test in the Detailed Discharge Mode1. This is where "what-if" questions can be answered for various power outputs, cell connections, and failure switches.

THEORETICAL CELL CAPACITY

The user-specified CELL PARAMETER which is the capacity (in amp-hours) of a cell as it moves from 0 to $100 \% \mathrm{Na}_{2} \mathrm{~S}_{3}$. 


\section{TIME INCREMENT}

The time increment for the DETAILED DISCHARGE calculations. Since all parameters are constant for this discrete interval, small intervals will give more accurate results. Appears in TEST CONDITIONS menu.

UNDER-VOLTAGE FAILURE

SEe OVER-DISCHARGE FAILURE.

UPPER ELECTROLYTE FAILURE VOLTAGE

A CELL PARAMETER equal to the maximum voltage a cell can withstand before electrolyte failure.

WEAROUT FAILURE (also called CELL-AGING FAILURE)

Failure to a cell caused by a natural, random wearout (as opposed to a FREEZE-THAW FAILURE). These types of failures are assumed to follow a WEIBULL DISTRIBUTION.

WEIBULL DISTRIBUTION

The statistical distribution which models WEAROUT FAILURES. The Weibull distribution is often used to model natural, random failures in reliability studies.

WEIBULL LOCATION PARAMETER

The minimum possible life of a cell. See Appendix A.

WEIBULL SCALE PARAMETER

The characteristic life of a cell. See Appendix A. 
WEIBULL SHAPE PARAMETER

The parameter which controls the shape of the distribution. The failure rate decreases, increases, or remains constant over time if this value is less than one, greater than one, or equal to one, respectively. See Appendix A. 


\subsection{EXAMPLE APPLICATIONS}

The suggested sequence for using the RELY package is shown in Figure 3.1. The purpose of the Life-Cycle Model is to approximate battery life based on specified cell parameters and failure rates. This estimate can be verified by the use of the Detailed Discharge Model. In this manner, an estimate of battery life can be obtained without a time-consuming detailed performance simulation of each discharge cycle.

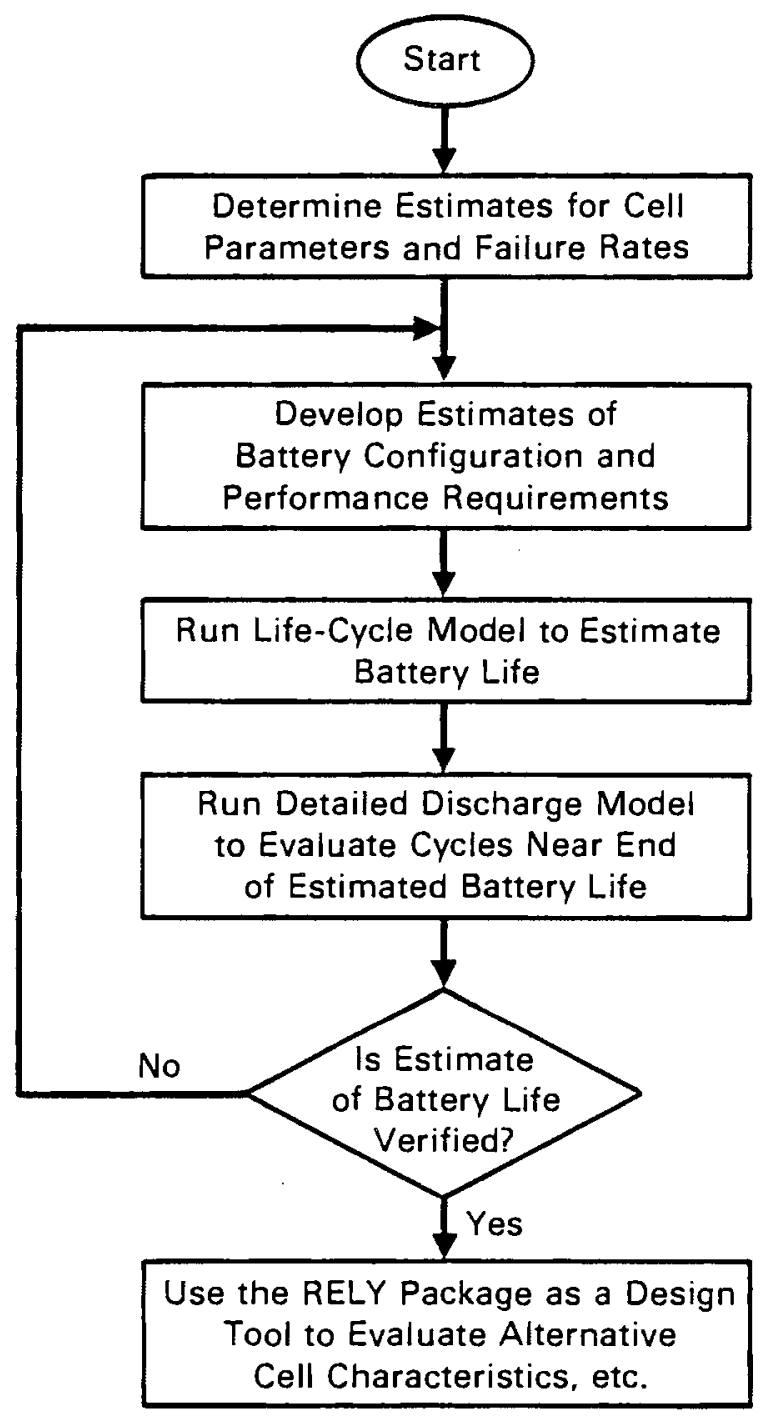

FIGURE 3.1. Suggested Use of the RELY Software Package 
Before running the Life-Cycle Model and after determining battery cell parameters, the user specifies the battery configuration, minimum performance requirements, and failure rates. Failure rates can be determined from benchtest data using the approach presented in Appendix $A$ and the failure distribution example menu selection. Failure rates are required for both freeze-thaw cell failures and cell failures due to wearout.

The Life-Cycle Model is then executed to determine an estimate of battery life. To verify the estimate of battery life, the Detailed Discharge Model can be used to simulate specific cycles near the end of expected battery life. For example, if the Life-Cycle Model estimates battery life to be 1,000 cycles, the Detailed Discharge Model could be used to simulate cycle 1,000 to determine if detailed performance requirements were being met. If not, the general performance requirements specified in the Life-Cycle Model need to be more restrictive. If performance requirements are easily being met at the end of the estimated cycle life, the Life-Cycle Model's performance requirements may be too restrictive. This process is repeated until the Life-Cycle Model accurately predicts battery life.

An example application of the Life-Cycle Model illustrating its input and output screens is presented in Section 3.1. An example use of the Detailed Discharge Model illustrating its input and output screens is presented in Section 3.2. The Cell Failure Distribution Model is presented in Section 3.3.

\subsection{THE LIFE-CYCLE MODEL}

The Life-Cycle Model performs independent Monte Carlo simulations of battery discharge cycles for user-defined battery configurations. In each simulation, the model predicts stochastic cell failures for two independent types of failure modes: freeze-thaw and cell wearout. Each simulation continues until the number of working cells, strings, and modules in the battery configuration falls below minimum user-defined failure criteria (i.e., until the battery fails).

Freeze-thaw conditions are simulated whenever the battery is allowed to cool and then reheat. The model generates uniformly distributed pseudorandom numbers to determine whether or not a cell has failed due to freeze-thaw. Both 
the freeze-thaw failure rate and the number of cycles between each cooling and reheating of the battery are specified by the user.

Wearout failure refers to cells randomly failing. The model generates Weibul1-distributed pseudorandom numbers to predict the cycle in which a cell will fail due to wearout.

If a cell fails before the end of a simulation run (i.e., before the battery fails), its failure mode, the cycle in which the failure occurred, and the location of the failed cell are stored in internal arrays. The cell failure information from the last simulation run is written to a disk file for subsequent use by the Detailed Discharge Model when the user selects the Detailed Discharge option on the main menu.

Statistics are obtained from the independent Monte Carlo simulations to provide estimates of the means and standard deviations of the number of cycles before the battery fails, the number of freeze-thaw failures, and the number of wearout failures. You are given the option to display the statistics on the computer screen or request that they be written to a disk file at the end of the simulation runs.

The input and output screens for the Life-Cycle Model obtained by selecting Options $A, B$, and $C$ in the Main Menu are described below.

\section{Main Menu Option A}

When you select option $A$ in the Main Menu, the program displays the input screen for the Life-Cycle Model labeled "Battery Test Configuration" (Figure $3.2)$. This screen prompts you to enter values for three input parameters for defining the battery configuration to be tested:

1. Number of cells in each string

2. Number of parallel strings in each module.

3. Number of modules in a series.

The arrangement of the cells, strings, and modules in the example battery configuration is shown in Figure 3.3. RELY allows up to 20 cells per string, 20 strings per module, and 20 modules per battery. When you are satisfied with the definition of the battery test configuration, enter $Y$ or $y$ for "yes" when queried on whether the input values on this screen are correct, and press 


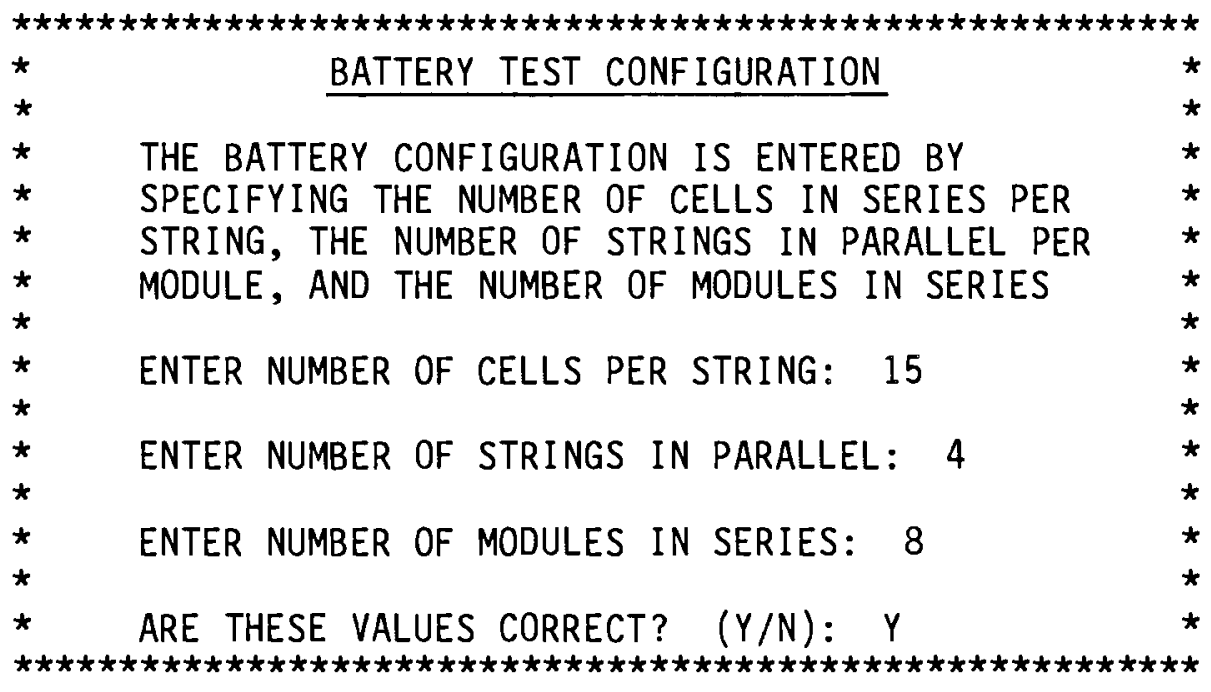

FIGURE 3.2. Input Screen for Battery Test Configuration in Life-Cycle Model

$\langle$ RETURN>. The program will then display the next input screen for the LifeCycle Model labeled "Performance Requirements".

The input screen labeled "Performance Requirements" is shown in Figure 3.4. This screen asks you to specify the battery's minimum performance requirements in terms of string, module, and battery requirements. These requirements indicate the number of sub-units that must be operating for the larger unit to remain in operation. For example, if cell failures reduce the number of operating cells below the string requirement, the string is no longer operable. The input performance parameters are as follows:

1. Minimum number of good cells required in each operating string

2. Minimum number of good strings required in each operating module

3. Minimum number of good modules required for minimum battery capacity. When you are satisfied with the definition of the battery performance requirements, enter $Y$ or $y$ for "yes" when queried on whether the input values on this screen are correct, and press <RETURN>. The program will then return you to the Main Menu for selection of Option B.

Main Menu Option B

When you select Option B in the Main Menu, the program displays the input screen for the Life-Cycle Model labeled "Freeze-Thaw Failures". The screen is 


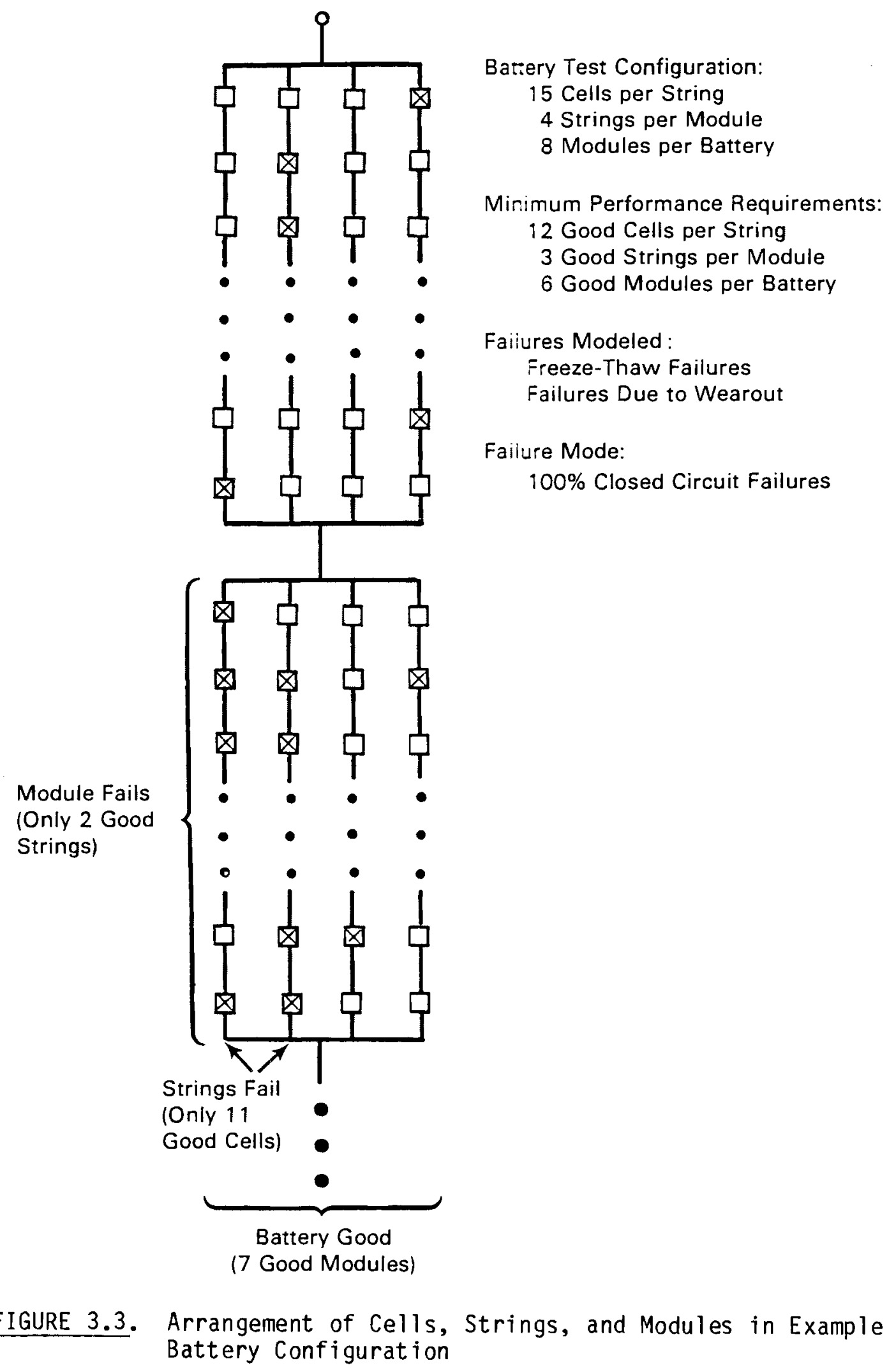




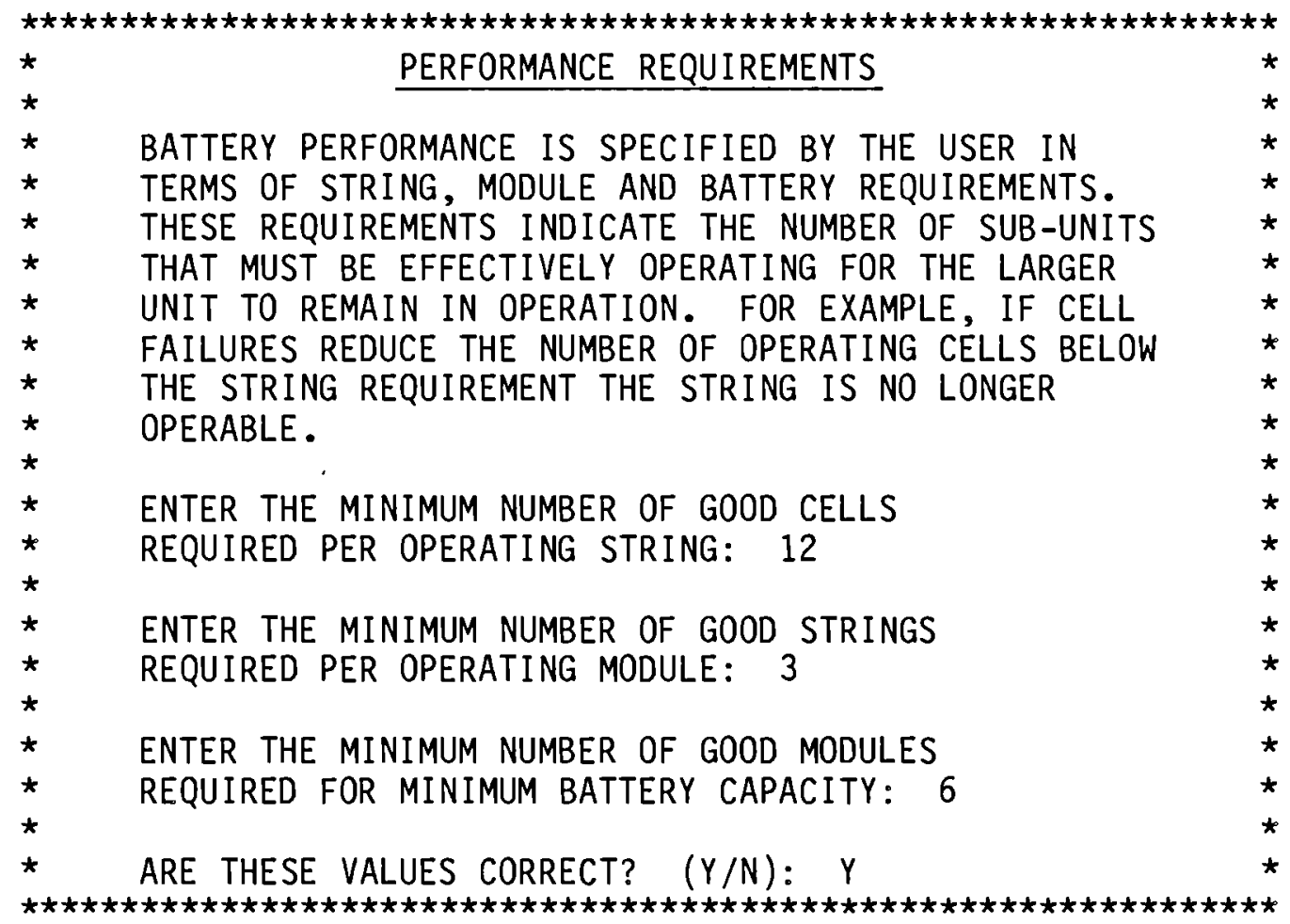

FIGURE 3.4. Input Screen for Performance Requirements in Life-Cycle Model

shown in Figure 3.5. This screen prompts you to enter values used for predicting freeze-thaw failures of sodium-sulfur cells and to specify the percentage of each type of post-failure resistance for cells that fail due to freezethaw. These types of failures result from stress cracking in the beta alumina electrolyte when the battery is allowed to cool and is then reheated. A certain percentage of the cells can be expected to fail during each freeze-thaw occurrence to which the battery is subjected. The first charge-discharge cycle is assumed to be a freeze-thaw.

The input parameters required to predict freeze-thaw failures and specify the percentage of each type of post-failure resistance of the failed cells are as follows:

1. Expected number of battery charge-discharge cycles between each freeze-thaw occurrence to which the battery is subjected.

2. Freeze-thaw failure rate, expressed as the probability of an individual cell failing during a freeze-thaw. 


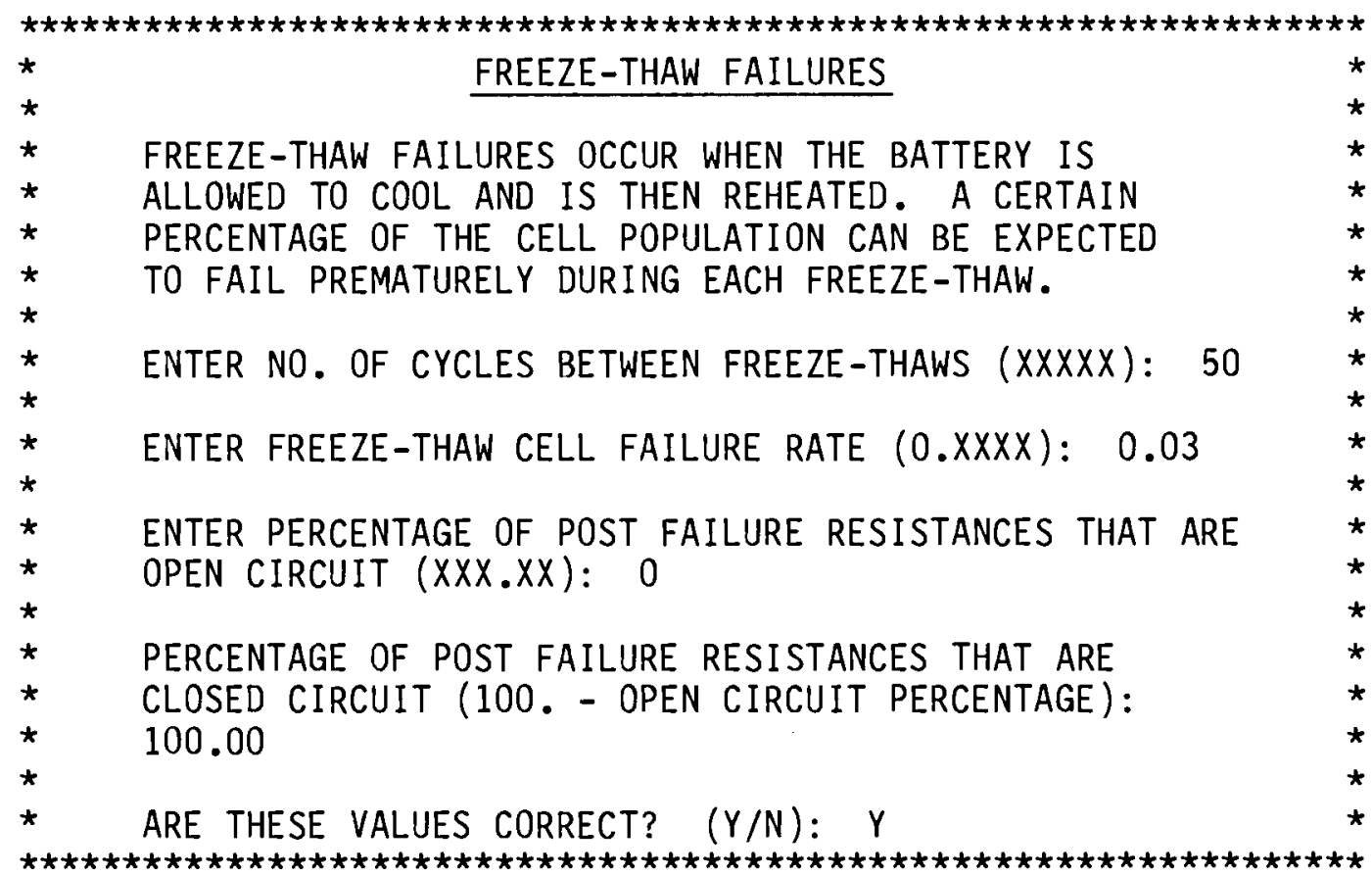

FIGURE 3.5. Input Screen for Freeze-Thaw Failures in Life-Cycle Model

3. Percentage of post failure resistances due to freeze-thaw that are open circuit; the percentage of post failure resistances due to freeze-thaw that are closed circuit are calculated as $100 \%$ minus the open circuit failure percentage.

Remember, that in the Life-Cycle Model when there is an open circuit failure, the cell is assumed to have an infinite post failure resistance and the entire string fails. Thus, in the Life-Cycle Model only the percentage of cells that would fail and effectively remove a string from service should be labeled as open circuit failures. In addition, when a cell fails, its initial post failure resistance may be much lower than it will be many cycles later. Thus, to get the most accurate estimate of battery life, the percentage of open and closed circuit failures used in the Life-Cycle Model should represent the expected failure distribution at the end of the battery life for this type of failure. Finally, if the failure switches are going to be used in the Detailed Discharge Model, the post failure resistance in the Life-Cycle Model should be set to $100 \%$ for the type of failure switch (either closed or open). 
When you are satisfied with the values you have entered for characterizing freeze-thaw failures, enter $Y$ or $y$ for "yes" when queried on whether the input values on this screen are correct, and press <RETURN>. The program will then display the next input screen for the Life-Cycle Model labeled "Failures Due to Wearout".

The input screen labeled "Failures Due to Wearout" is shown in Figure 3.6. This screen prompts you to enter values for predicting cell failures due to cells reaching their natural end of life (wearout) and to specify the type of post-failure resistance for cells that fail due to wearout. Cell wearout failures result from degradation due to normal charge-discharge cycling of the battery. The Weibull distribution is used to model stochastic cell failures due to wearout. The input parameters on this screen are as follows:

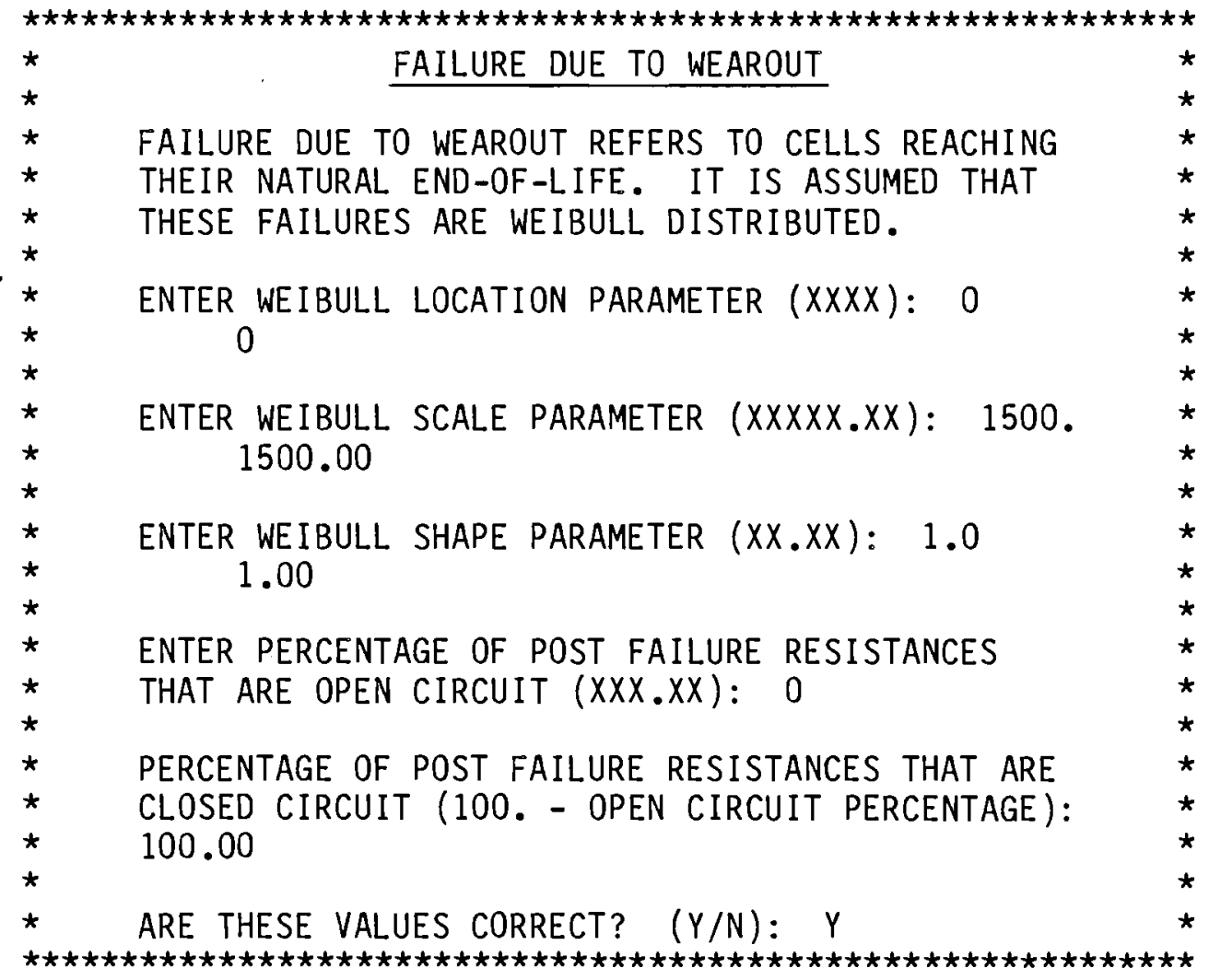

FIGURE 3.6. Input Screen for Failures Due to Wearout in Life-Cycle Model 
1. Weibull location parameter

2. Weibull scale parameter

3. Weibul1 shape parameter

4. Percentage of post failure resistances due to wearout that are open circuit; the percentage of post failure resistances due to wearout that are closed circuit are calculated as $100 \%$ minus the open circuit failure percentage.

Remember, that in the Life-Cycle Model when there is an open circuit failure, the cell is assumed to have an infinite post failure resistance and the entire string fails. Thus, in the Life-Cycle Model only the percentage of cells that would fail and effectively remove a string from service should be labeled as open circuit failures. In addition, when a cell fails, its initial post failure resistance may be much lower than it will be many cycles later. Thus, to get the most accurate estimate of battery life, the percentage of open and closed circuit failures used in the Life-Cycle Model should represent the expected failure distribution at the end of the battery life for this type of failure. Finally, if the failure switches are going to be used in the Detailed Discharge Model, the post failure resistance in the Life-Cycle Model should be set to $100 \%$ for the type of failure switch (either closed or open).

Definitions of the Weibull input parameters are given in the description of the Cell Failure Distribution Model in Section 3.3 and in Appendix $A$. When you are satisfied with the values you have entered for characterizing cell wearout failures, enter $Y$ or $y$ for "yes" when queried on whether the input values on this screen are correct, and press 〈RETURN>. The program will then return you to the Main Menu for selection of Option $C$.

\section{Main Menu Option C}

Option $C$ in the Main Menu is selected to execute the Life-Cycle Model once all input parameters have been defined using Options $A$ and $B$. When you select Option $C$, you are first asked to specify the number of independent Monte Carlo simulation runs you want the Life-Cycle Model to perform. Next, you are asked if the value you have entered for the number of simulation runs is correct. Finally, you are asked if the simulation output should be sent to a file or the 
screen, indicated by entering $F$ or $S$, respectively. After you have entered one of these values, press <RETURN> to execute the Life-Cycle Model.

If you entered $F$, the program will write the simulation output to the file RELY.OUT. If you entered $S$, the program will write the simulation output to the screen. Following the simulation output, you are asked if you want to execute the Life-Cycle Model again with the same input data, but using a different set of pseudorandom numbers. When you are finished with the Life-Cycle Model, enter $\mathrm{N}$ or $\mathrm{n}$ for "no" when asked if you want to repeat this process for the same initial data and press <RETURN>. The program will then return you to the Main Menu for selection of Option D.

\section{Output Screen}

If you selected to display the simulation output on the screen, the output screen shown in Figure 3.7 is displayed. If you opted to write the output to the file RELY.OUT, you can view the contents of the file after you are finished with the program and have selected Option $F$ to return to the computer operating system.

The output from the Life-Cycle Model shown in Figure 3.7 first echoes the values you entered for the input parameters in Options $A$ and $B$. Next, the output shows the number of charge-discharge cycles before the battery failed, the open, closed, and total freeze-thaw cell failures, and the open, closed, and total wearout cell failures in each Monte Carlo simulation. This is followed by statistical estimates of the means and sample standard deviations of these items. Finally, tabular histograms that are 50 cycles wide show the open, closed, and total freeze-thaw cell failures, and the open, closed, and total wearout cell failures in each histogram cell.

\subsection{DETAILED DISCHARGE MODEL}

The Detailed Discharge Model simulates a sodium-sulfur battery discharge cycle for the battery configuration, cell parameters, and test conditions input by the user. The stochastic cell failures and number of charge-discharge cycles the battery can perform before it fails are obtained from the last simulation run performed by the Life-Cycle Model. Any discharge cycle from the 


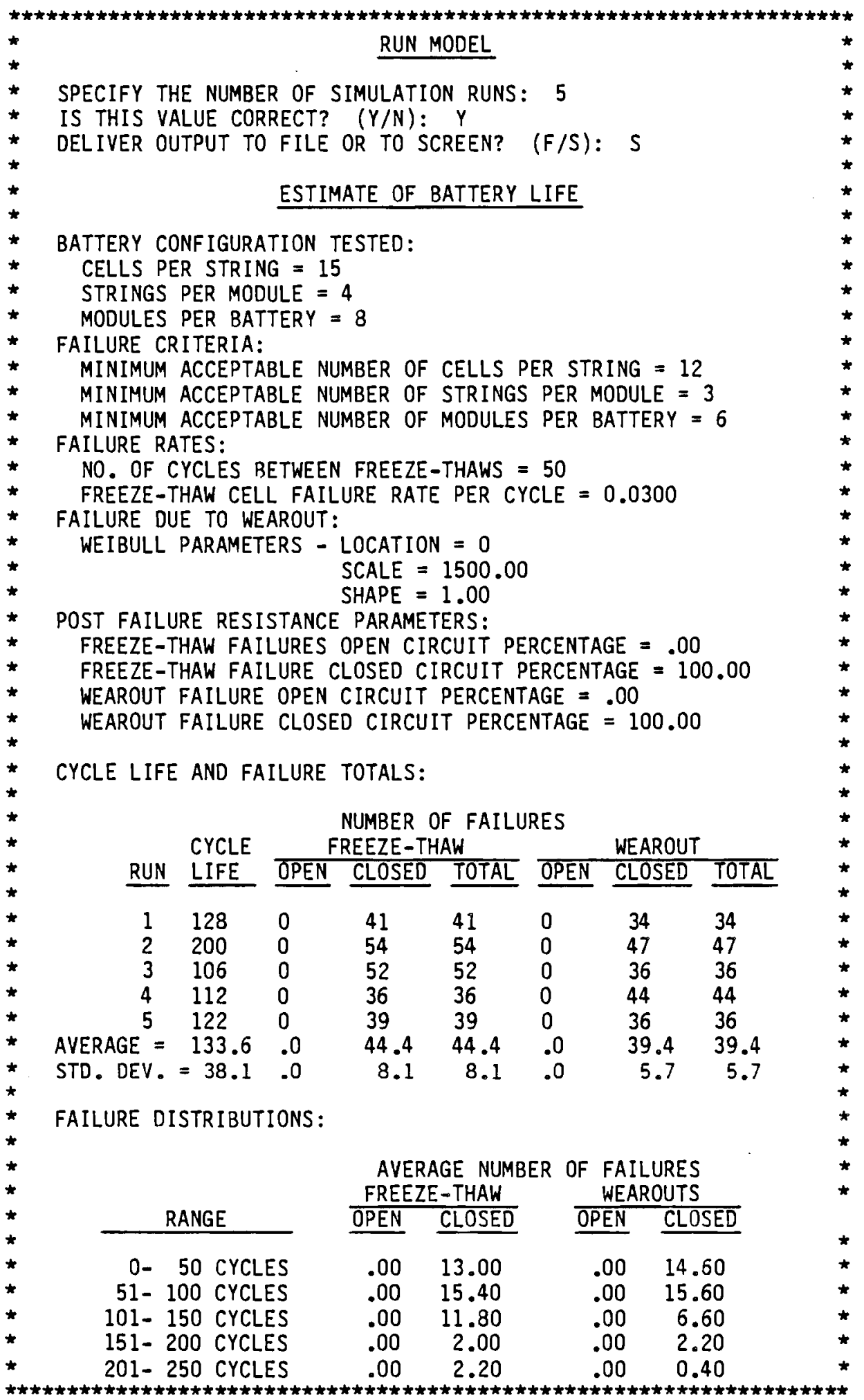

FIGURE 3.7. Output Screen from Life-Cycle Mode1 
first cycle to the last cycle before the battery failed in the last simulation run of the Life-Cycle Model can be simulated.

The Detailed Discharge Model calculates the output voltage in user-defined time increments from an individual cell based upon the current, internal resistance, and depth-of-discharge of the cell. This information is combined with the configuration of cells, strings of cells, and modules specified for the battery to calculate the current flows, resistances, and output voltages across the strings, modules, and battery for each time increment. The calculations account for the failed cells (cumulative number, location and failure modes) predicted for the user-specified discharge cycle by the last simulation run performed by the Life-Cycle Model. The discharge simulation continues until the discharge duration specified for the battery is exceeded or until the battery can no longer deliver the constant discharge current specified in the test conditions.

The simulation results are both tabularly displayed on the computer screen and written to a disk file called BAT2A.OUT. The results can also be displayed graphically on the computer screen. Nine system performance measures are output as a function of discharge duration at the user-defined time increments to summarize the battery's performance: total voltage, average module voltage, battery power, average voltage of working cells, minimum voltage of working cells, average capacity of working cells, average resistance of all cells, the number of under-voltage electrolyte cell failures, and the number of overvoltage electrolyte cell failures.

The input and output screens for the Detailed Discharge Model obtained by selecting Option $D$ in the Main Menu are described below.

Main Menu Option D

Option $D$ in the Main Menu is selected to execute the Detailed Discharge model after Options $A, B$, and $C$ have been selected to execute the Life-Cycle Model. When you select Option D, the program displays the Main Menu for the Detailed Discharge Model shown in Figure 3.8 .

If you select Option 1 in the Main Menu, the program displays the input screen shown in Figure 3.9. This screen allows you to select three editing 


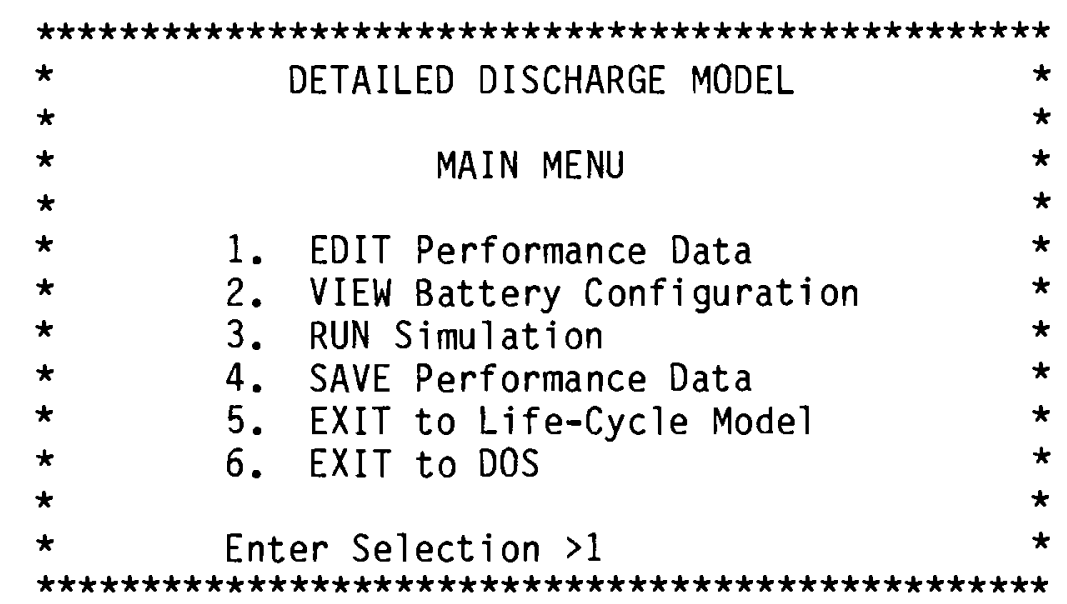

FIGURE 3.8. Main Menu for Detailed Discharge Model

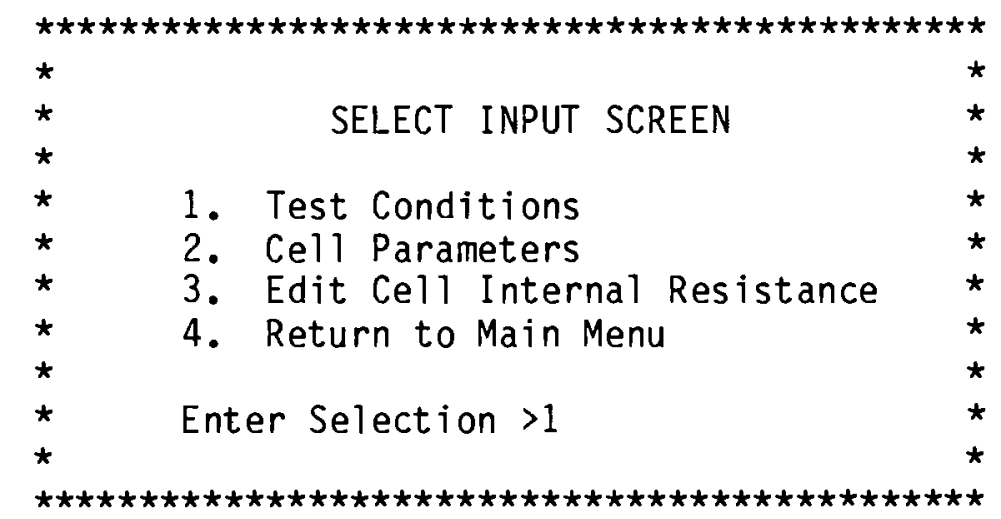

FIGURE 3.9. Input Screen to Select Editing Screens for Detailed Discharge Model

screens to view/change the input data to be used for the Detailed Discharge Model in simulating the discharge performance of the battery. The three editing screens are shown in Figure 3.10 .

The first two editing screens (the second screen is in two parts) display the parameter values for the battery test conditions and cell characteristics. The parameters defining the test conditions and cell characteristics were described in Section 2.2. The third editing screen displays a table of values showing the internal resistance of a operational cell as a function of its theoretical capacity (as defined in Section 2.2). The first resistance value listed in the table is for $95 \%$ of theoretical capacity. The Detailed 


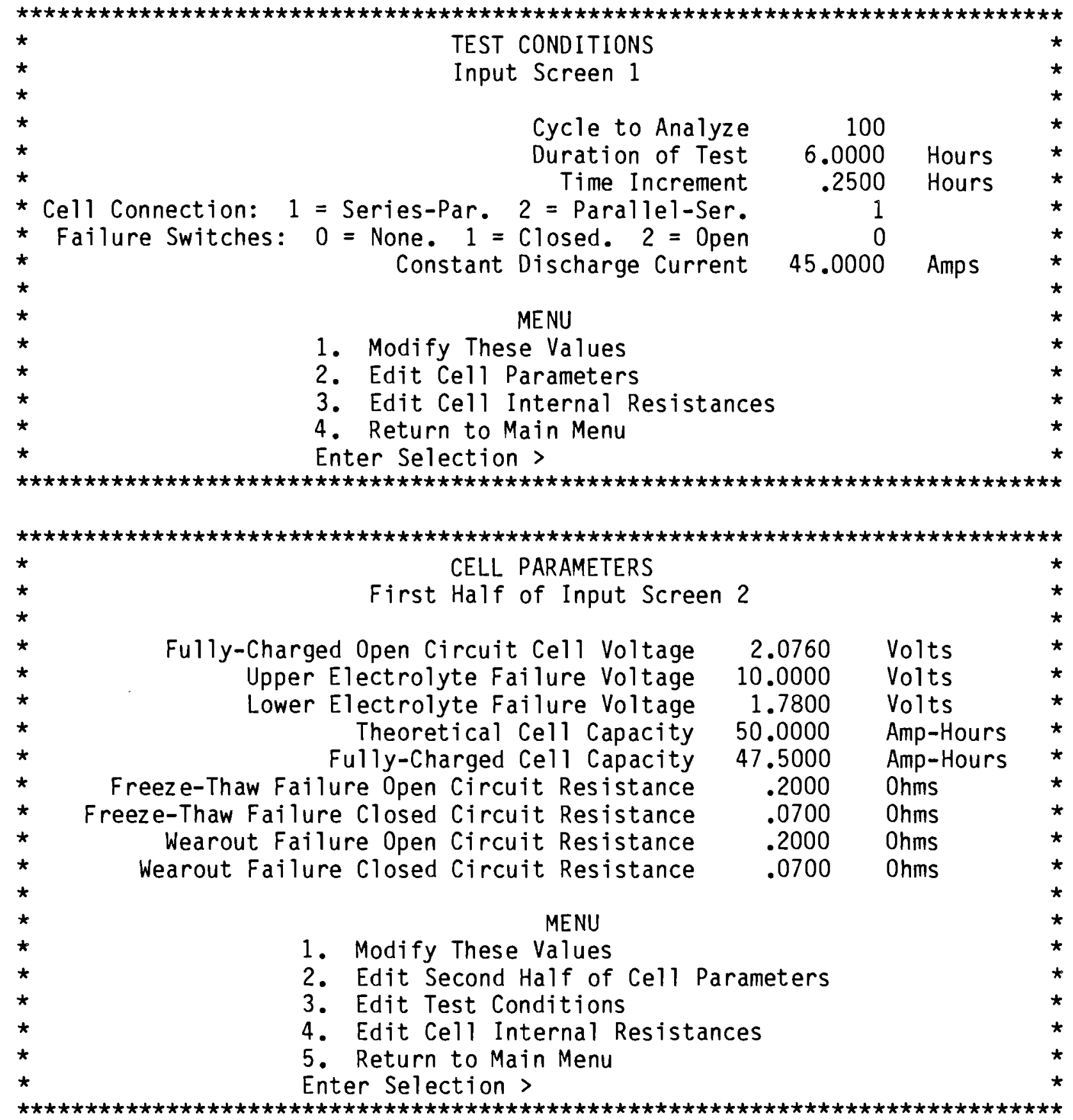

FIGURE 3.10. Input Screens for Editing Battery Performance Data in Detailed Discharge Model 


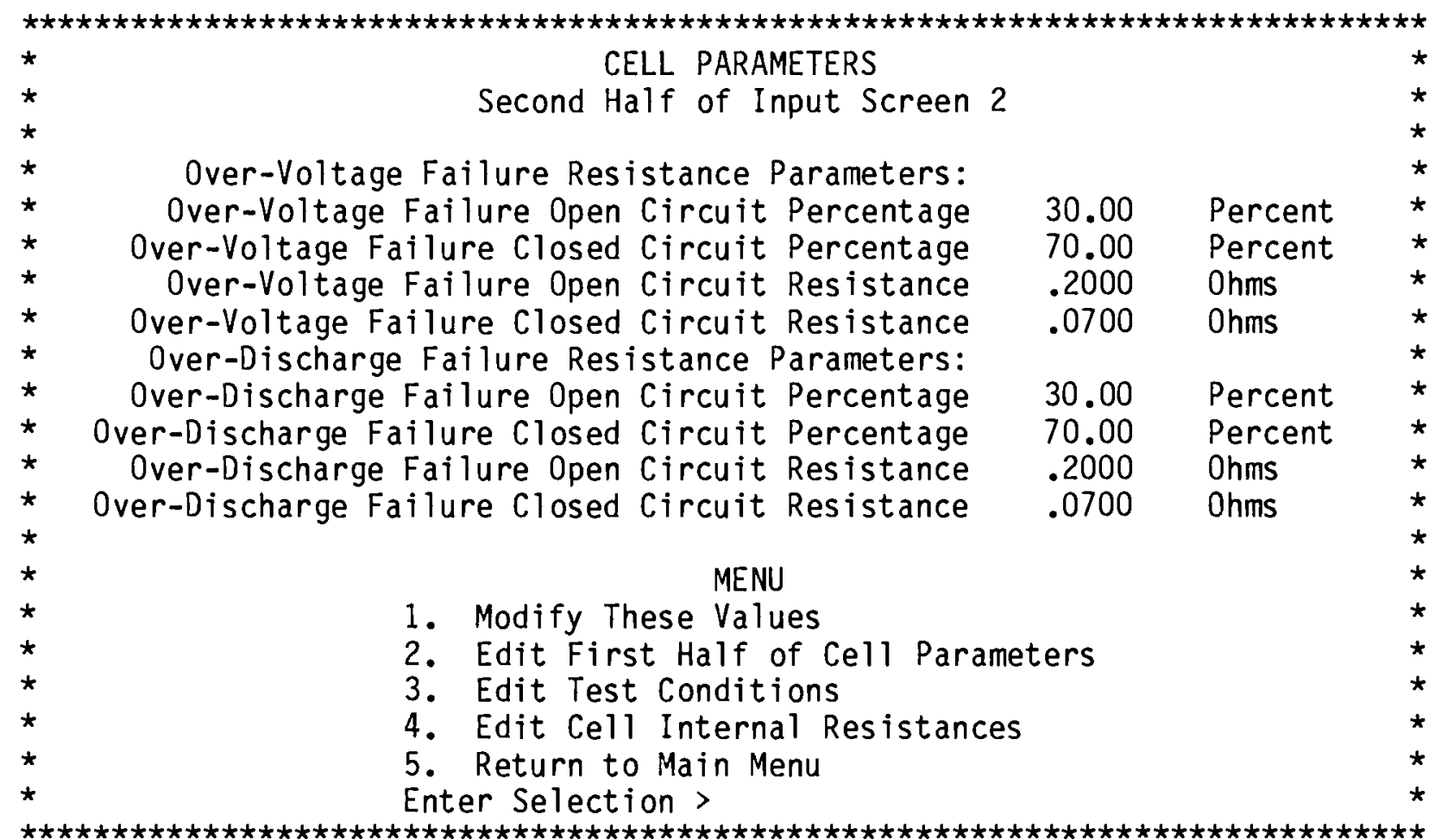

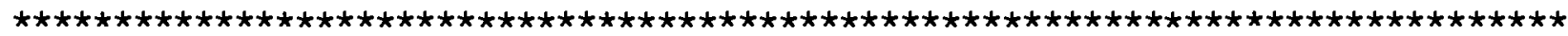

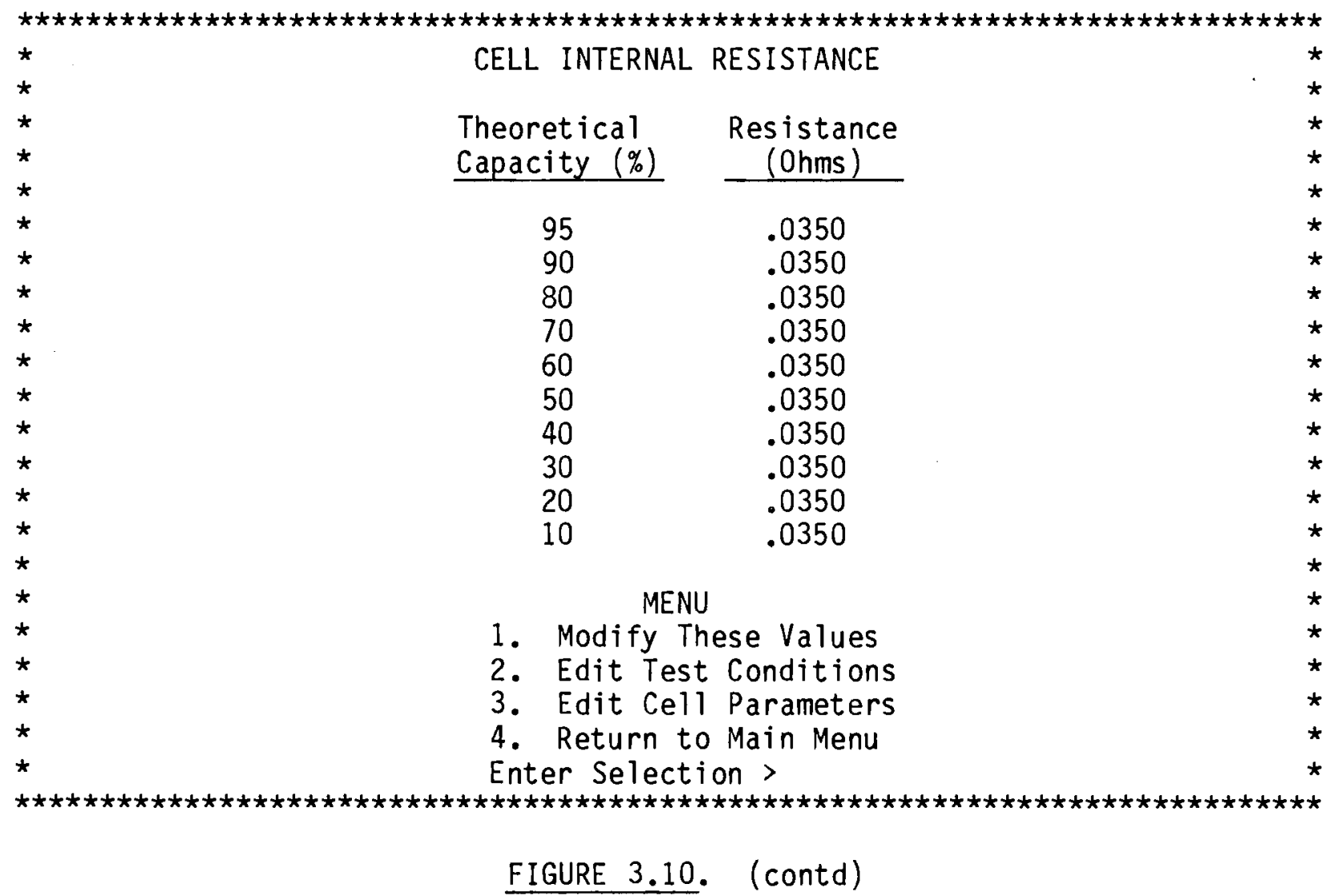


Discharge Model assumes that charging a cell above this value is impractical or impossible since the internal resistance rises so quickly for greater levels of charge. For cell capacities between 95 and $10 \%$ of theoretical the model interpolates between the values listed in the table. For capacities less than $10 \%$ of theoretical the $10 \%$ value is used.

The menus displayed on each of the editing screens allow you to either change the parameter values, switch to another editing screen, or return to the Main Menu shown in Figure 3.8. If you elect to change the parameter values displayed on an editing screen, the program positions the cursor to the first parameter value displayed on the editing screen. You can either enter a new value for the parameter and press 〈RETURN>, or simply press 〈RETURN> if you don't want to change the current parameter value. The program then displays the resulting parameter value and moves the cursor down to the next parameter value, and so forth.

If you select 0ption 2 in the Main Menu, the program displays the battery configuration screen shown in Figure 3.11. The parameter values defining the battery configuration were previously input by selecting option A for the LifeCycle Model in the Main Menu shown in Figure 2.1. Except for changing the cell connections from series-parallel to parallel-series, the battery configuration can only be changed by returning to the Life-Cycle Model (Option 5 in Figure 3.8 ) and re-executing that model. When the parallel-series cell connection option is selected in the Detailed Discharge Model the Life-Cycle Model results may no longer provide a reasonable estimate of battery life. This could occur if there had been open circuit failures in the Life-Cycle Model because they

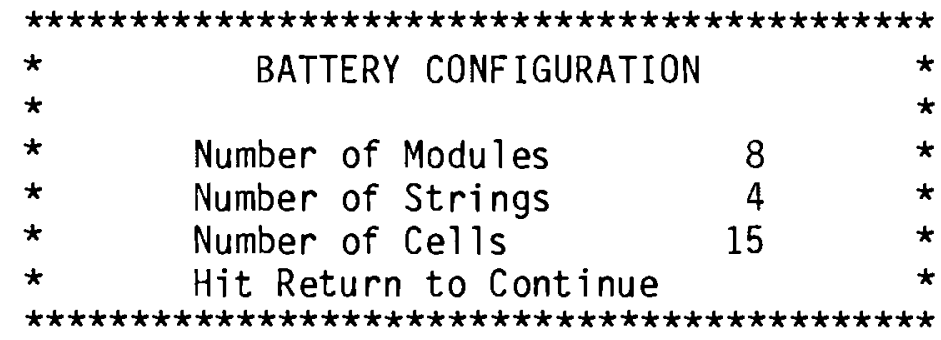

FIGURE 3.11. Screen Display of Battery Configuration for Detailed Discharge Model 
remove the entire string whereas they remove only the effected cell in a parallel-series configuration. To more accurately model a parallel-series arrangement in the Life-Cycle Model set the string length to 1 .

The parameter values initially shown for the test conditions, cell characteristics, and cell internal resistances when you execute the software package for the first time are default values set internally in the program by FORTRAN DATA statements. If you select Option 4 in the Main Menu after you have changed the parameter values, the program saves the new values by writing them to a disk file named BAT2A.\$DF. Thereafter, whenever you run the Detailed Discharge Mode1, regardless of whether you have returned to the DOS operating system, the program first reads the parameter values from the BAT2A.\$DF disk file. You can still change these parameter values if you wish by using the three editing screens shown in Figure 3.10 before running the simulation of the battery's discharge (Option 3 in Figure 3.8 ).

The Detailed Discharge Model allows the user to specify two post failure resistances (closed and open circuit failures), and the probability of each, for both over- and under-voltage failures. Typically over-discharge failure resistances can range from only slightly higher than normal resistance (not a severe over-discharge) to a resistance greater than an order of magnitude higher (severe over-discharge). While there is not detailed information avai1able on the distribution of the post failure resistances the distribution can be modeled by the user as bi-modal. Since these resistances tend to change over time the user should specify the resistances and probabilities such that the distribution of open and closed circuit failure resistances reflect the final resistance profile at battery failure. If slightly different resistances are used for each type of failure, this will help in identifying type of failure in the table of cells when analyzing the Detailed Discharge Model results.

Recall that you can analyze any discharge cycle from the first cycle to the last cycle before the battery failed in the last simulation run of the Life-Cycle Mode1. Using the sample output from the last simulation run of the Life-Cycle Model shown in Figure 3.7, any discharge cycle from 1 to 122 can be 
analyzed. For the purpose of illustrating the sample output from the Detailed Discharge Model, the 100th discharge cycle was selected, as shown by the first input screen in Figure 3.10 .

When you are satisfied with the parameter values displayed on the three editing screens, select Option 3 in the Main Menu shown in Figure 3.8 to run the simulation of the battery's discharge.

\section{Output Screens}

Once you have selected to run the simulation, the program will display the flashing message "Calculating Battery Discharge at Time $=X . X X X$ " on the screen. When the simulation is finished, the program will display the output screen shown in Figure 3.12. The results shown on this screen were generated by running the Detailed Discharge Model with the input data sets shown in Figures 3.10 and 3.11. The same information displayed on this screen is also written to a disk file BAT2A.0UT. You can view the contents of this file after you are finished with the program and have returned to the computer operating system.

The output screen first echoes the parameter values you selected for defining the battery configuration, test conditions, and cell characteristics. Next, the output screen displays a table of nine system performance measures calculated at the user-defined time increments during the battery's discharge to summarize the battery's performance. These are:

1. Total battery voltage

2. Average module voltage

3. Battery output power in kilowatts

4. Average voltage of working cells

5. Minimum voltage of working cells

6. Average capacity of working cells in amp-hours

7. Average resistance of all cells in ohms

8. Number of under-voltage electrolyte cell failures

9. Number of over-voltage electrolyte cell failures. 


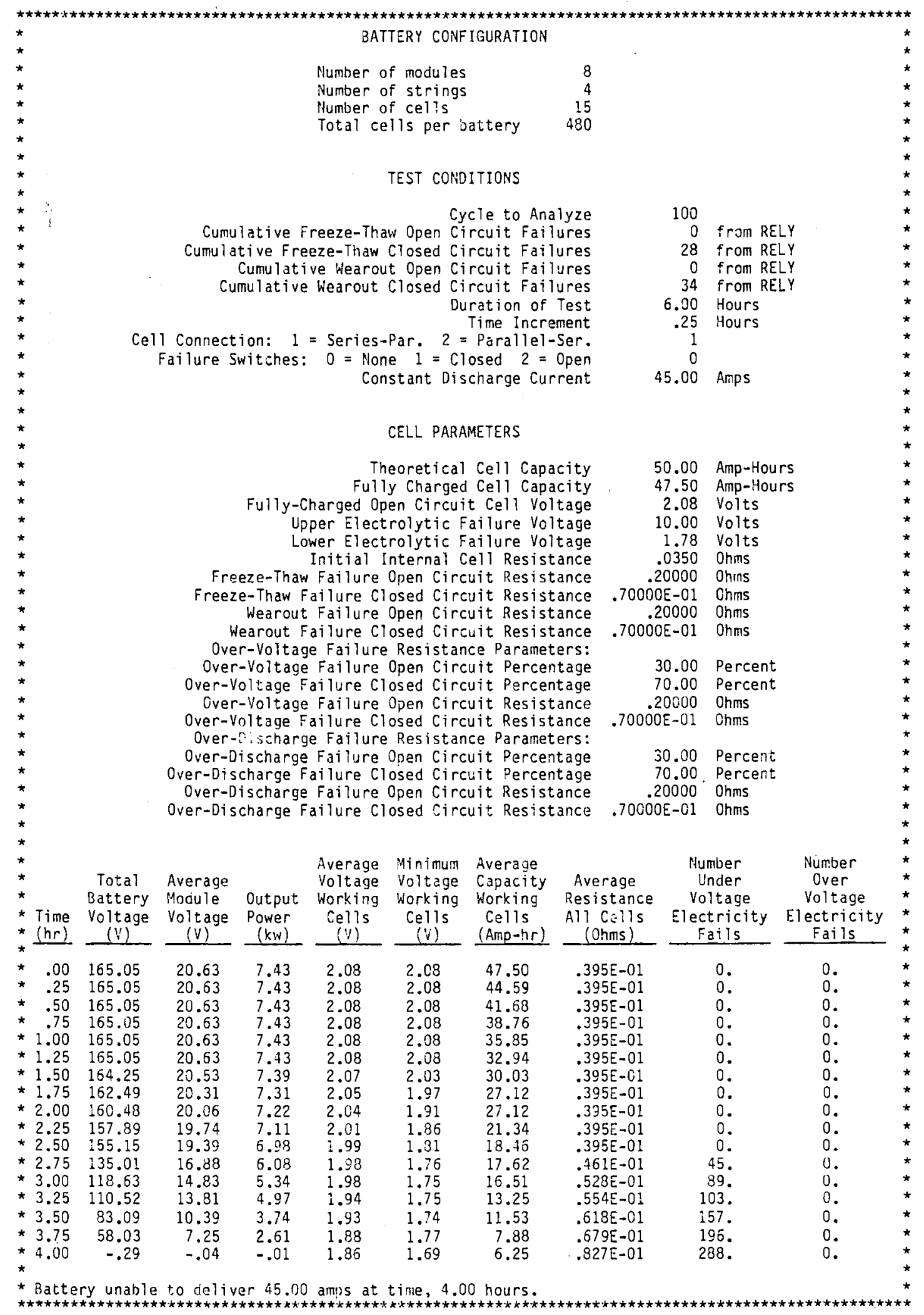

FIGURE 3.12. Output Screen from Detailed Discharge Model 
The simulation stops when the user-specified discharge duration is exceeded or when the battery is fully discharged.

Following the simulation output, the program displays the Analysis Menu shown in Figure 3.13. This menu allows you to display graphs of the simulation results (Option 1), display a table showing the status of the cells (Option 2), or return to the Main Menu for the Detailed Discharge Model (Option 3) shown in Figure 3.8 .

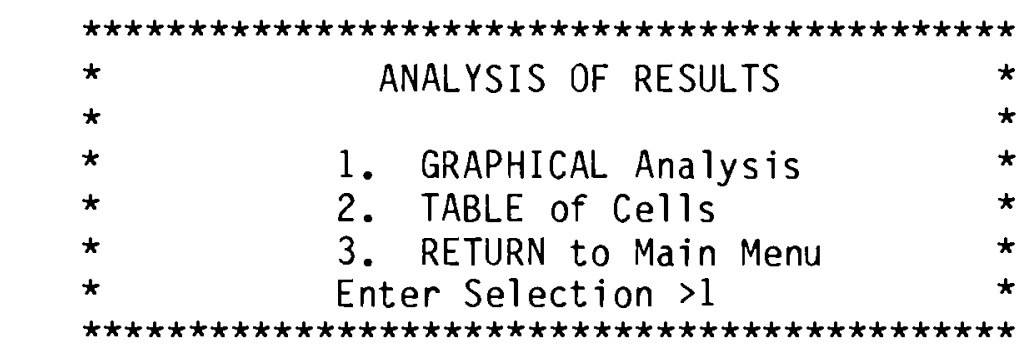

FIGURE 3.13. Input Screen for Analysis of Results

from Detailed Discharge Mode1

If you select Option 1, the program displays the Graphics Menu shown in Figure 3.14. This menu allows you to display graphs of the following system performance measures versus discharge time:

1. Total battery voltage

2. Average module voltage

3. Battery power.

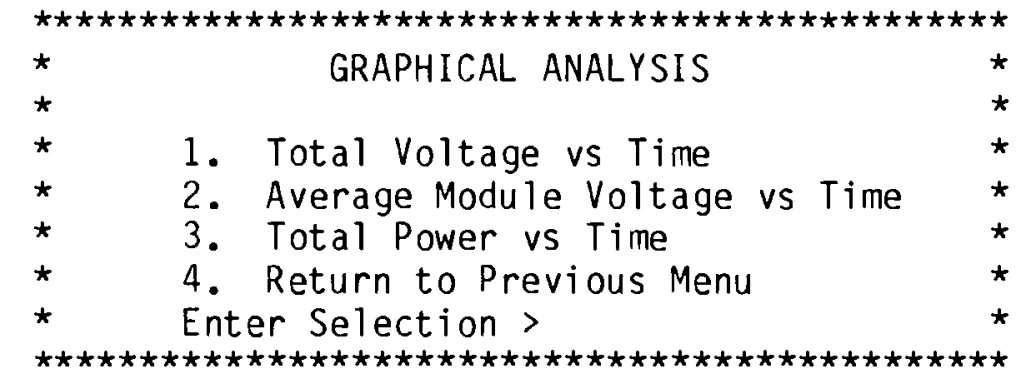

FIGURE 3.14. Input Screen for Graphics Output from Detailed Discharge Model 
The three graphs resulting from the simulation of the example data set used in Figures 3.10 and 3.11 are shown in Figure 3.15 .

If you select Option 2 in Figure 3.13, the program displays a table of the status of the cells at the time the battery failed or exceeded the userspecified discharge duration. Figure 3.16 shows a partial table of the status of the cells when the battery failed after discharging 4.0 hours during the 100th discharge cycle. The cells labeled "bad" represent all failures due to freeze-thaw or wearout that occurred prior to or on the 100th discharge cycle. These failures were passed from the last simulation run of the LifeCycle Model. The cells labeled "good" that have a failed resistance value $(0.2$ or 0.07 ohms in this example) for the final cell resistance represent cells that failed during battery discharge in the 100th discharge cycle due to overdischarging.

If you select Option 3 in Figure 3.13, the program returns you to the Main Menu for the Detailed Discharge Model shown in Figure 3.8. At this point, you can change the battery performance data if you wish and rerun the Detailed Discharge Model or return to the Main Menu for the software package shown in Figure 2.1.

\subsection{CELL FAILURE DISTRIBUTION MODEL}

This section describes the graphical package that can assist the user in understanding the statistical distribution which models the stochastic failure behavior of individual sodium-sulfur cells reaching their end of life due to cell wearout. The Weibull probability distribution was selected for this purpose because of its close correlation with test results on the reliability of sodium-sulfur cells and its flexibility in representing a wide range of failure patterns.

The Cell Failure Distribution Model provides two options for generating and displaying a graph of the Weibull probability density function from a set of three Weibull input parameters: location, scale, and shape. Option A 

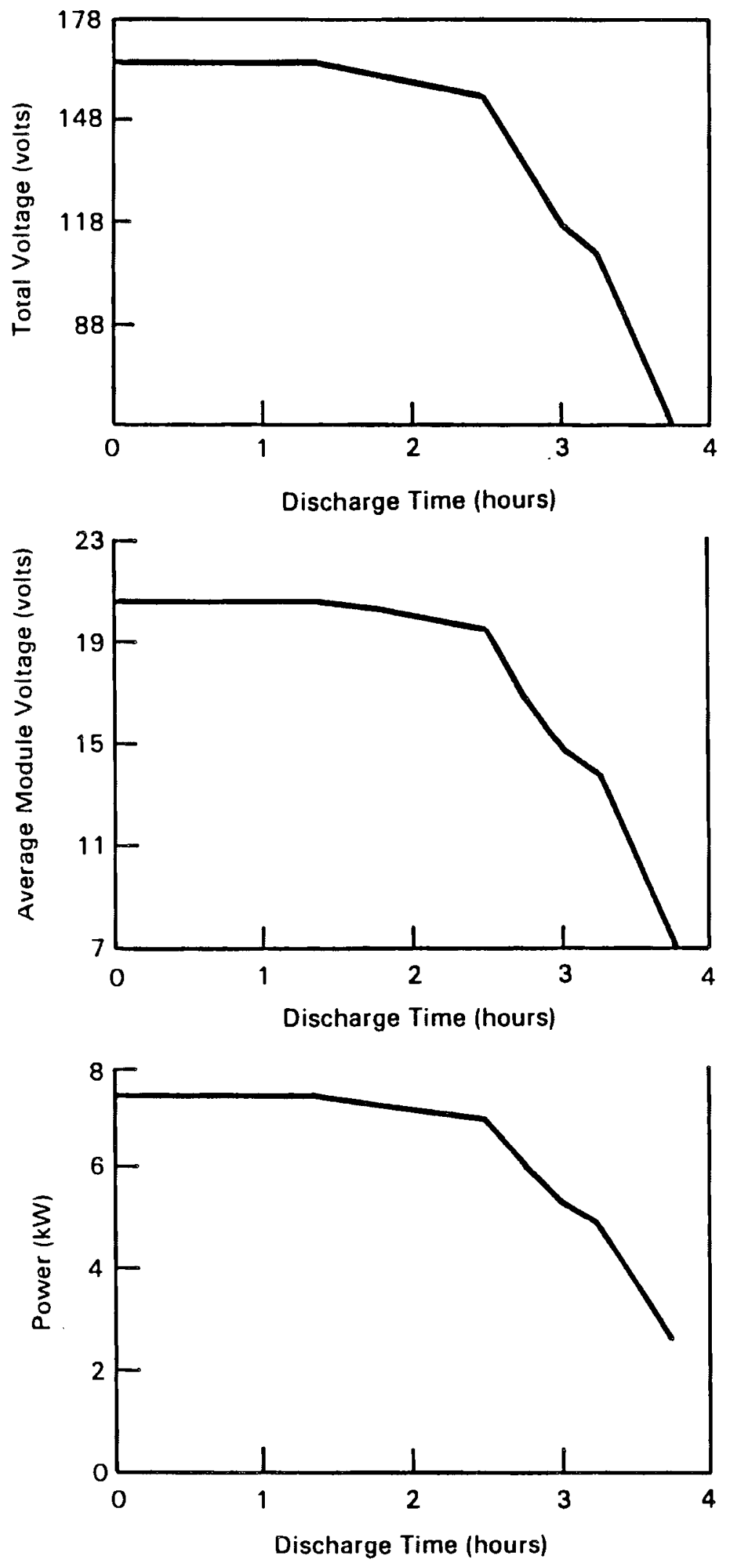

FIGURE 3.15. Graphics Output from Detailed Discharge Model 


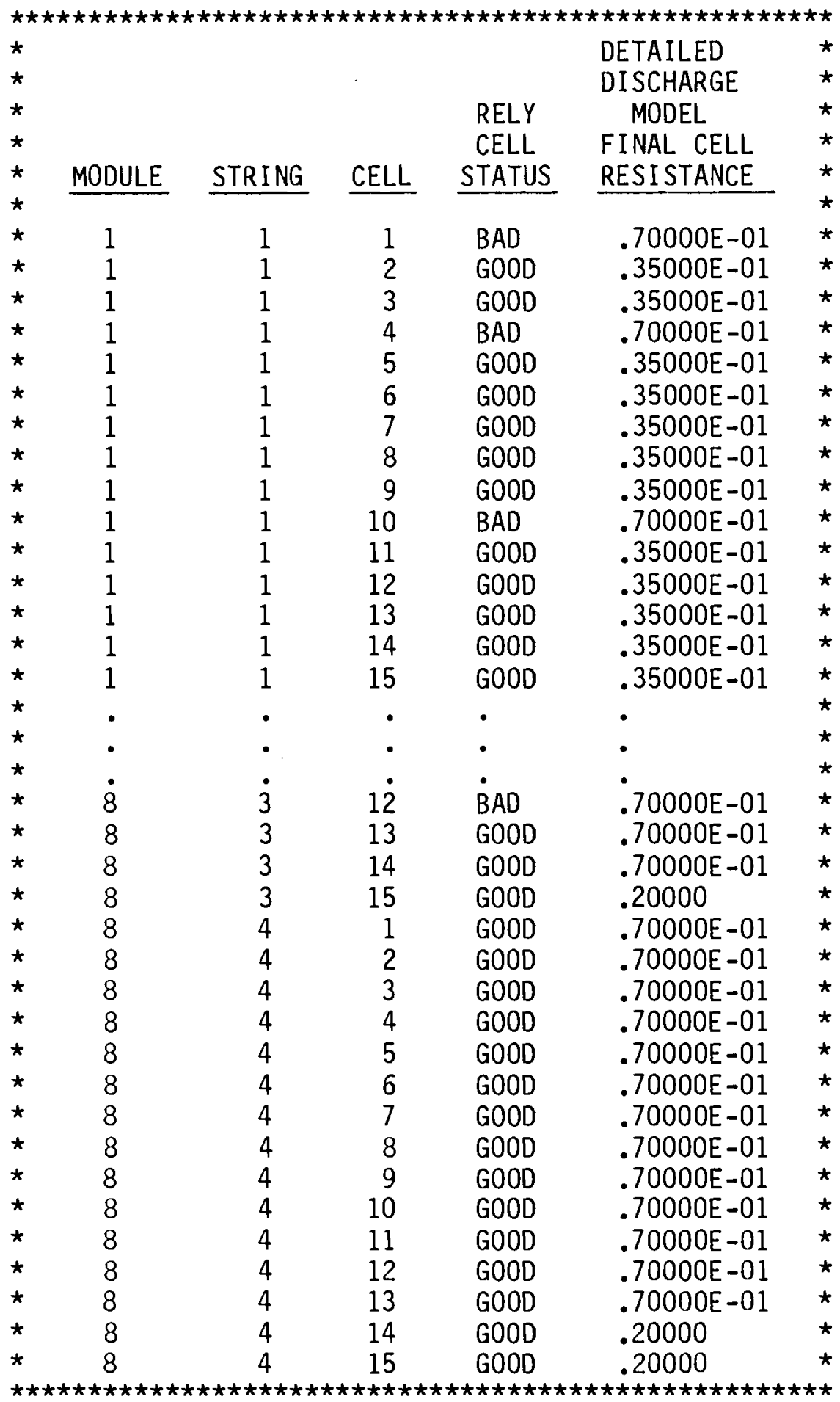

FIGURE 3.16. Partial Table of Cell Status at Time Battery Failed 
tabulates 100 equally-spaced points using the Weibull probability density function to generate the display of the density function. The density function is given as follows:

$$
f(x)=\frac{\beta}{\theta}\left(\frac{x-\delta}{\theta}\right)^{\beta-1} \exp \left[-\left(\frac{x-\delta}{\theta}\right)^{\beta}\right] \quad x \geqq \delta=\text { otherwise }
$$

where $\delta=$ the location parameter $(\delta \geqq 0$ in the Battery Reliability Model)

$$
\theta=\text { the scale parameter }(\theta>0)
$$$$
\beta=\text { the shape parameter }(\beta>0) \text {. }
$$

The mean of the Weibull distribution can be shown to be

$$
E(x)=\delta+\theta \Gamma\left(1+\frac{1}{\beta}\right)
$$

where $\Gamma$ is the Gamma function.

The tabulated data are connected by straight-line segments to generate the display of the Weibull probability density function.

Option B generates a pseudorandom sample of 100 to 1,000 (user-specified) observations from the Weibull distribution. The method is described in Appendix A. These data are grouped into a frequency histogram using 12 equallyspaced histogram cells. The number of observations in each cell is divided by the cell width and total sample size to obtain the height of each histogram cell. The height of each histogram cell is plotted on the ordinate against the midpoint of the cell on the abcissa. The points are then connected by straight line segments to approximate the Weibull probability density function used to model cell lifetimes.

Summaries of the Weibull parameters are given below. More detailed descriptions of the Weibull parameters and of a graphical procedure for estimating the Weibull parameters from test data are given in Appendix $A$. 


\section{Main Menu Option E}

If you select Option $E$ in the Main Menu, the program displays the input screen for the Cell Failure Distribution Model labeled "Example Weibull Distribution Model." The screen is shown in Figure 3.17. This screen prompts you to select Option A or B for generating and displaying the Weibull probability density function.

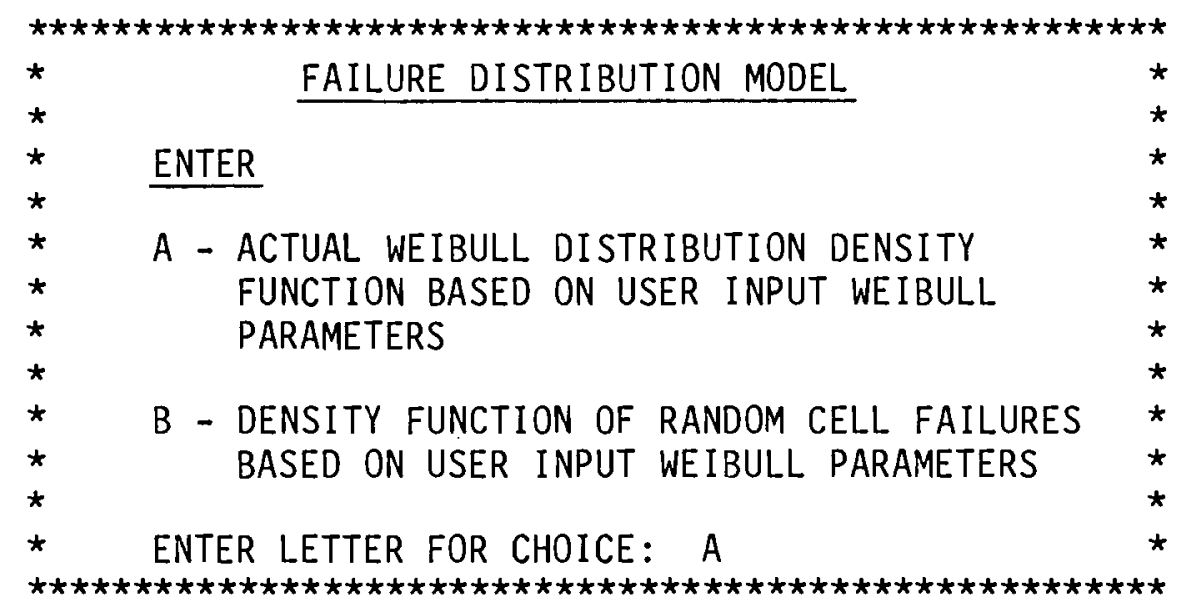

\section{FIGURE 3.17. Input Screen for Failure Distribution Model}

If you select Option A, the program displays the input screen shown in Figure 3.18. This screen prompts you to enter values for the three input parameters (location, scale, and shape) needed to define a Weibull distribution.

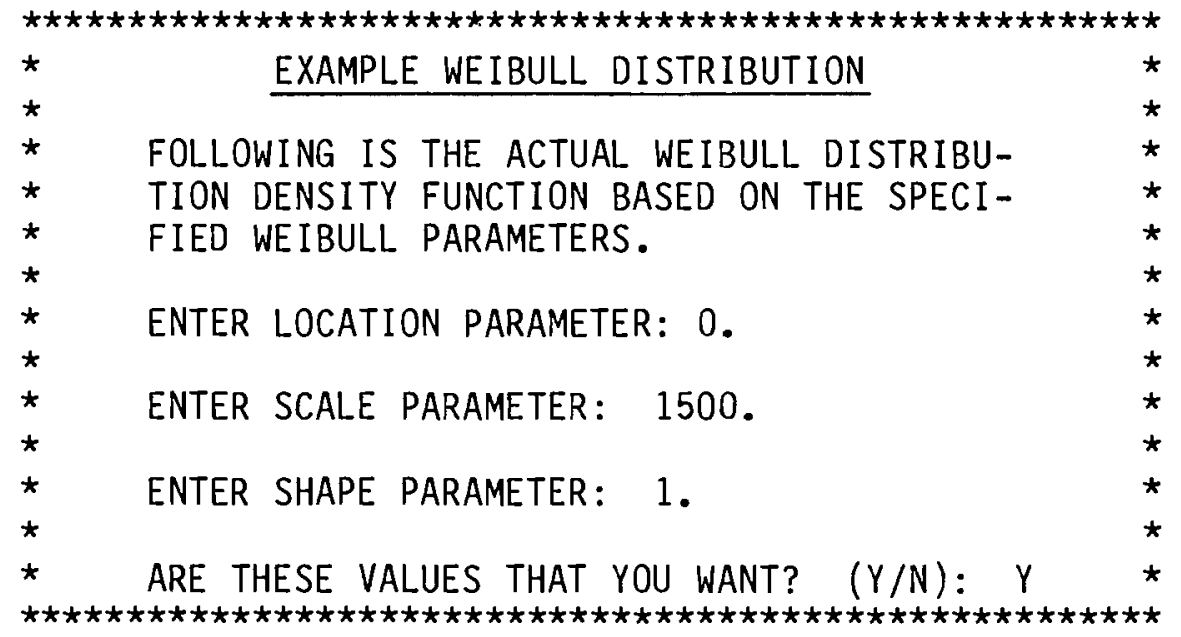

FIGURE 3.18. Input Screen for Example Weibull Distribution (Option A) 
If you select Option $B$, the program displays the input screen shown in Figure 3.19. This screen prompts you to enter values for the three Weibull input parameters (location, scale, and shape) and the number of pseudorandom observations you want to sample for the Weibull distribution.

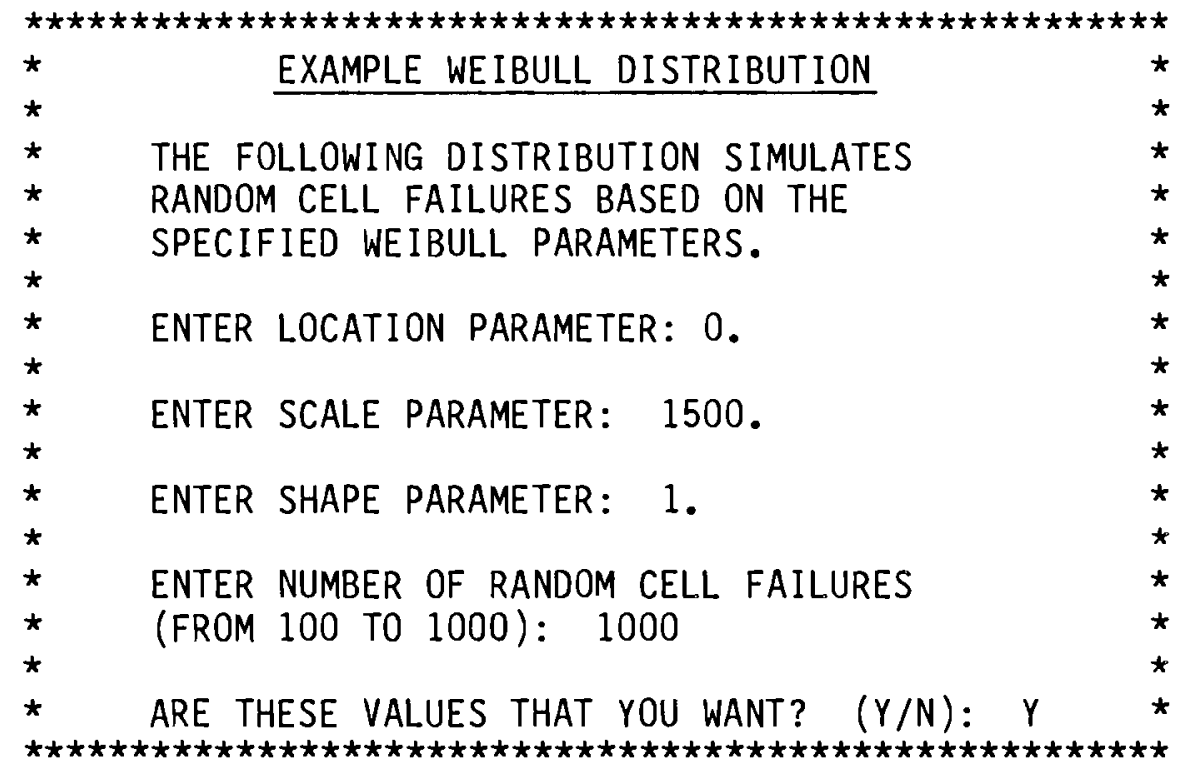

FIGURE 3.19. Input Screen for Example Weibull Distribution (Option B)

The three Weibull input parameters (location, scale, and shape) are summarized below:

1. The location parameter $\delta$, also known as the threshold parameter, represents the number of battery charge-discharge cycles before which no cell failures can occur due to wearout. It establishes the starting point of the left end of the distribution. A typical value to select for the location parameter in modeling sodium-sulfur cell-aging failures is 0 .

2. The scale parameter $\theta$, also known as the characteristic life, controls the amount of skewness, or spread from left to right, in the distribution. The probability of cell failure prior to $(\theta+\delta)$ is equal to 0.632 . Thus, for any Weibull distribution, $(\theta+\delta)$ divides the area under the probability density function into 0.632 and 0.368 
for all values of the shape parameter 8 . A typical value to select for the scale parameter $\theta$ in modeling sodium-sulfur cell-aging failures is 1,500 .

3. The shape parameter $\beta$ controls the shape of the distribution. Values less than 1 indicate a decreasing cell failure rate as the number of charge-discharge cycles increases, a value of 1 indicates a constant cell failure rate, and values greater than 1 indicate an increasing cell failure rate as the number of charge-discharge cycles increases. As $\beta$ increases, the mean of the Weibull distribution approaches $(\theta+\delta)$ and the variance approaches zero. The Weibull distribution with $\beta=1$ represents the exponential distribution and with $\beta \geqq 3.0$ approximates the normal distribution. A typical value to select for the shape parameter in modeling sodium-sulfur cell-aging failures is 1.0 .

When you are satisfied with the values you have entered for the Weibull input parameters, enter $Y$ or $y$ for "yes" when queried on whether the input values are correct, and press <RETURN> to execute the Cell Failure Distribution Model. After a delay of several seconds, a graph showing the Weibull density function will be displayed on the computer screen. An example of the graph generated by selecting Option $A$ is shown in Figure 3.20. This graph corresponds to the input values selected for the location, scale, and shape parameters in the input screen shown in Figure 3.18 .

After the Weibull graph is displayed, you will be asked if you want to display another sample Weibull density function. This option gives you the ability to perform rapid sensitivity studies on the Weibull failure distribution by experimenting with different parameter values and observing the effect on the resulting graphs displays of the Weibull density function. When you no longer want to look at sample Weibull density functions, enter $N$ or $n$ for "no" when queried on whether you want to repeat the process, and press 〈RETURN>. The program will then return you to RELY's Main Menu. 


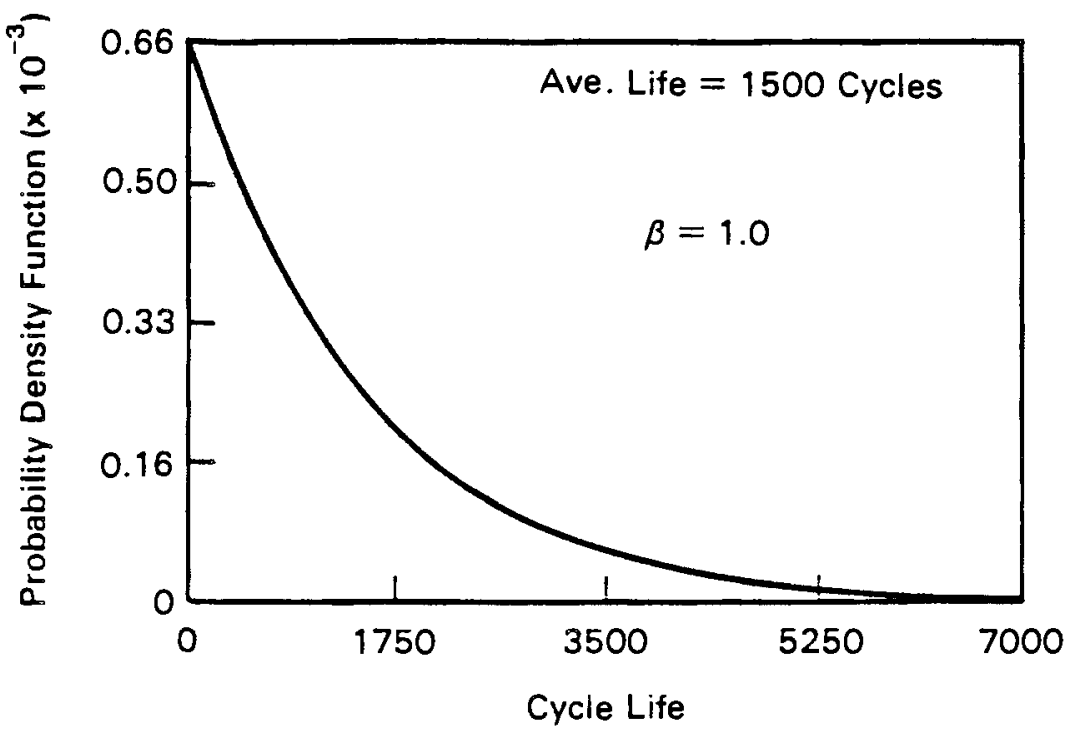

FIGURE 3.20. Weibul1 Probability Density Function Illustrated by Cell Failure Distribution Model (Option A) 


\section{REFERENCES}

Microsoft, Inc. 1983. Documentation for the Disk Operating System Version 2.0. Microsoft, Inc., Bellevue, Washington.

Microcompatibles. 1983. GRAFMATIC Documentation of GRAFMATIC Graphics Library. Microcompatibles, Silver Spring, Maryland.

Kapur, K. C., and L. R. Lamberson. 1977. Reliability in Engineering Design. John Wiley and Sons, Inc., New York.

King, J. R. 1971. Probability Charts for Decision Making. Industrial Press, Inc., New York.

Microsoft, Inc. 1985. Documentation for Microsoft FORTRAN Compiler Version 3.31. Microsoft, Inc., Bellevue, Washington.

U.S. Department of Energy, (DOE). 1977. Phenomenological Cell Modeling: A Tool for Planning and Analyzing Battery Testing at the BEST Facility. DOE Report 60025-1, U.S. Department of Energy, Washington, D.C. 

APPENDIX A

THE WEIBULL DISTRIBUTION PARAMETERS 

APPENDIX A

\section{THE WEIBULL DISTRIBUTION PARAMETERS}

The purpose of this appendix is to provide the user with a brief introduction to the Weibull distribution and to demonstrate how Weibull parameters can be estimated from test data. Wearout failures in the RELY software package are modeled using this statistical distribution. The Weibull distribution is often used in reliability analyses to model natural failures of devices.

The three parameters of the Weibull distribution are the location parameter delta $(\delta)$, the scale parameter theta $(\theta)$, and the shape parameter beta $(B)$. The location parameter is simply the minimum possible life. A typical value used in battery and electrical system analysis is zero. The only effect $\delta$ has on the Weibull distribution is the shifting of the distribution along the $x$-axis.

Due to the nature of the Weibull distribution, $63.2 \%$ of all failures occur between the minimum life value $\delta$ and the scale parameter value $\theta$. This is true regardless of the parameter values. The average life is linearly related to $\theta$ hence the term scale parameter.

The shape parameter $\beta$ determines the shape of the distribution. For large values of $B$, the shape of the distribution resembles that of the normal distribution. Furthermore, the value of $\beta$ determines whether the rate of failure decreases, increases, or remains constant over time. If $\beta<1$, the failure rate decreases over time, while if $\beta>1$, the failure rate increases. If $\beta=1$, the failure rate is constant over time, as with the exponential distribution. Figure A.1 displays example Weibull density functions. For all three plots, $\delta=0$ and $\theta=500$. Beta is varied from 0.5 to 1.0 to 4.0 . The differences caused by varying the $\beta$ values point out both an advantage and a warning in using the Weibull distribution. It is an extremely flexible distribution and thus it is widely used in reliability applications. However, because of its flexibility, the estimation of parameters must be as accurate as possible. 


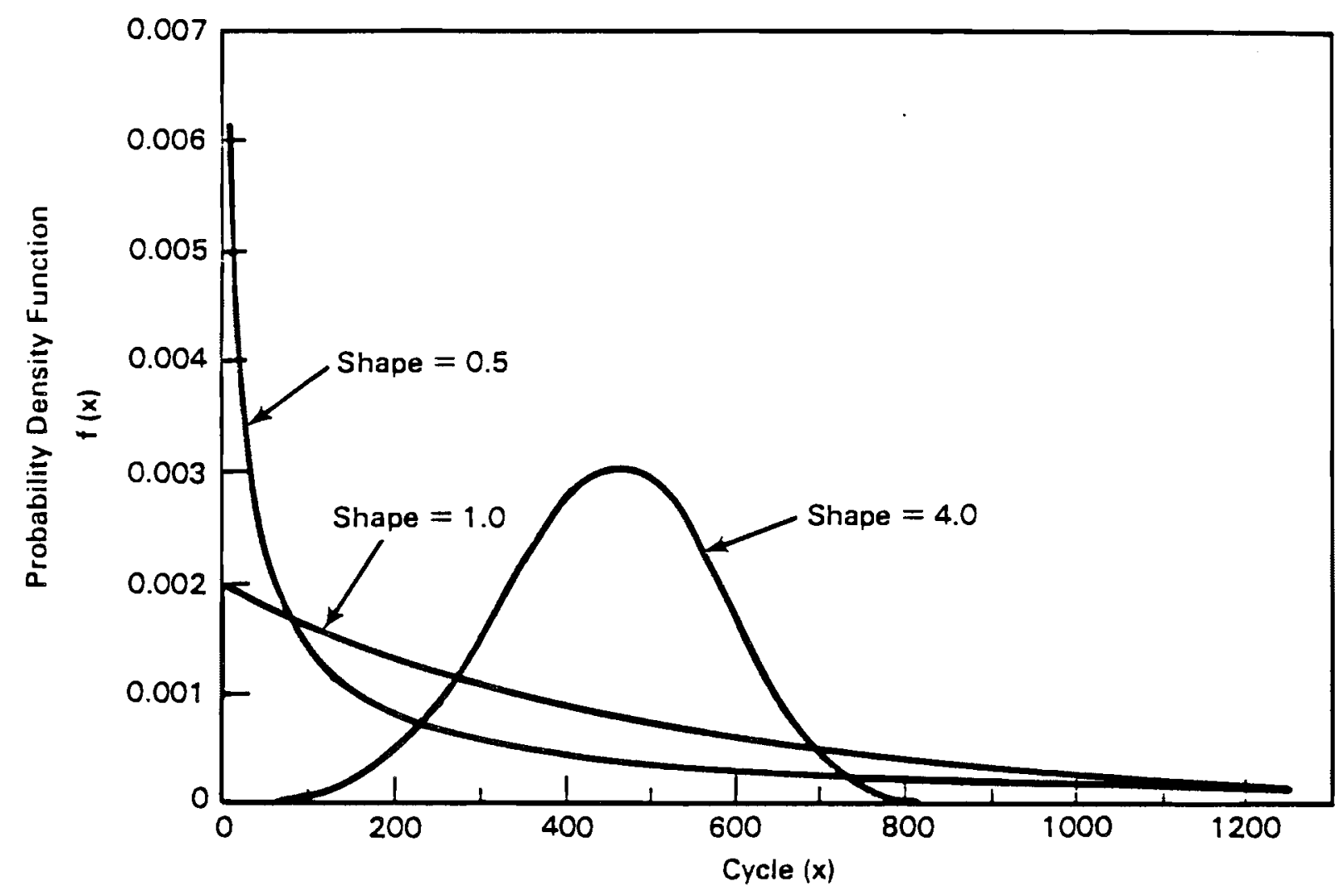

FIGURE A.1. Weibul1 Density Functions: $\delta=0, \theta=500$

This section describes how to graphically estimate Weibull distribution parameters from bench-test data. The graphical method is chosen for its simplicity and ease of application. More precise estimates can be developed using statistical estimation procedures if the user desires. Graphical estimation is done on Weibull probability paper. A blank sheet of this paper is shown in Figure A.2. The cumulative probability of failure is plotted against the observed failure cycles. The horizontal and vertical scales of Weibull probability paper are not linear, but are transformed such that if perfectly Weibul1-distributed data are plotted, a straight 1 ine results. Thus, graphical techniques can be used to: 1) determine if the data can reasonably be represented by a Weibull distribution, and 2) estimate the parameters of a Weibull distribution.

An example will be used to illustrate the graphical techniques. It is assumed in the example that the minimum possible life $\theta$ is zero, which is the 


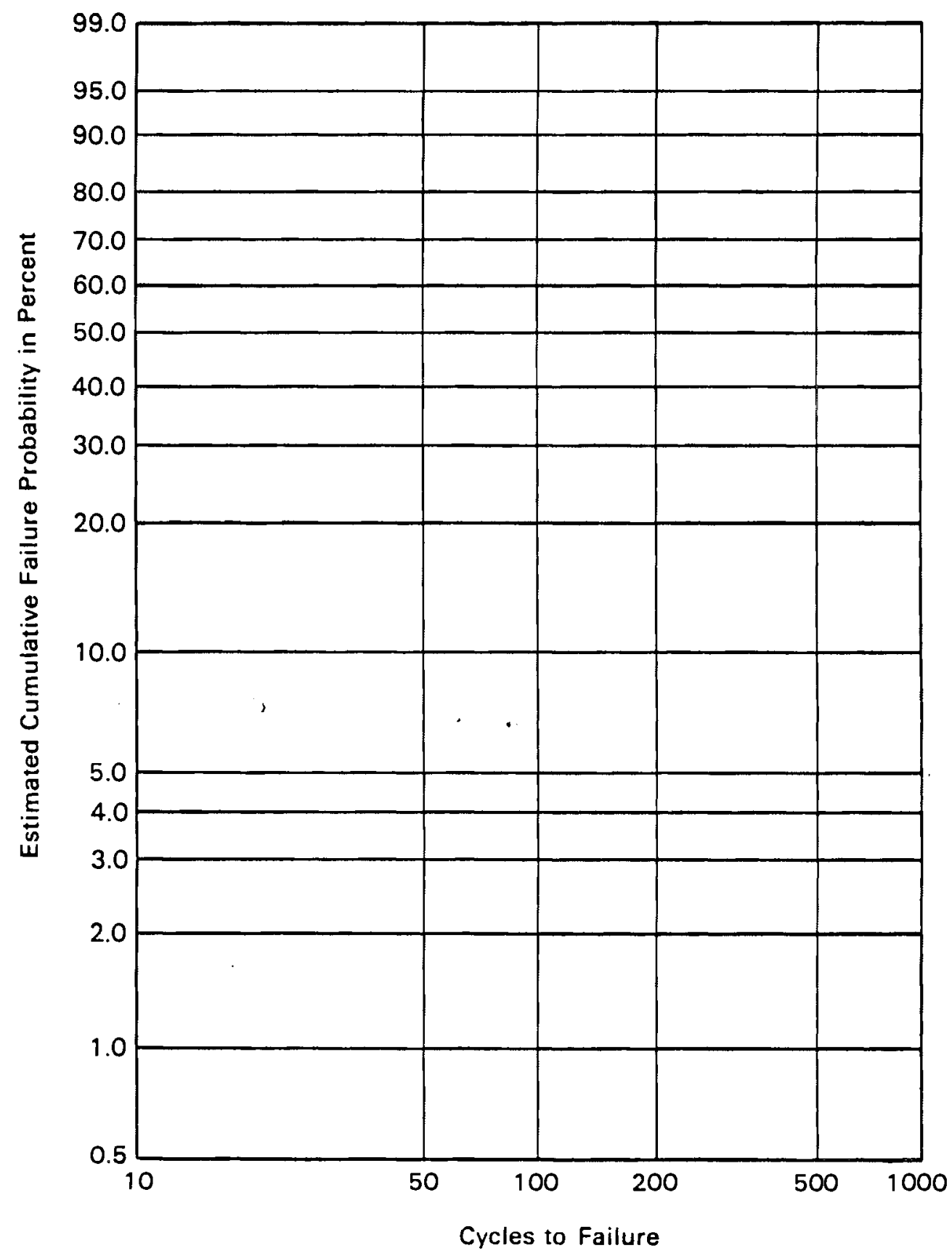

FIGURE A.2. Weibull Probability Paper

typical value for sodium-sulfur cell analysis. If, for some reason, the minimum possible life is not zero, a simple transformation to the original data can be made. For guidance in handling this situation, and for greater technical detail, the reader should consult Kapur and Lamberson (1977) and/or King (1971). 
Assume that a sample of $n=5$ cells are charged and discharged until failure. The cells fail on cycles $67,120,130,220$, and 290. King (1971) recommends an absolute minimum of five data points from which to estimate parameters for practical cases. Once the failure cycles are obtained, they are arranged in ascending order $(67,120,130,220,290)$ and a rank (denoted by $j$ ) is associated with each failure cycle. In this case, the rank of $j=1$ is assigned to $62, j=2$ to 120 , and so on until $j=5$ is associated with 290 . The assignment of ranks is essential for the determination of parameters by this method.

The ranks $(j=1,2,3,4,5)$ are used to compute the median rank value, which is an approximation to the fraction of cells failing prior to the $j$ th observation. The formula for the median rank value is $(j-0.3) /(n+0.4)$, where $j$ is the rank and $n$ is the sample size ( 5 in this case). For example, for $j=2$, which corresponds to the second lowest failure cycle (120), the median rank value is $(2-0.3) /(5+0.4)=0.314$. Thus, it is estimated that $31 \%$ of all cells would fail prior to cycle 120. The observations, their ranks, and their median rank values are shown in Table A.1.

Once the median rank values have been calculated, they are plotted against the corresponding failure cycles on Weibull probability paper as in Figure A.3. The line of best fit is then drawn through these points. The shape parameter $\beta$ is estimated as the slope of this line. This results in an estimate of $\beta=1.6$ because the line "rises" 1.6 inches for every 1 inch it "runs." The scale parameter $\theta$ is found by projecting a horizontal line from the $63.2 \%$ point on the vertical axis to the fitted line, and then projecting this line to the horizontal axis. The point at which this line intersects the axis is the

TABLE A.1. Example Failure Cycles, Ranks, and Median Rank Values Used to Estimate Weibull Parameters

\begin{tabular}{|c|c|c|}
\hline $\begin{array}{l}\text { Failure } \\
\text { Cycle } \\
\end{array}$ & $\begin{array}{l}\text { Rank } \\
(j)\end{array}$ & $\begin{array}{c}\text { Median Rank } \\
\text { Value } \\
\end{array}$ \\
\hline 67 & 1 & 0.129 \\
\hline 120 & 2 & 0.314 \\
\hline 130 & 3 & 0.500 \\
\hline 220 & 4 & 0.685 \\
\hline 290 & 5 & 0.870 \\
\hline
\end{tabular}




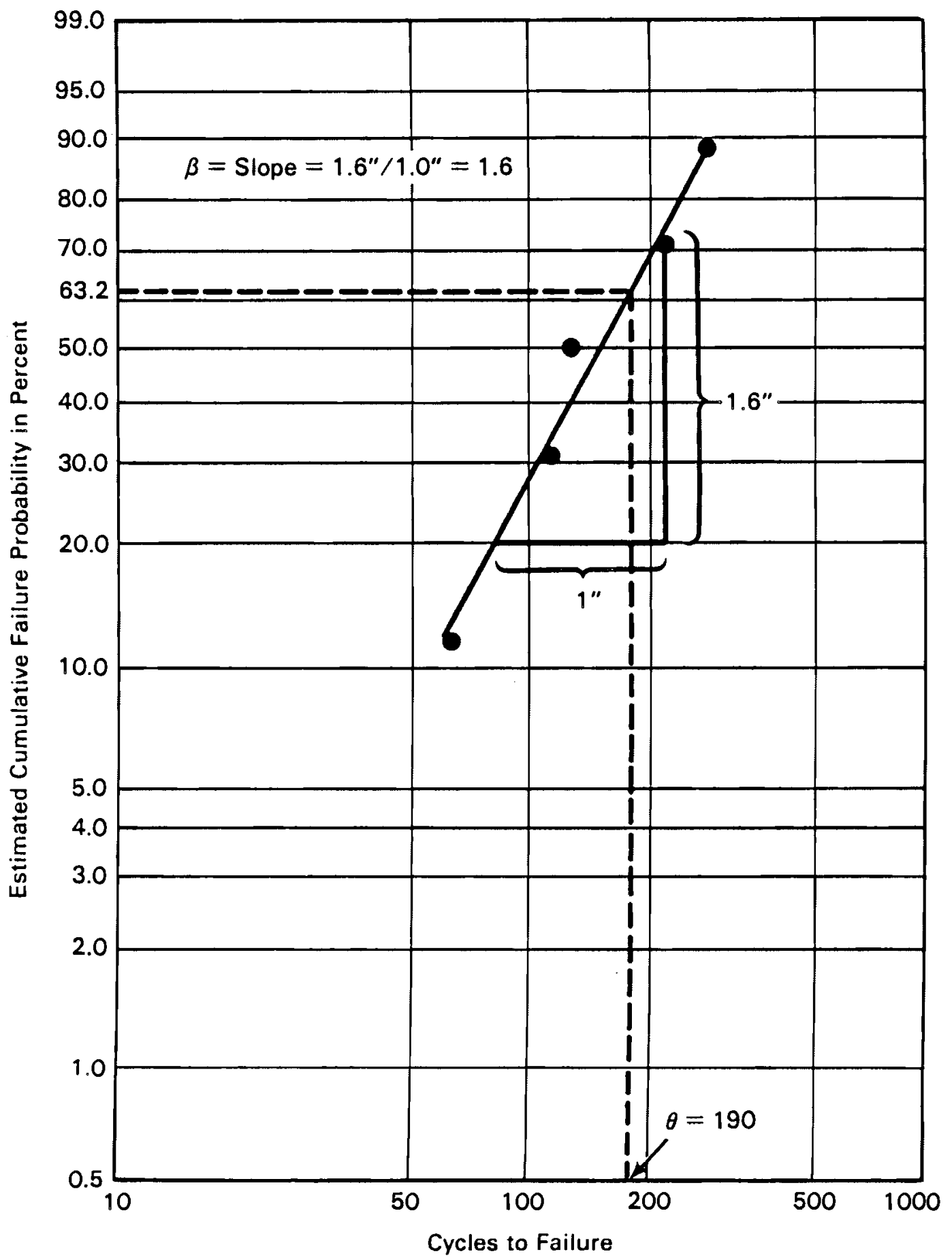

FIGURE A.3. Graphical Estimation of Weibull Parameters 
estimate of theta. In this case, $\theta=190$ cycles. It is assumed that the location parameter delta is zero, and the good fit of the straight line confirms this assumption.

If the bench-test data do not seem to follow a reasonably straight line when plotted on Weibull probability paper, it is best to consult the references. It may still be possible to use the Weibull distribution to model failures, perhaps with a non-zero location parameter. The Weibull distribution was chosen to model wearout failures in RELY because of its wide applicability to natural failures of devices. The references should also be consulted if more detailed statistical information is needed.

A step-by-step summary of graphical estimation of Weibull parameters is given below.

1. Order the failure cycles ( $n=$ sample size) in ascending order.

2. Assign ranks (values of $j$ ) to each of the $n$ failure cycles. For the earliest failure, $j=1$. For the latest, $j=n$.

3. Compute the median rank value for each observation, lising $(j-0.3) /(n+0.4)$.

4. Plot the median rank values expressed in percent (vertical axis) versus the failure cycles (horizontal axis) on Weibull probability paper.

5. Fit the "best" line to the points, either visually or by least squares regression.

6. If the line fits the data reasonably well, estimate the parameters: $\beta=$ slope of the fitted line and $\theta=$ cycle which corresponds to a cumulative failure probability of $63.2 \%$

7. If the data do not seem to follow a reasonably straight line, review the data for accuracy and consult the references.

After estimating values for the Weibull parameters, they can be input to the Cell Failure Distribution Model and other models of the software package. If test data are not available, preliminary estimates of the parameters are necessary. 
APPENDIX B

MODELING APPROACH 


\section{-}


APPENDIX B

MODELING APPROACH

The software package stored on the diskette in the jacket of this report consists of the following three files:

1. Disk Operating System (DOS) batch file BATTERY.BAT

2. Fortran-executable program file RELY.EXE

3. Fortran-executable program file BAT2A.EXE.

Figure B.1 shows a block diagram of the overall structure of the DOS batch file BATTERY.BAT. This file executes two Fortran-executable programs, RELY and BAT2A, to run the three simulation models: the Life-Cycle Model, the Detailed Discharge Model, and the Cell Failure Distribution Model.

RELY receives input from the user which defines the battery configuration and performance requirements, failure distribution parameters, and freeze-thaw conditions. The primary purpose of RELY is to estimate the expected battery life (in cycles). No detailed voltage, resistance, or power characteristics are considered in RELY. Cells fail only from freeze-thaw conditions or normal wearout conditions. An excellent application of RELY is to explore various battery geometries to determine their expected useful lives. From these results, the designer can begin to place requirements on the configuration of the battery and the reliability of a given cell.

Whereas RELY estimates the useful lifetime (in cycles) of the battery without considering the detailed conditions of each charge-discharge cycle, BAT2A simulates a particular cycle of the battery's life. Information about working and failed cells and the types of failures are passed from RELY to BAT2A. In addition, BAT2A solicits input from the user about certain cell and battery characteristics, such as cell capacity, voltage, and resistance. BAT2A simulates the user-specified discharge cycle of the battery for a specified test period. When the battery can no longer maintain the current required, the test ends. Graphs can be displayed showing total voltage, average module voltage, and battery power as functions of discharge time. 


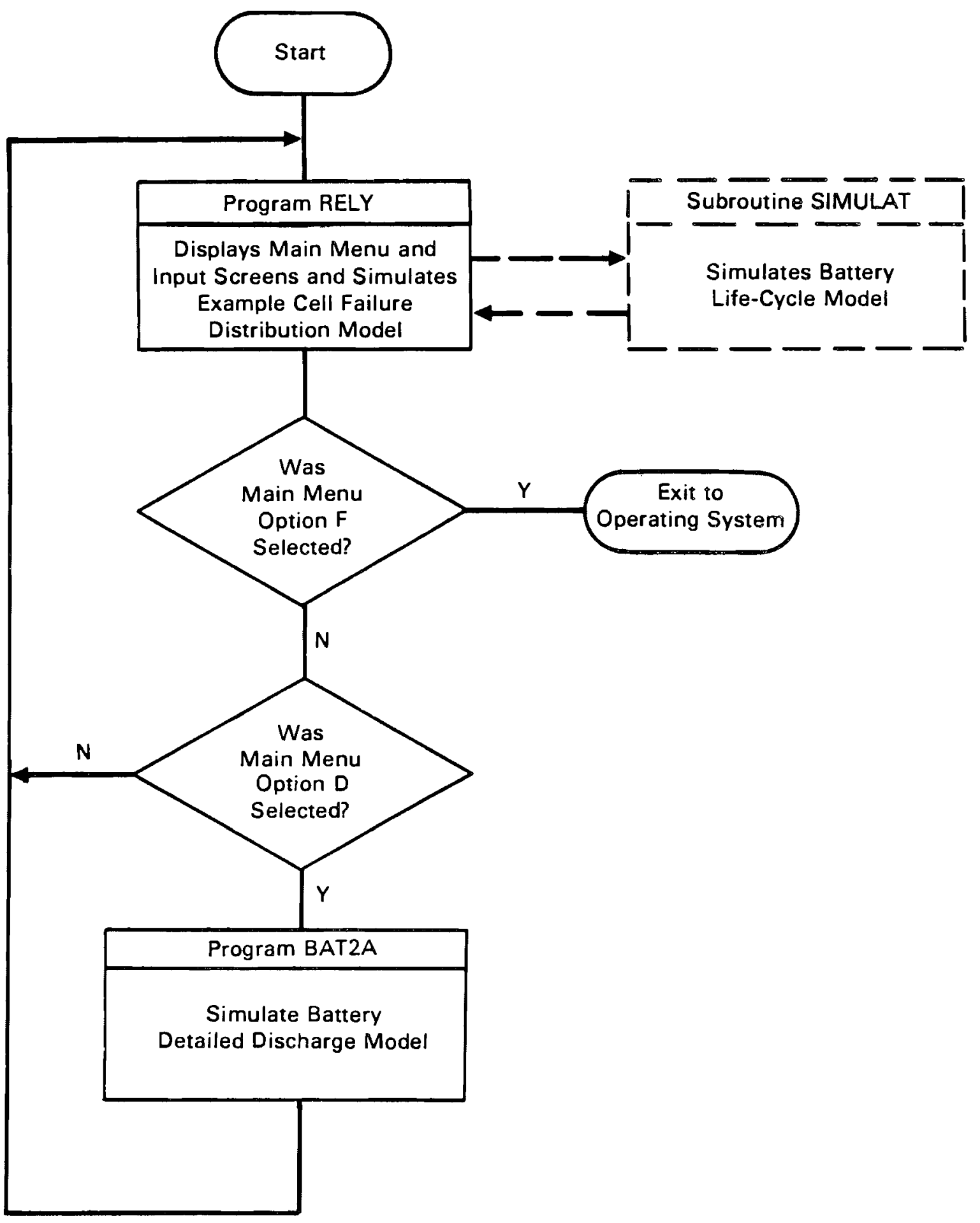

FIGURE B.1. Block Diagram of DOS Batch File BATTERY.BAT 
With BAT2A, the user can obtain detailed information about the battery's performance for any desired cycle. Theoretically, it would be possible to have one model simulate battery life and perform detailed calculations for each cycle. However, this approach would result in extremely long execution times. Since it is desirable to be able to run the simulation on an IBM-PC or compatible microcomputer, the two-model approach is an excellent compromise. RELY can be used to determine several "good" configurations, and BAT2A can be employed to analyze each configuration in detail.

Program RELY is executed first. The block diagram of program RELY is shown in Figure B.2. The principal functions performed by RELY are to:

1. Display the Main Menu to the user

2. Display the input screens to the Life-Cycle model and the Cell Failure Distribution model

3. Call the major subroutine SIMULAT, as indicated by the dashed lines shown in Figure B.1, to simulate the Life-Cycle model

4. Execute the Cell Failure Distribution model.

The block diagram of subroutine SIMULAT is shown in Figure B.3. Subroutine SIMULAT performs multiple, independent Monte Carlo simulations to estimate the expected battery cycle life. Cell failures due to freeze-thaw and wearout are modeled as randomly occurring phenomena based upon the uniform and Weibull distributions, respectively. Cell failures are modeled as producing a userspecified percentage of open and/or closed circuit post-failure resistance. The simulation continues until the number of working cells, strings, and modules in the user-specified battery configuration falls below minimum userspecified failure criteria, i.e., the battery fails. The stochastic cell failures and battery cycle life predicted in the last simulation run of the Life-Cycle Model are then written to a disk file BAT2A.TMP for subsequent use by program BAT2A when menu Option $D$ is selected.

The manner in which random numbers are used by subroutine SIMULAT in the Life-Cycle simulation is explained below. Cells are "frozen" and then "thawed" at regular frequencies, as specified by the user. In addition, the user enters the probability of a cell failing during a freeze-thaw cycle. Suppose this 


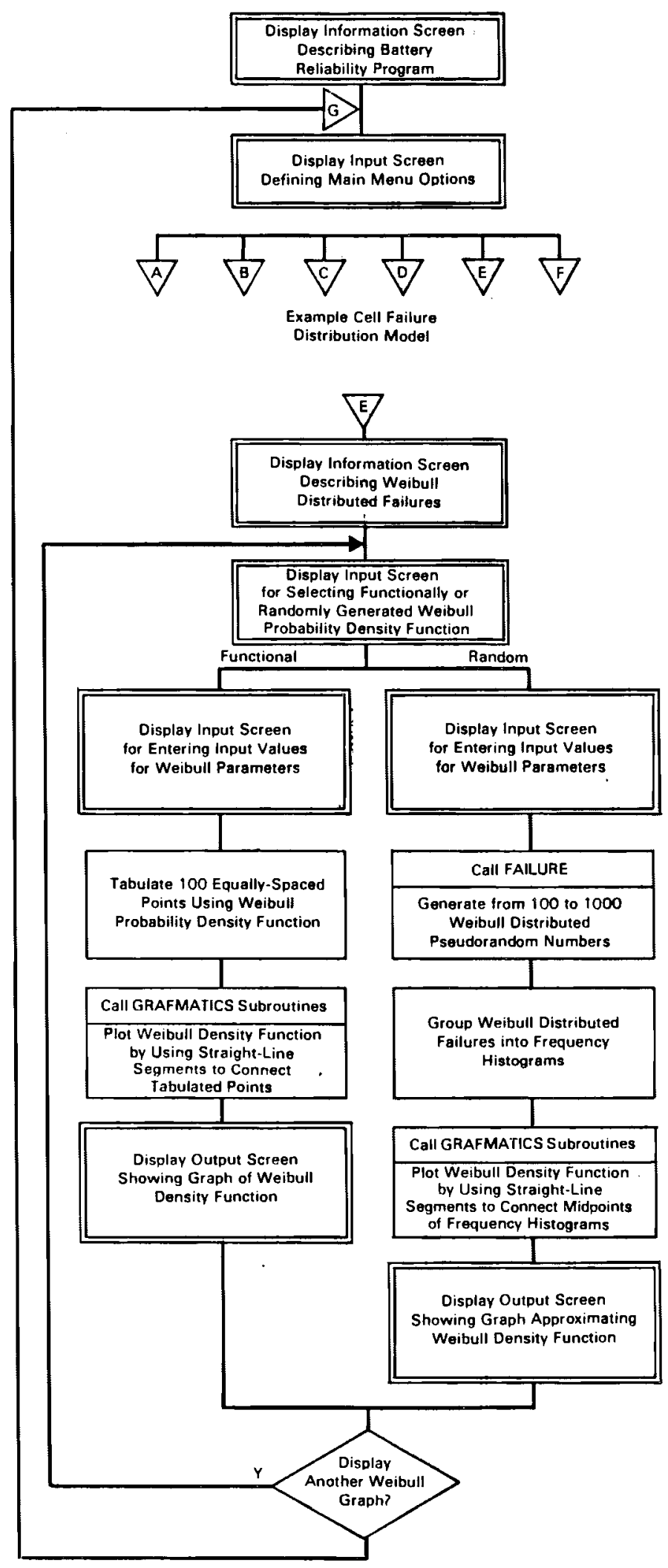

FIGURE B.2. Block Diagram of Program RELY

B. 4 
Input Screens for Failure Data in Life-Cycle Model

Input Screens for Battery Data in Life-Cycle Model

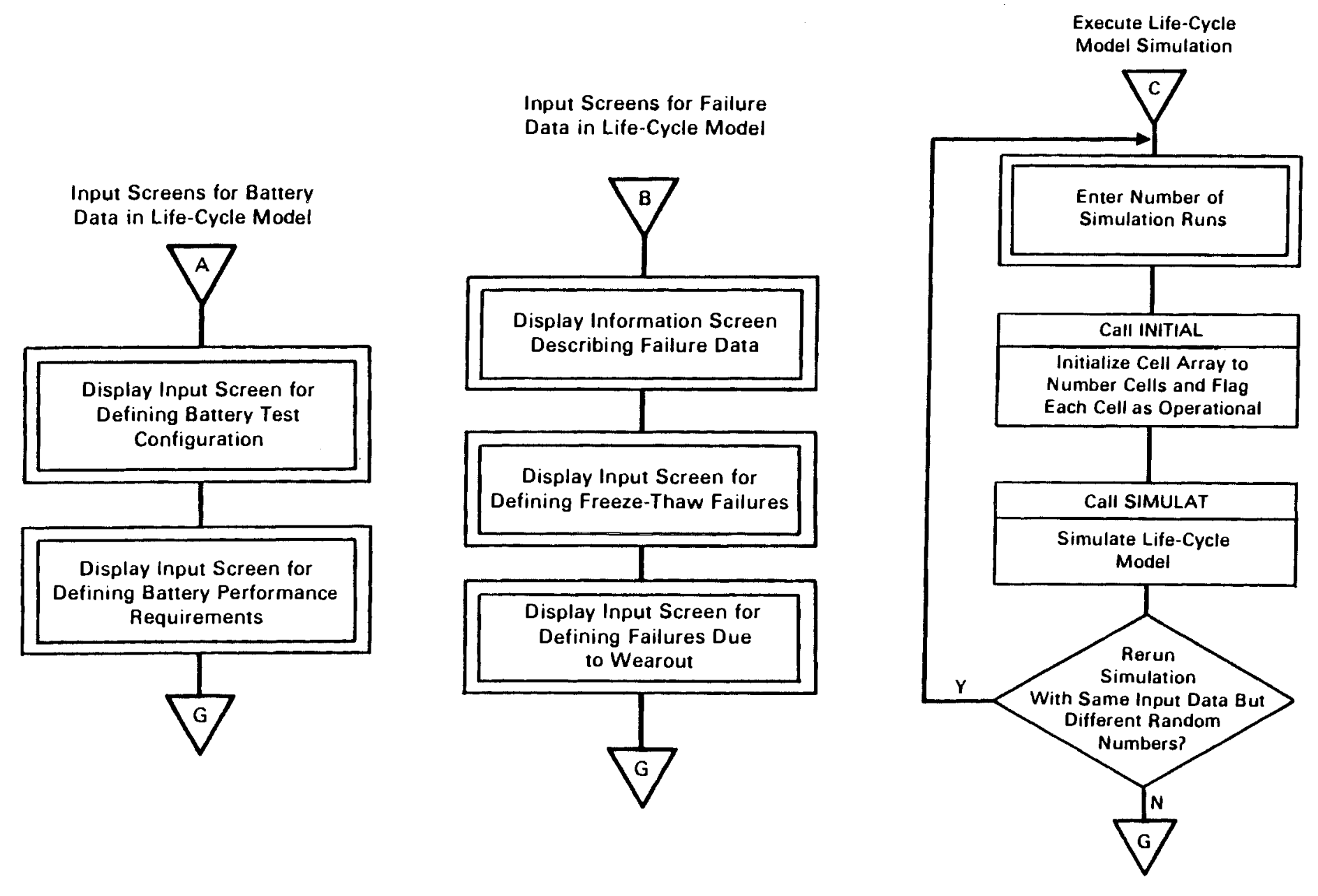

FIGURE B.2. (contd)

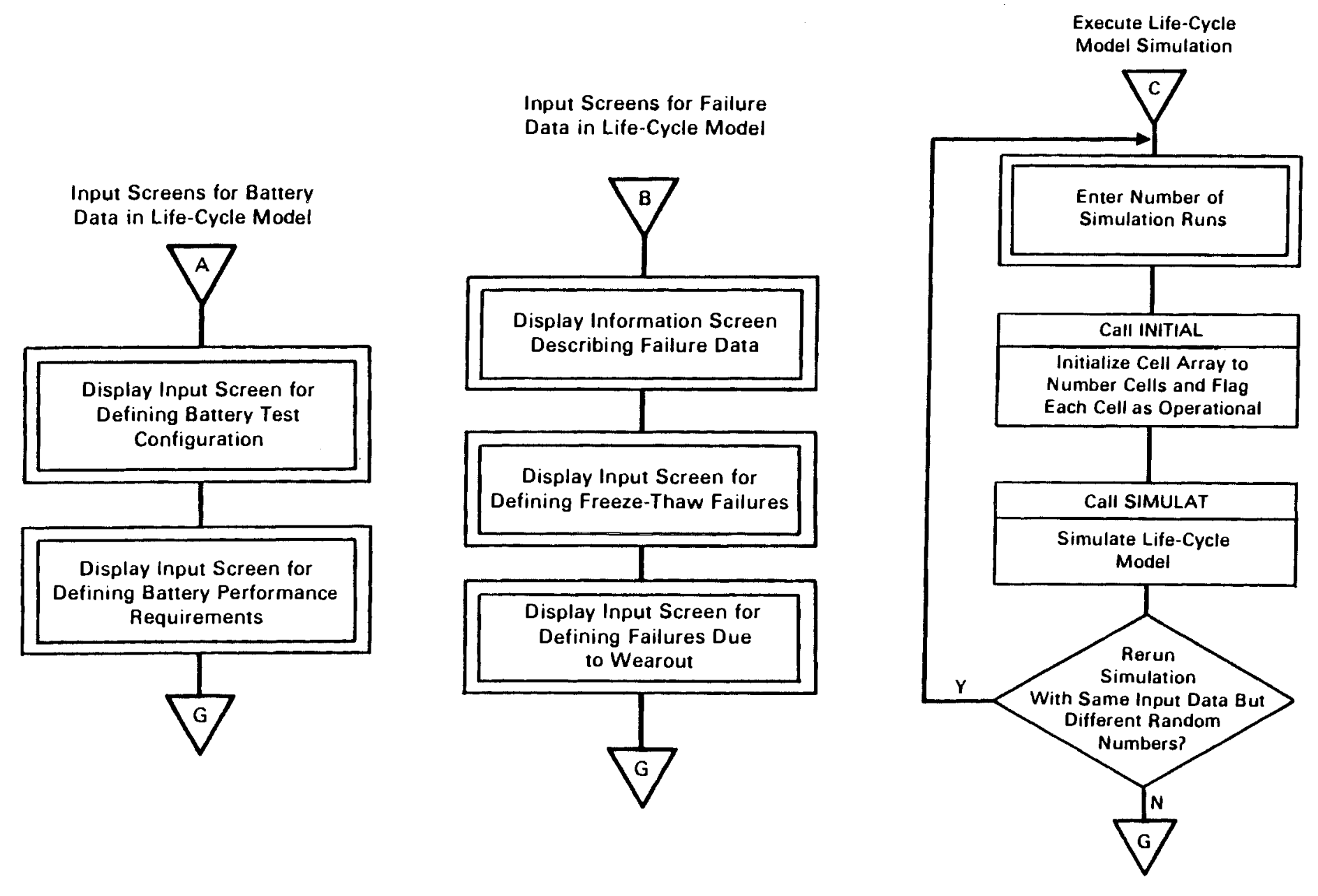

Execute Life-Cycle

Model Simulation

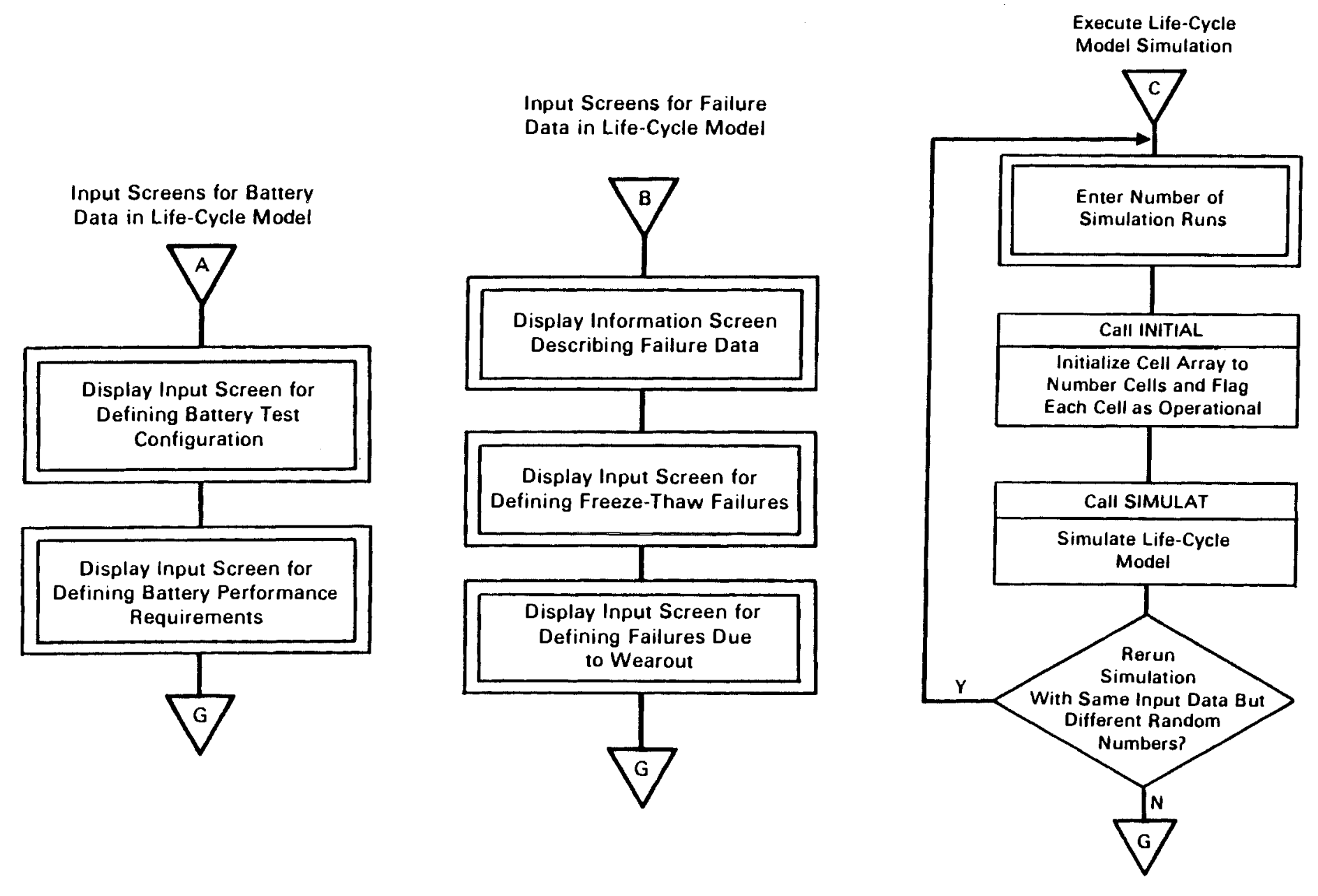


Save Failure Data from

Life-Cycle Model Simulation
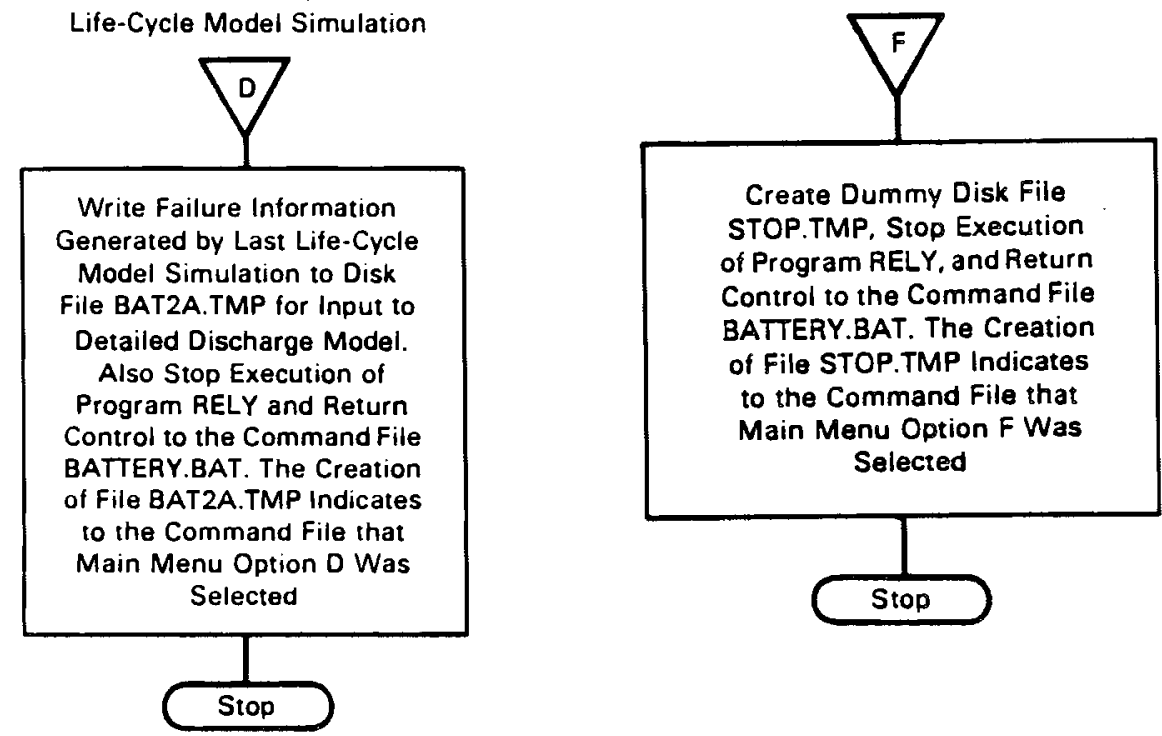

FIGURE B.2. (contd)

probability is 0.05 . If the current cycle being simulated is a freeze-thaw cycle, a uniformly distributed number between 0 and 1 is generated by a call to subroutine RANF. If this random number is less than or equal to the probability of failure during a freeze-thaw, the cell fails. For example, suppose the random number generated is 0.769 . Since $0.769>0.05$, the cell survives the freeze-thaw. If, however, the random number is 0.0128 , the cell fails.

Wearout failures are modeled differently than freeze-thaw failures. The cycle during which a cell wears out is assumed to be distributed as a Weibull random variable. The Weibull distribution is often used in reliability engineering to model failures. With changes in the parameters (discussed in Appendix A), it takes on various characteristics. This discussion is provided as a brief synopsis of how Weibull random numbers are generated.

Every probability distribution is associated with a particular cumulative distribution. The cumulative distribution gives the probability (between 0 and 1) that a generated random number, say $x$, will be less than or equal to a specified value, say $A$. In general, the cumulative distribution can be written as a function of $x$. This function, by its definition, always results in a value between 0 and 1 . In this sense, $X$ is the "input," and $U$, the number between 0 


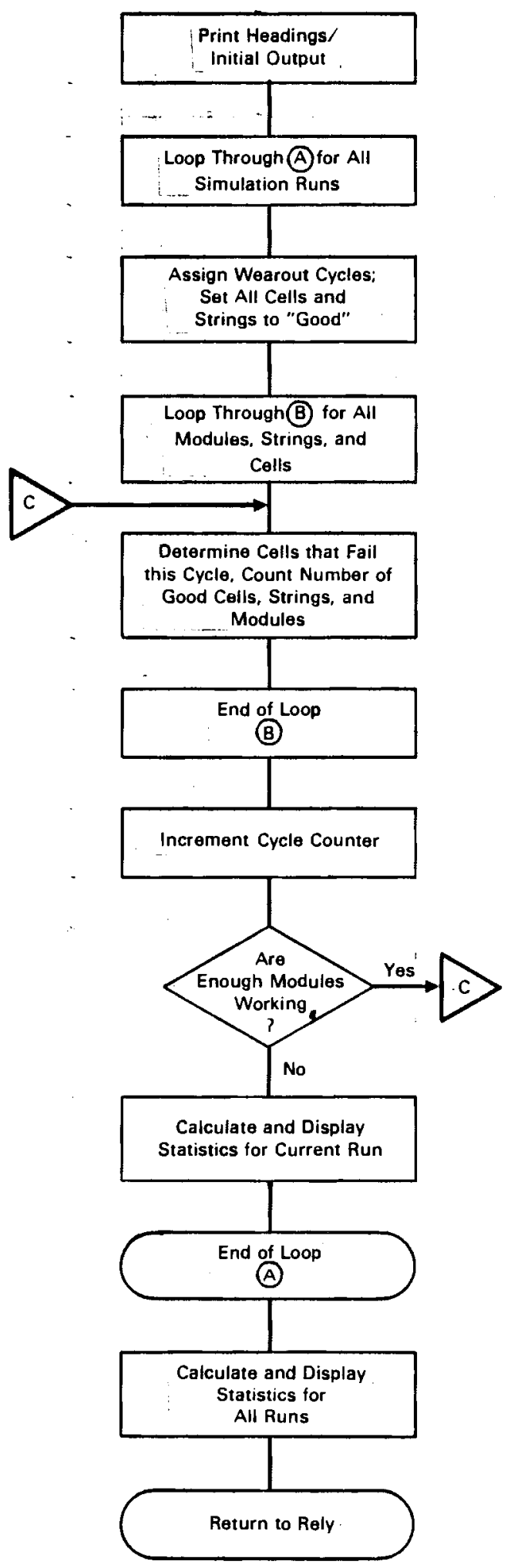

FIGURE B.3. Block Diagram of Subroutine SIMULAT 
and 1 , is the "output." When generating random numbers, the process is reversed, such that $U$ is the input and $X$ is the output. Mathematically, this is known as the inverse transform method of generating random numbers from a particular distribution.

Figure B.4 graphically displays how this procedure is carried out. The graph is the cumulative Weibull distribution with parameters: location $\delta=0$, scale $\theta=500$, and shape $\beta=2$. First, a uniform number between 0 and 1 is generated by a call to subroutine RANF. This number is labeled $U$ on the graph, and equal to 0.60 in Figure B.4. Then, in a graphical sense, the point on the horizontal axis that corresponds with $U$ is determined. This value is approximately 480 in Figure B.4. This number is a random sample from a Weibull distribution with the specified parameters. The FORTRAN subroutine FAILURE generates these random numbers using mathematical formulas underlying the

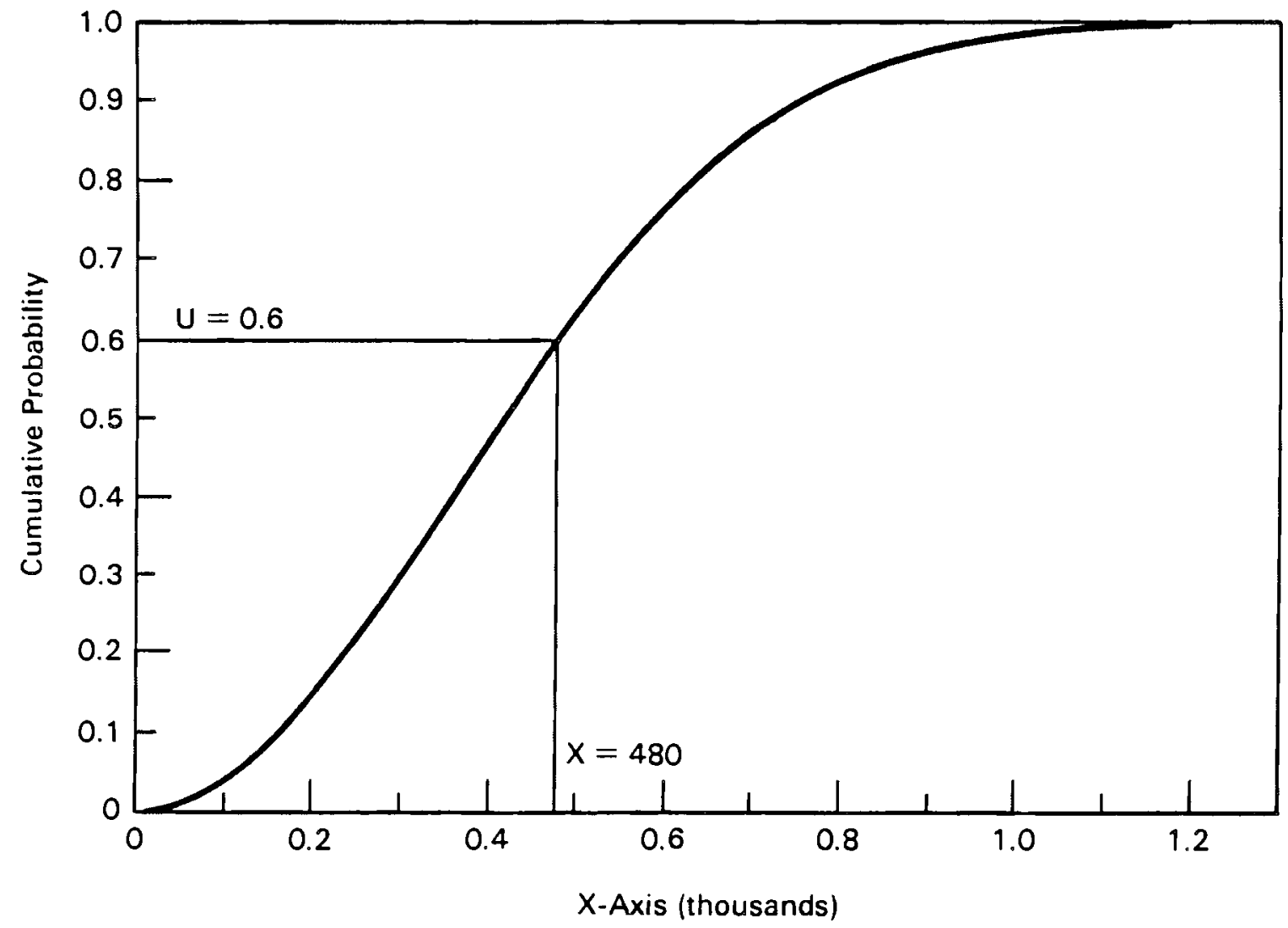

FIGURE B.4. Generation of Weibull Random Numbers for Location $\delta=0$, Scale $\theta=500$, and Shape $\beta=2$ 
graph. The random numbers generated are the cycles during which the cells of the battery will wear out, if they do not fail during a prior freeze-thaw. Thus, in this case, the particular cell will wear out during cycle 480 .

Program RELY includes a block of code comprising the Cell Failure Distribution Model. This model gives the user the option to become acquainted with the general shape of the Weibull density function before running the Life-Cycle Model. The Cell Failure Distribution Model allows the user two options to generate and display a graph of the Weibull probability density function on the computer screen. With each option, the user inputs values for the location, scale, and shape parameters of the Weibull distribution. Option A tabulates 100 equally-spaced points using the Weibull probability density function to generate the plot data. Option B calls subroutine FAILURE from 100 to 1,000 times (user-input) to generate a pseudorandom sample of observations from the Weibull distribution to generate the plot data. The plot data are then used to display a graph of the corresponding Weibull probability density function.

By changing the input values for the Weibull parameters, the user can immediately observe the effect on the shape of the Weibull density function. This can assist the user in determining the adequacy of Weibull parameter estimates obtained from bench-test data to model cell wearout failures before running the Life-Cycle Model.

The selection of menu Options $D$ or $F$ in program RELY terminates execution of RELY and returns control to the DOS batch file BATTERY.BAT. As shown in Figure B.1, the batch file checks to determine which of the two options was selected to terminate RELY. If Option $F$ was selected, the batch file exits to the operating system. If Option $D$ was selected, the batch file executes program BAT2A.

Program BAT2A simulates the Detailed Discharge Model. The block diagram for program BAT2A is shown in Figure B.5. Program BAT2A estimates battery discharge performance based on constant current discharge in terms of its voltage and power. The calculations are based on a current-voltage depth-of-discharge model of sodium-sulfur cell performance for a user-specified discharge cycle. The model accounts for the impact that the cumulative number and types of failed cells will have upon battery performance in the user-specified discharge 


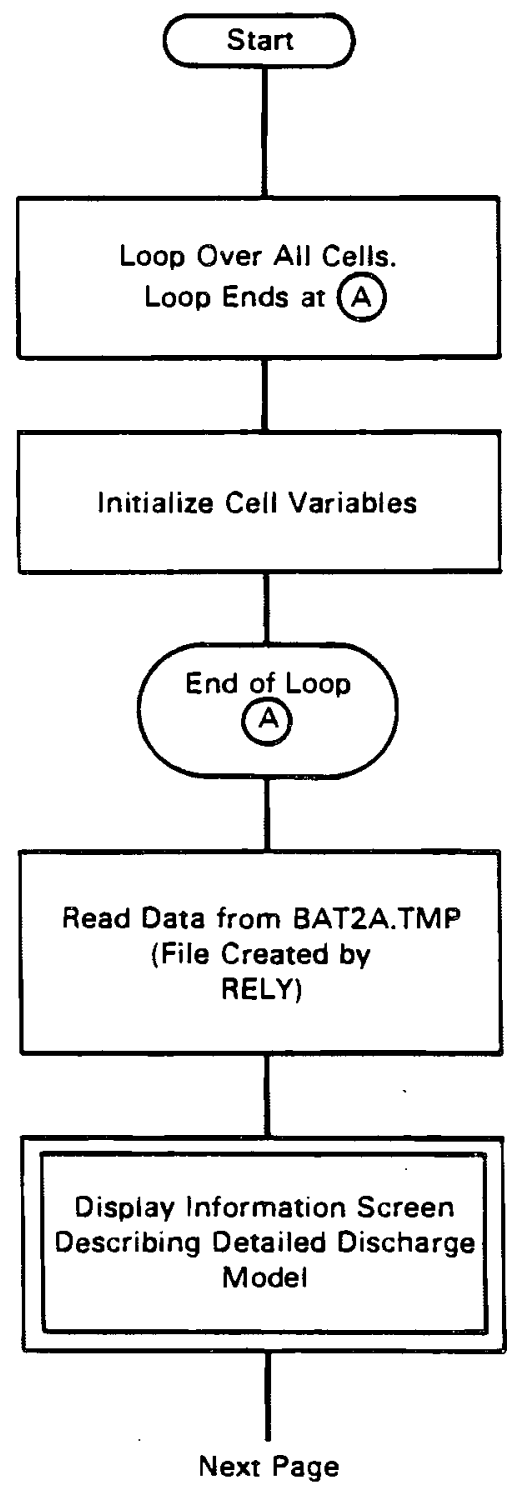

FIGURE B.5. Block Diagram of Program BAT2A 


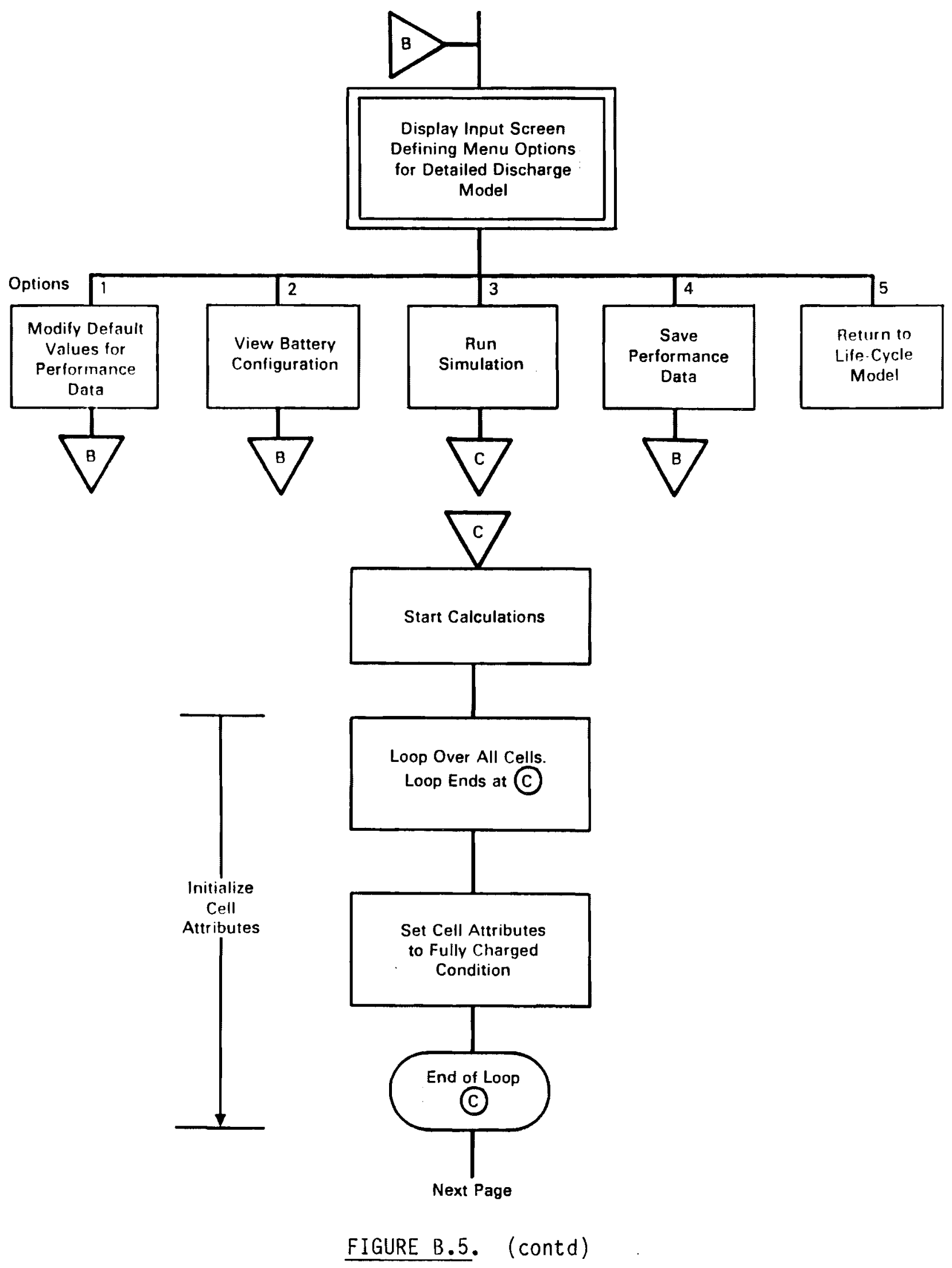

B. 11 


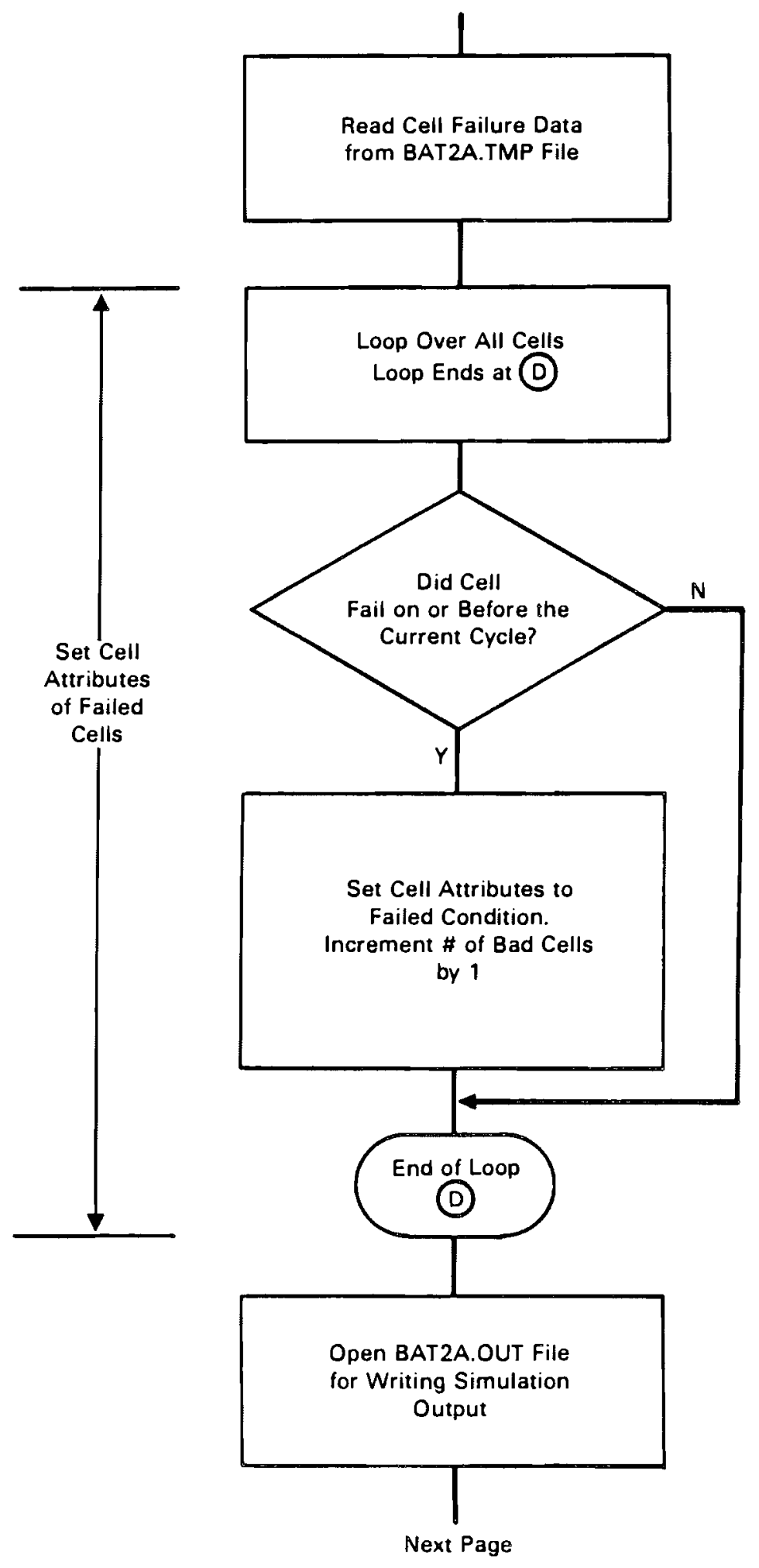

FIGURE B.5. (contd) 


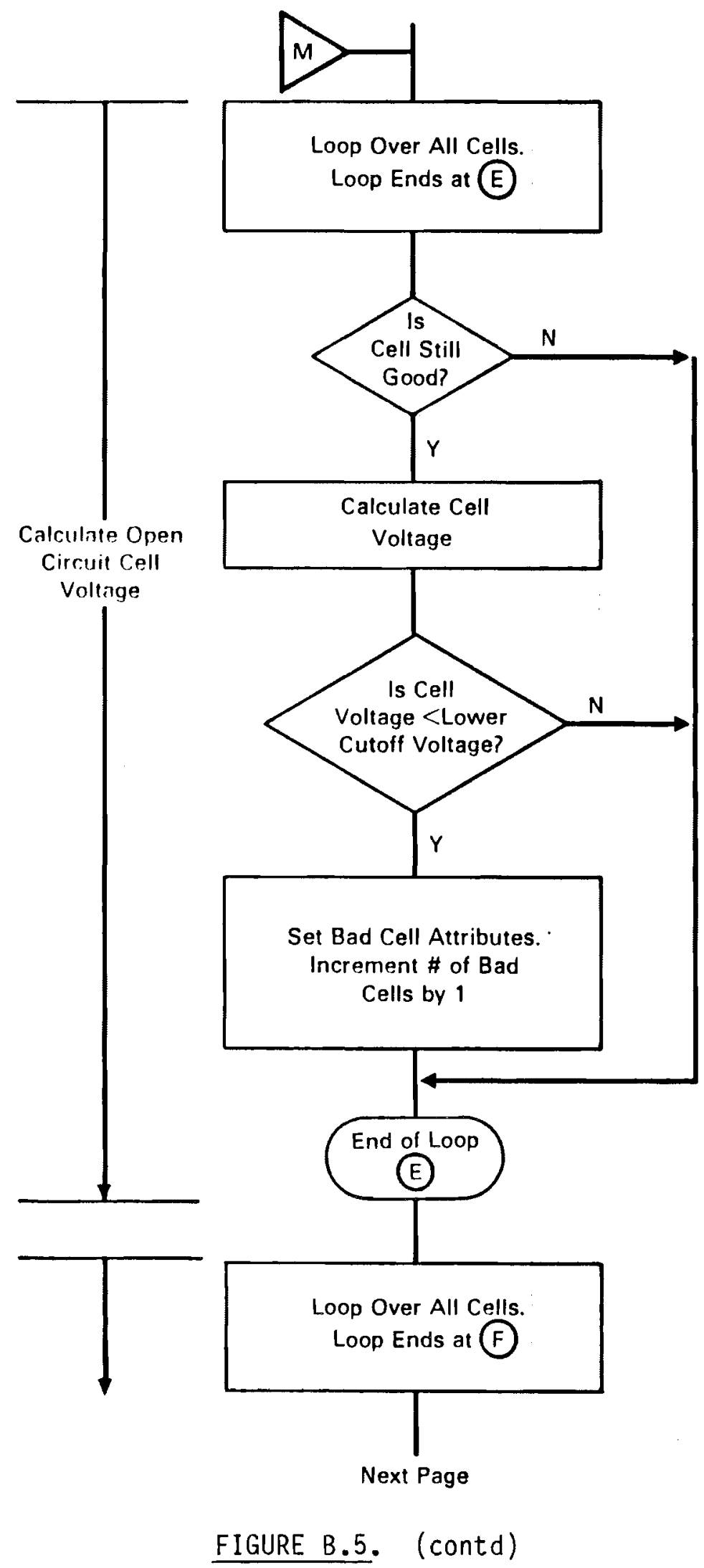

B. 13 


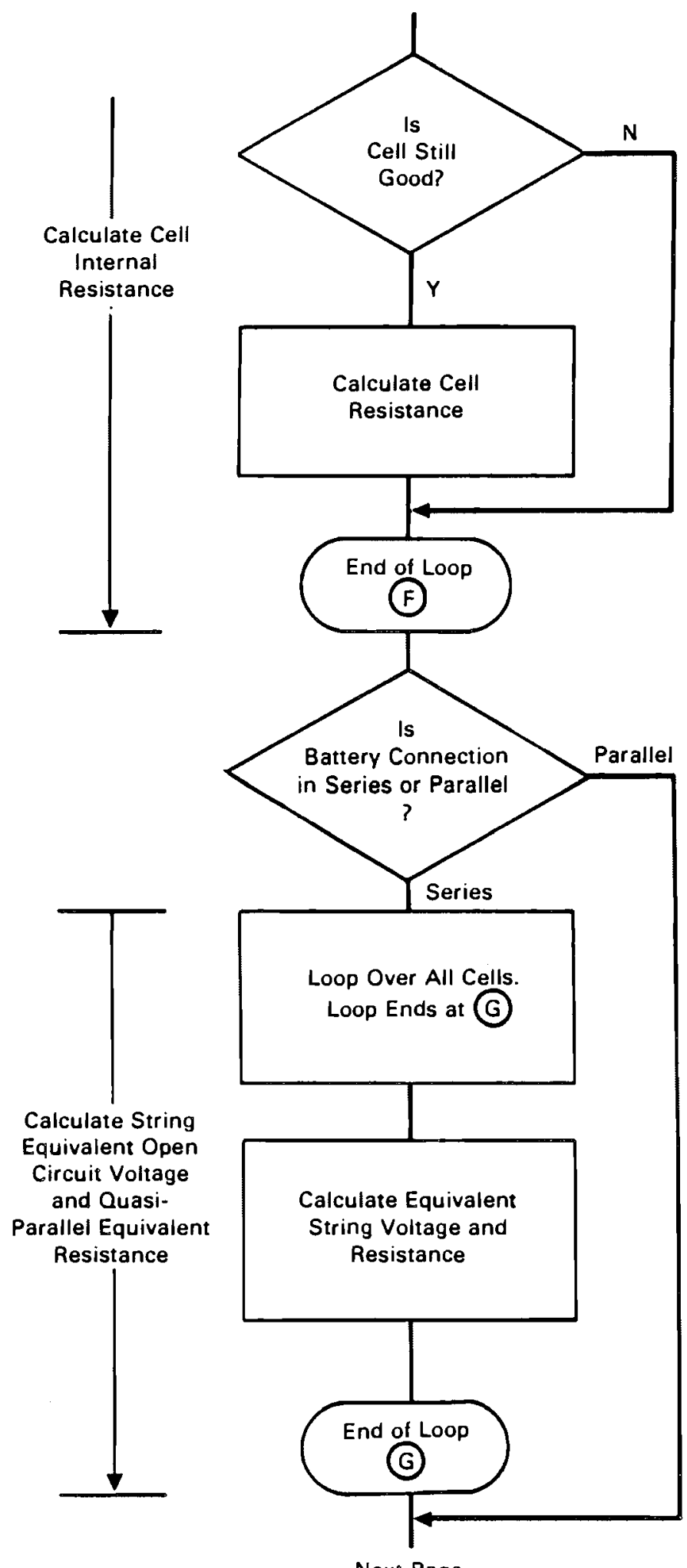

Nexi Page

FIGURE B.5. (contd) 

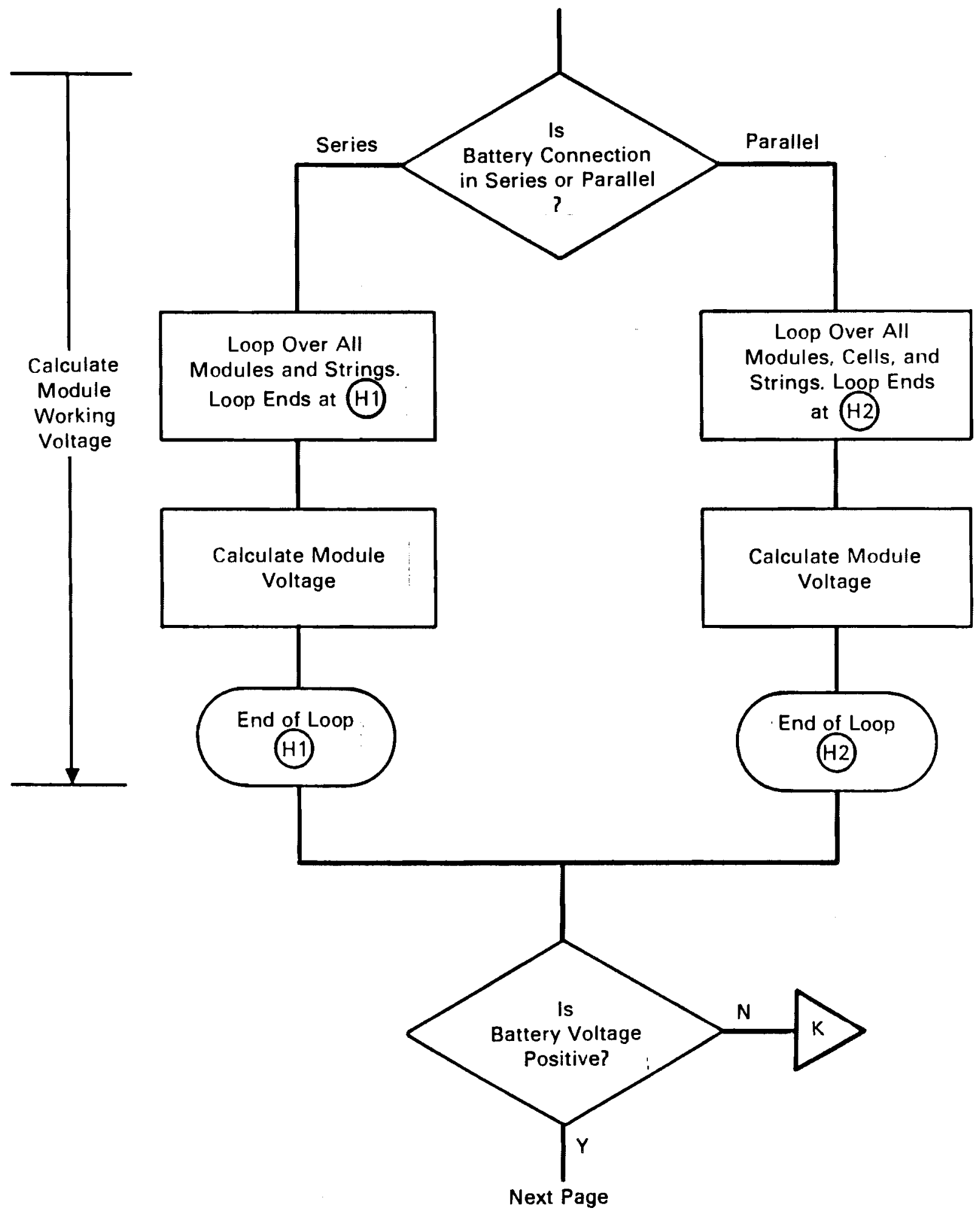

FIGURE B.5. (contd) 


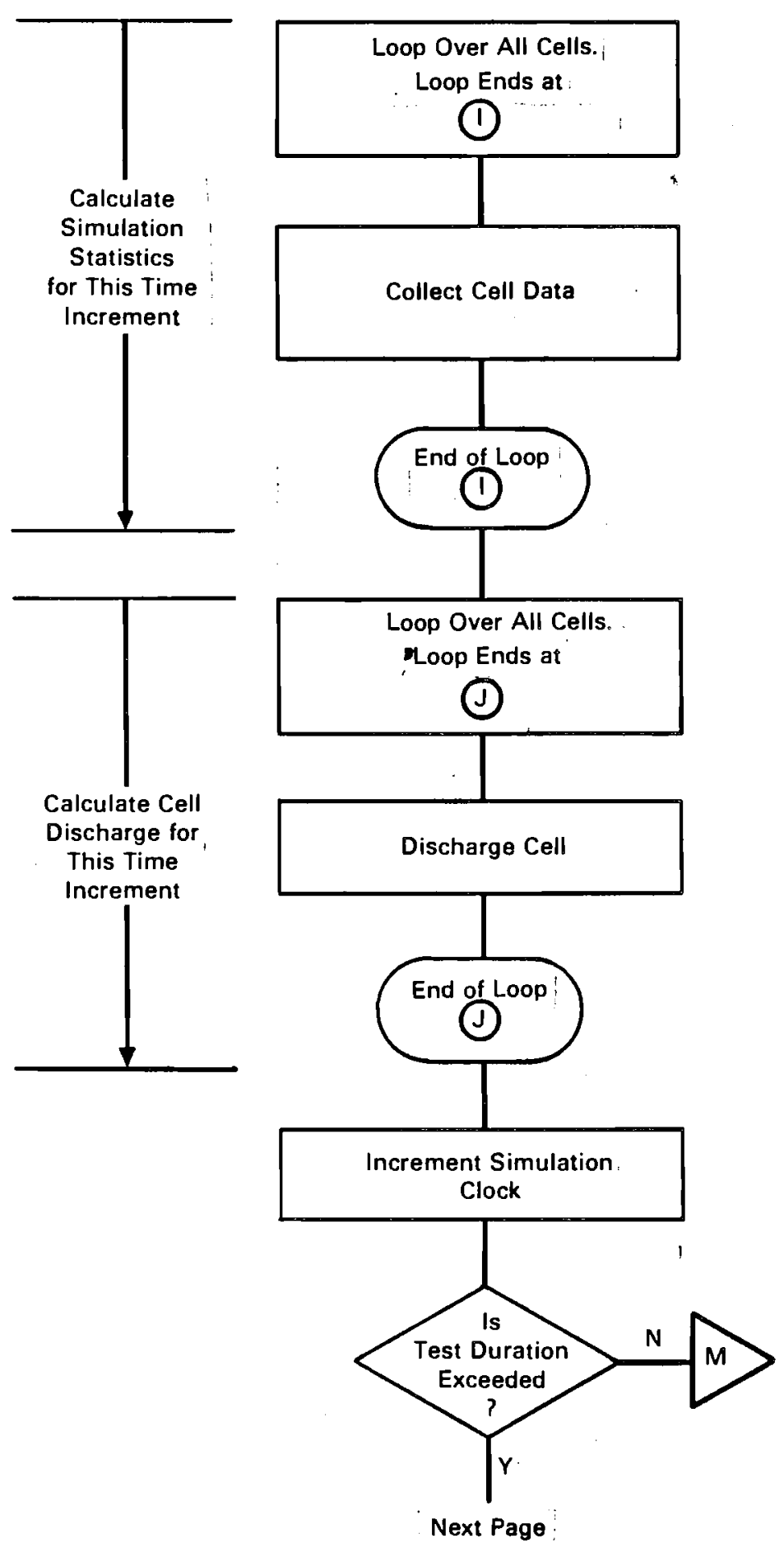

FIGURE B.5. (contd) 


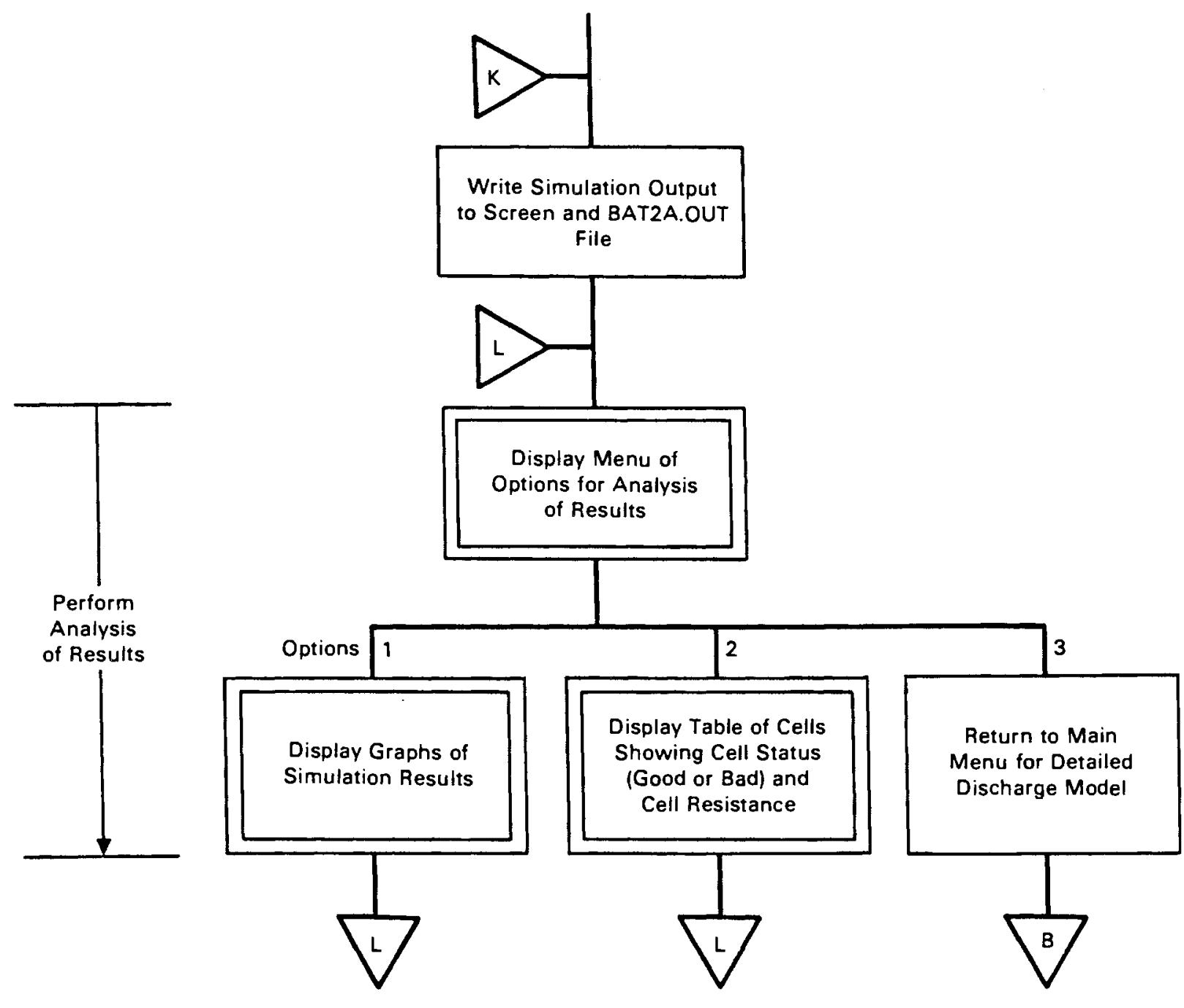

FIGURE B.5. (contd)

cycle. The cell failure information is obtained from the disk file BAT2A.TMP that was generated from the last simulation run performed by the Life-Cycle Model in subroutine SIMULAT. Program BAT2A provides the user with the option of adding switches within the battery configuration to minimize the impact of the failed cells.

Following execution of program BAT2A, the batch file re-executes program RELY. This displays the main menu again and offers the user the option to 
continue with more simulations of the three models or to select option $F$ to terminate program RELY. If option $F$ is selected, the batch file terminates and exits to the operating system.

The smaller, supporting subroutines called by programs RELY and BAT2A and subroutine SIMULAT are summarized in Table B.1. Six of these subroutines are used to enhance the screen displays, such as causing the computer to beep, causing the display to flash, reversing the foreground/background color schemes to highlight the screen, clearing the screen, erasing parts of the screen, and positioning the cursor. These subroutines are: BEEPER, BLINK, CLRSCN, MOVE, RESTORE, and REVERSE. The other nineteen subroutines listed in Table B.1 are used to initialize cell arrays, generate Weibull pseudorandom numbers, and perform Fortran I/O functions. Table B.2 summarizes the subroutines from the GRAFMATIC graphics library that are called by programs RELY and BAT2A to produce two-dimensional plots on the computer screen. 
TABLE B.1. Summary of Supporting Subroutines

Subroutine

BEEPER

BLINK

CLRSCN

FAILURE

GAMMA

INTEGER

GRPHMENU

INITIAL

MAINMENU

MOVE

OUTPG1
Description

Issues a beep when the simulation of the Detailed Discharge Model is done.

Uses the extended screen and keyboard control features described in Chapter 2 of the DOS Technical Reference (Microsoft, Inc. 1983) to cause the screen display to blink.

Uses the extended screen and keyboard control features to clear the screen.

Generates a Weibull-distributed pseudorandom number used to predict the battery chargedischarge cycle in which a cell will fail due to wearout.

Calculates the Gamma function of $(1+x)$ for $0 \leqq x \leqq 1$. This function subroutine is used to calculate the theoretical mean of the Weibull distribution.

Checks whether the user has input an integer value for parameters that require an integer input.

Displays the graphical analysis menu in the Detailed Discharge Model.

Numbers the cells consecutively over all strings and modules and sets a status flag using the four-dimensional cell array CELLDAT to indicate that the cell is working at the beginning of the Life-Cycle Model simulation.

Displays the main menu for the Detailed Discharge Model

Uses the extended screen and keyboard control features to move the cursor to any screen position specified by its row and column screen coordinates.

Echoes input data to the Life-Cycle Model back to the screen or to a user-specified disk file.
Calling Routine

BAT2A

BAT2A

RELY, BAT2A

RELY, SIMULAT

RELY

RELY

BAT2A

RELY

BAT2A

BAT2A

SIMULAT 
TABLE B.1. (contd)

Subroutine Description

Calling Routine

PERCENT Checks whether the user has input a decimal fraction for the cell freeze-thaw failure rate.

PG2HEAD

Writes the page headings for the second page of simulation output from the Life-Cycle Model to the screen or a user-specified disk file.

PG3HEAD

Writes the page headings for the third page of simulation output from the Life-Cycle Model to the screen or a user-specified disk file.

PG3LN1

Writes the final lines of simulation output from the Life-Cycle Model showing the failure frequency distribution of cell freeze-thaw and wearout failures by cycle ranges.

RANF

Returns a pseudonym number uniformly distributed between 0 and 1 .

SIMULAT

SIMULAT

SIMULAT

RANGE

Checks whether the user has input a reasonable value, i.e., between 0 and an acceptable maximum value. If reasonable data are not input, subroutine RANGE prompts the user for a new input value and continues to do so until the user inputs a value that is valid within the operational limits of the program.

RESCHCK Called when a cell fails. Subroutine RESCHCK sets the corresponding entry of the CELLDAT array equal to either plus or minus the current cycle, depending on whether the failed cell has an open or closed circuit failure mode. In addition, if the cell has an open circuit failure mode, subroutine RESCHCK sets a flag for the current string containing the cell to indicate that the string has failed.

RESTORE Uses the extended screen and keyboard control features to restore the normal light foreground and dark background color schemes used in the screen displays.

SIMULAT

RELY, SIMULAT, BAT2A

RELY

RELY, BAT2A 
TABLE B.1. (contd)

Subroutine Description

Calling Routine

REVERSE

Uses the extended screen and keyboard control features to reverse the normal foreground/backRELY, BAT2A ground color scheme used in the screen displays from a dark background and light foreground (displayed letters) to a light background and dark foreground to highlight the screen display.

RSLTMENU

Displays a menu giving the user the choice between graphical analysis, listing a table of cells, and returning to the main menu in the Detailed Discharge Model.

SCRNMENU Displays the screen selection menu below the main menu and prompts the user to select an input screen in the Detailed Discharge Model.

UPCAS

Translates a lower case input consisting of one character to the equivalent upper case character.

XSCAL Scales $X$-axis array for plotting Weibull probability density function.

YSCAL Scales $Y$-axis array for plotting Weibull probability density function.

RELY

BAT2A 
TABLE B.2. Summary of GRAFMATIC Subroutines Called by Programs RELY and BAT2A

Subroutine

QCMOV

QPTABL

QPTXT

QSETUP

QSMODE
Description

Moves cursor to the specified column and row on the screen.

Provides a two-dimensional plot on the screen of an $X-Y$ table of data. Subroutine QPTABL scales the graph, draws the axes, and plots a series of straight-line segments connecting the tabular points.

Writes text in the specified color on the screen graph starting at the specified column and row.

Defines the color and type (solid or dashed) used to plot lines and the color and symbol used to mark data on tabular plots.

Clears the screen and sets the resolution (number of columns and rows) in effect on the screen graphics.
Calling Routine

RELY

RELY, BAT2A

RELY, BAT2A

RELY, BAT2A

RELY, BAT2A 
APPENDIX C

SOURCE LISTINGS 
PROGRAM RELY

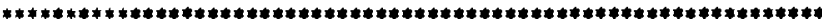

PURPOSE: estimates life of battery

LIMITATIONS AND PREREQUISITES:

LOGICAL NAMES AND FILES USED

2 = logical unit for output data file

ROUTINES USED

CLRSCN, REVERSE, RESTORE, RANGE, INTEGER, FAILURE

PERCNT, UPCAS, SIMLLAT, GALAM, XSCAL, YSCAL QSMDDE, QSETUP, QPTABL, QPTXT, QCMOV

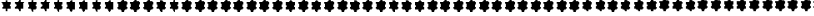

DEVEOPMENT INFORMATION:

CREATED BY : JANIS LITTLEFIED ON : 1985

PHIL COOPER

HARLAN HUBER JOHN DOVEY

AT : Battelle Pacific Northwest Laboratories Richland, Washington 99352

MACHINE/OPERATING SYSTEM: PC DOS V2.19

COMPILER : MICROSOFT FORTRAN77 V3.30

COMPILER SWITCHES : Dof ault

MODIFICATION HISTORY: none

MODIFIED BY :

ON :

REASON FOR MODIFICATION:

DESCRIPTION OF MODIFICATION:

CONSTANTS (PARAMETER STATEMENTS)

PARAMETER (NSAMPL $=1009$, NCELS $=12$ )

COMMON BLOCKS:

IMPLICIT

SINCLUDE: 'PARM. INC'

SINCLUDE: 'REYY. INC'

SINCLUDE: 'WEIBUL. INC'

PARM.INC -- size of battery

REYY.INC -- data info for RB $Y$

WEIBUL.INC -- Weibul distribution paraneters

VARIABLES:

CHARACTER:20 CHAR, XLABE, YLABE

CHARACTER 29 XLABI

CHARACTER $\$ 36$ XLAB2

CHARACTER 1 CHOICE

CHARACTER Ans*10

INTEGER COUNTER, $N, R$, TOPS, RUN, J, CYCLIF, IPOWER

INTEGER*2 NDOTS, LKOLOR, ISYMBL, KLRSYM, ICOL, IRO

INTEGER $* 2$ MODE, IORG, NPT, ITYPE, NCHAR, KOLOR $\begin{array}{ll}\text { REAL } & \text { XARRAY (NSAMPL), YARRAY (NSAMPL), XX (NSAMPL), YY (NSAMPL) } \\ \text { REAL } & \text { BAD, ROUND, R1, R2, XPSCALE, YPSCALE }\end{array}$

REAL

LOGICAL SECTA, SECTB, SECTC, SECTD, SECTE

VARIABLES USED IN THE WEIBULL EXAMPLE ONLY:

NDOTS, LKOLOR, ISYMBL, KLRSYM

MOOE, IORG, NPT, ITYPE, NCHAR, KOLOR, R

ICOL, IROW , ICOUNT, XLABE, XLEN

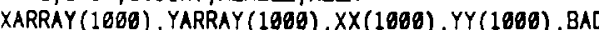

VARIABLES SET GY THE USER:

SHAPE, SCALE, PRENAY

CELREQ, STRGREQ, NODREQ

RUN, COUNTER, FDATA $(4,106)$, LOCATE, N

RESIST

VARIABLES REPRESENTING THE BATTERY CONFIGURATIDN:

CELLDAT $(10,10,20,1)$
C *** Get current screen sode -- reset before progran stops Call ORUODE (ModeBeg, ModeCol)

C *** Check to see if Detailed Discharge Model has just been run Open (3, file= 'STOP1. TuP', IOStat=IOChek)

IF (IDChek .eq. 6) then

Close (3)

go to 560

endif

$C * *$ Write title screen

CAU CLRSCN

WRITE $(*, 1)$ '

CALL REVERSE

1 FORMAT $(1 X$, A55)

WRITE $(*, 5)$

FORMAT $(1)$

WRITE $(*, 1)$ '

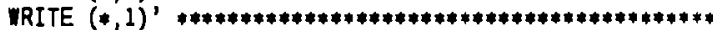

WRITE $(*, 1)$,

IRITE $(*, 1) '$ REIABILITY MODELING SYSTEY FOR ANALYSIS OF

WRITE (*,1)' SODIUM-SUUFUR BATTERY CONFIGURATIONS

WRITE $(*, 1)$ '

WRITE $(*, 1)$ ' PREPARED BY PNL FDR THE OFFICE OF ENERGY

WRITE $(*, 1)$ ' STORAGE AND DISTRIBUTION.

IRITE $(*, 1)$ '

WRITE $(*, 1)$ ' UNITED STATES DEPARTMENT OF ENERGY

WRITE $(*, 1)$ ' PROJECT MONITOR : J.E. QUINN

WRITE $(*, 1)$,

WRITE $(*, 1)$ ' AUTHORS: JANIS LITTLEIELD

TRITE $(*, 1)$ ' PHIL CDOPER

WRITE $(*, 1)$ ' HARLAN HUBER

WRITE $(*, 1)$ ' JDHN DOVEY

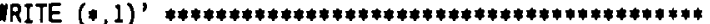

WRITE $(* 1)$ '

CAL RESTORE

2 FORUAT $(1 X, A 55)$

WRITE $(*, 2)$ '

WRITE $(*, 2)$ 'PROGRAM ESTIMATES SODIUM-SULFR GATTERY LIFE AND WRITE $(*, 2)$ 'PERFORMANCE CIVEN BATTERY CONFIGJRATION AND REIARITE $(*, 2)$ 'BILITY DATA.

WRITE $(*, 2)$ ' '

WRITE $(*, 2)$ '

READ $(*, 3) C$

TO BEGIN - HIT RETURN

FORWAT (AI)

596 CONTINUE

$M D D E=2$

CALL QSMODE (MODE)

Call CIrSen

IRITE $(*, 1)$

CALL REVERSE

WRITE $(*, 5)$

WRITE $(*, 1)$

TRITE $(*, 1)$

WRITE $(*, 1)$

WRITE $(*, 1)$ '

WRITE $(*, 1)$ 'ENTER

IRITE $(*, 1)^{\prime} \ldots$

WRITE $(*, 1) ' A$ - INPUT BATTERY TEST CONFIGURATION, CELL

WRITE $(*, 1)$

WRITE $(*, 1)$

WRITE $(*, 1)$ ' B - INPUT FAILURE RATES

WRITE $(*, 1)$ ' 
WRITE $(*, 1)$ ' C - RUN LIFE-CYCLE MODE

WRITE $(*, 1)^{\prime}$

WRITE $(*, 1)$ ' D - RUN DETAILED DISCHARGE MODE

WRITE $(*, 1)$ '

WRITE $(*, 1)^{\prime}$ E - DESCRIPTION OF FAILURE DISTRIBUTION MODE

WRITE $(*, 1)$,

WRITE $(*, 1)$ ' $F$ - EXIT PROGRAM

WRITE (*1)'

CALL RESTORE

WRITE $(*, 2)$, ,

WRITE $(*, 2)$ ' '

1001 WRITE (*'(A)')' ENTER LETTER FOR CHOICE: '

READ (*,' (BN, A1)', ERR=1001) CHOICE

IF (CHOICE.EQ. 'A' .OR. CHOICE .EQ. 'a') GOTO 200

IF (CHOICE. EQ. 'B' .OR. CHOICE .EQ. ' $b$ ') GOTO 306

IF (CHOICE.EQ. 'C' OR. CHOICE .ER. ' $c$ ') COTO 400

IF (CHOICE.EQ. ' $D$ ' .OR. CHOICE .EQ. 'd') GOTO BOQ

IF (CHOICE. EQ. 'E' .OR. CHOICE .EQ. 'O') COTO 108

IF (CHOICE.EQ. 'F' .OR. CHOICE .EQ ' '') COTO 690

GOTO 1001

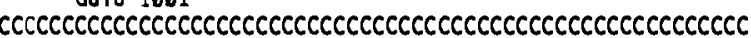

CCCC MENU ITEN A:

CCCC input battery test configuration, cell CCCC

$C C C C$ characteristics and performance requ i renents $C C C C$

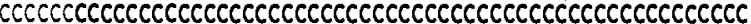

200 CONTINUE

SECTB $=$. TRUE.

CALI CLRSCN

WRITE $(*, 1)^{*}$

CALL REYERSE

WRITE $(*, 5)$

WRITE $(*, 1)$ '

WRITE $(*, 1)$

WRITE $(*, 1)$

WRITE $(*, 1)$

WRITE $(*, 1)$ ' THE BATTERY CONFIGURATION IS ENTERED BY

WRITE $(*, 1)$ ' SPECIFYING THE NUMBER OF CE $\perp S$ IN SERIES PER

WRITE $(, 1)$ ' STRING, THE NUMBER OF STRINGS IN PARNLE PER

MRITE $(*, 1)$ ' MODUL, AND THE NUMBER OF MOOULES IN SERIES.

WRITE $(*, 1)^{\prime}$

CALL RESTORE

MRITE $(*, 1)^{\prime}$

1007 WRITE(*,'(AI)')' ENTER NUMBER OF CELIS PER STRING: '

$\operatorname{READ}\left({ }^{\prime}, '(A 1 \theta)\right.$ ', ERR=1007) Ans

IF (Ans EQ. '") Go To 1687

Read (Ans, 2082, Err $=1807$ ) Tenp

CALL RANGE (Tenp, Rea I (PLNSIZ), 1.)

Cells = Teap

WRITE $(*, 1)^{\prime}$,

1008 WRITE $\left.(*, '(A))^{\prime}\right) '$ ' ENTER NUMGER OF STRINCS IN PARALE: '

READ (*, ' (A16) ', ERR=1068) Ans

IF (Ans .EQ. ' ') Go To 1068

Read (Ans, 2602, Err $=1068$ ) Tenp

CALL RANGE (Teap, Real (COLSIZ), 1.)

String $=$ Teap

MRITE $(*, 1)^{\prime}$,

1009 WRITE $\left.(*, '(A))^{\prime}\right)$ ' ENTER MUMBER OF MODULES IN SERIES: '

READ (*,' (A1B)', ERR=1089) Ans

IF (Ans .EQ. '',) Go To 1089

Read (Ans, 2002, Err = 1009) Tenp

CALL RANGE'(Temp, Real (ROWSIZ) , 1.)

Nodule = Teap

WRITE $(*, 1)$ '

WRITE $(*, 1)$,

1010 WRITE ( ' (A) ')' ARE THESE VALUES CORRECT? (Y/N) :

$\operatorname{READ}\left(*, '(A 1)^{\prime}\right.$, ERR=1610) $C$

IF ( NÓT. (C .EQ 'Y' OR. $C$ EQ. ' $y$ ' OR.

C.EQ. ' $N$ ' OR. ( E EQ. ' $n$ ')) GO TO 1610

c
201 CONTIMUE

CNI CLRSCM

WRITE $(*, 1)$ '

CNI REVERSE

WRITE $(*, 5)$

VRITE $(*, 1)$

WRITE $(*, 1)$ '

WRITE $(*, 1)$

VRITE $(*, 1)$

TRITE $(*, 1)$ ' BATTERY PERFORUANCE IS SPECIFIED BY THE USER IN

VRITE $(*, 1)$ ' TERIS OF STRING, MODUE AND BATTERY REQUIREMENTS.

WRITE $(*, 1)$ ' THESE REQUIRENENTS INDICATE THE NUMBER OF SUB-UNITS

VRITE $(1,1)$ ' THAT VUST BE GFECTIVEY OPERATING FOR THE LARGER

IRITE $(*, 1)$ ' UNIT TO REMAIN IN OPERATION. FOR EXAMPLE, IF CELL

WRITE $(*, 1)$ ' FAILURES REDUCE THE NUMBER OF OPERATING CELLS BEOH

WRITE $(*, 1)$ ' THE STRING RERUIREMENT THE STRING IS NO LONGER

WRITE $(*, 1)$ ' OPERABLE.

WRITE $(*, 1)$,

CAL RESTORE

MRITE $(*, 1)$, ,

1611 RITE (', '(A)')' ENTER THE MINIMN NUMBER OF GOOD CELS

WRITE(*' (AU)') ' RERUIRED PER OPERATING STRING: '

$\operatorname{READ}(*, '(A 1 \theta)$ ', ERR=1011) Ans

IF (Ans EQ.',') Go To 1011

Read (Ans, 2002, Err = 1011) Tenp

CNI RANGE (Teap, Real (CE $\perp S), 1$.)

CollReq = Tenp

IRITE $(*, 1)^{\prime}$ '

1612 WRITE(*,'(A)')' ENTER THE MINIMM NUMBER OF GOOD STRINGS

WRITE(*', (AI)') ' RERUIRED PER OPERATING MODUE: '

READ (*,' $(A 16)$ ' , ERR=1012) Ans

IF (Ans .EQ. ' ") Go To 1012

Read (Ans, 2062, Err = 1012) Tenp

CAL RANGE (Teap, Real (STRING), 1.)

StrgReq $=$ Tenp

WRITE $(*, 1)^{\prime}$

1013 WRITE (*,' $\left.(A)^{\prime}\right)$ ' ENTER THE MINIMUM NUMBER OF GOOD MODULES WRITE (*, '(A) ') ' REQUIRED FOR MINIMUM BATTERY CAPACITY:

READ (*', (A10)', ERR=1013) Ans

IF (Ans .ER. ' ') Go To 1613

Read (Ans, 2062, Err = 1013) Tenp

CNI RANGE (Teap, Real (MODULE), 1.)

HodReq = Teap

WITE $(*, 1)^{\prime}$

1014 WRITE $\left.(*, '(A))^{\prime}\right)$ ' ARE THESE VALUES CORRECT? $(Y / N)$ : '

$\operatorname{READ}(*, '(B N, A 1)$ ', ERR $=1014) C$

IF (.NOT. (C .EQ. ' $Y$ ' OR. C .EQ. ' $y$ ' .OR

1 (C.EQ. ' $N$ ' OR. C.EQ.' $n$ ')) CO TO 1014

IF (C.EQ.' ' $N$ ' OR.C.EQ. ' $n$ ') GO TO 201

GO TO 500

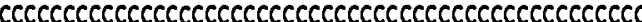

CCCC MENU ITEA B: CCCC

CCCC input failuro data $\quad$ CCCC

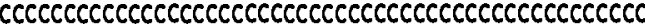

360 CONTINUE

SECTC $=$ TRUE

CALL CLRSCN

IRITE $(*, 1)$ '

CALL REYERSE

TRITE $(*, 5)$

WRITE $(*, 1)$ '

MRITE $(*, 1)$

WRITE $(*, 1)$

FAILURE DATA

WRITE $(*, 1)$

WRITE $(*, 1)$ ' FAILURE DATA RERUIRED INCLUDES INFORMATION IRITE $(*, 1)$ ' ON TYPES OF FAILURES, FAILURE RATES, AND POSTWRITE $(*, 1)$ ' FAILURE RESISTANCE. THIS PROGRAM HAS THE WRITE $(*, 1)$ ' CAPABILITY OF MODELING 2 TYPES OF INDEPENDENT WRITE $(*, 1)$ ' FAILURES 


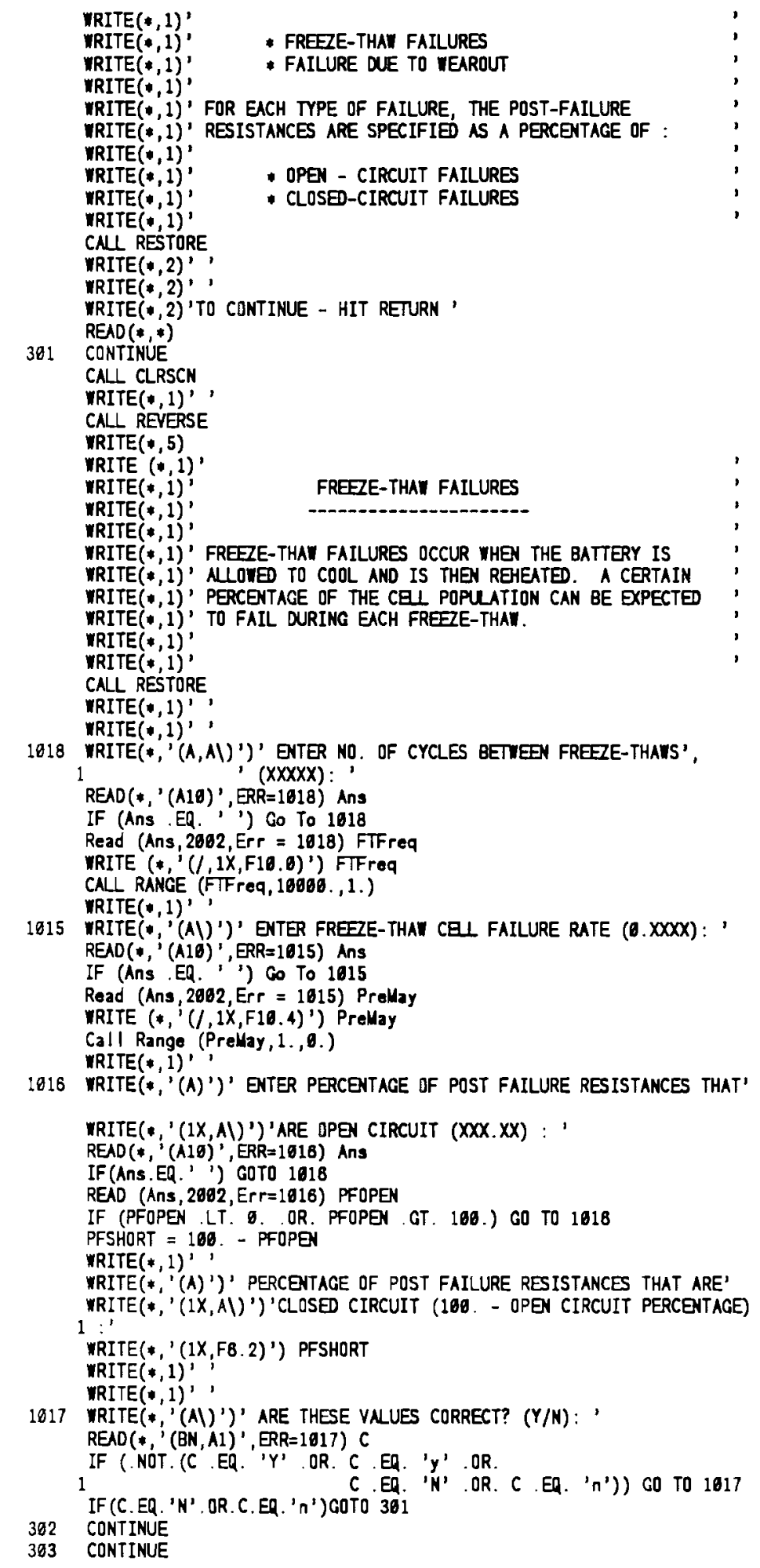

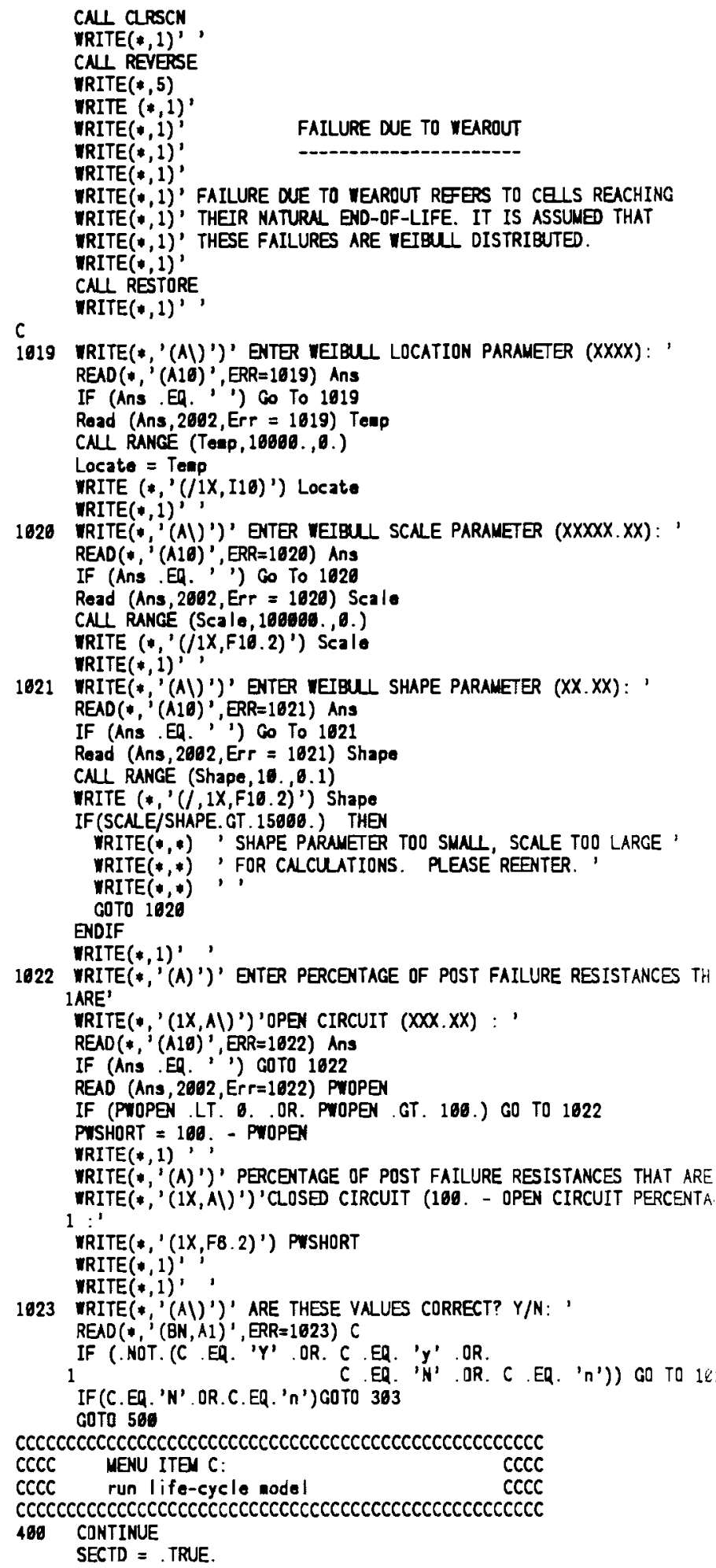

C. 3 
IF (. NOT. (SECTB .AND. SECTC)) THEN

WRITE $(*, 4000)$

4000

FORMAT(' YOU WUST DO BOTH DPTIONS A AND B BEFORE OPTION $C$ ') IRITE $(*, 4001)$

4001 FORMAT (' TO CONTINUE - HIT RETURN')

READ (*,*)

ENDIF

$c$

CALL CLRSCH

MRITE $(*, 1)^{\prime}$,

CAIL REVERSE

WRITE $(*, 5)$

WRTTE $(*, 1)$

WRITE $(*, 1)$,

WRITE $(*, 1)$

CALL RESTORE

WRITE $(*, 1)^{\prime}$

WRITE $(*, 1)^{\prime}$

1024 WRITE $(*, '(A))$ ')' SPECIFY THE NUMBER OF SIMULATION RUNS: '

READ (*,' (A10)', ERR =1024) Ans

IF (Ans .EQ. ' ') Go To 1024

Read (Ans, 2002, Err $=1024$ ) Tenp

CNL RANGE (Teap, 16006.,1.)

Run $=$ Temp

WRITE $(*, 1)$ ',

WRITE $(*, 1)$,',

1925 WRITE (*', 'AU)')' IS THIS VALUE CORRECT? (Y/M):

READ (*, '(BN, A1)', ERR $=1025) C$

IF (.NOT. (C . EQ. 'Y' OR. C .ER. ' $y$ ' .OR.

1 C.EQ. ' $N$ ' OR. $C$. ER. ' $n$ ' $\left.\left.{ }^{2}\right)\right)$ GO TO 1025

IF(C.EQ.' 'N'.OR.C.EQ. 'n') GOTO 400

CALL CLRSCN

WRITE $(*, 1)$ '

COUNTER $=0$

CALL SIMULAT (RUN, COUNTER, CYCLIF)

C

WRITE $(*, *) '$,

WRITE $(*, *), 1$

WRITE $(*, *)$,

1926 CAL MOVE $(25,1)$

WRITE(*,' (A) ')

1 ' REPEAT THIS PROCESS FOR SAME INITINL DATA? (Y/N):'

READ (*, ' (BN, A1)', ERR =1026) C

IF (NOT. (C .EQ ' 'Y' OR. C ER ' ' $Y$ ' OR

1. C.EQ. 'N' OR. C .EQ. ' $n$ ')) GO TO 1026

IF ( $C$. EQ. ' $Y$ ' . OR. C .EQ. ' $Y$ ') ' GOTO 408

cccceccececcecceccecccccccccccccccccccccccccccc

CCCC MENU ITEN D:

CCCC run detailed dischargo nodel $\quad C C C C$

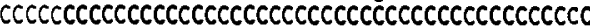

800 IF (.NOT. (SECTB . AND. SECTC . AND. SECTD)) THEN WRITE $(*, *)$

1 'YOU MUST DO MEIU OPTIONS A B AND C FIRST WRITE $(*, *)$ 'TO CONTINUE - HIT RETURN' $\operatorname{READ}(*, 3) \mathrm{C}$

ENDIF GO TO 500

OPEY (2, FILE='BAT2A. TMP', STATUS='NEW' ,FORLE'FORMATTED')

WRITE $(2,801)$ MODUE, STRING, CELS, LOCATE, SHAPE, SCNLE

891 FORMAT (4I16,2F28.16)

WRITE $(2,802)$ CYCLIF

892 FORMAT (I10)

WRITE $(2,863$, Err $=804)$

883 FORMAT (4F28.18)

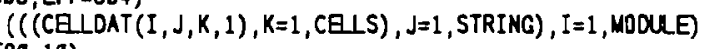

CLOSE (2)

Call QSMODE (ModeBog)
STOP ',

$C$ *** Branch to 804 neans a file error has occurred

804 Call QSMODE (HodeBog)

Call Clisen

Write $(*, *)$ 'Additional Storage Space Needed."

Vrite $(*)$, Use Data Disk or Hard Disk.

co To 801

cccecccccccccccccccccccccccccccccccccccccccccccccccccccccc

CCCC WEN ITEU E:

CCCC description of failure distribution model $C C C C$

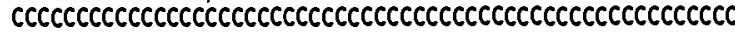

100 CONTINUE

SECTA $=$.TRUE

CALI CLRSCN

WRITE $(*, 1)$ '

CNLL REVERSE

WRITE $(*, 5)$

WRITE $(*, 1)$,

IRITE $(* 1)^{\prime}$ ' DESCRIPTION OF FAILURE DISTRIBUTION MODE.

WRITE $(*, 1)$,

WRITE $(*, 1)$

WRITE $(* 1)$ ' FAILURES DUE TO MEAROUT (NATURAL END OF LIFE)

WRITE $(*, 1)^{\prime}$ ARE ASSUMED TO BE WEIBUL DISTRIBUTED. THE

WRITE $(*, 1)$ ' DISTRIBUTION HAS THREE PARAMETERS THAT MUST

WRITE $(*, 1)$ ' BE SPECIFIED

WRITE $(*, 1)^{3}$

WRITE $(*, 1)$ ' LOCATION PARAMETER - MINIMM POSSIBLE NUMBER

WRITE $(*, 1)$ ?

WRITE $(*, 1)$

WRITE $(*, 1)$ ',

MRITE $(*, 1)$,

(TYPICA VALUE $=1599.9)$

URITE $(*, 1)$ ' SHAPE PARMMETER - CONTROLS SHAPE OF

URITE $(*, 1)$ "

WRITE $(*, 1)$

CAL RESTORE

URITE $(*, 2)$ '

WRITE $(*, 2)$ ',

WRITE $(*, 1)$ 'TO CONTINUE - HIT RETURN'

READ $(* ; *)$

CNI CLRSCH

URITE $(*, 1)$ '

CNII REVERSE

WRITE $(*, 5)$

WRITE $(*, 1)$

WRITE $(*, 1)$

WRITE (*1)'A WEIBUL SHAPE PARAMETER CONTROLS THE SHAPE

WRITE $(*, 1)$ 'OF THE FAILURE OISTRIBUTION. FOR SHAPE

WRITE $(*, 1)$ 'PARAMETERS GREATER THAN 1 THE FAILURE RATE IS

WRITE $(*, 1)$ 'INCREASING WITH TIME. A SHAPE PARAMETER EQUAL

WRITE $(*, 1)$ 'TO 1 MEANS THE FAILURE RATE IS CONSTANT. SHAPE

WRITE $(*, 1)$ 'PARAMETER VALUES LESS THAN 1 MEAN THE FAILURE

WRITE $(*, 1)$ 'RATE IS DECREASING WITH TIME.

WRITE $(*, 1)$ '

WRITE $(*, 1)$

CALI RESTORE

WRITE $(*, 2)^{\prime}$

WRITE $(*, 2)$ '

IRITE $(*, 2)$ 'TO CONTINUE - HIT RETURN'

$\operatorname{READ}(*, *)$

221 CONTINUE

C

MODE $=2$

CAIL QSUODE(MODE)

CAI CLRSCN

VRITE $(*, 1)$

CAIL REVERSE

WRITE $(*, 5)$

WRITE $(*, 1)$ ' 
WRITE $(*, 1)$;

WRITE $(*, 1)$ '

WRITE $(*, 1)$ '

WRITE $(*, 1)$ '

WRITE $(\bullet, 1)$ 'ENTER

WRITE $(0,1)$ '..-

WRITE $(\bullet, 1)$ '

WRITE $(*, 1) ' \wedge$ - ACTUAL WEIBUL DISTRIBUTION DENSITY FUNCTION

WRITE $(*, 1)$, BASED ON USER INPUT WEIBUL PARAMETERS

VRITE $(*, 1)$ '

WRITE $(*, 1) ' B$ - DENSITY FUNCTION OF RANDOM CEL FAILURES

MRITE $(*, 1)$ '

WRITE $(*, 1)^{\prime}$

CALL RESTORE

WRITE $(*, 1)$ ' :

WRITE $(*, 1)$ ',

222 MRITE (*' (AI)')' ENTER LETTER FOR CHOICE: '

READ (, ' (BN, $A 1)$ ', ERR=222) CHOICE

IF (CHOICE .ER. 'A' .OR. CHOICE .ER. ' $a$ ' .OR. CHOICE .ER. 'B'

1 . OR. CHOICE .EQ. 'b') GOTO 223

GOTO 222

$223 \quad \mathrm{MDDE}=2$

CALL QSMODE(MODE)

CONTINUE

CALL CLRSCN

WRITE $(*, 1)^{\prime}$

CNLL REVERSE

WRITE $(*, 5)$

TRITE $(*, 1)$

WRITE $(*, 1)$ '

WRITE $(*, 1)$

WRITE $(*, 1)$

EXMMPLE WEIBULL DISTRIBUTION

IF(CHOICE. EQ ' $A$ ' OR. CHOICE ER ' ') THEN

WRITE $(*, 1)$ 'FOL LOWING IS THE ACTUN WEIBUL DISTRIBUTION DENSITY' WRITE $(*, 1)$ 'FUHCTION BASED ON THE SPECIFIED MEIBULL PARAMETERS.

BSE

WRITE $(*, 1)$ 'THE FOLLOWING DISTRIBUTION SIMLATES RANDON CEL WRITE $(*, 1)$ 'FAILURES BASED OH THE SPECIFIED WEIBUL PARMMETERS, ENDIF

WRITE $(*, 1)^{\prime}$

CALL RESTORE

TRITE $(*, 1)^{\prime}$,

WRITE $(*, 1)$ ',

WRITE $(*, 1)$ '

1002 WRITE (*', '(AI)')' ENTER LOCATION PARAMETER: '

READ (*' ' (A10)', ERR=1062) Ans

IF (Ans .EQ. ' ') Go To 1002

Read (Ans, 2062, Err = 1982) Tomp

CALL RANGE (Teap, 10000., Ө.)

Locate $=$ Teap

MRITE $(*, 1)^{\prime}$,

WRITE $(*, 1)$, ,

1003 VRITE( '(A) ')' ENTER SCALE PARAMETER:

READ (*, ' (A10)', ERR=1003) Ans

IF (Ans .EQ. "') Go To 1603

Read (Ans, 2002, Err = 1063) Scalo

CALL RAMGE (Scalo, 108000.,0.00001)

WRITE $(*, 1)$,

WRITE $(*, 1)$ ',

IF (LOCATE/SCALE GT , 1.EB) THEN

WRITE $(*, *)$ ' LOCATE/SCALE CANNOT EXCEED 1,000,000 '

WRITE $(*, *)$, FOR PLOTTIMG. PLEASE REENTER.

WRITE $(*, *)$,

GO TO 1002

ENDIF

1004 MRITE(*, '(AY)')' ENTER SHAPE PARAMETER: '

READ (*,' (A10)', ERR $=1604)$ Ans

IF (Ans .EQ. "' ') Go To 1004

Read (Ans, 2002, Err = 1804) Shape

CALL RANGE (Shapo, 10.,0.1)

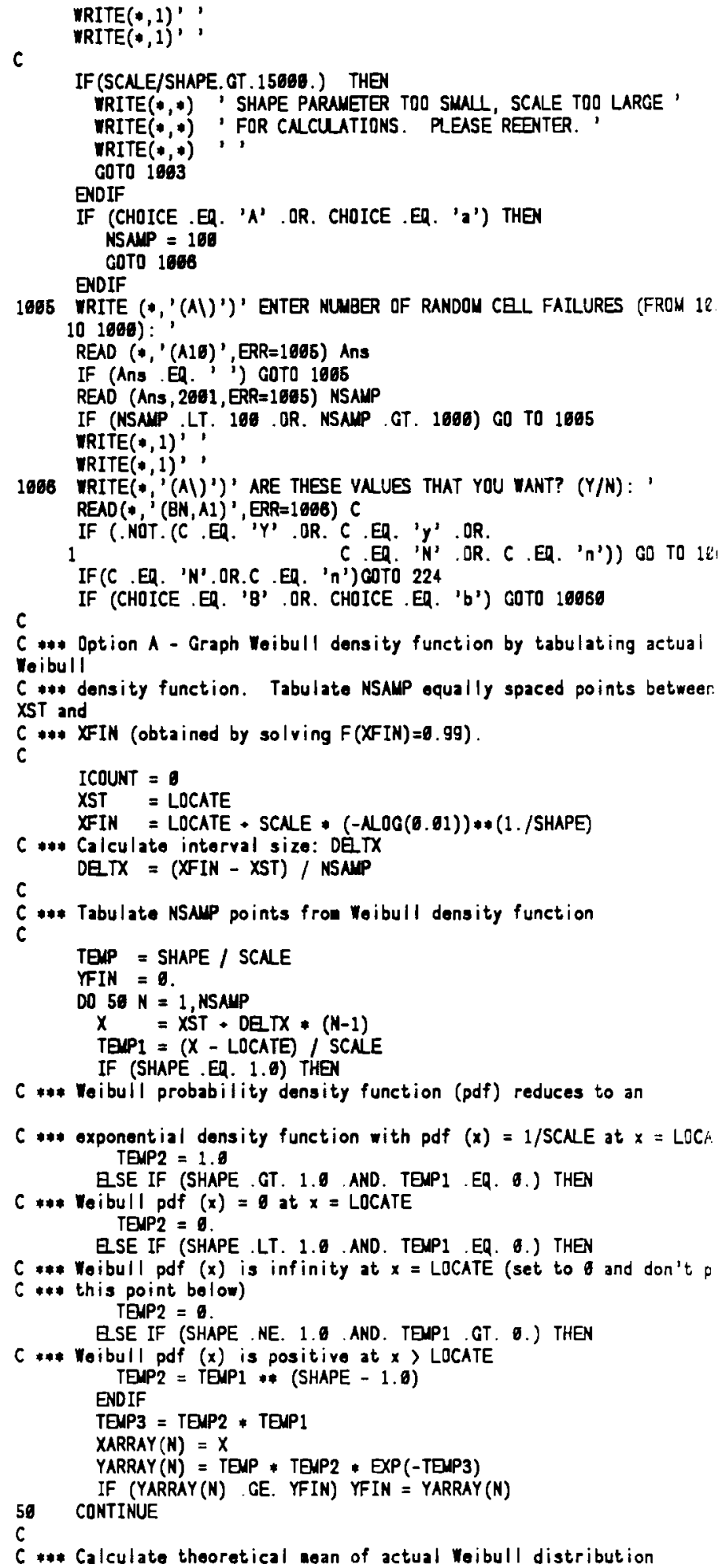

C *.* Option A - Graph Moibull density function by tabulating actual Woibull

C *w density function. Tabulate NSAMP equally spaced points between XST and

$C$ *** XFIN (obtained by solving $F(X F I N)=0.99$ )

C

ICOUNT $=0$

XST = LOCATE

XFIN = LOCATE + SCALE * (-NOG(0.01))**(1./SHAPE)

$C *$ Calculato interval sizo: DE TX

DETX = (XFIN - XST) / NSNMP

$C$ ** Tabulate NSAPP points fron Woibull density function

TEUP = SHAPE / SCNLE

VFIN $=0$

DO $50 \mathrm{~N}=1$, NSAMP

$X=X S T \cdot D E T X *(N-1)$

TEAPI $=(X$ - LOCATE $)$ / SCALE

IF (SHAPE .EQ. 1.6) THEN

$C$ *** Veibull probability density function (pdf) reduces to an

$C$ *** exponential density function with pdf $(x)=1 /$ SCNE at $x=$ LOC TEMP2 = 1.0

BSE IF (SHAPE GT 1. AND. TEMP1 EQ. 0.) THEN

$C$ *** Veibull pdf $(x)=0$ at $x=$ LOCATE TEXP2 $=0$.

日SE IF (SHAPE .LT. 1.0 AND. TEMP1 EQ. B.) THEN

$C$ *** Woibull pdf $(x)$ is infinity at $x=$ LOCATE (set to $\theta$ and don't $p$

$C$ *.* this point bolow) TEMP2 $=0$.

ESE IF (SHAPE .NE. 1. AND. TEMP1 GT. . .) THEM

C *** Woibull pdf $(x)$ is positive at $x$ ) LaCATE TEAP2 = TEXP1 ** (SHAPE -1.0$)$

ENDIF

TEUP3 = TEUP2 * TEUP1

XARRAY $(N)=X$

YARRAY $(N)=$ TEXP * TEAP2 * EXP $(-$ TEMP3 $)$

50 CONTINUE

IF (YARRAY(N) . GE. YFIN) YFIN = YARRAY(N)

c

C *** Calculate thooretical moan of actual Woibull distribution 
c

$A R G=1 . / S H A P E$

GAN = GAMM (ARG)

AVE = LOCATE * SCALE * GA

C*** Scale for plotting

C

CALI YSCN (YFIN, IPOWER, YPSCALE)

IF (YPSCALE . NE. 1.) THEN

DO $51 N=1$, NSALP

YARRAY $(N)=$ YARRAY $(N) /$ YPSCALE

51 CONTINUE

ENDIF

SUN $=6$.

NPT $=$ NSAMP

$Y S T=0$

GOTO 72

C

$C$ *** Option B - Graph Weibull density function by randoely sanpling Neibull

$C$ *** distribution and grouping into histogran cells.

$C$ *** Initialize variables.

18060 ICOUNT $=0$

DO $60 N=1$, NSAMP

$X X(N)=0.0$

$Y Y(N)=0.0$

XARRAY $(N)=0.0$

60

$\operatorname{YARRAY}(\mathrm{N})=0.0$

CONTINUE

SUM $=0.0$

XMAX $=0.0$

DO $76 N=1$, NSAMP

$X X(N)=N$

CAI FAILURE(YY(N))

$\operatorname{IF}(Y Y(N) . G T . X N U X) \quad X U N X=Y Y(N)$

SUM = SUN $\cdot$ YY (N)

70 CONTINUE

$C$ ** Calculate average of sanpled weibull distribution

AVE = SUM / NSAMP

NDCEL = (XMAX-LOCATE)/NCELS

$C$ *** Number of cell intervals to plot

NPT = NCELIS 1

DO $80 N=1, N P T$

$X 1=$ LOCATE+ $(N-1) *$ WOCGL

$X_{2}=X_{1}+$ WDCEL

$\operatorname{XARRAY}(N)=\left(X_{1}+X_{2}\right) / 2$

DO $71 K=1$ MSAYP

$\operatorname{IF}(Y Y(K)$.GE.X1 . AND. YY $(K) \cdot L T . X 2) \quad Y$ ARRAY $(N)=Y \operatorname{ARRAY}(N)+1$

71 CONTINUE
80 CONTINUE

FRC $=1 . /$ (NSAMP $*$ WDCEL)

DO $86 K=1$, NPT

$\operatorname{YARRAY}(K)=\operatorname{YARRAY}(K) * F R C$

$$
86 \text { CONTINUE }
$$

$C$ *** Use the value of the weibull probability density function (pdf)

$C * * *$ at $x=$ LOCATE as the first plat point in the array to be plotted

IF (SHAPE .EQ. 1.6) THEN

C *** Weibull pdf at $x=$ LOCATE

YLOCATE $=1 . /$ SCALE

ESE IF (SHAPE .GT. 1.6) THEN

$C * *$ Weibull pdf at $x=$ LOCATE YLOCATE $=0$

ELSE IF (SHAPE .LT, 1.6) THEN

$C * *$ Infinite so set to $\theta$ and don't plot this point below YLOCATE $=0$

$c$
$C$ w. Insert this plot point as the first point in the plot arrays

C

DO $87 K=1$, MPT

$N=$ NPT $-K+1$

$\operatorname{XARRAY}(N+1)=$ XARRAY $(N)$

YARRAY $(N+1)=$ YARRAY $(N)$

87 CONTINUE

NPT $=$ NPT * 1

XARRAY $(1)=$ LOCATE

YARRAY $(1)=$ YOCATE

$\operatorname{MAX}=0.0$

DO $555 \quad N=1$, NPT

IF (YARRAY (N) . GE. MUX) MUX = YARRAY $(N)$

555 CONTINUE

$C * * *$ Scale for plotting

c

CAL YSCAL (YMAX, IPOTER, YPSCALE)

IF (YPSCNE ME 1.) THE

DO $556 \mathrm{~N}=1, \mathrm{NPT}$ YARRAY(N) $=$ YARRAY(N) / YPSCALE

556 CONTINUE

ENDIF

XST $=$ LOCATE

XFIN $=$ XWAX + WDCEL/2.

YST $=0$.

YFIN $=$ YNAX

$C$

$C$ ** Subtract LOCATE fron $x$-array before plotting and label $x$-axis

$C$ *** accordingly in order to plot with Grafuatics software

72 DO $73 K=1, N P T$

XARRAY $(K)=$ XARRAY(K) - LOCATE

73 CONTINUE

XST = XST - LOCATE

$X F I N=X F I N-$ LOCATE

C

$C$ we* Scale translated $X$ values as power of 10 if necessary in order

$C$ *** plot with Grafeatics software

74 CAL XSCN (XFIN, ICOUNT, XPSCNE

IF (XPSCALE NE, 1.0) THEY

XST $=$ XST $/$ XPSCALE

DO $75 I=1$, NPT

XARRAY (I) $=$ XARRAY (I) $/$ XPSCNE

75 CONTINUE

ENDIF

$C$ **: Sotup and call Grafmatic graphics package for plot

$$
\text { IF (SHAPE .LT. 1.6) THEY }
$$

C * Skip first plat point if Weibull shape parameter $<1.0$ since

$C * *$ Weibull pdf is inf inite at $x=$ LOCATE NPT $=$ NPT -1

DO $76 K=1$, NPT

XARRAY $(K)=$ XARRAY $(K+1)$

76 $\operatorname{YARRAY}(K)=$ YARRAY $(K+1)$

ENDIF$$
\text { CONTINUE }
$$

CA CLRSCH

IORG $=1$

XSCNLE $=1$

NDOTS $=0$

LKOLOR $=3$

ISYMBL $=-1$

KLRSYN $=1$

MODE $=6$

CNL OSHODE(MDDE)

CAL QSETUP(NDOTS, LKOLOR, ISYMEL, KLRSYM)

$M D D E=2$ 


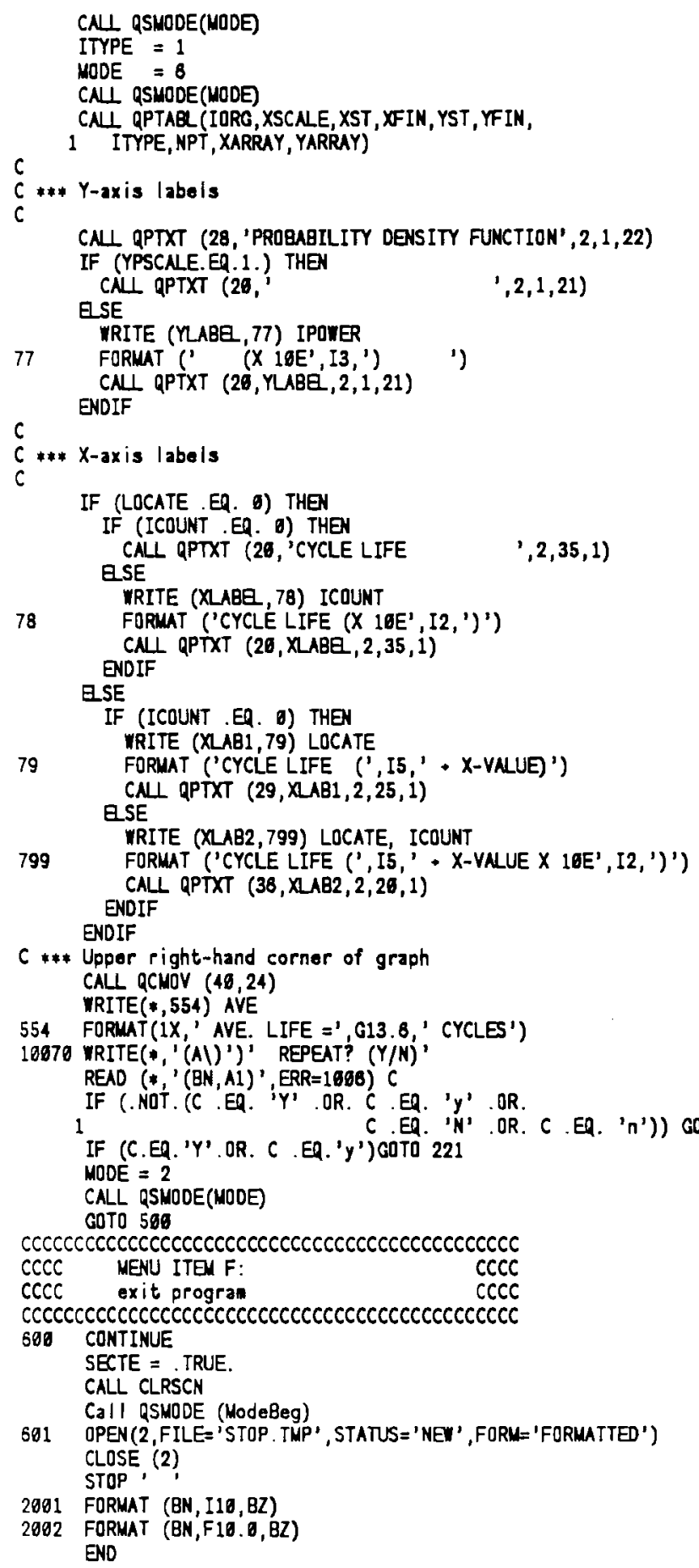


PROGRAM BAT2A

管

PURPOSE: Runs conplex nodel battery siaulation.

\section{LIMITATIONS AMD PREREQUISITES:}

aust run REY first, enu option ' $O$ ' to build paraneter filo 'BAT2A. TMP' - read by this progran to perform the conplex nodel.

LOGICAL MAMES AND FILES USED:

$$
\begin{aligned}
& 2 \text { = input data file 'BAT2A.TNP' fron RGY progran } \\
& 3 \text { = input data file of default test } 2 \text { cell paranoters } \\
& 7 \text { = output data file 'BAT2A.OUT' }
\end{aligned}
$$

ROUTINES USED:

CLRSCN, REVERSE, RESTORE, NOVE, BLINK, RANF, BEEPER MAINIMENU, GRPHMENU, RSLTMENU, SCRNMENU

QRMODE, QSWODE, QSETUP, QPTAQL, QPTXT

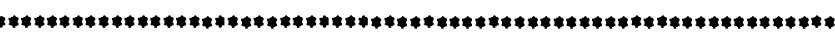
DEVEOPNENT INFORMATION:

CREATED BY : Cody J. Hostick ON : 1985 - Aug. 1988 John V. Dovey Ron K. Nakaoka Carl H. Iahoff

AT : Battelle Pacific Northwest Laboratories Richland, Washington 99352

MACHINE/OPERATING SYSTEM: PC DOS V2.10

COMPILER : NICROSOFT FORTRAN77 V3.31

COMPILER SWITCHES : Dofault

CONSTANTS (PARAYETER STATEMENTS) :

IMPLICIT CHARACTERः I (C)

IMPLICIT REAL $\$ 4$ (0)

PARAMETER (NOINCR $=99$ )

PARAMETER (NOINRR = NOINCR + 1)

COMNOK BLOCKS:

' INCLUDE- 'PARU INC'

SINCLUDE: 'BAT2A. INC'

IINCLUDE: 'WEIBUL. INC'

COMMON /BAT2A9/ BCE I

COMMON /BAT216/ HIRES

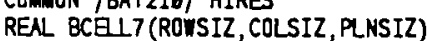

INTEGER *2 HIRES(ROWSIZ, COLSIZ, PLNSIZ)

BAT2A. INC -- battery info for BAT2A

PARM. INC -- size of battery

MEIBUL. INC -- Meibul distribution paraneters

VARIABLES

CHARACTER 15 ANS FNAME

CHARACTER 40 CHAR

INTECER 2 MODE, IORG, ITYPE, NPT, NCHAR, KOLOR, ICOL, IROW

INTECER 2 NDOTS, LKOLOR, ISYMEL, KLRSYM

INTECER MODULE, STRING, CEL Y Y , Q, N, X5, X6, CYCREQ, BAOCE,

INTEGER CELPF, CELP, FSWTCH, SWITCH, ITIME, J, OVROIS, X, MAXCYC, OVRCHG INTEGER TOTCE, GOODCE, NFTOCF, NFTCCF, NWOOCF, NWOCCF

REAL XARRAY (NOINRR), YARRAY (NOINRR), BIN , CEL VOL, CELRES, CELCHG

REAL DCR(10), TCARAY (10)

REAL TIME, RI', R2, ROUND, YEN, QINIT, E, FCHARGE

REAL OQTP BUAX ICE, RCE REUAIN SRESIST

REAL POCOPEN, POCCLOS, PODOPEN, POOCLOS

REAL FTFOCR, FTFCCR, WOFOCR, WOFCCR, OCFOCR, OCFCCR, ODFOCR, OOFCCR

REAL XFIFOCR, XFTFCCR, XWOFOCR, XWOFCCR, XOCFOCR XOCFCCR, XODFOCR

REAL XODFCCR, CAPMAX

DIMENSION OUT (NOINRR, 10)

LDGICAL GOOD, XRESIS, TIMEUP, PARLE, STRON, SETCAP

$$
\text { ,SETCP }
$$

C

DATA STATEMENT:

DATA QINIT, E, EIIN, Elax $/ 56.6,2.978,1.78,10.8 /$

DATA T, TESTI TEST CYCRED $/ .25,45,6,6 \%$

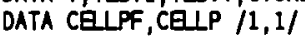

DATA OQTP SUITCH /3.6.6/

DATA FIFOCR, FTFCCR, WOFOCR, WOFCCR /8. 2, $8.878,8.2,6.878 /$

DATA POCOPE , OCFOCR, OCFCCR /38., 0.2, 6.070/

DATA PODOPEN, OOFOCR, OOFCCR /30.,0.2,0.079/

DATA OCR $/ .035, .035, .035, .035, .035, .035, .035, .035, .035, .035 /$

DATA TCARAY /.95, .98, .89,.76,.68,.58, .48, .38,.28,.19/

DATA XRESIS, PARLE, SETCAP /.FALSE., , FALSE. , FALSE. /

DATA SETCP /.FALSE. /

C

C *** Definitions of new variables in Detailed Discharge Model FCHARGE = fully charged cell capacity

C.** Definitions of post-failure resistance percentages in Detailed

C *** Dischargo Wodol (progran BAT2A)

C POCOPEY = percentage of over-charge failures that are open circ

POCCLOS = percentage of over-charge failures that are closed circuit (180. - POCOPEN)

PODOPEI = percentage of over-discharge failures that are open circuit

PODCLOS = percentage of over-discharge failures that are closec circuit (100. - PODOPEN)

*** Definitions of 8 types of failure resistances in Detailed

C *** Discharge Lodel (progran BAT2A)

FTFOCR = freeze-thaw failure open-circuit resistance FTFCCR = freeze-thaw failure closed-circuit resistance WOFOCR = wearout failure open-circuit resistance WOFCCR = wearout failure closed-circuit resistance OCFOCR = over-charge failure open-circuit resistance OCFCCR = over-charge failure closed-circuit resistance OOFOCR = over-discharge failure open-circuit resistance OOFCCR = over-discharge failure closed-circuit resistance

*** Dofinitions of cell counters

TOTCE = nuaber of total cells

COODCE = number of good colls

NFTOCF = nuaber of freeze-than open-circuit failures

NFTCCF = number of freeze-thaw closed-circuit failures

NWOOCF = nunber of wearout open-circuit failures

NWOCCF = nuabar of woaraut closed-circuit failures

C.

Section 1: Default Values for Input Screen

*a* Got Current Sereen Modo - - Reset before progran stops Call QRMODE (WodeBeg, WodeCol)

$C *$ Read Dofault Input Values, if they exist on disk

Open (3, file= 'BAT2A. SOF', IOStat=IOChek)

IF (IOChek . NE. g) co To 599

Read $(3, *, E R=508)$ CycRea

Read (3, ERR=508) Test T

Read (3,*,ERR=508) T

Read $(3, *, E R R=508)$ Cel IPF

Read (3,*ERR=508) Switeh

Read (3,*ERR=508) Test I

Read $(3, *, E R R=508)$ Qinit

Read (3,*,ERR=568) $E$

Read (3,*,ERR=508) EMax

Read $(3, *, E R R=568)$ ENin

Read $(3, *, E R R=598)$ FTFOCR

Read $(3, *, E R R=568)$ FIFCCR

Read $(3, *, E R R=588)$ WOFOCR

Read $(3, *, E R R=568)$ WOFCCR

Read $(3, *$ ERR=568) POCOPEN

Read $(3, *, E R R=568)$ OCFOCR 

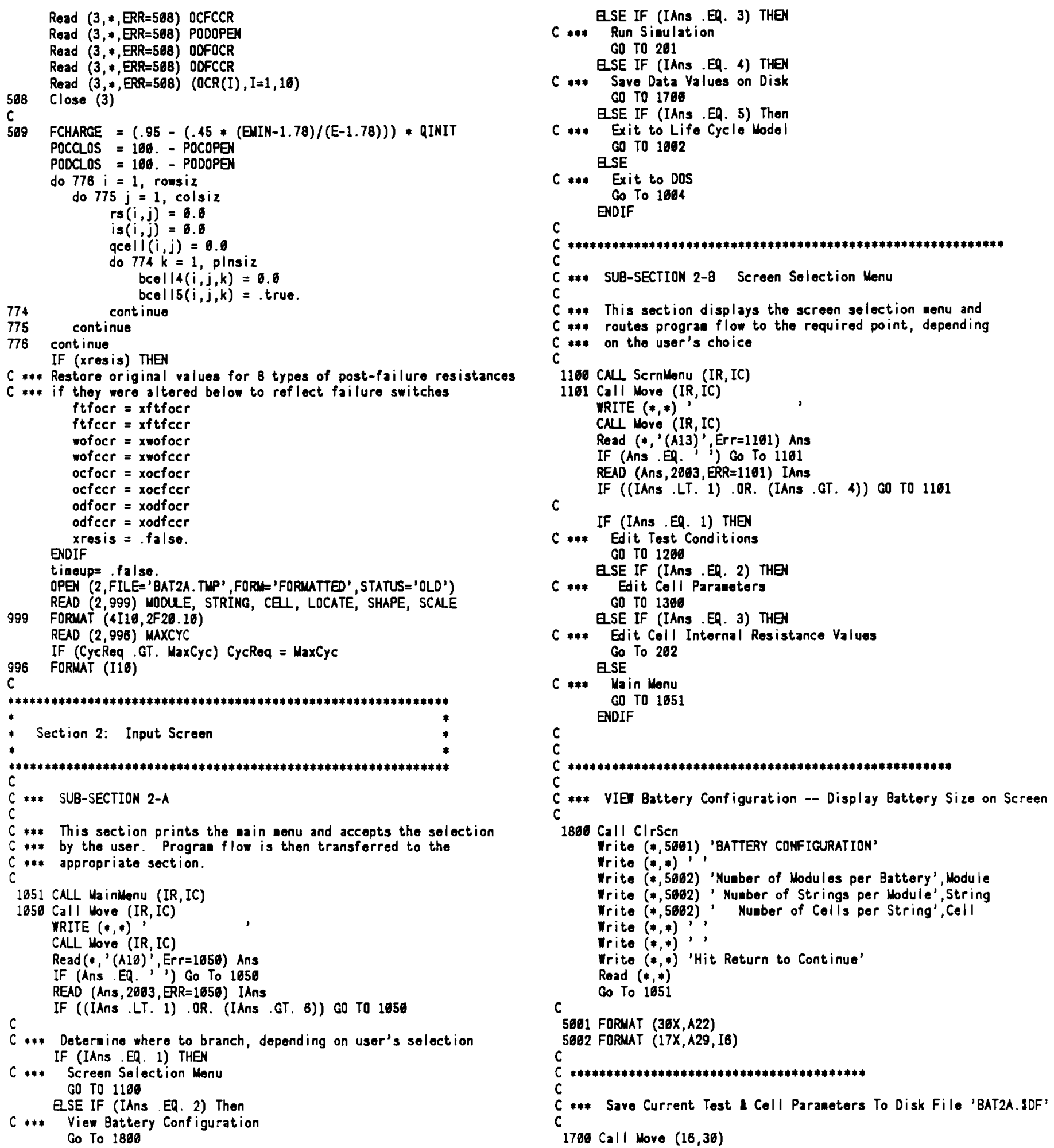
Write $(*, *)$ 'Are you sure? (Y/N)

Call Move $(16,52)$

Read (*, '(a)', orr $=1780$ ) Ans

IF (.Not. ( (Ans . EQ. ' $Y$ ') . OR. (Ans .EQ. ' $y$ ') OR

1 (Ans .ER. ' $N$ ') .OR. (Ans .ER. ' $n$ '))) Go To 1700

IF ((Ans .EQ. 'N') .OR. (Ans .EQ. ' $n$ ')) Go To 1651

Cali Nove (IR, IC)

Call Blink

Call Hove (IR, IC)

Write $\left(*, 1(a, i)^{\prime}\right)$ 'Saring'

Open ( 3 , f i le ='Bat2a .'Sdf', status= 'new')

Irite $(3,7001$, ERR=1608) CycReq

Write $(3,7062, E R R=1606)$ Test $T$

irite $(3,7082, E R R=1606) \mathrm{T}$

Write $(3,7001, E R R=1606)$ CollPF

Write $(3,7861, \in R R=1686)$ Switch

Write $(3,7002, E R R=1608)$ TestI

Write $(3,7002, E R R=1606)$ QIn it

wite $(3,7082, E R R=1006) \mathrm{E}$

Irite $(3,7802, E R R=1806)$ Elax

Write $(3,7002, E R R=1608)$ ENin

write $(3,7002$, ERR=1006) FTFOCR

Write $(3,7002, \in R R=1086)$ FTFCCR

Irite $(3,7002, E R R=1606)$ WOFOCR

Write $(3,7002, E R R=1606)$ YOFCCR

Write $(3,7002$, ERR $=1006)$ POCOPEN

write $(3,7002$, ERR $=1608)$ OCFOCR

Write $(3,7062, E R R=1606)$ OCFCCR

irite $(3,7002, E R R=1606)$ PODOPEN

wite $(3,7082$, ERR $=1006)$ ODFOCR

Write $(3,7082, E R R=1808)$ ODFCCR

MRITE $(3,7062, \operatorname{ERR}=1006) \quad(O C R(I), I=1,10)$

Close (3)

Call Restore

c

co To 1051

7001 Format (i20)

7802 Format (F30.15)

$c$

C

C *** Input Screen 1 (TEST CONDITIONS)

1200 CALL CI ISSCN

$I R=1$

IC $=1$

CALI Hove (IR, IC)

WRITE $(*, 2801)$ 'TEST CONDITIONS'

WRITE $(*, 2001)$ 'Input Screen 1 '

WRITE $(*, *)$ ',

MITE $(*, 2062)$

1 CycReq+1,

WRITE $(*, 2014)$,

l TostT,'

WRITE $(*, 2014)$ '

L Hours,

Cycle to Analyze',

Duration of Test'.

WRITE (*,2002)

WRITE $\left(*, 20 \cos ^{\prime}\right)$ '

'Switch,'

WRITE $(*, 2614)^{\prime}$

L Testi, 1 Aaps

Connecti

Failure Switches: $\theta=$ None. $1=C$ losed. $2=0$ pen',

Constant Discharge Current',

WRITE $(*, *)$
IR $=I R * 10$

$c$

C "** Display Menu

WITE $(*, 2610)$

WRITE $(*, 2810)$

WRITE $(*, 2016)$

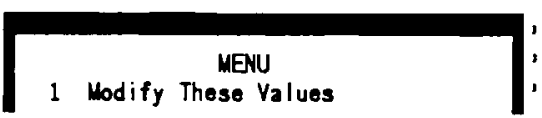

WRITE $(*, 2010)$ '] 2 Edit Coll Paranoters

WRITE $(*, 2016)$ ' 3 Edit Coll Internal Resistances

WRITE $(\cdot, 2016)$ '

Entor Selection --->

IR $=$ IR $* 6$

$I C=45$

$1210 \mathrm{CAll}$ Hove (IR, IC)

WRITE $(*, *)$,

CAL Hove (IR, IC)

Read (*,' (A13)', Err=1210) Ans

IF (Ans .ER. ' ') Co To 1218

REND (Ans, 2603, ERR=1216) IAns

IF ((IAns .LT. 1) .OR. (IAns .GT. 4)) Go To 1210

IF (IAns EQ 1) Then

C *** Edit these values

Go To 1250

日SE IF (IAns. En. 2) Then

C*** Edit Coll Paraneters co To 1380

B-SE IF (IAns .EQ. 3) Then

$C * * *$ Edit Coll Internal Resistances co To 282

$C * *$ Main Menu

Go To 1051

ENDIF

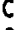

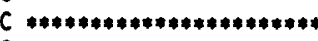

$C$ *** Monu Option 1 edit these values

C

1258 IR $=4$

IC $=50$

DO 1275 ILP $=1,6$

1255 CNL Move (IR, IC)

CALL Roverse

WRITE (*,' (A)')

CALL Hove (IR, IC)

READ (*' '(A16)') Ans

If (Ans . NE.' ') Then

IF (ILP .ER. 1) Thon

READ (Ans, 2083, ERR =1255) CycReq

CycRea = CycRea -1

IF (CycReq .LE. 日) Then CycRea $=0$

E.SE IF (CycRea GT. MaxCyc) Then CycReq $=$ MaxCyc

ENDIF

ESE IF (ILP EQ . 2) Then

READ (Ans, 2084, ERR=1255) Test T IF (TestT . LT. B.) Test T $=$-Test T

日SE IF (ILP. ER. 3) Then READ (Ans, 2084, ERR=1255) T IF ( $T$.LT. G.) $T=-T$

ESE IF (ILP . ER. 4) Then READ (Ans, 2003, ERR=1255) ColIPF

且SE IF (ILP. ER. 5) Then

READ (Ans, 2003, ERR=1255) Switch

日.SE IF (ILP.EQ. 8) Then

READ (Ans, 2804, ERR=1255) TestI

$$
\begin{aligned}
& \text { ENDIF } \\
& \text { ENDIF }
\end{aligned}
$$

$c$

$C$ *** Write Input Back to User

CNIL Restore

CALl Hove (IR, IC)

IF (ILP .EQ. 1) Then

WRITE $(* 2808)$ CycRea+1

ESE IF (ILP .EQ. 2) Then 

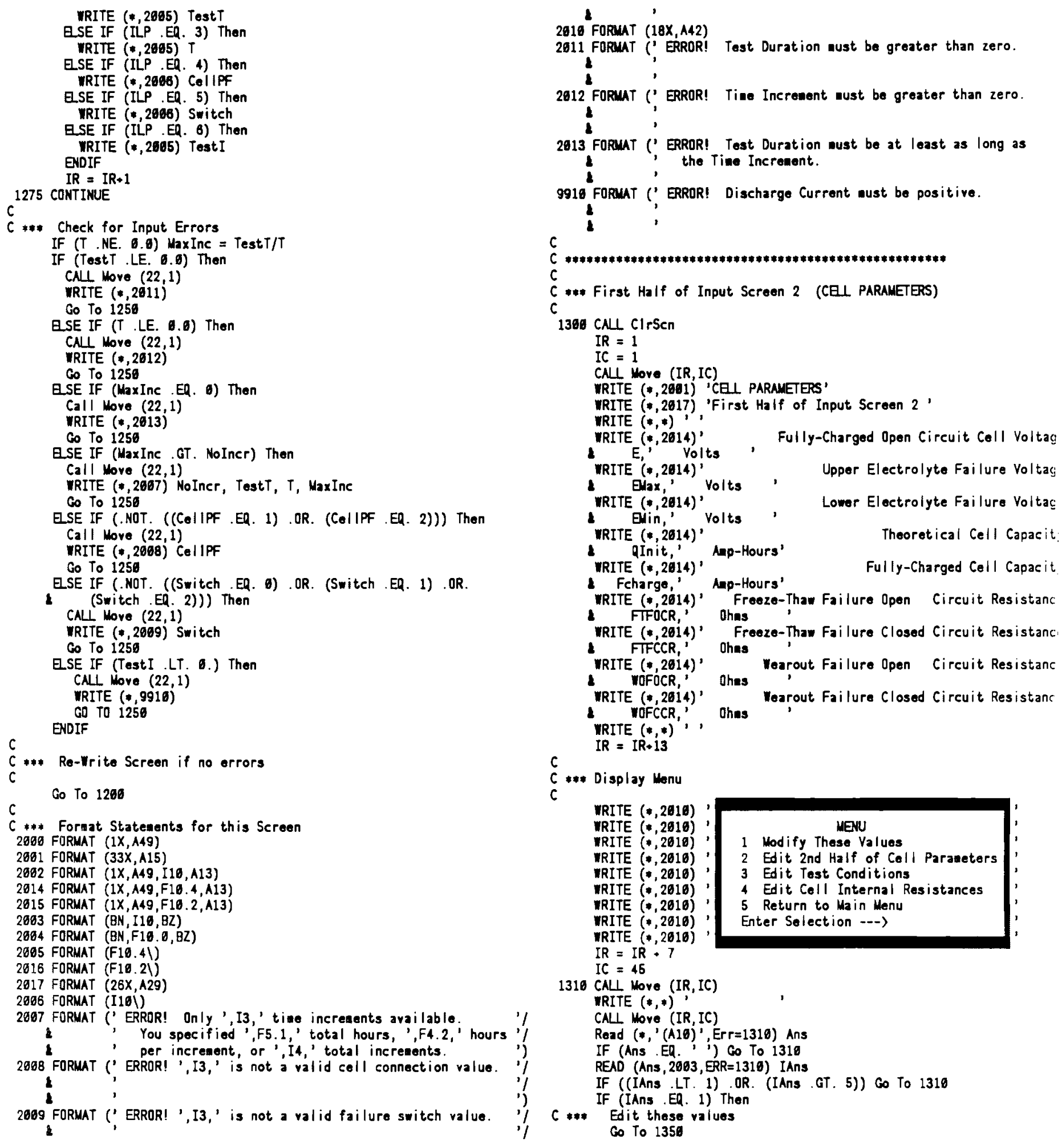


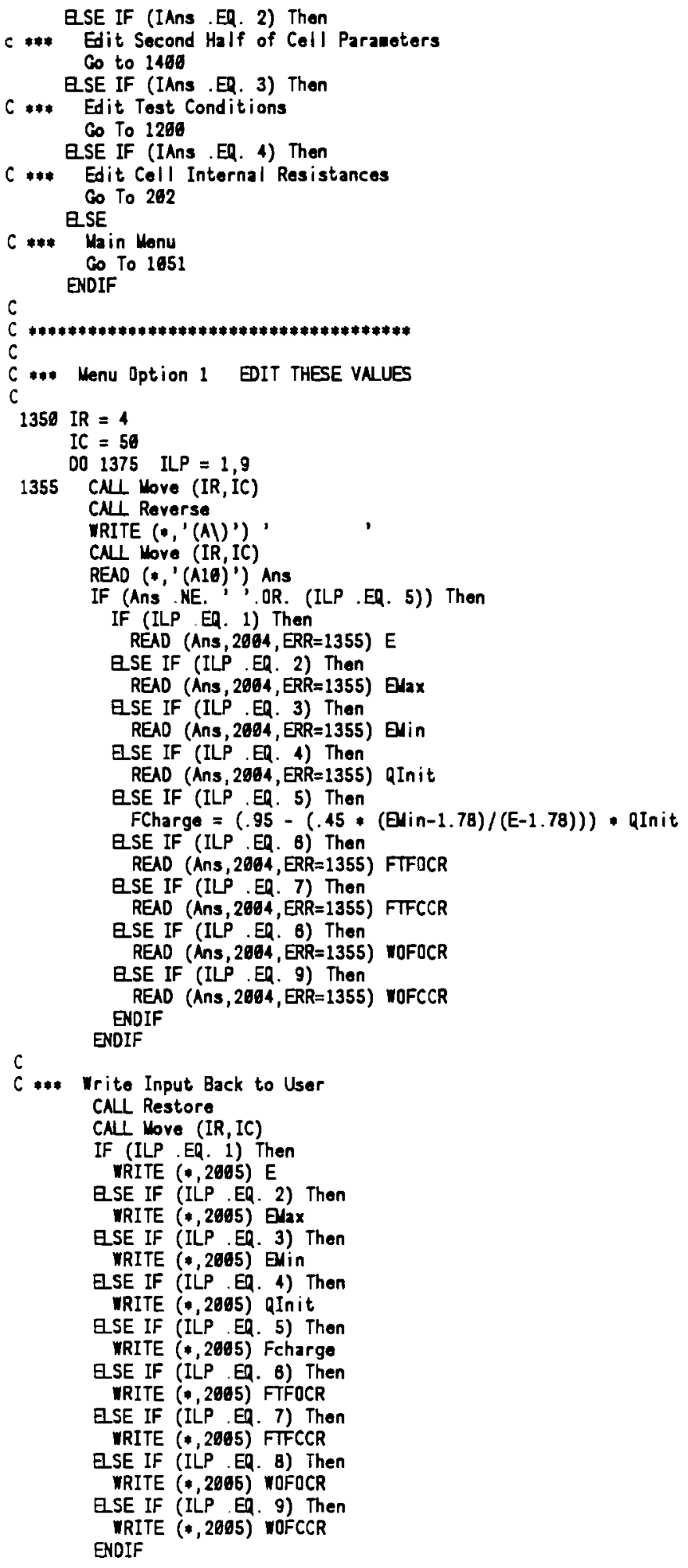

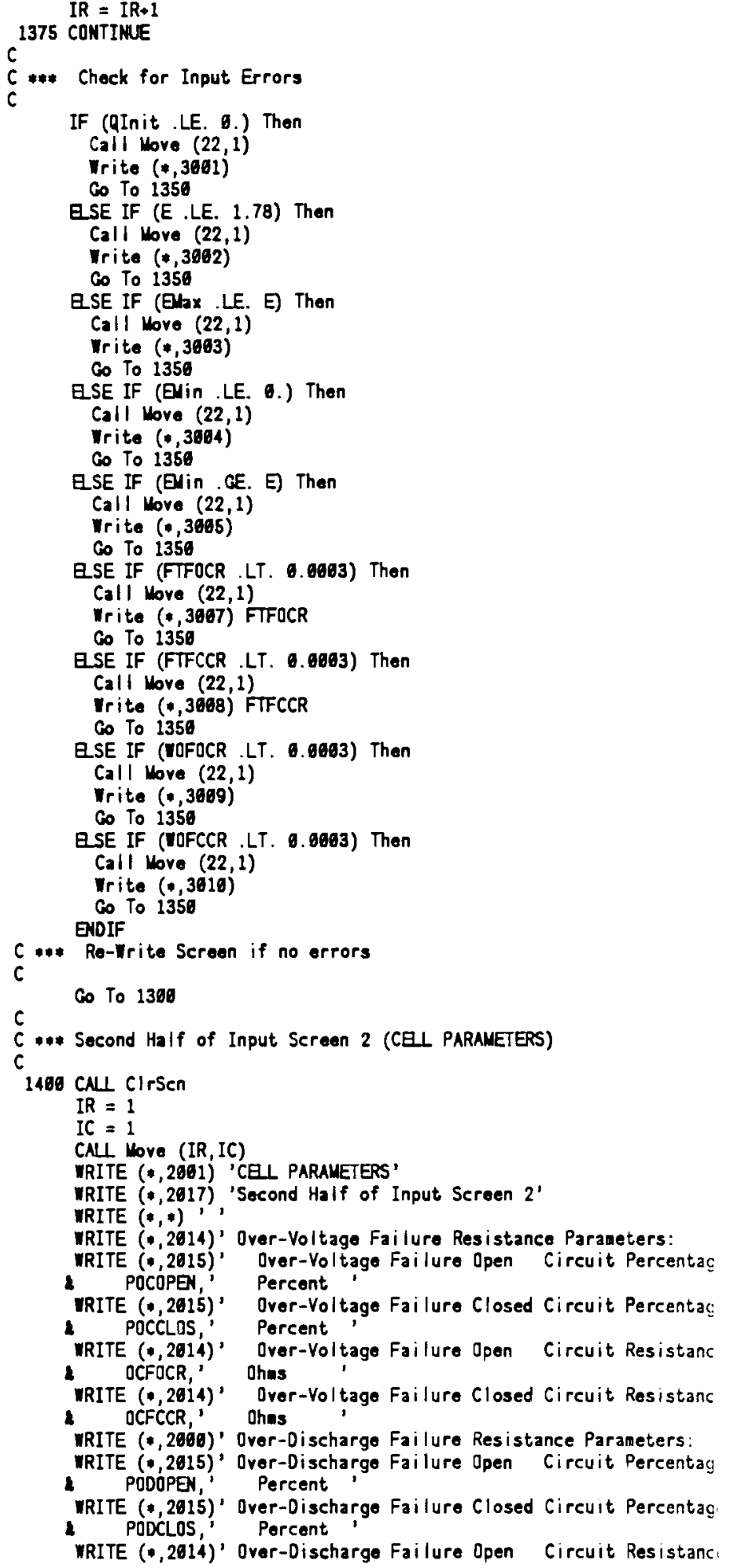




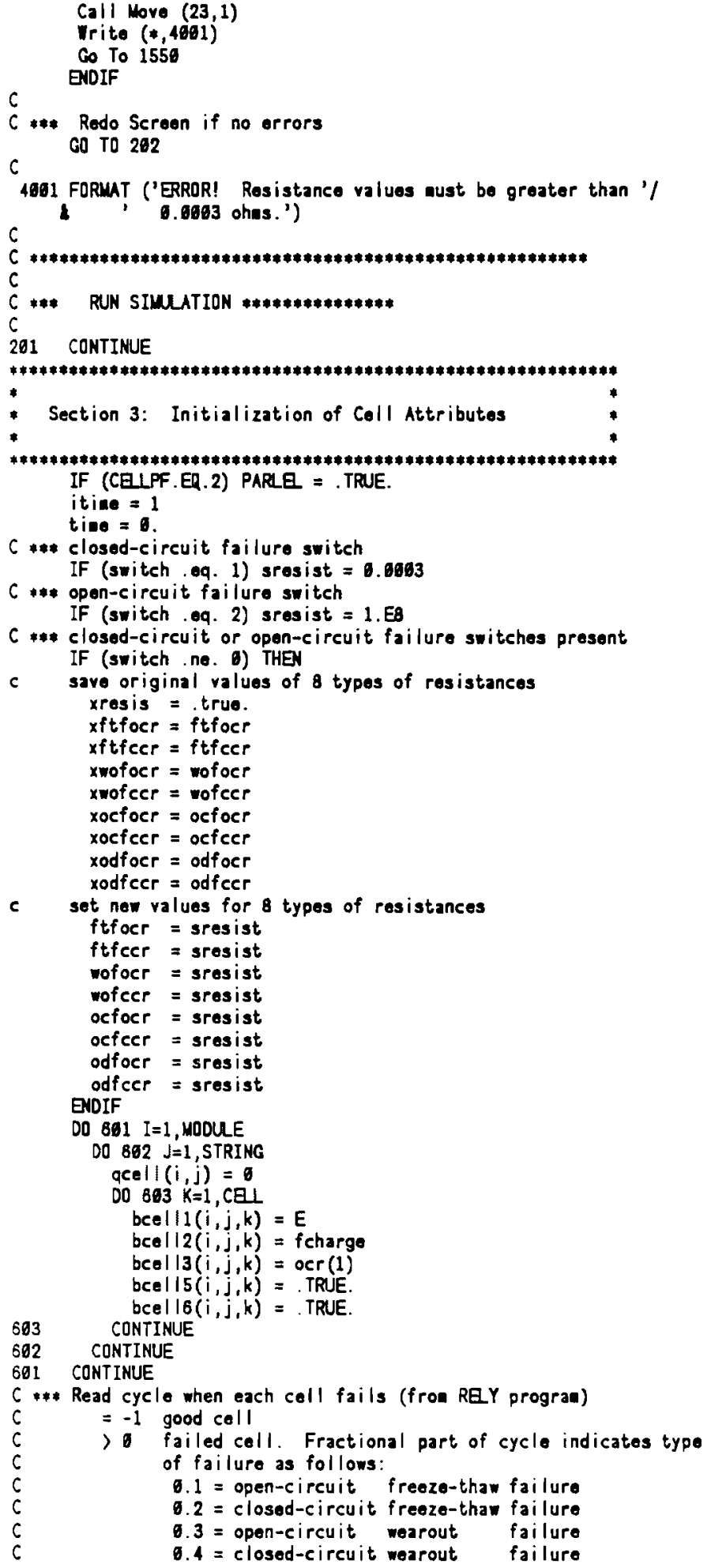

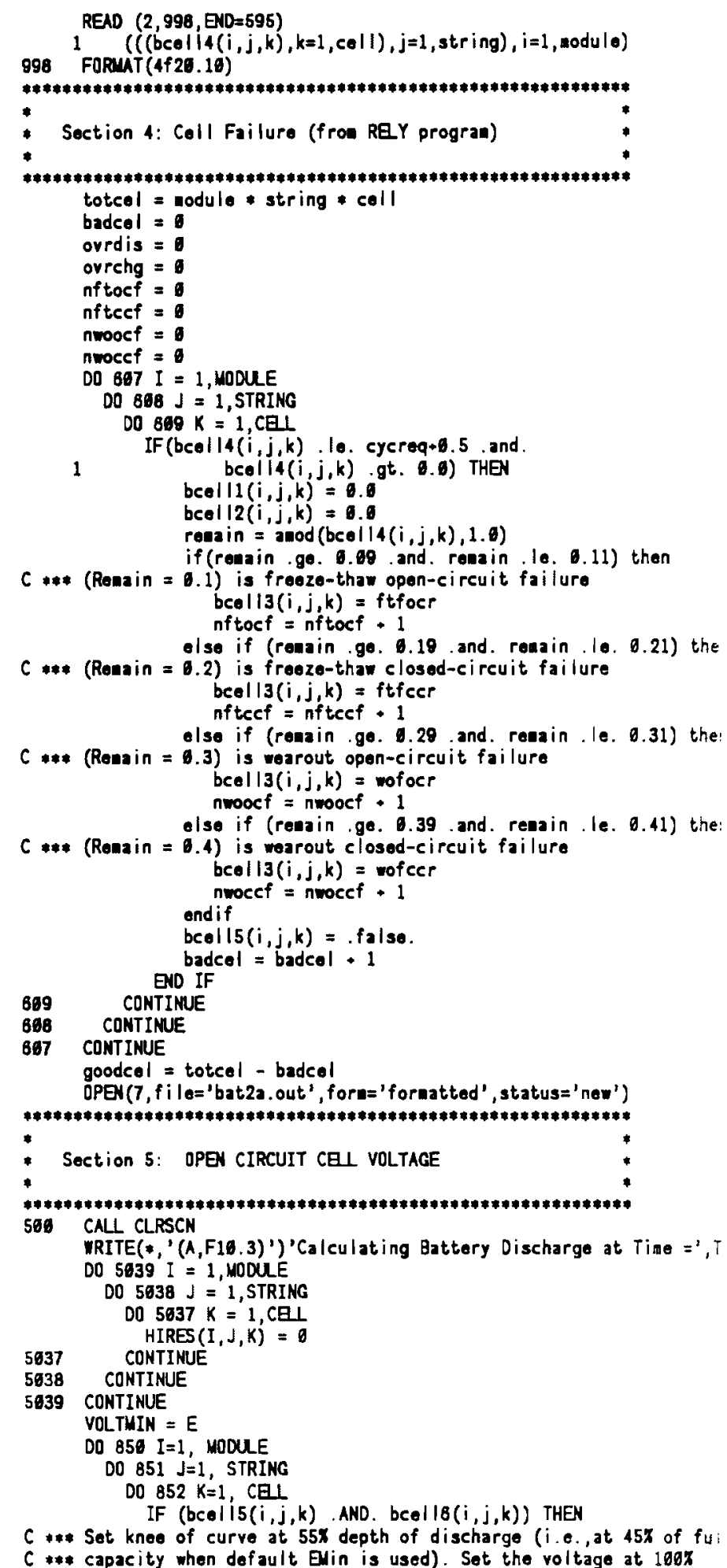

C. 15 
$C * *$ depth of discharge to be 1.78 volts.

If (bcell $2(i, j, k)$. It. fcharge-e.5*qinit) THEY

beoll1 $(i, j, k)=($ bcell2( $i, j, k)$ -

1 (fcharge - gIn it $* 0.95)) /$ In $i t) *((E-1.78) / .45) * 1.78$

If (bcell $1(i, j, k)$. It. voltain) voltain $=$ beelli $(i, j, k)$

if (beell1 $(i, j, k)$. lo. on in) THEN

bcolll $1, j, k)=0$

bcol $12(i, j, k)=0.0$

if (podopen eq. B.) then

C *** All over-discharge failures are closed-circuit open $=1$.

-lse if (podopen .gt. O. and. podopen . It. 166.) then

C *** Deternine over-dischargo failures that aro open-circuit by

$C$ *** randouly sampling and compare with input percentage (PODOPEN) call ranf (open, I)

else if (podopen .eq. 100.) then

C ***All over-discharge failures aro open-circuit open $=0$.

$c$ end if

if (open .le. podopen/100.) then

$C$ *** Over-discharge failure open-circuit resistance bcel $13(i, j, k)=$ odfocr

$C$ *** Over-discharge failure closed-circuit resistance ise bcel $\mid 3(i, j, k)=\operatorname{odfccr}$ end if

beelle $(i, j, k)=$. false.

badcel = badcel +1

orrdis = orrdis -1

ondif

ENDIF

END IF

CONTINUE

CONTINUE

858 CONTINUE

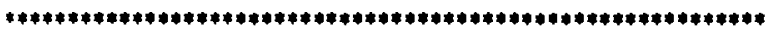

Section 6: CEL INTERNAL RESISTANCE

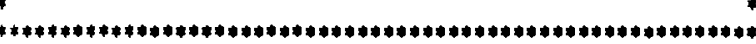

DO $853 \mathrm{I}=1$, MODULE

DO $854 \mathrm{~J}=1$, STRING

DO $855 K=1, C E \perp$

$c$

$C * * *$ Calculate current charge on coll as percent of Theoretical for

$C$ *** Resistance Calculation (TFRC). Then do a binary search on a

$C$ *** monotonically decreasing table (TCARAY (ind $x$ ), ind $x=1,10$ ) and

$C * * *$ linearly interpolate to obtain Coll Resistance as a function of

C *** Theoretical Coll Capacity for Caleulating Resistance.

C

IF (bcell5(i,j,k) AND. bcel $18(i, j, k)$ ) THEN

tfre $=($ bcel $12(i, j, k)-($ fcharge $-.95 * q$ init $)) /$ qinit

If (tcaray (1) - tfre) $161,161,162$

161 beell $3(i, j, k)=\operatorname{ocr}(1)$

Go To 179

IF (tcaray (18) - tfrc) $164,163,163$

bcel $13(i, j, k)=\operatorname{ocr}(10)$

Go To 170

ind $x=5$

If (tcaray (indx) - tfrc) $187,186,168$

bcel $3(i, j, k)=\operatorname{ocr}($ ind $x)$

Go To 176

ind $x=$ ind $x-1$

Go To 165

ind $x=i n d x+1$

If (tearay (indx) - tfre) $169,166,168$

frac $=($ tf re-tcaray (ind $x)) /($ tearay (ind $x-1)-$ tearay (ind $x))$

beel $13(i, j, k)=\operatorname{ocr}($ ind $x) * \operatorname{frac} *(\operatorname{ocr}($ ind $x-1)-\operatorname{ocr}($ ind $x))$

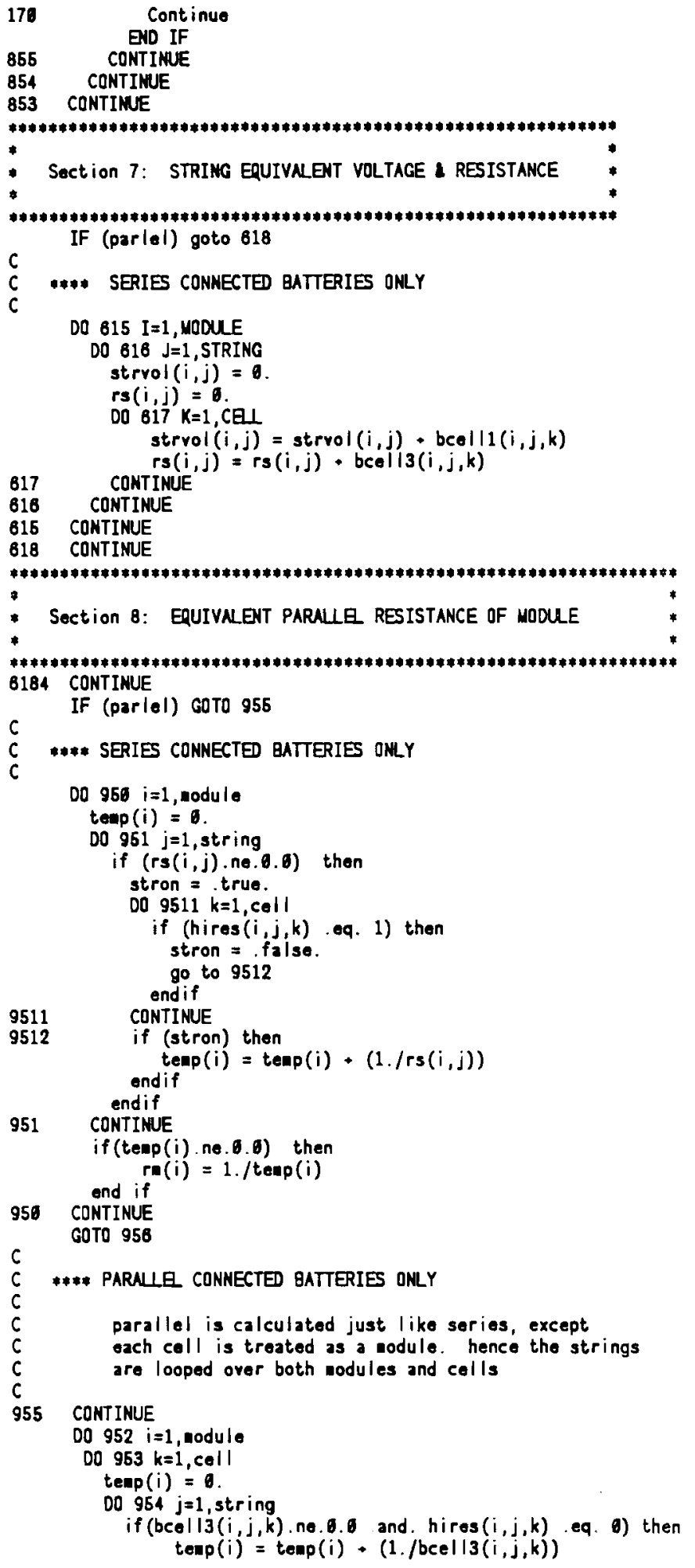




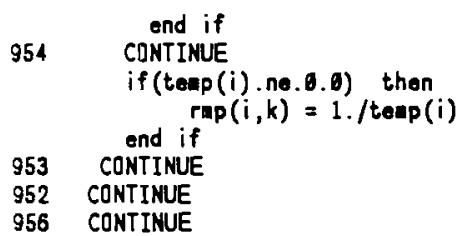

C **** PARALLE CONNECTED BATTERIES OMLY

c parallel is calculated just like series, except

C each cell is troated as a module. hence the strings

c

412 CONTINUE

totrol $=0$

Do $414 i=1$, sodulo

DO $415 k=1, c e l 1$

tmpv $\mid p(i, k)=0$

DO $416 j=1$, string

if (beol| $3(i, j, k)$. ne.0.0 and. hires $(i, j, k)$.oq. 0$)$ then $\operatorname{tapr}|p(i, k)=\operatorname{tapr}| p(i, k)+(b c e l|1(i, j, k) / b c e l| 3(i, j, k))$ end if

$416 \quad$ CONTINUE

$\operatorname{vap}(i, k)=\operatorname{rap}(i, k) *(-\operatorname{test} i+\operatorname{tapv} l p(i, k))$

totroi =totrol + rmp $(i, k)$

CONTINUE

414 CONTINUE

413 CONTINUE

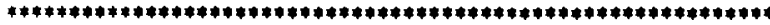

- Section 10: Data collection

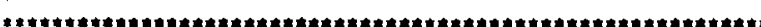

celvol $=0.0$

celchg $=0.0$ colres $=0.0$

out (itine, 1$)=$ tine

out (itine, 2)=totrol

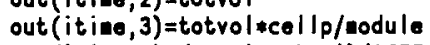

out (itine, 4) $=($ test $i$ totrol $) / 1006.0$

DO $355 \mathrm{i}=1$, eodule

DO $351 \mathrm{j}=1$, string

DO $352 k=1$, cell

celvol = colvol $\cdot$ beall $1(i, j, k)$

colchg = colchg - bcel $\mid 2(i, j, k)$

colres = colres $-b c e l l 3(i, j, k)$

352

351

CONTINUE

CONTINUE

CONTINUE

$x=$ cell *string*nodule-badce l

c

c $x=$ the nubber of working cells.

if $(x$. ne. $\theta)$ then

out $($ itiec, 5$)=$ colvol $/ x$

out $($ itime, 6$)=$ celchg $/ x$

out (itine, 7$)=$ celres $/(x$-badcell $)$

- Ise

out (itine, 5$)=0.0$

out (itine, 6$)=0.0$

out (itino, 7) = celres/badcell

totvol $=0.0$

endif

out (itime, 8$)=$ ovrdis

out (itimo, 9 ) = ovrchg

out (itine, 10) = voltrin

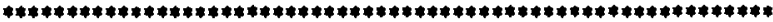

-

- Section 11: Output conditions

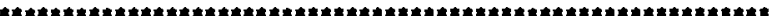

6

IF(totrol . le. 601) GO TO 501

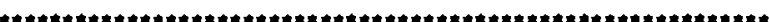

Section 12: Coll Discharge

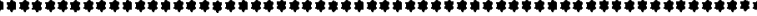

Charging by neighboring strings can push a cell to its charging linit. The 1 's in the HIRES matrix mark colls that have reache the theorotical fully charged capacity linit inposed by this

nodel (95x of theoretical capacity when the default values are

used). At this point, tho internal resistance of the marked

cells is assuaed to be a virtual open circuit. Later when

conditions allow these cells to discharge, noral internal

resistance resunes.

QIN95 = FCHARGE * 001

Save initial coll capacity

DO 6874 I = 1, MODULE

DO $6873 \mathrm{~J}=1$, STRING

DO $6872 \mathrm{~K}=1, \mathrm{CE}$

$B C E \perp 7(I, J, K)=B C B \perp 2(I, J, K)$

6872 CONTINUE

6873 CONTINUE

6874 CONTINUE

IF (parlol) GOTO 883

c *** SERIES CONNECTED BATTERIES ONLY

DO $682 \mathrm{I}=1$, NOOUE

DO $681 \mathrm{~J}=1$, STRINC

if $(r s(i, j) .10,1.6 E-6) r s(i, j)=1.0 E-6$

is $(i, j)=(\operatorname{strvol}(i, j)-\operatorname{va}(i)) / r s(i, j)$

C. 17 


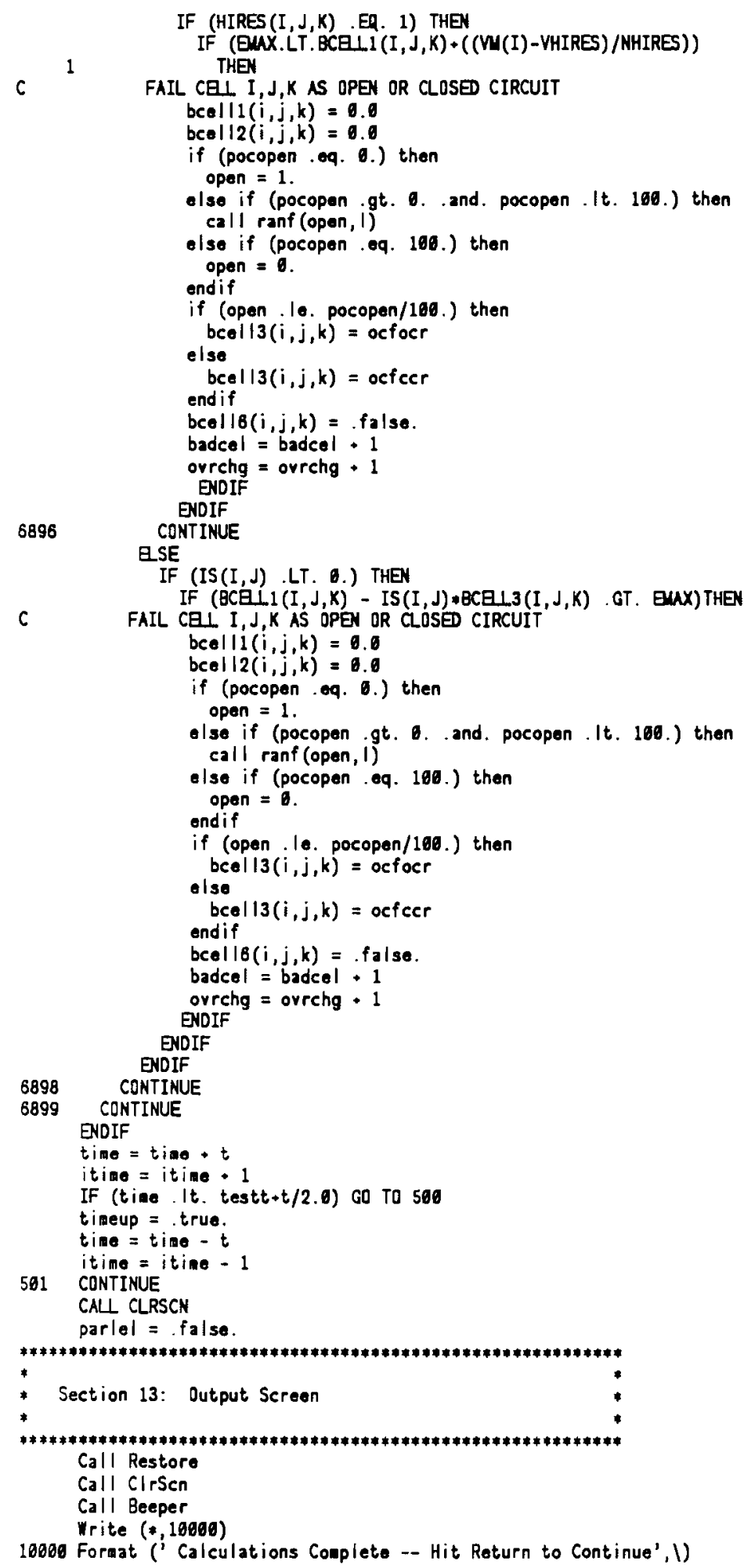

FAIL CB丩 I,J,K AS OPEN OR CLOSED CIRCUIT

bcoll $1(i, j, k)=0.0$

bcell $2(i, j, k)=0.0$

if (pocopen .oq. 0.) then

open $=1$.

- Ise if (pocopen .gt. O. and. pocopen .lt. 160.) then

ca l I ranf (open, I)

else if (pocopen .eq. 106.) then

open $=0$.

endif

if (open .le. pocopen/100.) then

bcell $3(i, j, k)=$ ocfocr

else

beel $\mid 3(i, j, k)=$ ocfecr

endif

beol $\mid 8(i, j, k)=$ false.

badcel = badcel .1

ourchg = ourchg .

ENDIF

CONTINUE

6896

ESE

IF (IS (I, J) .LT. 6.) THE

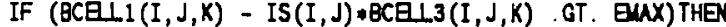

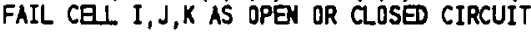

bcell $1(i, j, k)=0.0$

beol $\mid 2(i, j, k)=0.0$

if (pocopen .oq. 6.) then open $=1$.

- lse if (pocopen .gt. 0. and pocopen .It. 160.) then call ranf (open, 1)

else if (pocopen .oq. 106.) then open $=6$.

ond if

if (open . le. pocopen/100.) then

bcell $3(i, j, k)=$ ocfocr

olse

beol $13(i, j, k)=$ ocfecr

endif

bcell $6(i, j, k)=$ false

badcel = badcel +1

ovrchg $=$ ovrehg +1 ENDIF $\begin{array}{cc} & \text { ENDIF } \\ \text { ENDIF } \\ 6898 \\ \text { CONTINUE } \\ \text { CONTINUE } \\ \text { ENDIF }\end{array}$

time $=$ timo $+t$

itime = itime 1

IF (tiae. It. testt-t/2.0) GO TO 500

timeup $=$.true.

time $=$ tine $-t$

itime $=$ itine -1

501 CONTINUE

$C A \amalg$ CLRSCN

par|el = false.

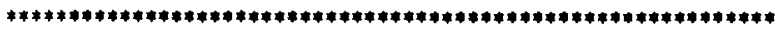

* Section 13: Output Screen

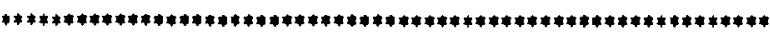

Call Restore

Call Clrsen

Call Beeper

Write $(*, 10000)$

10000 Format ('Calculations Complete -- Hit Return to Continue', I)

Read $(*, *)$

Call CIrSen

$n=I N T(t e s t t / t+1)$

write $(*, 025)$

vrite $(7,025, E R R=1066)$

025 forat $(/, /)$

writ. $(*, 026)$

write $(7,026, E R R=1006)$

026 fornat (7x,'Battery Conf iguration')

write $(*, 627)$

write $(7,027, E R R=1006)$

627

foraat $(7 x$,

mrite $(\$, 028)$ module

mite $(7,028, E R R=1006)$ module

028 format (7x, 'Number of Modules per Battery $=1, i 8$ )

write $(*, 029)$ string

write $(7,029$, ERR=1068) string

929 format (7x,'Nuaber of Strings per Modulo = ',i 18 )

write $(*, 03 \theta)$ call

orite $(7,030, E R R=1008)$ coll

030 fornat (7x,'Nuaber of Cells per String = ',i6) write $(*, 301)$ totcel

urite $(7,301, E R R=1806)$ totcel

361 format (7x,'Total Colls per Battery =,$i 8)$

Write $(*, 6061)$

Write $(7,6001$, ERR=1008)

6001 Foraat (// 7X, 'Test Conditions')

Write $(*, 6082)$

Write $(7,8002, E R R=1006)$

6062 Forant $\left(7 X^{\prime}\right.$,

Write $(*, 6003)$ CycReq +1

Write $(7,6003, E R R=1606)$ CycReq +1

6063 Fornat (7X, 'Cycle to Analyze

1 i12)

Write $(4,392)$ nftocf

Write $(7,302$, ERR $=1008)$ nftocf

382 Fornat $(7 x$, 'Cunulative Freeze-Thay Open Circuit Failures ='

1

Write $(*, 303)$ nftecf

Write $(7,383, E R R=1006)$ nftecf

36

Fornat (7x, 'Cunulative Freeze-Thaw Closed Circuit Failures =

- i12,' fron REY')

Write $(*, 304)$ nwoocf

Write $(7,384, E R R=1068)$ nwoocf

304 Format $(7 x$, ' Cumulative Wearout

1 i12,'from REY')

Write $(1,385)$ nwoccf

Write $(7,305, \boxminus R R=1006)$ nmocef

385 Fornat $(7 x$,' Cunulative Wearout Closed Circuit Failures =

- i12,' fron REY')

Write $(*, 6084)$ TestT

Write $(7,6064, E R=1608)$ Tost $T$

6064 Format (7X. 'Duration of Test

I F12.2,' Hours')

Irite $(*, 6065) \mathrm{T}$

Write $(7,6005, \mathrm{ERR}=1006) \mathrm{T}$

8005 Format (7X, 'Tiae Increwent

\& F12.2,' Hours')

Write $(*, 6086)$ CellPF

Write $(7,6068, E R R=1068)$ CellPF

806B Foraat(7X, 'Coll Connection: 1=Series-Par. 2=Parallel-Ser.

1

Write $(*, 6007)$ Switch

Write $(7,6007, E R R=1006)$ Switch

6087 Format (7X, 'Failure Sritches: $\theta=$ Hone. $1=C$ losed. 2=0pen.

1 i12)

Write $(*, 6808)$ Test I

Write $(7,8008$, ERR $=1008)$ TestI

6008 Foraat ( $7 X$, 'Constant Discharge Current

1 F12.2,'Amps') 
write (*,'(a) ') ' Hit Return to Continue'

Read (*,*)

call cl rsen

wite $(*, 031)$

write $(7,031, E R R=1006)$

031 format $(/ / 7 x$, 'Coll Paranoters')

write $(*, 032)$

write $(7,032, E R R=1096)$

832

write $(\$, 034)$ ginit

writo $(7,034, E R R=1006)$ qinit

034 format (7x.'Theoretical Coll Capacity

lf12.2,'Aap-Hours')

write $(*, 6010)$ feharge

write $(7,6819, E R R=1086)$ fcharge

6010 Format (7x, 'Fully-Charged Coll Capacity

2 (12.2,' Aap-Hours')

write $(*, 633) \odot$

write $(7,633, E R R=1806)$ e

633 foraat ( $7 x_{1}$ 'Fully Charged Open Circuit Cell Voltage

$2 f 12.2$,' Volts')

Write $(7,6899)$ Blax

Write $(7,6809, E R R=1008)$ Blax

6069 Forat (7X, 'Upper El ectrolyte Failure Voltage

( F12.2, 'Volts')

write $(036)$ en in

write $(7,636, E R R=1068)$ ea in

036 format ( $7 x$, 'Lower Electrolyte Failure Voltage

1 f 12.2 ' Volts')

write $(*, 035)$ ocr $(1)$

write $(7,035, E R R=1006)$ ocr (1)

035 format( $7 x$,'Initial internal cell resistance

- f12.4,' Ohas')

wito $(*, 6011)$ FTFOCR

write $(7,6011, E R R=1006)$ FTFOCR

6011 format ( $7 x$, 'Freeze-Thaw Failure Open Circuit Resistance $=$ "

2 g12.5,' Ohas')

rite $(*, 6012)$ FTFCCR

write $(7,6812, E R R=1908)$ FTFCCR

6012 format ( $7 x$, 'Freeze-Thaw Failure Closed Circuit Resistance ='

I g12.5,' Ohas')

urite $($ 6913) VOFOCR

write $(7,6813$, ERR $=1086)$ WOFOCR

6013 foraat $(7 x$, 'Wearout Failure Open

1 g12.5,'Ohas')

wite $(*, 6914)$ YOFCCR

wite $(7,6014, E R R=1606)$ WOFCCR

6014 forat (7x,' Wearout Failure Closed Circuit Resistance

i 12.5 ' Ohas')

wite $(*, 6015)$

wite $(7,6015, E R R=1606)$

6015 format (7x, 'Over-Voltage Failure Resistance Paraneters:') wite $(*, 6616)$ PACOPEN

wite $(7,6816, E R R=1686)$ POCOPEN

6016 format $\left(7 x,{ }^{\prime}\right.$ 'Over-Voltage Failure Open Circuit Percentage ='

1. f12.2 'Percent')

write $(*, 6017)$ POCCLOS

write $(7,6017, E R R=1006)$ POCCLOS

6017 format ( $7 x$, 'Over-Voltage Failure Closed Circuit Percentage =',

If 12.2 ,' Percent ')

write $(*, 5018)$ OCFOCR

write $(7,6618$, ERR=1866) OCFOCR

6818 format $(7 x$, 'Over-Voltage Failure Open Circuit Resistance =',

1 g12.5,' Ohms')

wite $(8,8019)$ OCFCCR

wito $(7,6819, E R R=1008)$ OCFCCR

6019 format ( $7 x$, 'Over-Voltage Failure Closed Circuit Resistance = ', g12.5,' Ohms')

urite $(0,5620)$

wite $(7,6026, E R R=1606)$
6020 format (7x, 'Over-Discharge Failure Resistance Paraneters: ') wite $(*, 6021)$ PODOPEN

wite $(7,6021, E R R=1086)$ PODOPEN

6021 format (7x, 'Over-Discharge Failure Open Circuit Percentage = 1 (12.2,' Percent')

wite $(*, 6022)$ PODCLOS

write $(7,6022, E R R=1686)$ PODCLOS

6922 format $(7 x$, 'Over-Discharge Failure Closed Circuit Percentage = 1 f12.2, 'Porcent')

write $(*, 6023)$ ODFOCR

write $(7,6823, E R R=1086)$ ODFOCR

$=' \quad 6923$ format (7x, 'Over-Discharge Failure Open Circuit Resistance $=$ ( g12.5,' Ohas')

write $(*, 6024)$ OOFCCR

write $(7,6024, E R R=1006)$ ODFCCR

$=' \quad 6024$ forat $(7 x$, 'Over-Dischargo Failure Closed Circuit Resistance = 1 g12.5,' Ohas')

write (*, '(a) ')' Hit Return to Continue'

Read $(*, *)$

call cliscn

write $(*, 025)$

write $(7,025, E R R=1006)$

wito $(* 781)$

$=$ write $(7,701$, ERR $=1006)$

701 format $(14 x, 16 x$, 'Average', 1x, 'Min inum' ' $1 x$, 'Average', 2x, 'Average'

write $(\bullet, 762)$

$=$ ', write $(7,702$, ERR $=1606)$

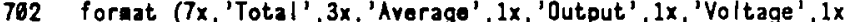

1 'Voltago', 1x, 'Capacity', 1x, 'Resist. ',' Voltage', ' Voltage' write $(*, 638)$

$=1$ rite $(7,636$, ERR $=1068)$

038 format (7x, 'Battery', 2x, 'Module', 1x, 'Powor', 2x, 'Work ing',

$1 \quad 1 x$, 'Working', $1 x$, 'Working', $4 x$, 'Ali ',' 'Electr. ', 'Electr.' write $(*, 839)$

write $(7,039, E R R=1068)$

839 format(2x, 'Tine', 1x, 'Yoltage', 1x, 'Yoltage', 1x, '(kw)', 3x, ' Cells $1,1 x_{1}^{\prime}$ Colls ', $1 x^{\prime}$ ' Cells ', $2 x^{\prime}$ ' Cells ', Fails',' Fails') write $(0,040)$

write $(7,640, E R R=1086)$

040 format $\left(2 x,{ }^{\prime}(H r)^{\prime}, 3 x_{1}^{\prime}(V)^{\prime}, 5 x,{ }^{\prime}(V)^{\prime}, 12 x,{ }^{\prime}(V) ', 5 x,{ }^{\prime}(V)^{\prime}, 3 x,{ }^{\prime}(A m\right.$ 1) ', $2 x$, '(Ohns)' 1 )

DO $628 Q=1$, itiec

write $(4,041)$ out $(q, 1)$, out $(q, 2)$, out $(q, 3)$, out $(q, 4)$, out $(q, 5)$,

- $\quad \operatorname{out}(q, 19)$, out $(q, 8)$, out $(q, 7)$, out $(q, 8)$, out $(q, 9)$

write $(7,041$, ERR=1086) out $(q, 1)$, out $(q, 2)$, out $(q, 3)$, out $(q, 4)$,

* $\operatorname{out}(q, 5)$, out $(q, 10)$, out $(q, 6)$, out $(q, 7)$, out $(q, 8)$, out $(q, 9)$

$=1041$ format $(1 x, f 5.2,2 x, f 8.2,1 x, f 7.2,1 x, f 5.2, f 8.2, f 8.2,2 x$

- $\quad f 6.2,2 x, 818.3,1 x, f 5.6,1 x, f 7.6)$

628 CONTINUE

$y^{3}=5.8$

if (tineup) then

urite $(* 042)$ time

write $(7,842, E R R=1686)$ tine

fornat $(/, 2 x$, 'Discharge Stopped at ', $f 7.2$,' hours', $/)$

- lse

write $(*, 048)$ testi, tine

urite $(7,848, E R R=1006)$ test $i$, time

48 fornat ( $/, 1 x$,'Battory unable to deliver ' $\$ 7.2$.

1

and if

' anps at time ',f7.2,' hours', $i$ )

write $(*, 8)$ 'Results have been written to BAT2A. OUT'

Write $\left.\left(*^{\prime},(a)\right)^{\prime}\right)$ ' Hit Return to Continue'

Read $(*, *)$

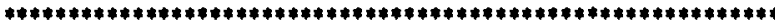

- Section 14: Graphics Screen

-

$9868 \mathrm{Ca} \mid$ | Rs/tuonu (IR, IC) 


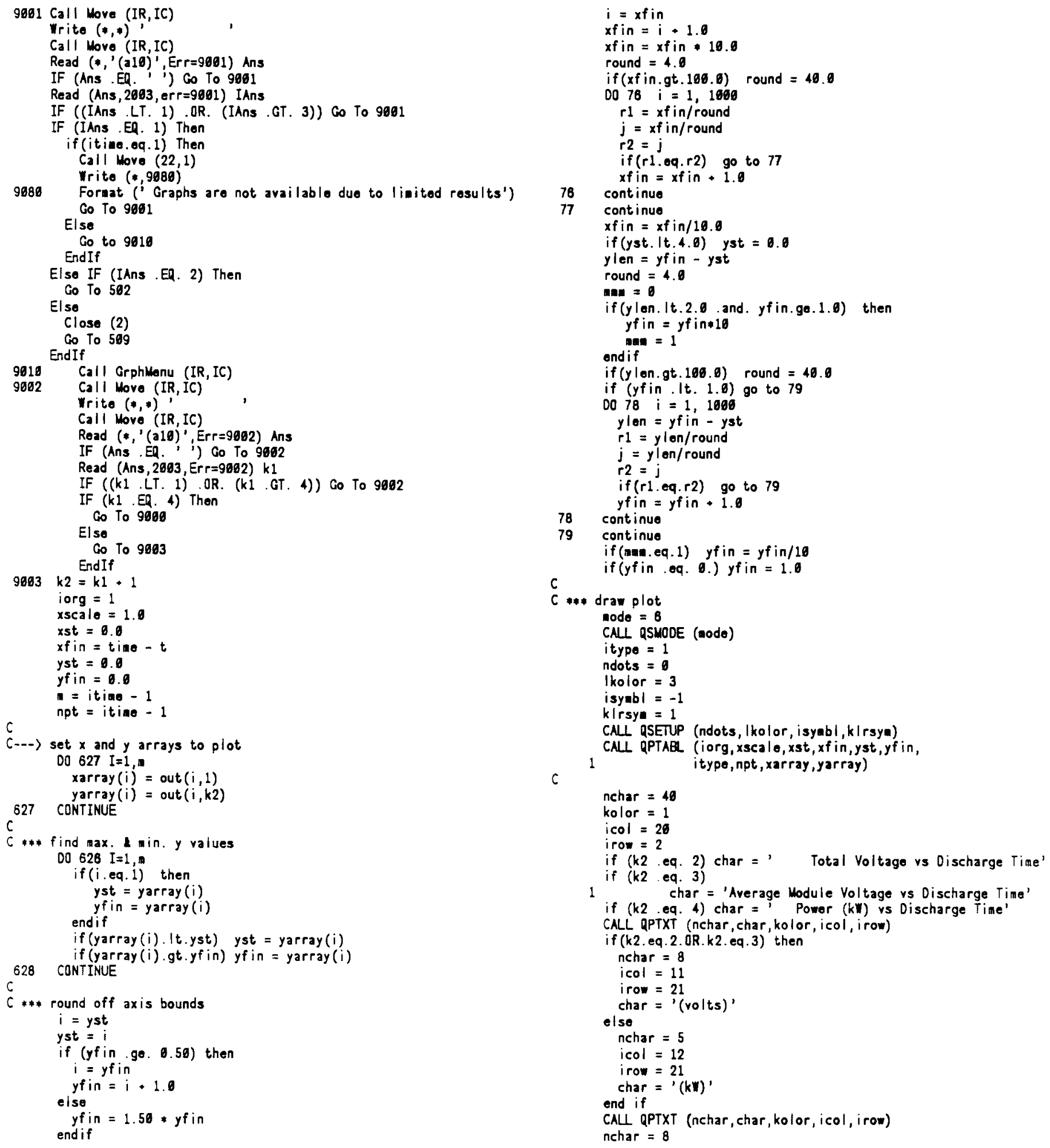




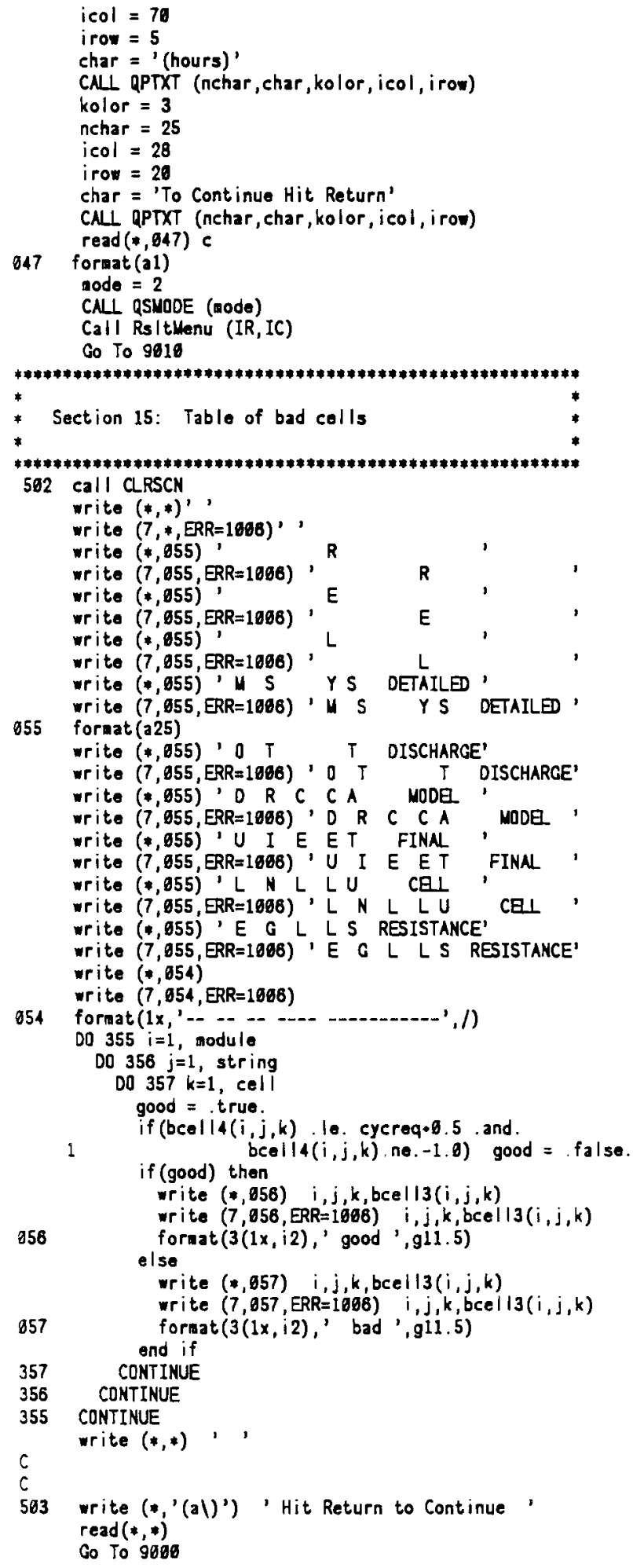

write $\left.(*, '(a))^{\prime}\right)$ ' Hit Return to Continue.

$\operatorname{read}(*, *)$

Go To 9000

1080 goto 1082

595 TRITE $(*, *)$ 'nismatch on size of battery'

$C * * *$ Branch to $1802 \Rightarrow$ Exit to Life Cycle Model

1002 Open (3, file = 'STOP1. TUP', Status = 'NEW') Close (3)

C *** Branch to $1084 \Rightarrow$ Exit to DOS

1004 Call Clirsen

Call QSUDDE (llodeBeg) Stop?:

C *** Branc to $1698=>$ File Error Decurred

1008 Call CirSen

Irite $(*, *)$; Additional Storage Space Needed.' Mrite (*,*)' Use Data Disk or Hard Disk.

Call QSMDDE (NodeBeg)

Stno',

END 
SUBROUTINE YSCAL (MUX, IPOWER, PSCALE)

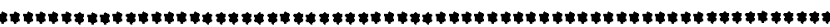
DESCRIPTION: DETERUINES THE POWER OF 10 SUCH THAT THE MAXIMU Y-AXIS ARRAY VALUE FOR PLOTTING CAN BE REPRESENTED IN SCIENTIFIC NOTATION AS A MANTISSA $>=0.1$ AND < 10. TIMES THIS POUER OF 10. THE LATTER IS USED AS THE SCALING FACTOR TO APPLY TO THE Y-AXIS ARRAY PRIOR TO PLOTTING.

ARGUMENTS:

maX (INPUT AND OUTPUT) = MAXIMMM VALUE OF Y-AXIS ARRAY BEORE SCALING ON INPUT AND AFTER SCALING ON OUTPUT FROM THIS ROUTINE

IPOWER (OUTPUT) = INTEGRNL POWER OF 10

PSCALE (OUTPUT) = SCALING FACTOR TO APPLY TO Y-AXIS

ARRAY PRIOR TO PLOTTING

LOGICAL NAMES AND FILES USED: NONE

ROUTINES USED: NONE

Constants (PaRameter statenents): none

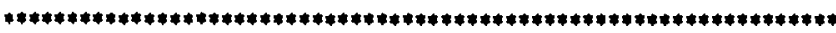

IPONER $=8$

IF (YNAX .GE. 10.) THEN

IPOWER = IPOWER *

YMAX $=$ YMAX / 10

GO TO 1

ENDIF

2 IF (YUAX .LT. B. 1) THEN

IPOWER = IPOWER - 1

YMAX $=$ YMAX *16.

GO TO 2

ENDIF

PSCALE $=10 . *$ IPOWER

RETURN

END

SUBROUTINE XSCAL (XMAX, IPOWER, PSCALE)

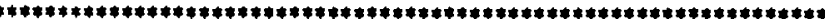
DESCRIPTION: DETERMINES THE POWER OF 10 SUCH THAT THE MAXIMUM $X$-AXIS ARRAY VALUE FOR PLOTTING CAN BE REPRESENTED IN SCIENTIFIC NOTATION AS A WANTISSA $)=0.1$ ANO $<10,000$ TIMES THIS POWER OF 10. THE LATTER IS USED AS THE SCALING FACTOR TO APPLY TO THE X-AXIS ARRAY PRTOR TO PLOTTING.

ARGUMENTS: $\quad$ XMAX (INPUT AND OUTPUT) = MAXIMUN VALUE OF $X$-AXIS ARRAY BEFORE SCALING ON INPUT AND AFTER SCALING ON OUTPUT FROM THIS ROUTINE.

IPOWER (OUTPUT) = INTEGRA POWER OF 10

PSCALE (OUTPUT) = SCALING FACTOR TO APPLY TO X-AXIS ARRAY PRIOR TO PLOTIING

LOGICAL NAMES AND FILES USED: NONE

ROUTINES USED: NONE
CONSTANTS (PARAMETER STATEMENTS): NONE

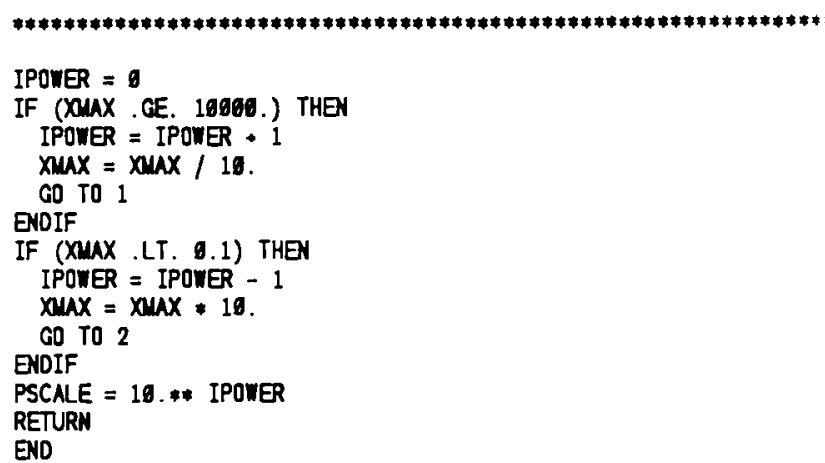

SUBROUTINE FAILURE(BAD)

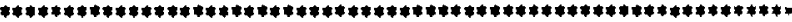
DESCRIPTION: calculates randon cell failure value.

ARCUNENTS :

BAD (O) = randon failure value

LOGICAL NANES AND FILES USED: (NONE)

ROUTINES USED:

RANF = roturns randon

CONSTANTS (PARAMETER STATEMENTS): (NONE)

COMNON BOCKS :

INCLUDE: 'WEIBU. INC'

WEIBU. INC -- Maibul distribution paraneters YARIABLES:

RENL BAD

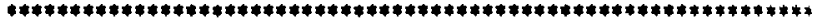

$\rightarrow \rightarrow$ calculate randon failure

RANF returns randon number between 0.0 and 1.8

ALOG is natural log

neg. sign akes nuaber pos. (natural logs of $\delta-1$ are neg CAL RANF $(R, L)$

$8 A D=\operatorname{LOCATE}+\operatorname{SCALE} *((-A L O G(R)) * *(1 /$ SHAPE $)$

RETURN

END

FUNCTION GAMMA(X)

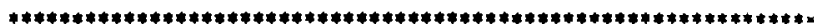

DESCRIPTION: CALCULATES GAMM FUNCTION OF $(1 . * x)$ USING ALGORIT FROM 'APPROXIMATIONS FOR DIGITAL COMPUTERS'

(PAGE 158) BY C. HASTINGS (1955) 


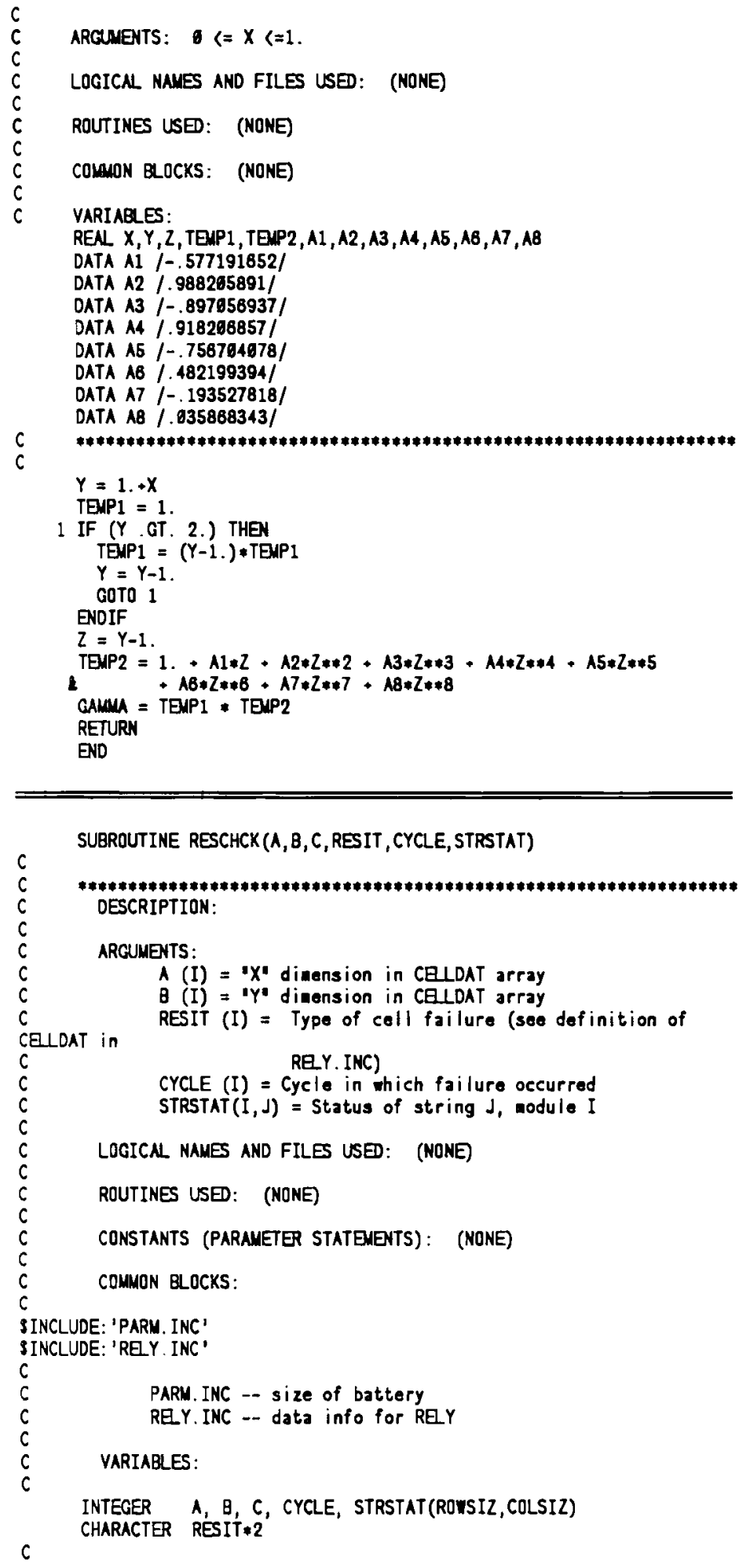

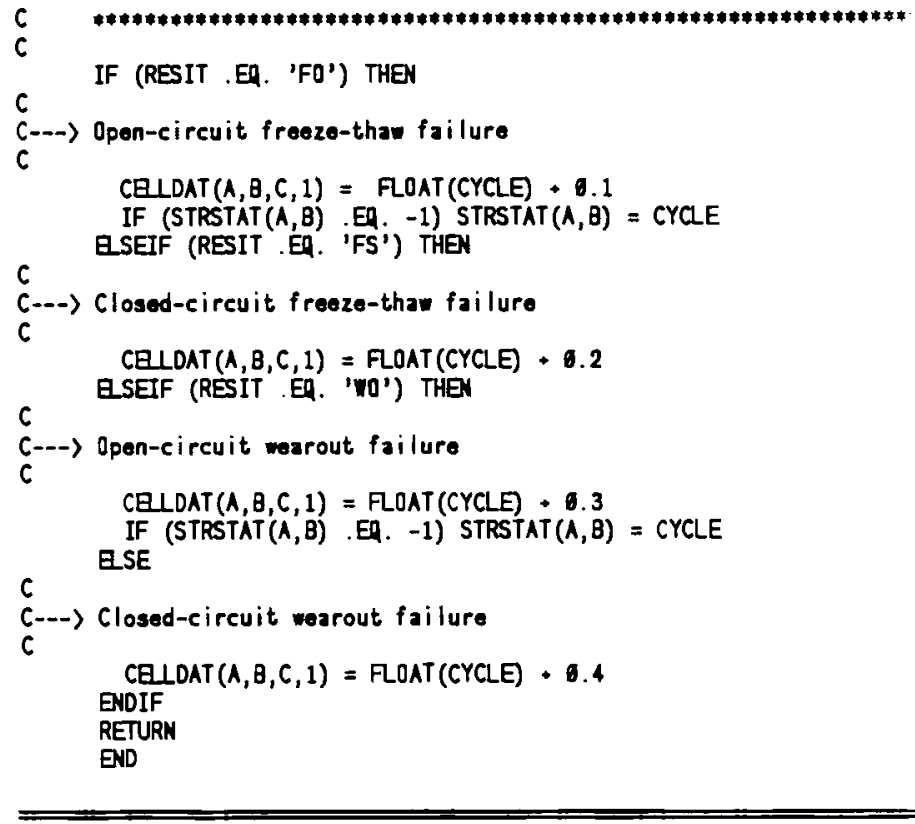

SUBROUTINE PG2HEAD(OPN)

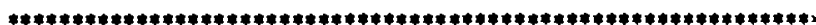
DESCRIPTION: Writes the page heading for the second output $P$

ARCUNEMTS:

$$
\begin{aligned}
\text { OPY (I) = } & \text { output mode - if } \% \text {, output to screen, } \\
& \text { if not } 0 \text {, output written to logical unit } \\
& \text { OPY output file }
\end{aligned}
$$

LOGICAL NAMES AND FILES USED: OPY = logical unit for output file

ROUTINES USED: (NONE)

CONSTANTS (PARAMETER STATEMEMTS): (NONE)

COMNON BLOCKS: (NONE)

VARIABLES:

INTEGER AP

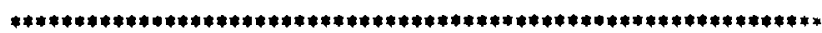

WRITE (OPM, 95)

WRITE (OPM,97) 'CYCLE LIFE AND FAILURE TOTALS:'

WRITE (OPM, 98)

IF (OPM .ED. O) THE

WRITE (*' '(A) ') ' Hit Return to Continue

$\operatorname{READ}(*, *)$

CALL CLRSCH

EYDIF

WRITE (OPM, ' $\left.(/ / / /)^{\prime}\right)$

WRITE (OPM, 98) 'NUMBER OF FAILURES'

WRITE (OPM, 99) ' FREEZE-THAI WEAROUTS'

WRITE (OPN,99) 'CYCLE -........

WRITE (OPM,97) 'RUN LIFE OPEN CLOSED TOTAL OPEN CLOSED TOTAL

WRITE (OPM, 97) '-. -.. -

WRITE (OPN, 96) 

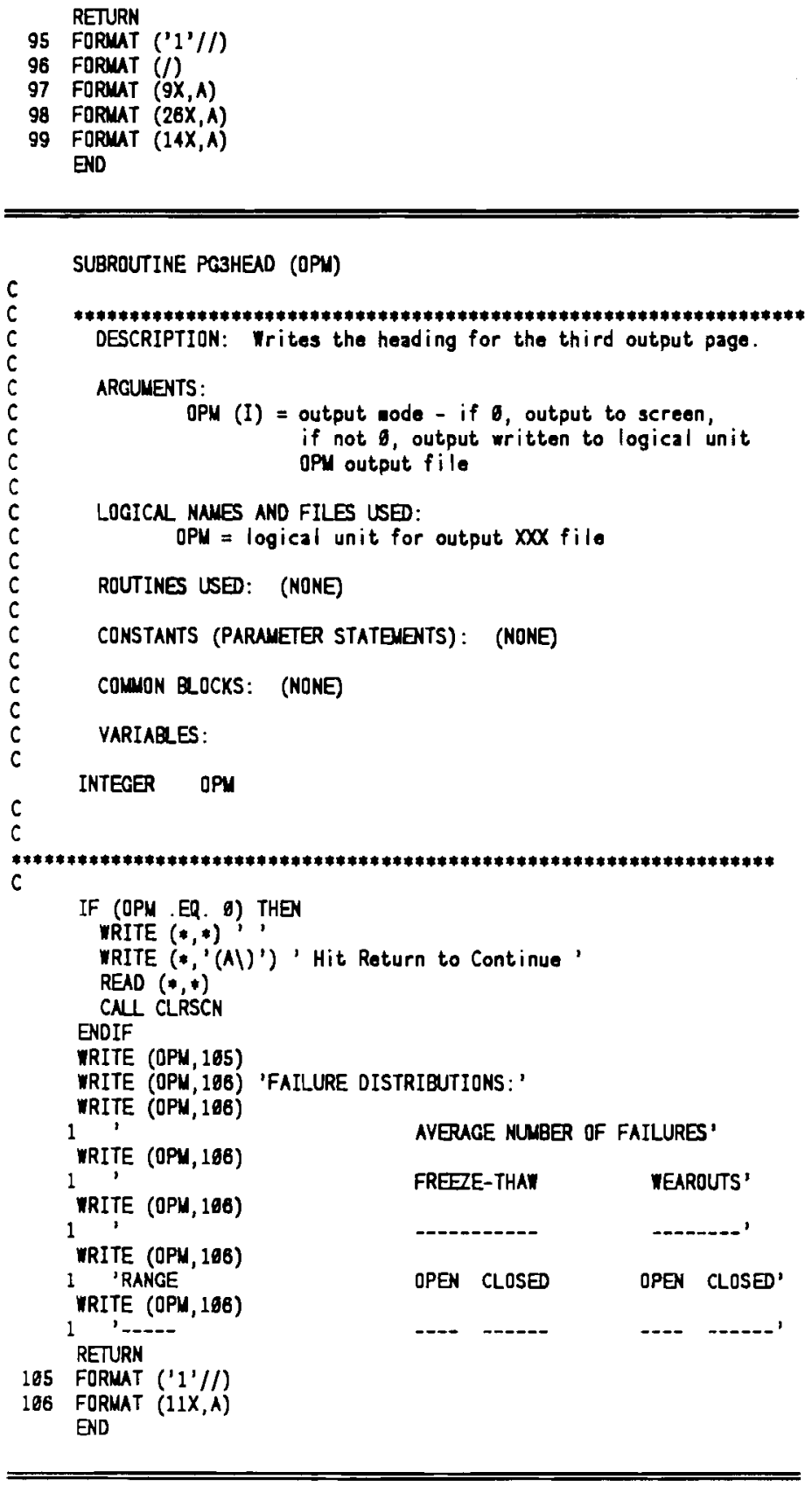

$c$
$c$
$c$
$c$
$c$
$c$
$c$
$c$

SUBRDUTINE RANF $(R, L)$

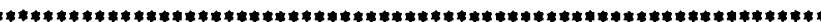
DESCRIPTION: returns a pseudo-randon number rectangularly distributed between 0 and 1 .

algoritha AS 183 APPL.STATIST. (1982) VOL.31, NO.2 ARGUMENTS:

$$
R(0)=\text { randon nuaber }
$$

LOGICAL NAMES AND FILES USED: (NONE)

ROUTINES USED: (NONE)

CONSTANTS (PARAMETER STATEMENTS): (NONE)

COMON BLOCKS: (NONE)

VARIABLES:

INTEGER IX, IY, IZ

DATA IX, IY, IZ / 1111, 2222, 3333 /

IX, IY, and IZ should be set to integer values between 1 and 39,060 before first ontry.

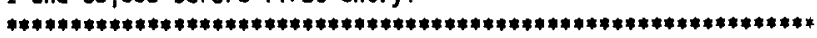

$I X=M 0 O(171 * I X, 36269)$

$I Y=M O D(172 * I Y, 36367)$

$I Z=M O D(176 * I Z, 36323)$

$c$

C---> calculate randou nuaber

$R=$ ANOD (FLAT (IX) / 36269.6 * FLOAT(IY) / 38307.6.

- FlOAT(IZ) / 36323.6, 1.6)

$L=L \cdot 1$

RETURN

END

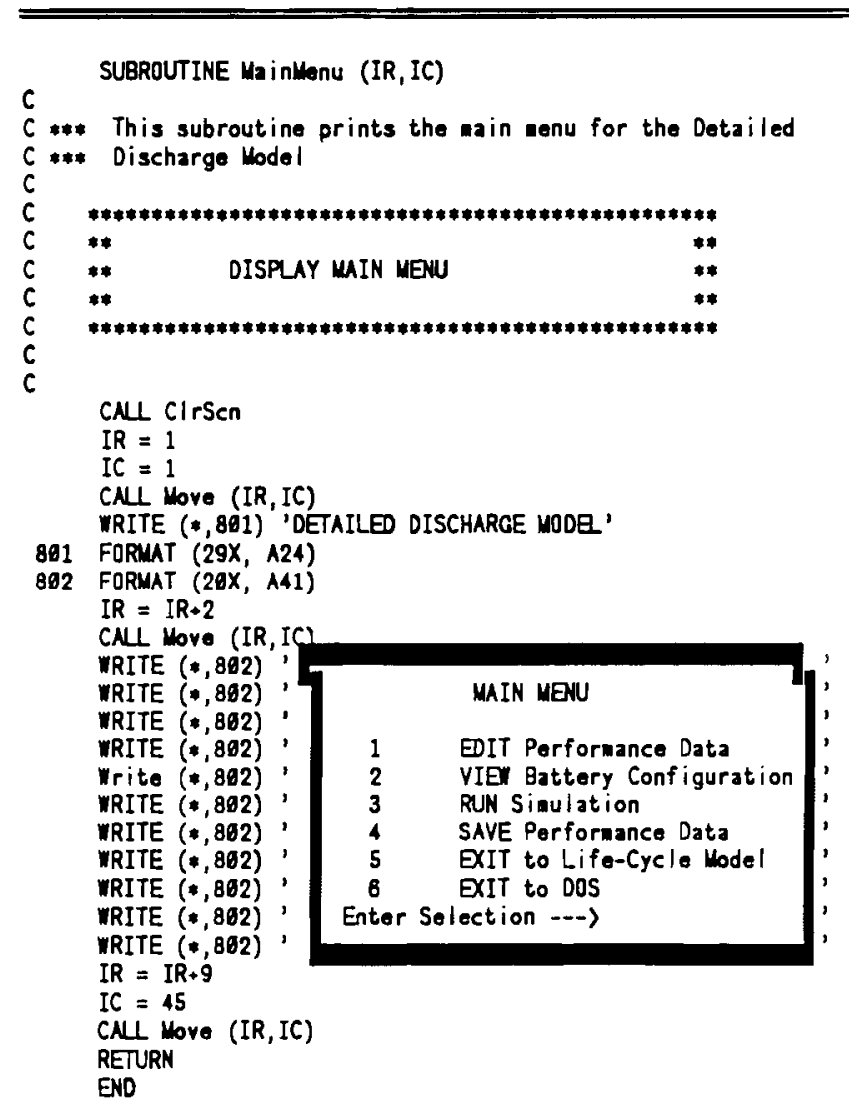




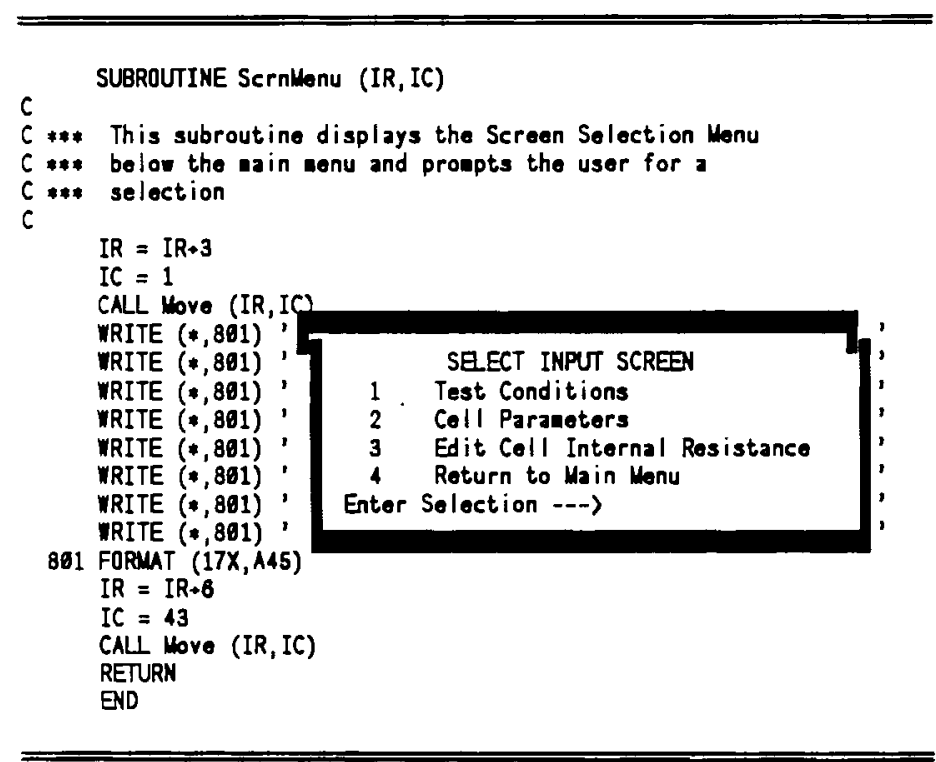

SUBROUTINE Rs/tMenU (IR, IC)

$C * * *$ This senu gives the user the choice between graphical

$C * *$ analysis, listing a table of cells, and returning to

$C * * *$ the main menu.

c

CALL CIrSen

IR $=3$

$\mathrm{IC}=1$

CALL Nove (IR, IC)

891 FORMAT $(29 X, 124)$

892 FORMAT $(29 \mathrm{X}, \mathrm{A41}$

WRITE $(*, 802)$ '

WRITE $(*, 892)$ '

WRITE $(*, 882)$

WRITE $(* 882)$

Write $(*, 802)$

WRITE $(*, 802)$

WRITE $(*, 892)$

RITE $(* 802)$

$I R=I R+6$

$I C=45$

CALL Move (IR, IC)

RETURN

END

SUBROUTINE GrphHenU (IR,IC)

$C * * *$ This menu gives the user the choice of several graphs

$C$ *** to help interpret the results

C

$I R=I R+3$

$I C=1$

CALL Move (IR, IC)

WRITE $(*, 801)$

WRITE $(*, 881)$

WRITE $(*, 801)$

WRITE $(*, 801)$ '

WRITE $(*, 801)$

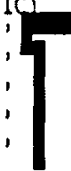

GRAPHICN ANALYSIS

Total Voltage vs Time

Average Module Voltage vs Tine

Total Power vs Tine

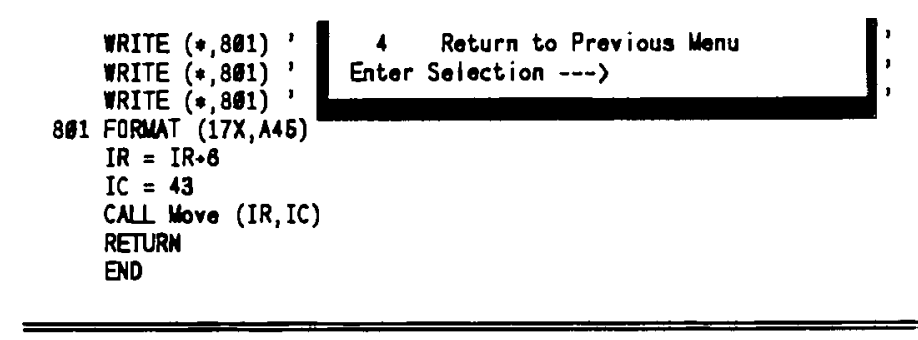

SUBROUTINE OUTPG1 (OUT, OPY)

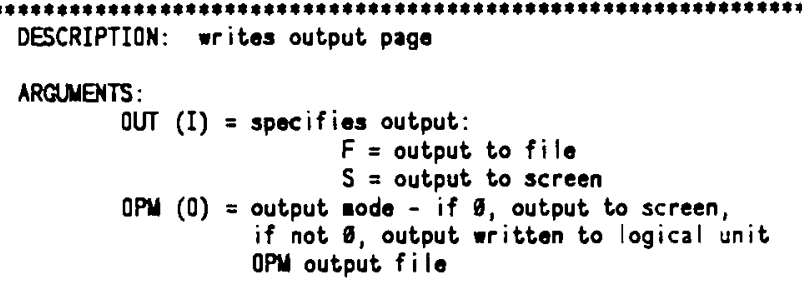

LOGICAL NAMES AND FILES USED:

if OPW not equal to zoro, output file created

ROUTINES USED: (NONE)

CONSTANTS (PARMMETER STATEMENTS): (NONE)

COMON BLOCXS:

SINCLUDE: 'PARY. INC'

SINCLUDE.' 'REY Y INC'

SINCLUDE: 'NEIBU. INC'

PAPY. INC -- size of battery

REY.INC -- data info for REY

WEIBU.INC - Noibul distribution paraneters

VARIABLE:

CHARACTER OUT:1

LOGICN OPF

INTEGER OPN

DATA OPFLAG /.TRUE./

NOTE : THE COMMON VARIABLES CELDAT aND FDATA

ARE NOT USED IN THIS SUBROUTINE.

PARAMETERS SET BY THE USER IN THE MAIN PROGRAM:

SHAPE, SCALE, PREMAY, DIMCAPA

CELRER, STRGREQ, MODREQ, LOCATE

FDATA $(4,100)$

RESIST

VARIABEES DESCRIBING THE CE I CONFIGURATION:

CELDAT $(16,10,20,3)$

MODUE, STRING, CELS

VARIABLES SIGNIFYING THE OUTPUT MODE:

OUT:1, OPM, OPFLAO

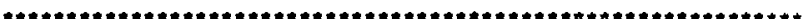

$\rightarrow$ prepare output mode: clear screen or open output file IF (OUT EQ. 'S') THEN CAL CLRSCN 


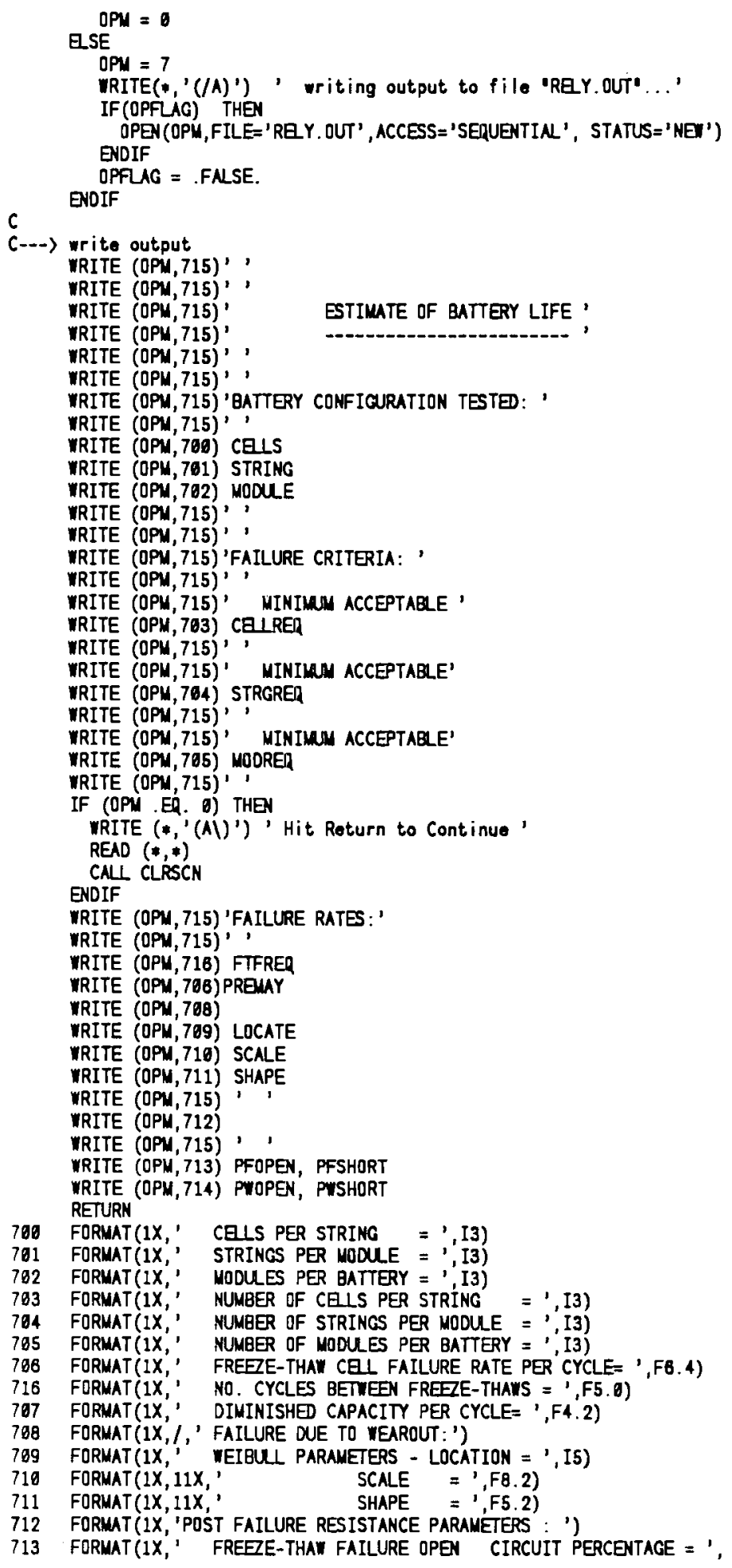

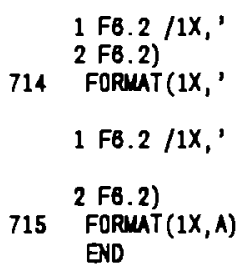

1 FB. $2 / 1 X_{1}^{\prime}$ 2 FB. 2)

714 FORMAT(1X,'

$1 \mathrm{FB} .2 / 1 \mathrm{X},{ }^{\prime}$

2 F6.2)

715 FORMT $(1 X, A)$

END 


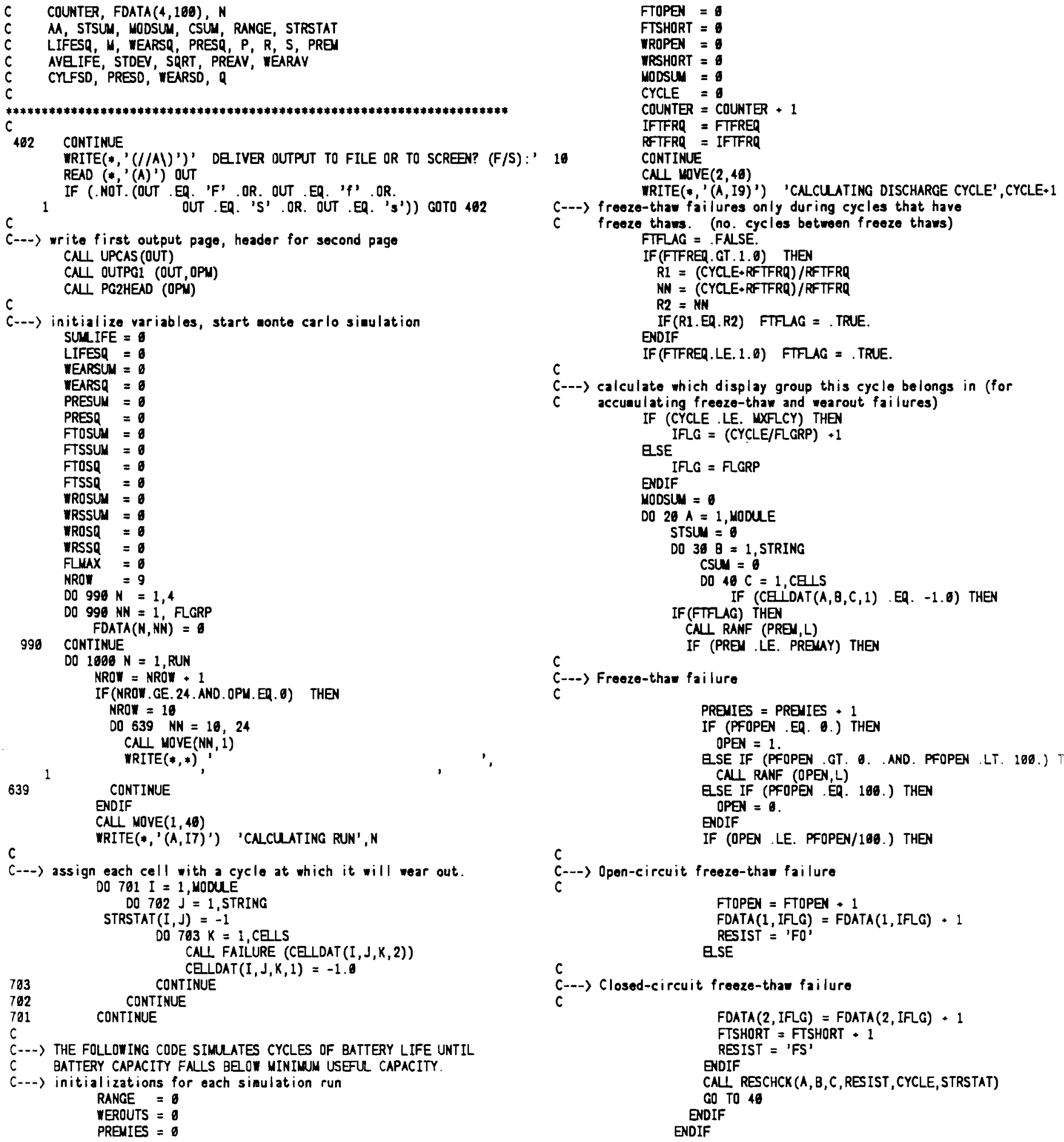


IF (INT (CELDAT $(A, B, C, 2))$.EQ. CYCLE) THEY

C---) Wearout failure

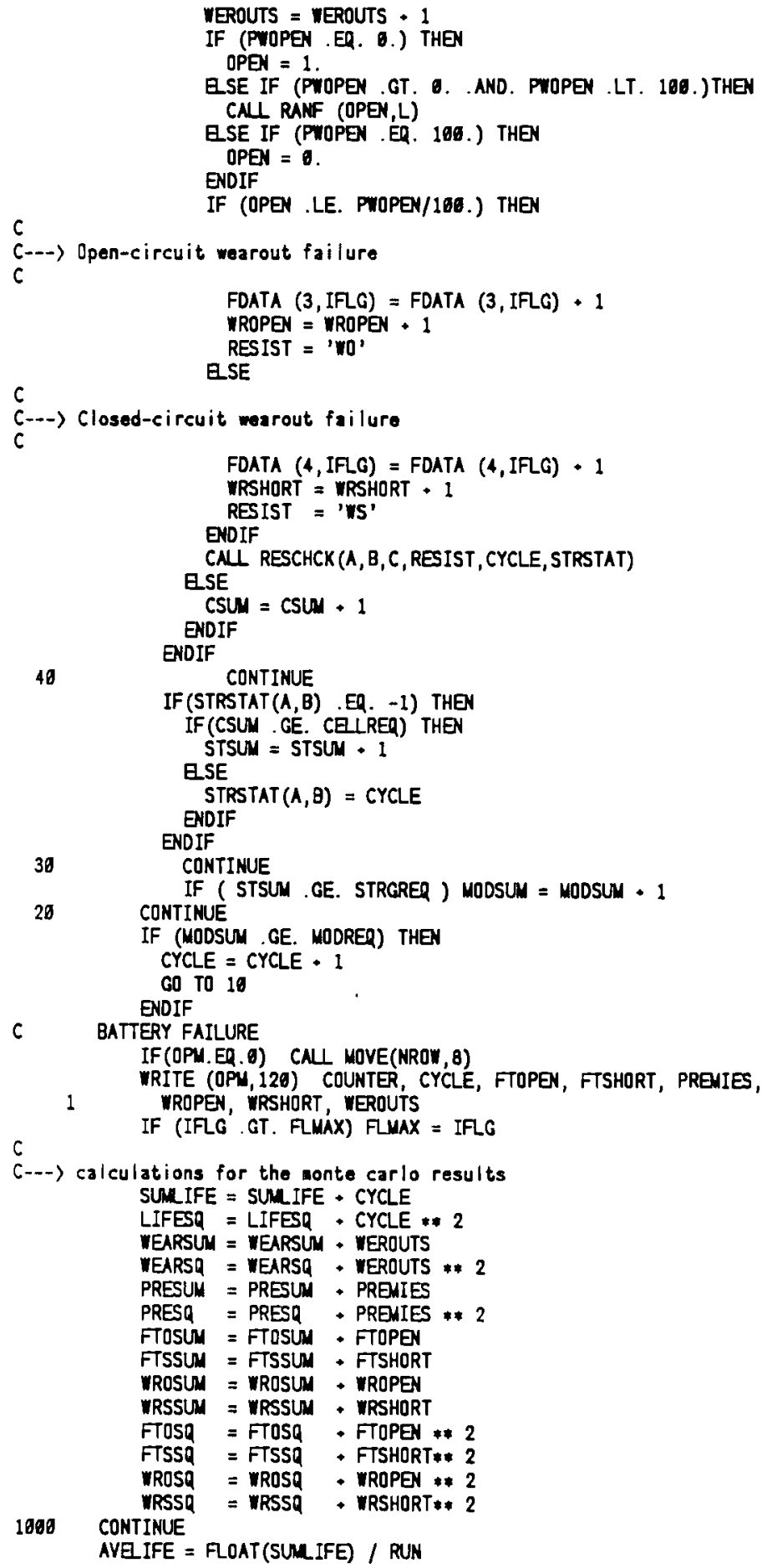

AVEIFE = FLOAT(SUNLIFE) / RUN

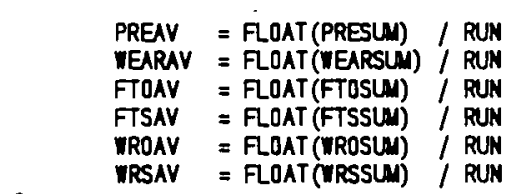

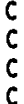

Return to progran BAT2A the last working battery cycle in the last sieulation run

CYCLE $=$ CYCLE - 1

WRITE (OPM, ' $(/ /)^{\prime}$ )

WRITE (OPM, 130) 'AVERAGE', AVEIFE, FTOAV, FTSAV, PREAV,

1 WROAV, WRSAV, IEARAV

CYFSD = STDEV (LIFESQ, AVEIFE, SUMLIFE, RUN)

PRESD = STDEY (PRESQ, PREAY, PRESU, RUN)

WEARSD = STDEY (WEARSQ, WEARAV, WEARSUM, RUN)

FTOSD = STDEY (FTOSA, FTOAY, FTOSUM, RUN)

FTSSD = STDEV (FTSSQ, FTSAV, FTSSUM, RUN)

WROSD = STDEV (WROSQ, WROAV, WROSUM, RUN)

WRSSD = STDEV (WRSSQ, WRSAV, WRSSU, RUN)

WRITE (OPM, 130) 'STD DEV', CY'FSD, FTOSD, FTSSD, PRESD, WROSC

1 WRSSD, WEARSD

$c$

C--D) write output page 3

CAL PGZHEAD (OPM)

CAL PG3LN1 (OPN, FLMAX, RUN)

FETURN

120 FORWAT (T9, I4, T14, I5, T26, I5, T26, I5, T32, I5, T36, I5, T45, I5, T56, I

130 FORUAT $\left.(T 2, A 7]^{\prime}=', T 11, F 8.1, F 6.1, F 7.1, F 6.1, F 6.1, F 7.1, F 6.1\right)$

END

\section{SUBROUTINE PG3LN1 (OPM, FLMAX, RUN)}

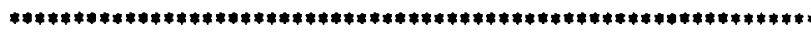
DESCRIPTION: Caleulates and writes output lines for page 3

ARGUMENTS:

OPM (I) = output rodo - if 6 , output to screen, if not 6 , output written to logical unit OPN output file

FLMAX $(I)=$ max. vidth of FDATA array

RUN (I) = number of simulation runs

LOGICN NAMES AND FILES USED:

OPM = output; screen or output file

ROUTINES USED: (NONE)

Constants (Parameter statenents): (NONE)

COMMON BLOCKS:

SINCLUDE: ' PARM. INC'

SINCLUDE: 'REY Y INC

PARM. INC -- size of battery

REY.INC -- data info for REY

VARIABLES:

INTEGER K, OPM, FLMAX, RUN

DO $1110 K=0$, FLMAX-1

R1 = FLOAT (FDATA $(1, K+1)) /$ FLOAT (RUN) 


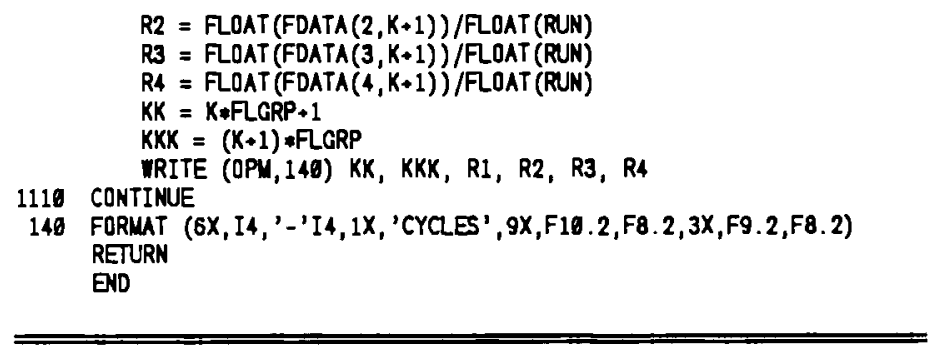

SUBROUTIME CLRSCN

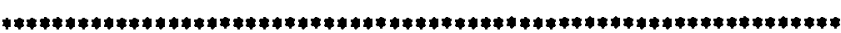
DESCRIPTION: Clears screen

ARGMENTS: (NONE)

LOGICAL NAMES AND FILES USED: (NONE)

ROUTINES USED:

$$
\text { MOVE }(1,1)
$$

CONSTANTS (PARAMETER STATEMENTS): (NONE)

COMMON BLOCKS: (NONE)

VARIABLES:

CHARACTER 1 CLRSTR(4)

DATA CLRSTR /',' '[','2','J'/

C

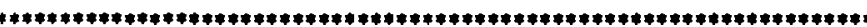

6

CLRSTR(1) $=\operatorname{CHAR}(27)$

WRITE (*,' (1X,4A1U)') CLRSTR

CALL MOVE $(1,1)$

RETURN

END

SUBROUTINE MOVE (IR, IC)

OECRTPTIOK: DESCRIPTION: perfores misc. screen operations

ARGMUENTS

IR (I) = specifies screen command

IC (I) = specifies screen comand

LOGICAL NAMES AND FILES USED: (NONE)

ROUTINES USED: (NONE)

CONSTANTS (PARAMETER STATEMENTS): (NDNE)

COMMON BLOCKS: (NONE)

VARIABLES:

CHARACTER*8 MOVSTR

CHARACTER*1 BRAC, SEMI, H

DATA BRAC, SEMI, H / ' $\left[{ }^{\prime}, '{ }^{\prime}, '{ }^{\prime}\right.$ ''

C

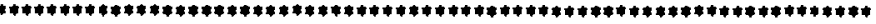

$c$

WRITE (MOVSTR, 5) CHAR(27), BRAC, IR, SEII, IC, H

FORUAT $(2 A 1,12.2, A 1, I 2.2, A 1)$

VRITE $(*, 6)$ MOVSTR

6 FORMAT (IX,A8Y)

RETURN

END

\section{SUBROUTINE QLINK}

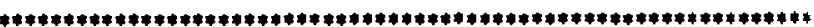
DESCRIPTION: nakes the screen blink

ARCUMENTS: (NONE)

LOGICAL NAMES AND FILES USED: (NONE)

ROUTINES USED: (NONE)

Constants (PARAMETER StatementS): (NONE)

COMON BLOCXS: (NONE)

VARIABLES:

CHARACTER 1 INK (4)

DATA WINK $/, 1, '\left[{ }^{\prime}, ' 5,, '=1\right.$

$c$
$c$

INKK(1) $=$ CHAR(27)

WRITE (*, '(1X,4AIY)') WINK

RETURN

END

SUBROUTINE REVERSE

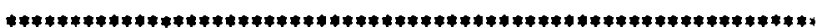
DESCRIPTION: changes seroen to negative - frou bright charac dark background to dark characters, bright background.

C ARCUMENTS: (NONE

LOGICN haMes and files USED: (NONE)

ROUTIMES USED: (NONE)

CONSTANTS (PARAMETER StatenentS): (NONE)

COMNON BLOCKS: (NONE)

VARIABQES:

CHARACTER*1 REV(4)

DATA REV $/, ',{ }^{\prime}, ' 7^{\prime},{ }^{\prime}$ '।

$c$
$c$
$c$

$\operatorname{REV}(1)=$ CHAR $(27)$

WRITE $(*, '(1 X, 4 A 1 \backslash)$ ') REV

RETURN

END 


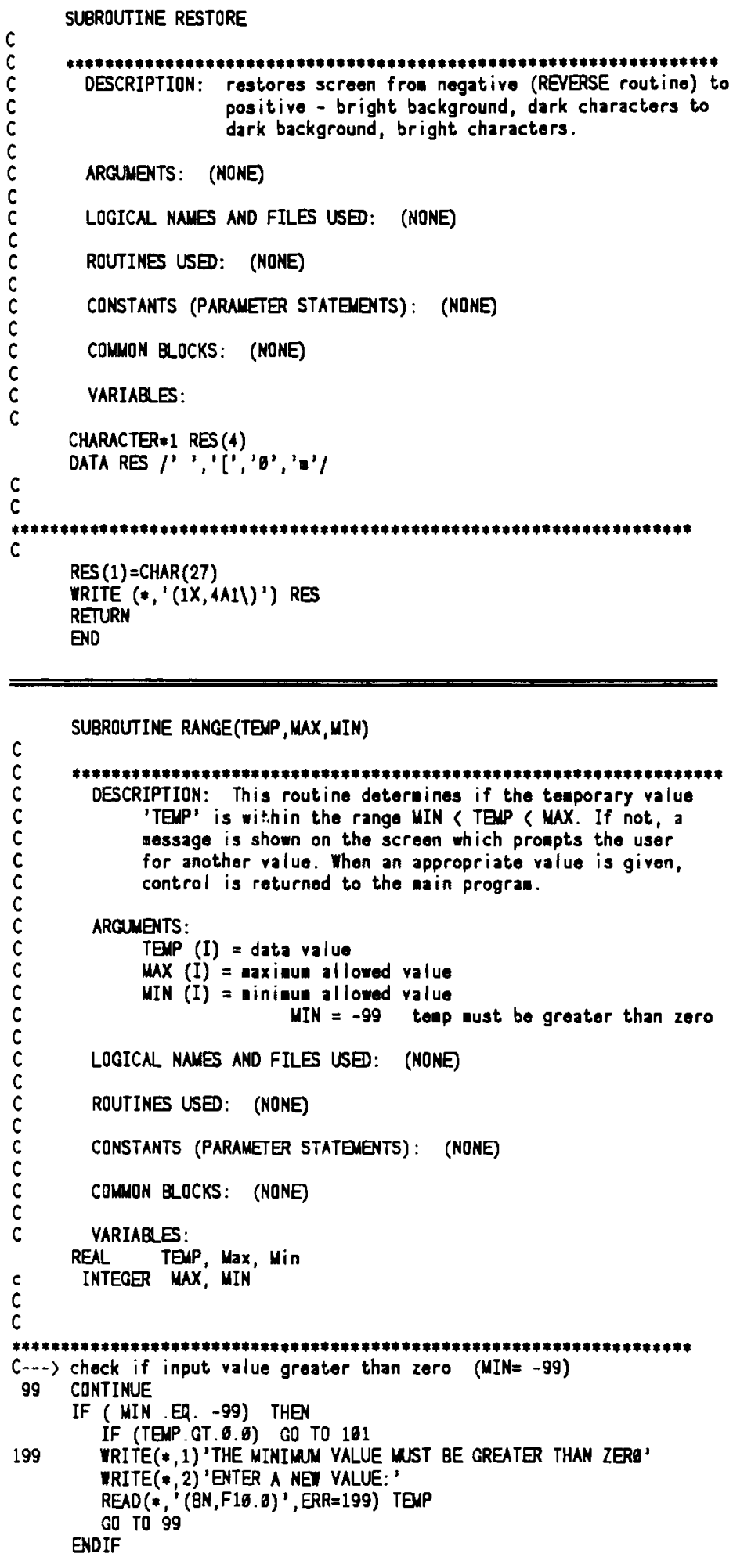

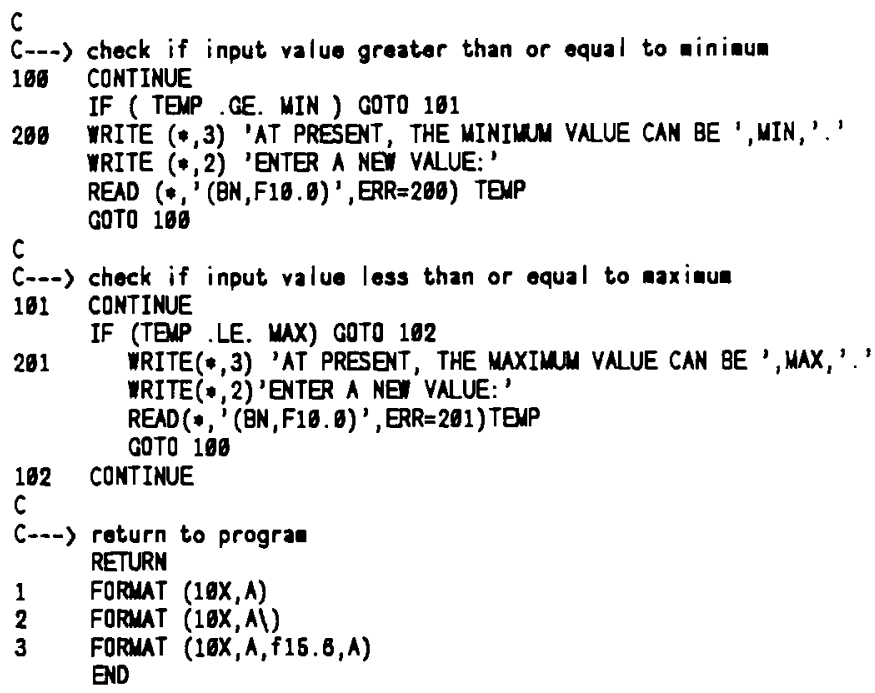

ARGUMENT:

$$
\text { TEMP (I) = input integer value }
$$

FINAL $(0)=$ final return integer

LOGICAL NAMES AND FILES USED: (NONE)

ROUTINES USED: (NONE)

CONSTANTS (PARANETER STATENENTS): (NONE)

COMMON BLOCKS: (NONE)

VARIABLES:

INTEGER FINAL

RENL ANOD, TENP, RENIN

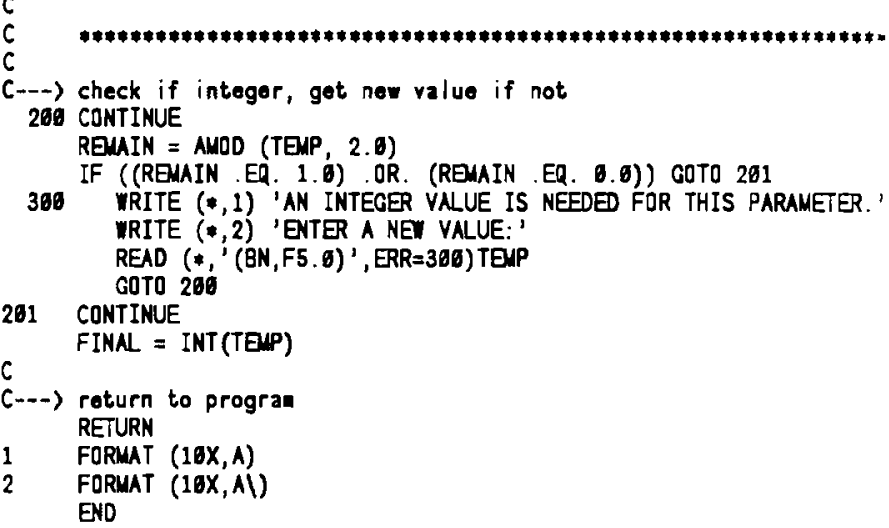



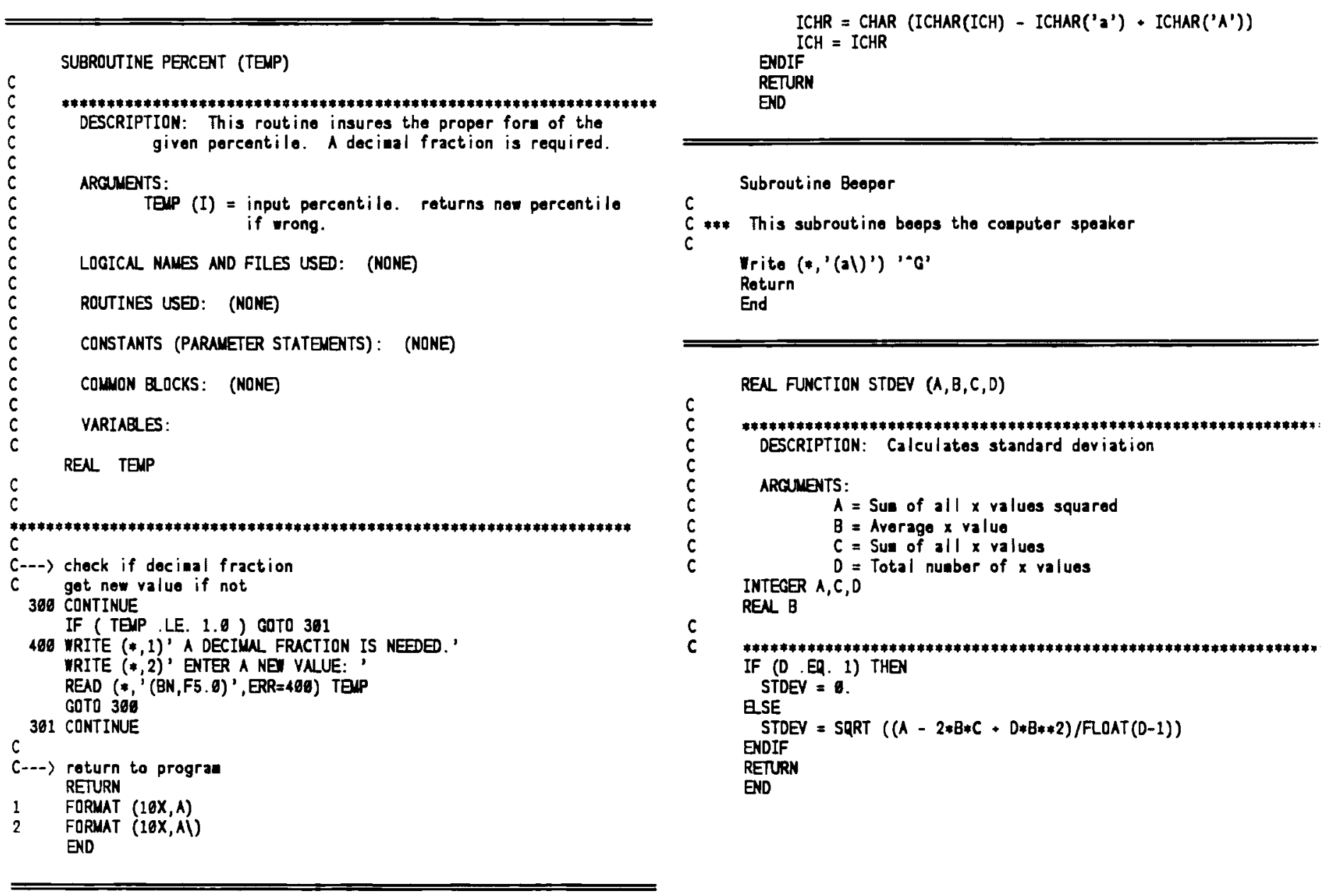

RENL FUNCTION STDEY $(A, B, C, D)$
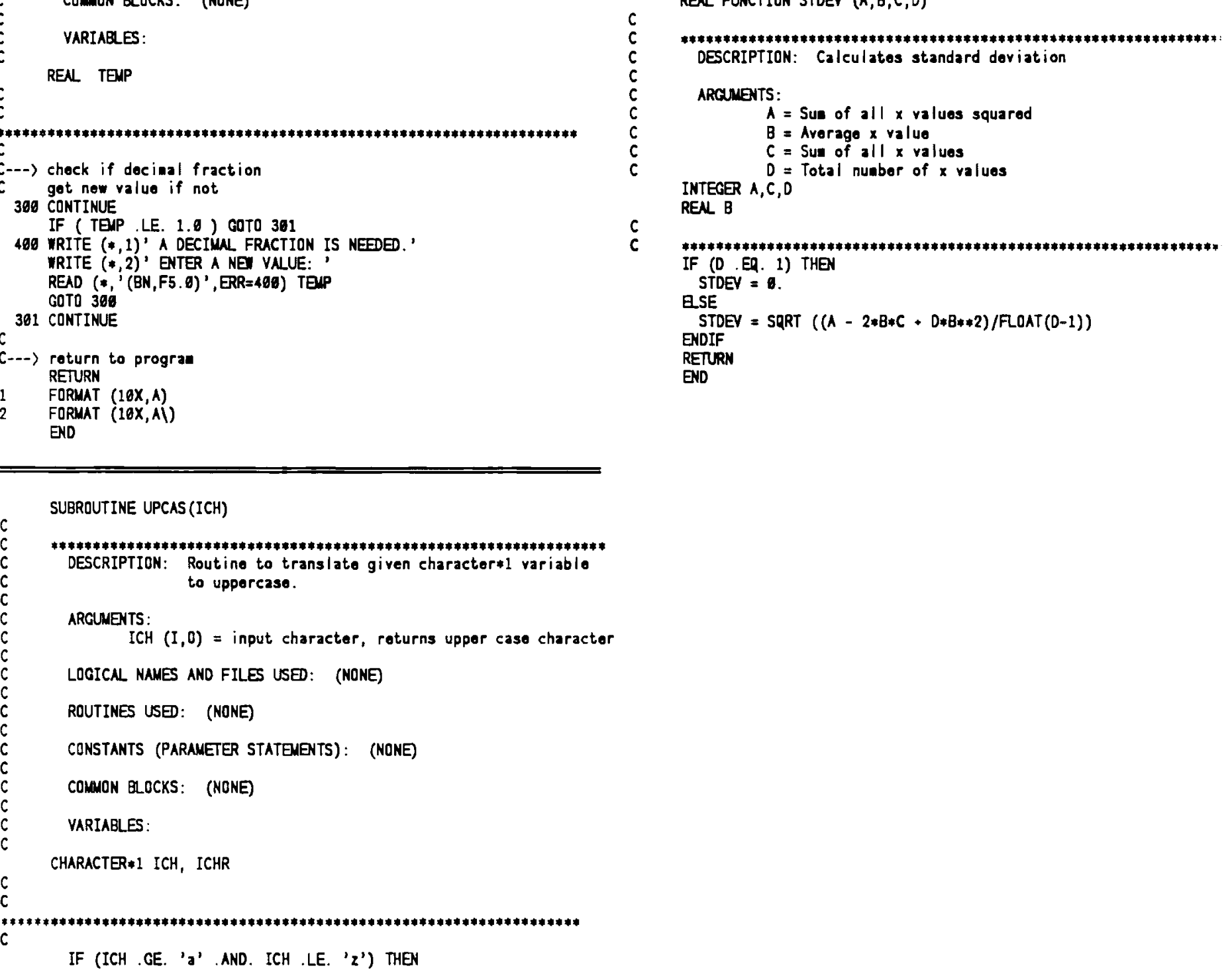


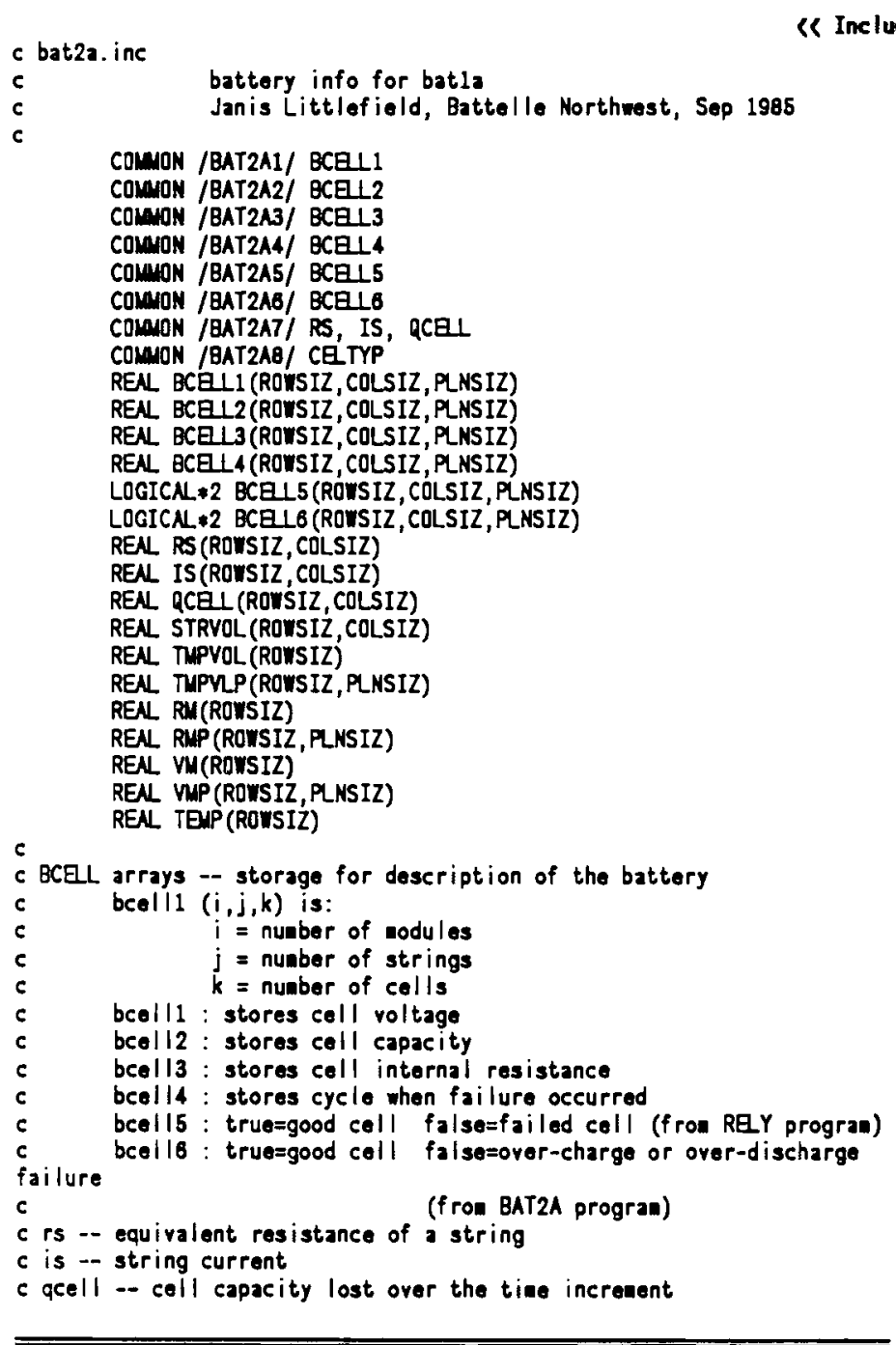

C parm.ine

c contains size for battery. To change size of battery you nust change these

c parameter statements and then recompile all routines used in prograns rely

$c$ and batla.

INTEGER ROWSIZ, COLSIZ, PLNSIZ

PARAMETER (ROWSIZ $=20$ )

PARAMETER (COLSIZ $=20$ )

PARAMETER (PLNSIZ $=20$ )

c rowsiz -- nuaber of aodules

c colsiz -- number of strings

$c$ pinsiz -- nuaber of colls
Filos $>$

C REY.INC

INTEGER WXFLCY, WXFLPT, FLGRP

PARANETER (NXFLCY $=5009)$

PARAMETER (MXFLPT $=100$ )

PARAMETER (FLGRP = WXFLCY $/$ MXFLPT)

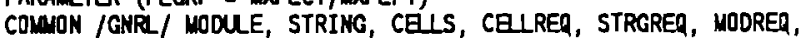

1 PREMYY, DIUCAPA, RESIST, FTFREQ, PFOPEN, PFSHORT, 2 PWOPEN, PUSHORT

COMON /FDAT/ FDATA

REN CELDAT (RONSIZ, COLSIZ, PLNSIZ, 2), PREMAY, FTFREQ

INTEGER MODUE, STRING, CELS, CELREA, STRGREA, MODRER INTEGER FDATA (4,FLGRP) CHARACTER 2 RESIST

c celldat -- contains data about the battery being siaulated.

c 1st subscript -- number of nodules

c 2nd subscript -- number of strings in a module

c 3rd subscript -- number of cells in a string

c 4th subscript -- info about the cell

value 1 -- whether cell has failed or not and its type of failu $=-1$ has not failed; is still live

\rangle$=0.0$ has failed. Integer part of value indicates which cycle failure occurred. This cy. number includes both prenature and wea failures. Fractional part of value

indicates

type of failure as follows:

0.1 = open-circuit freeze-thaw failt 0.2 = closed-circuit freeze-thaw faill 0.3 = open-circuit vearout failure 0.4 = closed-circuit wearout failure

value 2 -- cycle nubber at which this cell will fail if it does not prenaturely fail (obtained from routine FAILURE)

fdata -- contains info about type of failures. Each row in fdata $c$ has data about the failures during a particular group of cycles. c It is assuned that 5000 cycles is an overstatenent of battery life. c It is conjectured that 100 point can be displayed graphically to show prenature and wearout failures. Thus the grouping, FlCRF

$c$ is 5age/100 or 50 cycles for each data point. For each row, the c colunns are:

1 -- number of open-circuit freeze-thaw failures

2 -n nuber of elosed-circuit freeze-thav failures 3 -- nuaber of open-circuit wearout failures 4 -- number of short-circuit wearout failures

c weibul.inc -- include file for Meibul distribution paraneters

COMMON / WEIBUL/ LOCATE, SHAPE, SCALE INTEGER LOCATE

REAL SHAPE, SCNLE 

APPENDIX D

MODEL VERIFICATION 

APPENDIX D

MODEL VERIFICATION

This appendix contains verifications of the two primary models, the Life Cycle Model and the Detailed Discharge Model.

\section{D.I VERIFICATION OF THE LIFE-CYCLE MODEL}

Two example battery systems are presented in this appendix to verify the logic of the RELY program. RELY simulates a battery's life by generating random numbers to determine whether a given cell fails on the current chargedischarge cycle. Thus, in order to verify the logic, it is necessary to use precisely the same random numbers.

Both systems discussed here use parameters for the Weibull distribution of: i) $\operatorname{LOCATION}=0.0$, ii) $\mathrm{SCALE}=20.0$, and $i i i)$ SHAPE $=1.0$. The configuration of both systems is $[(3,3,2),(2,2,2)]$ as shown in Figure 0.1 . That is, there are 3 cells per string, 3 strings per module, and 2 modules per battery. The minimum operating requirements are 2 cells per string, 2 strings per module, and two modules. Freeze-thaw conditions are assumed to occur every 3 cycles, with a freeze-thaw failure probability of 0.10 . The differences between the two systems are the failure modes: System I has $100 \% \mathrm{closed-}$ circuit failure modes for both wearout and freeze-thaw failures, while System II has $100 \%$ open circuit failure modes. Thus, in System II, an entire string fails as soon as one cell in the string fails.

In the discussion below, cell $(i, j, k)$ refers to the $k^{\text {th }}$ cell of the $j^{\text {th }}$ string of the $i^{\text {th }}$ module. Similarly, string $(i, j)$ means the $j^{\text {th }}$ string of the $i_{\text {th }}$ module. References to specific cells and strings can easily be made with this terminology. 

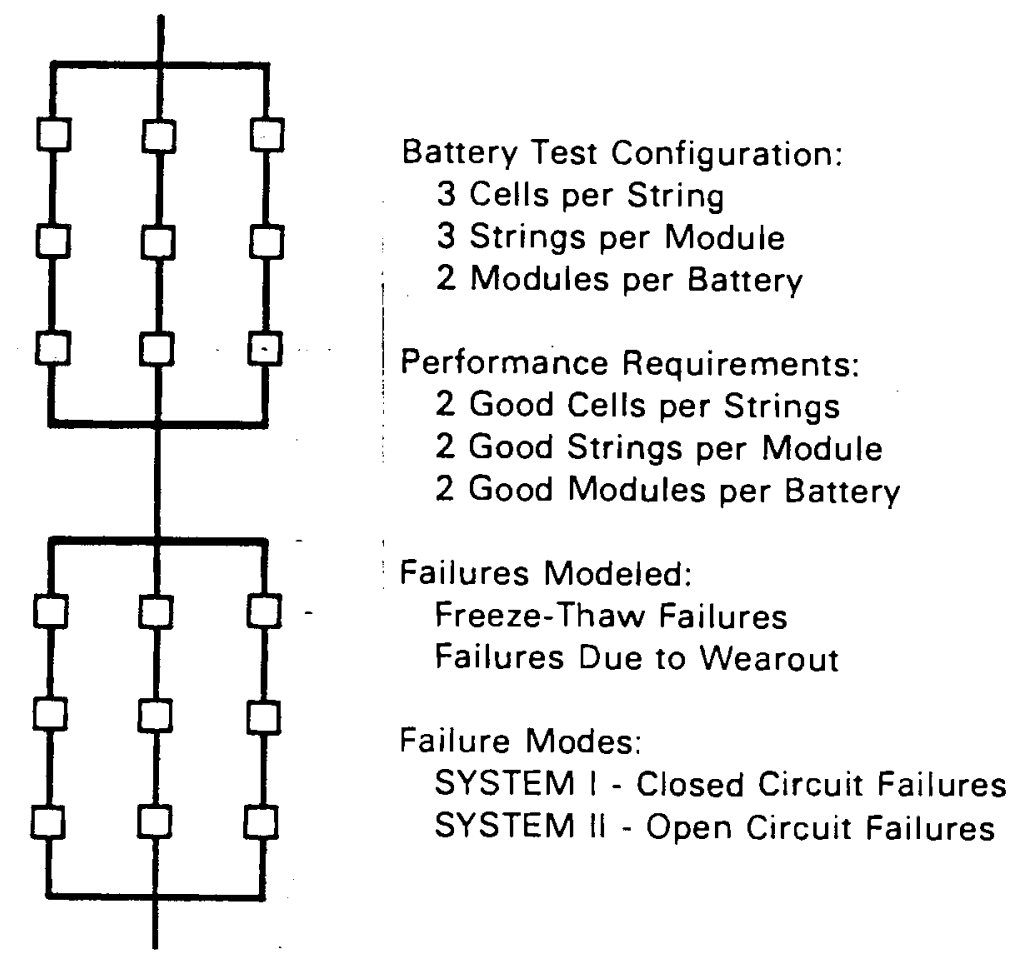

\section{FIGURE D.1. Model Verification Battery Configuration}

\section{D.1.1 System I}

After user input is obtained, RELY calculates the cycle during which each cell will wear out (using the Weibull distribution), if the cell has not previously failed due to a freeze-thaw. These wearout cycles are shown in Table D.1.

The first cycle is a freeze-thaw cycle (they occur every three cycles), so a uniform random number between zero and one is generated to determine if a

\section{TABLE D.1. Individual Cell Wearout Cycles}

Module 1

\begin{tabular}{rrrrr} 
& & \multicolumn{3}{c}{ String } \\
\cline { 3 - 5 } Cell & 1 & 12 & 26 & 1 \\
& 2 & 4 & 5 & 12 \\
& 3 & 11 & 2 & 2
\end{tabular}

Module 2

\begin{tabular}{rrrrr} 
& & \multicolumn{3}{c}{ String } \\
\cline { 3 - 5 } Ce11 & 1 & 17 & 11 & 5 \\
& 2 & 10 & 17 & 51 \\
& 3 & 17 & 7 & 10
\end{tabular}


cell fails after a freeze-thaw. If the generated number is less than the freeze-thaw failure probability ( 0.10 in this case), the cell fails prematurely.

lst Cycle (freeze-thaw occurs)

Freeze-Thaw Failure: cell $(1,1,2)$ (uniform $\#=0.05<0.10$ )

Wearout Failure: cell $(1,3,1)$

Result: Since system I has $100 \%$ closed circuit failure modes, all strings remain operational.

2nd Cycle (no freeze-thaw)

Wearout Failures: cells $(1,2,3)$ and $(1,3,3)$

Result: String $(1,3)$ fails, since 2 of its cells are failed. However, module 1 is still operational, since 2 strings remain functional.

3rd Cycle (no freeze-thaw)

No Wearouts

4 th Cycle (freeze-thaw occurs)

Freeze-Thaw Failures: cell $(2,1,1)$ (uniform \# $=0.018$ )

cell $(2,3,1)$ (uniform \# $=0.026$ )

No Wearouts

Result: Battery functions, because strings $(2,1)$ and $(2,3)$ still have two operating cells each, resulting in module 2 being functional.

5th Cycle (no freeze-thaw)

Wearout Failure: cell $(1,2,2)$

Result: String $(1,2)$ fails, since two of its cells $((1,2,2)$ and $(1,2,3)$ have failed. Module 1 fails because strings $(1,2)$ and $(1,3)$ are failed. Since two modules are required, the battery ceases to function. 
BATTERY FUNCTIONS FOUR CYCLES

Total Wearout Failures: 4

Total Freeze-Thaw Failures: 3

\section{D.1.2 System II}

The difference between the two systems is that System I has closed-circuit failure modes, while system II has open-circuit failure modes. Thus, the wearout cycles generated previously (Table D.1) also apply to this system. 1st cycle (freeze-thaw occurs)

Freeze-Thaw Failure: cell $(1,1,2)$

Wearout Failure: cell $(1,3,1)$

Result: Strings $(1,1)$ and $(1,3)$ fail due to the open-circuit failure mode. Hence, module 1 fails because two strings are failed. Thus, the entire battery fails.

\section{BATTERY FUNCTIONS ZERO CYCLES}

Total Wearout Failures: 1

Total Freeze-Thaw Failures: 1

The results obtained in this appendix can be duplicated by running RELY with the two systems. To be certain that random numbers are "matched," RELY should be started from the directory prompt (e.g., "A>") for each system.

\section{D.2 VERIFICATION OF THE DETAILED DISCHARGE MODEL}

The Detailed Discharge Model was verified by inserting instructions to dump all the state variables. Dumps were inserted to occur before and after each calculation block. Calculation blocks are the way in which the Fortran source code is laid out, the first few blocks being open circuit cell voltage, internal cell resistance, string equivalent voltage and resistance. This output was then directly verified by hand calculations.

To reduce the number of hand calculations required, a sampling of the output was verified. This approach enabled reasonableness checks and 
analytical verification of the model workings. As a final measure, the version of the detailed discharge submodel that prints all state variables was compared to the unmodified version.

The battery configuration used in the Detailed Discharge Model verification is $[(3,2,2),(2,2,2)]$. That is, there are 3 cells per string, 2 strings per module, and 2 modules per battery. The minimum operating requirements used in running the Life-Cycle Model were 2 cells per string, 2 strings per module, and two modules. As in the Life-Cycle Model verification, the freeze-thaw conditions were assumed to occur every 3 cycles; however, the freeze-thaw failure probability was set to 0 so that a case with no failures could be evaluated. For wearout failures, the Weibull distribution parameters used were: i) $\angle O C A T I O N=1.0$, ii) $\operatorname{SCALE}=20.0$, and $i i i)$ SHAPE $=1.0$. Since the location parameter was set to one, this will assure that the first cycle will have no failures.

What follows is a sampling of the output from the variable dump version. The total output obtained during the verification process was considerable and the small example of the output contained in this document should not be interpreted as the total effort undertaken to assure the performance of this model. Numbers in parentheses illustrate the calculations matched by hand.

\begin{tabular}{|c|c|}
\hline Number of modules per battery & \\
\hline Number of strings per module & \\
\hline Number of cells per string & \\
\hline Total Cells per Battery & \\
\hline
\end{tabular}

\section{Test Conditions}

Cycle to analyze $\quad=1$

Cumulative Freeze-Thaw Open Open Circuit Failures $=0$ from RELY

Cumulative Freeze-Thaw Closed Circuit Failures $=0$ from RELY

Cumulative Wearout Open Circuit Failures $\quad=0$ from RELY

Cumulative Wearout Closed Circuit Failures $\quad=0$ from RELY

Duration of Test $\quad=6.00$ Hours 
Test Conditions (contd)

Time Increment

Cel1 Connection: 1=Series-Par. 2=Parallel-Ser.

$=.25$ Hours

Failure Switches: $0=$ None. $1=C$ losed. 2=0pen 1

Constant Discharge Current

0

$=45.00$ Amps

\section{Cell Parameters}

Theoretical Cell Capacity

Fully Charged Cell Capacity

Fully Charged Open Circuit Cell Voltage

$=50.00$ Amp-Hours

Upper Cutoff Voltage

$=47.50$ Amp-Hours

Lower Cutoff Voltage

Initial Internal Cell Resistance

$=2.08$ Volts

$=10.00$ Volts

$=1.78$ Volts

Freeze-Thaw Failure Open Circuit Resistance

$=.0350 \mathrm{Ohms}$

Freeze-Thaw Failure Closed Circuit Resistance

$=.200000 \mathrm{hms}$

Wearout Failure Open Circuit Resistance

Wearout Failure Closed Circuit Resistance

$=.70000 \mathrm{E}-010 \mathrm{hms}$

$=.200000 \mathrm{hms}$

$=.70000 \mathrm{E}-010 \mathrm{hms}$

Over-Voltage Failure Resistance Parameters:

Over-Voltage Failure Open Circuit Percentage

$=30.00$ Percent

Over-Voltage Failure Closed Circuit Percentage

$=70.00$ Percent

Over-Voltage Failure Open Circuit Resistance

Over-Voltage Failure Closed Circuit Resistance

$=.200000 \mathrm{hms}$

Over Discharge Failure Resistance Parameters:

Over-Discharge Failure Open Circuit Percentage $\quad=30.00$ Percent

Over-Discharge Failure Closed Circuit Percentage $=70.00$ Percent

Over-Discharge Failure Open Circuit Resistance $=.20000$ Ohms

Over-Discharge Failure Closed Circuit Resistance $=.70000 \mathrm{E}-010 \mathrm{hms}$ 


\begin{tabular}{|c|c|c|c|c|c|}
\hline $\begin{array}{l}\text { Time } \\
(\mathrm{Hr}) \\
\end{array}$ & $\begin{array}{c}\text { Total } \\
\text { Voltage } \\
\text { Battery } \\
\text { (v) } \\
\end{array}$ & $\begin{array}{c}\text { Average } \\
\text { Module } \\
\text { Voltage } \\
\text { (v) } \\
\end{array}$ & $\begin{array}{l}\text { Output } \\
\text { Power } \\
\text { (kw) } \\
\end{array}$ & $\begin{array}{c}\text { Average } \\
\text { Voltage } \\
\text { Working } \\
\text { Cel Is } \\
\text { (V) }\end{array}$ & $\begin{array}{c}\text { Minimum } \\
\text { Voltage } \\
\text { Working } \\
\text { Cel Is } \\
\text { (V) }\end{array}$ \\
\hline $\begin{array}{l}.00 \\
.25 \\
.50 \\
.75 \\
1.00 \\
1.25 \\
1.50 \\
1.75 \\
2.00 \\
2.25\end{array}$ & $\begin{array}{r}7.73 \\
7.73 \\
7.73 \\
7.73 \\
7.73 \\
7.48 \\
7.04 \\
6.60 \\
6.15 \\
-10.57\end{array}$ & $\begin{array}{r}3.87 \\
3.87 \\
3.87 \\
3.87 \\
3.87 \\
3.74 \\
3.52 \\
3.30 \\
3.08 \\
-5.28\end{array}$ & $\begin{array}{r}.35 \\
.35 \\
.35 \\
.35 \\
.35 \\
.34 \\
.32 \\
.30 \\
.28 \\
-.48\end{array}$ & $\begin{array}{l}2.08 \\
2.08 \\
2.08 \\
2.08 \\
2.08 \\
2.03 \\
1.96 \\
1.89 \\
1.81 \\
1.74\end{array}$ & $\begin{array}{l}2.08 \\
2.08 \\
2.08 \\
2.08 \\
2.08 \\
2.03 \\
1.96 \\
1.89 \\
1.81 \\
1.74\end{array}$ \\
\hline
\end{tabular}

\begin{tabular}{|c|c|c|c|}
\hline $\begin{array}{l}\text { Average } \\
\text { Capacity } \\
\text { Working } \\
\text { Cells } \\
\text { (Amp-Hr) } \\
\end{array}$ & $\begin{array}{c}\text { Average } \\
\text { Res istance } \\
\text { Al I } \\
\text { Cel Is } \\
\text { (Ohms) } \\
\end{array}$ & $\begin{array}{l}\text { \# Under } \\
\text { Voltage } \\
\text { Electr. } \\
\text { Fails } \\
\end{array}$ & $\begin{array}{l}\text { \# Over } \\
\text { Voltage } \\
\text { Electr. } \\
\text { Fails }\end{array}$ \\
\hline $\begin{array}{r}47.50 \\
41.88 \\
36.25 \\
30.63 \\
25.00 \\
19.38 \\
13.75 \\
8.13 \\
2.50 \\
.00\end{array}$ & $\begin{array}{l}.350 \mathrm{E}-01 \\
.350 \mathrm{E}-01 \\
.350 \mathrm{E}-01 \\
.350 \mathrm{E}-01 \\
.350 \mathrm{E}-01 \\
.350 \mathrm{E}-01 \\
.350 \mathrm{E}-01 \\
.350 \mathrm{E}-01 \\
.350 \mathrm{E}-01 \\
.808 \mathrm{E}-01\end{array}$ & $\begin{array}{l}0 . \\
0 . \\
0 . \\
0 . \\
0 . \\
0 . \\
0 . \\
0 . \\
0 . \\
12 .\end{array}$ & $\begin{array}{l}0 . \\
0 . \\
0 . \\
0 . \\
0 . \\
0 . \\
0 . \\
0 . \\
0 . \\
0 .\end{array}$ \\
\hline
\end{tabular}

Battery unable to deliver

45.00 amps at time

2.25 hours

time: $\quad .00$

LOCATION: SECTION 5: OPEN CIRCUIT CELL VOLTAGE

\begin{tabular}{|c|c|c|c|c|c|}
\hline MOD & STR & Cel1 & OCV & Charge & Resis. \\
\hline \multirow[t]{2}{*}{1} & 1 & 1 & 2.0760 & 47.500 & $.35000 E-01$ \\
\hline & & & 2.0760 & 47.500 & $.35000 E-01$ \\
\hline \multirow[t]{2}{*}{1} & 1 & 2 & 2.0760 & 47.500 & $.35000 E-01$ \\
\hline & & & 2.0760 & 47.500 & $.35000 E-01$ \\
\hline \multirow[t]{2}{*}{1} & 1 & 3 & 2.0760 & 47.500 & $.35000 E-01$ \\
\hline & & & 2.0760 & 47.500 & $.35000 E-01$ \\
\hline \multirow[t]{2}{*}{1} & 2 & 1 & 2.0760 & 47.500 & $.35000 E-01$ \\
\hline & & & 2.0760 & 47.500 & $.35000 E-01$ \\
\hline \multirow[t]{2}{*}{1} & 2 & 2 & 2.0760 & 47.500 & $.35000 E-01$ \\
\hline & & & 2.0760 & 47.500 & $.35000 E-01$ \\
\hline
\end{tabular}

time: $\quad .00$

LOCATION: SECTION 6: CELL INTERNAL RESISTANCE

\begin{tabular}{|c|c|c|c|c|c|}
\hline MOD & STR & Cell & OCV & Charge & Resis. \\
\hline \multirow[t]{2}{*}{1} & 1 & 1 & 2.0760 & 47.500 & $.35000 E-01$ \\
\hline & & & 2.0760 & $(47.500)$ & $.35000 E-01$ \\
\hline \multirow[t]{2}{*}{1} & 1 & 2 & $(2.0760)$ & 47.500 & $.35000 E-01$ \\
\hline & & & 2.0760 & 47.500 & $.35000 E-01$ \\
\hline \multirow[t]{2}{*}{1} & 1 & 3 & 2.0760 & 47.500 & $(.35000 E-01)$ \\
\hline & & & 2.0760 & 47.500 & $.35000 \mathrm{E}-01$ \\
\hline \multirow[t]{2}{*}{1} & 2 & 1 & 2.0760 & 47.500 & $.35000 E-01$ \\
\hline & & & 2.0760 & 47.500 & $.35000 E-01$ \\
\hline
\end{tabular}


time: $\quad .00$

\begin{tabular}{|c|c|c|c|}
\hline $\begin{array}{l}\text { LOCATION: } \\
\text { MOD }\end{array}$ & $\begin{array}{l}\text { SECTION 7: } \\
\text { STR }\end{array}$ & $\begin{array}{l}\text { STRING VOLTAGE AND } \\
\text { OCV }\end{array}$ & $\begin{array}{l}\text { RESISTANCE } \\
\text { Resis. }\end{array}$ \\
\hline \multirow[t]{2}{*}{1} & 1 & .0000 & .00000 \\
\hline & & $(6.2280)$ & .10500 \\
\hline \multirow[t]{2}{*}{1} & 2 & .0000 & .00000 \\
\hline & & 6.2280 & .10500 \\
\hline \multirow[t]{2}{*}{2} & 1 & .0000 & .00000 \\
\hline & & 6.2280 & .10500 \\
\hline \multirow[t]{2}{*}{2} & 2 & .0000 & .00000 \\
\hline & & 6.2280 & .10500 \\
\hline
\end{tabular}

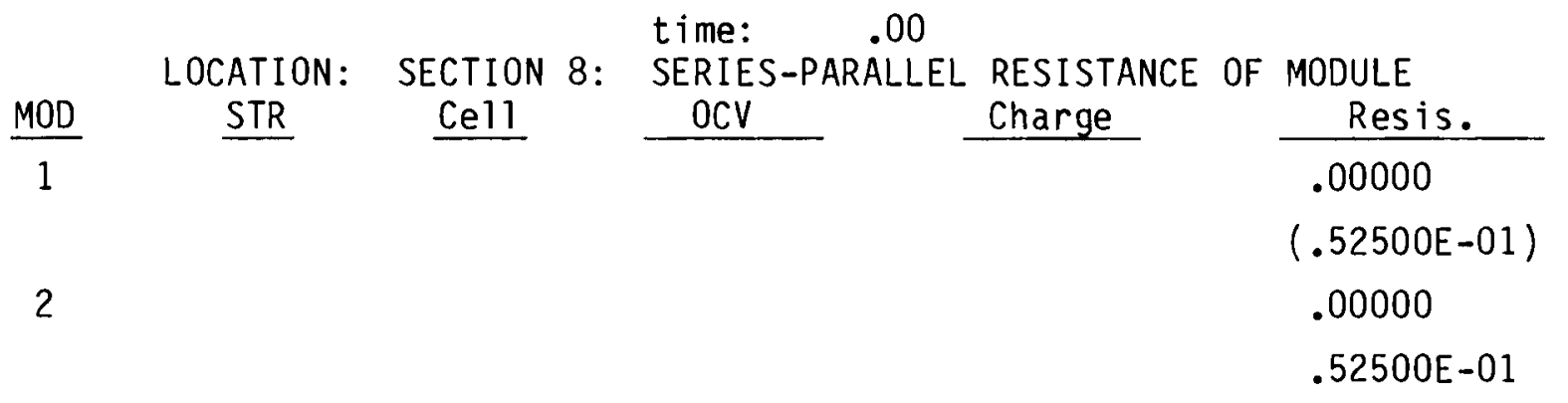

\begin{tabular}{|c|c|c|c|c|c|}
\hline MOD & STR & $\begin{array}{l}\text { LOCATION: } \\
\text { Cel11 }\end{array}$ & $\begin{array}{l}\text { time: } \\
\text { SECTION 10: } \\
\text { OCV } \\
\end{array}$ & $\begin{array}{l}.00 \\
\text { DATA COLLECTION } \\
\text { Charge }\end{array}$ & Resis. \\
\hline \multirow[t]{2}{*}{1} & 1 & 1 & 2.0760 & 47.500 & $.35000 E-01$ \\
\hline & & & 2.0760 & 47.500 & $.35000 E-01$ \\
\hline \multirow[t]{2}{*}{1} & 1 & 2 & 2.0760 & 47.500 & $.35000 E-01$ \\
\hline & & & 2.0760 & 47.500 & $.35000 E-01$ \\
\hline \multirow[t]{2}{*}{1} & 1 & 3 & 2.0760 & 47.500 & $.35000 E-01$ \\
\hline & & & 2.0760 & 47.500 & $.35000 E-01$ \\
\hline
\end{tabular}




$\begin{array}{lc}\text { time } & (.00000) \\ \text { total battery voltage } & (7.7310) \\ \text { avg. module voltage } & (3.8655) \\ \text { output power } & (.34790) \\ \text { average voltage } & (2.0760) \\ \text { Minimum voltage working cells } & (2.0760) \\ \text { average capacity working cells } & (47.500) \\ \text { average resistance all cells } & (.35000 \mathrm{E}-01) \\ \text { \# under voltage electrolyte failures } & (.00000) \\ \# \text { over voltage electrolyte failures } & (.00000)\end{array}$

\begin{tabular}{|c|c|c|c|c|c|}
\hline MOD & $\underline{\text { STR }}$ & $\begin{array}{l}\text { LOCATION: } \\
\text { Cell }\end{array}$ & $\begin{array}{l}\text { time: } \\
\text { SECTION 12: } \\
\text { OCV } \\
\end{array}$ & $\begin{array}{l}.00 \\
\text { CELL DISCHARGE } \\
\text { Charge }\end{array}$ & Resis. \\
\hline \multirow[t]{2}{*}{1} & 1 & 1 & 2.0760 & 47.500 & $.35000 E-01$ \\
\hline & & & 2.0760 & $(41.875)$ & $.35000 E-01$ \\
\hline \multirow[t]{2}{*}{1} & 1 & 2 & 2.0760 & 47.500 & $.35000 E-01$ \\
\hline & & & 2.0760 & 41.875 & $.35000 E-01$ \\
\hline \multirow[t]{2}{*}{1} & 1 & 3 & 2.0760 & 47.500 & $.35000 E-01$ \\
\hline & & & 2.0760 & 41.875 & $.35000 E-01$ \\
\hline \multirow[t]{2}{*}{1} & 2 & 1 & 2.0760 & 47.500 & $.35000 \mathrm{E}-01$ \\
\hline & & & 2.0760 & 41.875 & $.35000 E-01$ \\
\hline
\end{tabular}

\begin{tabular}{|c|c|c|c|c|c|}
\hline & LOCATION: & SECTION & $\begin{array}{l}\text { ime: } \\
\text { 5: OPEN }\end{array}$ & $\begin{array}{l}.25 \\
\text { CIRCUIT CELL }\end{array}$ & VOLTAGE \\
\hline MOD & STR & Cell & $\mathrm{OCV}$ & Charge & Resis. \\
\hline \multirow[t]{2}{*}{1} & 1 & 1 & 2.0760 & 41.875 & $.35000 E-01$ \\
\hline & & & 2.0760 & $(41.875)$ & $.35000 E-01$ \\
\hline \multirow[t]{2}{*}{1} & 1 & 2 & 2.0760 & 41.875 & $.35000 E-01$ \\
\hline & & & 2.0760 & 41.875 & $.35000 E-01$ \\
\hline \multirow[t]{2}{*}{1} & 1 & 3 & 2.0760 & 41.875 & $.35000 E-01$ \\
\hline & & & 2.0760 & 41.875 & $.35000 E-01$ \\
\hline
\end{tabular}


time: $\quad 1.50$

LOCATION: SECTION 5: OPEN CIRCUIT CELL VOLTAGE

\begin{tabular}{|c|c|c|c|c|c|}
\hline MOD & STR & Cell & OCV & Charge & Resis. \\
\hline \multirow[t]{2}{*}{1} & 1 & 1 & 2.0349 & 47.500 & $.35000 \mathrm{E}-01$ \\
\hline & & & $(1.9609)$ & 47.500 & $.35000 \mathrm{E}-01$ \\
\hline \multirow[t]{2}{*}{1} & 1 & 2 & 2.0349 & $(47.500)$ & $.35000 \mathrm{E}-01$ \\
\hline & & & 1.9609 & 47.500 & $.35000 \mathrm{E}-01$ \\
\hline \multirow[t]{2}{*}{1} & 1 & 3 & $(2.0349)$ & 47.500 & $(.35000 E-01)$ \\
\hline & & & 1.9609 & 47.500 & $.35000 \mathrm{E}-01$ \\
\hline
\end{tabular}

time: $\quad 2.00$

LOCATION: SECTION 5: OPEN CIRCUIT CELL VOLTAGE

\begin{tabular}{|c|c|c|c|c|c|}
\hline MOD & STR & Cell & OCV & Charge & Resis. \\
\hline \multirow[t]{2}{*}{1} & 1 & 1 & 1.8129 & $(2.5000)$ & $.35000 E-01$ \\
\hline & & & 1.8129 & $(-3.1250)$ & $.35000 E-01$ \\
\hline \multirow[t]{2}{*}{1} & 1 & 2 & 1.8129 & 2.5000 & $.35000 E-01$ \\
\hline & & & 1.8129 & -3.1250 & $.35000 \mathrm{E}-01$ \\
\hline \multirow[t]{2}{*}{1} & 1 & 3 & 1.8129 & 2.5000 & $.35000 \mathrm{E}-01$ \\
\hline & & & 1.8129 & -3.1250 & $.35000 E-01$ \\
\hline \multirow[t]{2}{*}{1} & 2 & 1 & 1.8129 & 2.5000 & $.35000 E-01$ \\
\hline & & & 1.8129 & -3.1250 & $.35000 \mathrm{E}-01$ \\
\hline
\end{tabular}

time: $\quad 2.25$

LOCATION: SECTION 5: OPEN CIRCUIT CELL VOLTAGE

\begin{tabular}{|c|c|c|c|c|c|}
\hline MOD & STR & Cell & OCV & Charge & Resis. \\
\hline \multirow[t]{2}{*}{1} & 1 & 1 & 1.8129 & $(-3.1250)$ & $.35000 \mathrm{E}-01$ \\
\hline & & & .00000 & $(.00000)$ & $.70000 E-01$ \\
\hline \multirow[t]{2}{*}{1} & 1 & 2 & $(1.8129)$ & -3.1250 & $.35000 E-01$ \\
\hline & & & $(.00000)$ & .00000 & $.70000 E-01$ \\
\hline \multirow[t]{2}{*}{1} & 1 & 3 & 1.8129 & -3.1250 & $.35000 E-01$ \\
\hline & & & .00000 & .00000 & $.70000 \mathrm{E}-01$ \\
\hline \multirow[t]{2}{*}{1} & 2 & 1 & 1.8129 & -3.1250 & $.35000 E-01$ \\
\hline & & & .0000 & .0000 & .20000 \\
\hline
\end{tabular}


This example just shows part of one case, using default parameters and all cells in the battery are working at time zero. At PNL other cases confirmed the operation of all the options available, on both good and initially failed cells. 


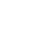




\section{DISTRIBUTION}

No. of

Copies

OFFSITE

$10 \mathrm{Mr}$. J. Quinn

U.S. Department of Energy

Forrestal Building, RM 6A049

1000 Independence Ave., SW

Washington, D.C. 20585

5 Dr. A. R. Landgrebe

U.S. Department of Energy

CE-141, MS 5 E-036

Forrestal Building

1000 Independence Ave., SW

Washington, D.C. 20585

30 DOE Technical Information

Center

Dr. George E. Blomgren

Corporate Technology Fellow

Union Carbide Corporation

P.0. Box 45035

Westlake, $\mathrm{OH} 44145$

Elton J. Cairns

Head, Applied Science Division

Lawrence Berkeley Laboratory

University of California

Berkeley, CA 94720

Sanjay L. Deshpande

Vice President, Engineering

GNB Incorporated

2010 Cabot Boulevard West

Langhorne, PA 19047

Dr. Curtis F. Holmes

Vice President, Technology

Electrochem Industries

10000 Wehrle Drive

Clarence, NT 14031
No. of

Copies

J. J. I annucci

Program Manager

Pacific Gas and Electric Co.

3400 Crow Canyon Road

San Ramon, CA 94583

Tadao Ishikawa

Senior Research Engineer

Electrical Engineering Laboratory

Central Research Institute of Electric Power Industry

11-1, Iwato Kita 2-Chome Komae-Shi

Tokyo 201 Japan

Kazumasa Matsui

Acting Supervisory Manager

1st Research Department

Central Laboratory

Yuasa Battery Co., LTD.

Takatsuki, Osaka, Japan

Henry Oman

Electrical Power Systems

MS 19-27

Boeing Aerospace Co.

P.0. Box 3999

Seattle, WA 98124

James R. Rasmussen

Program Manager

Ceramatec, Inc.

163 West 1700 South

Salt Lake City, UT 84115

Hiry B. West

Product Engineering Manager

McGraw-Edison Co.

P.0. Box 28

Bloomfield, NJ 07003 
No. of

Copies

David Yalom

Consultant

Catalyst Research Corp.

1421 Clarkview Road

Baltimore, MD 21209

Jon W. Hurwitch

Energetics, Inc.

9210 Route 108

Dolumbia, MD 21045

ONSITE

DOE-Richland Operations

J. J. Sutey

44 Pacific Northwest Laboratory

W. B. Ashton

R. V. Badalamente

D. R. Brown

J. A. Dirks (5)

W. H. Doggett (2)

J. V. Dovey

L. L. Fassbender

R. B. Grinde (2)

C. J. Hostick (10)

H. D. Huber (2)

H. K. Humphreys

C. H. Imhoff

J. S. Littlefield

P. C. Rieke

R. K. Sen

C. Winter (5)

Publishing Coordination MH (2)

Technical Information (5) 